\title{
UMA CONTRIBUIÇÃO AO PROCESSO DE GESTÃO DA PRODUÇÃO PELO USO DA COLETA AUTOMÁTICA DE DADOS DE CHÃO DE FÁBRICA
}

Fábio Favaretto

Tese apresentada à Escola de Engenharia de São Carlos, da Universidade de São Paulo, como parte dos requisitos para obtenção do título de Doutor em Engenharia Mecânica

ORIENTADOR: Prof. Dr. Carlos Bremer

São Carlos 
Dedicatória

Ao meu pai, minha mãe e à Cau 


\section{Agradecimentos}

Ao amigo e orientador Carlos Bremer por tudo.

A todos aqueles com quem tive o enorme prazer de trabalhar no NUMA ao longo desses anos.

Ao Freire e Optimal pelo apoio.

A todos os meus amigos. 


\section{SUMÁRIO}

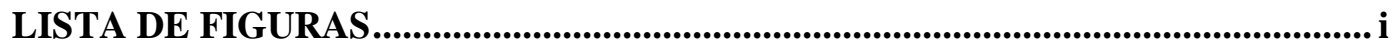

LISTA DE ABRVIATURAS E SIGLAS .................................................................... iv

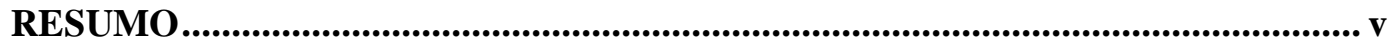

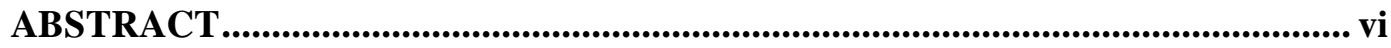

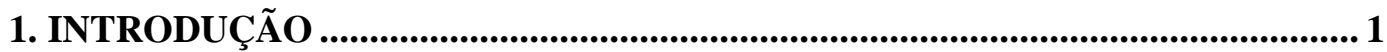

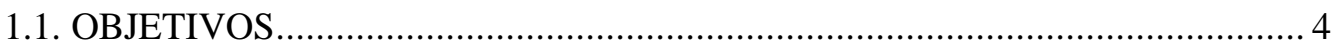

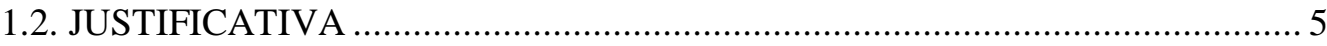

2. METODOLOGIA DE PESQUISA ............................................................................ 7

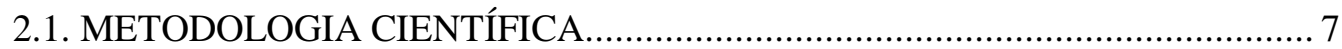

2.2. VISÃO GERAL DE METODOLOGIAS DE PESQUISA …................................ 8

2.2.1. Classes de coleta de dados...................................................................... 10

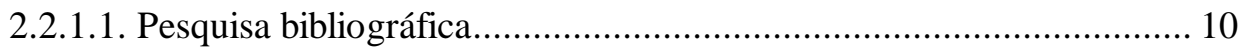

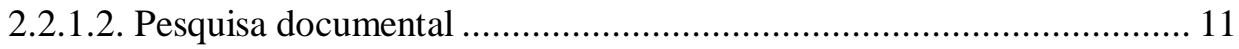

2.2.1.3. Pesquisa experimental .................................................................. 11

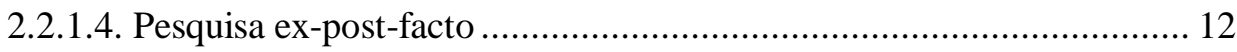

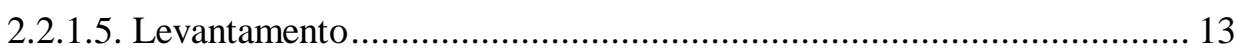

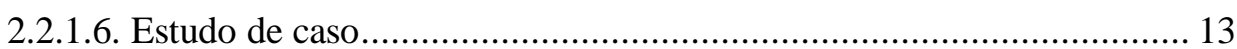

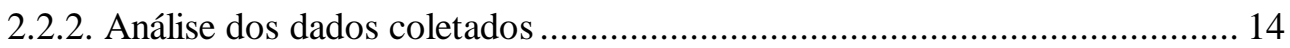

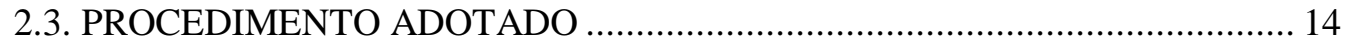

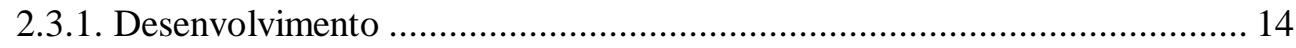

2.3.2. Definição do problema e hipóteses .............................................................. 17

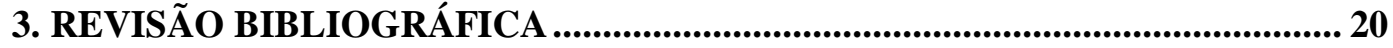

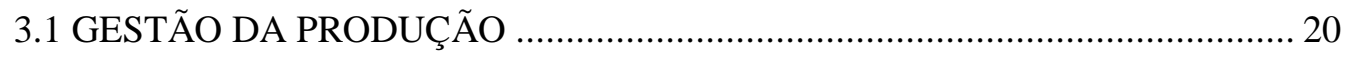

3.1.1 Processos de planejamento, programação e controle da produção ............... 21

3.1.2 Sistemas de administração da produção ……........................................... 23 
3.1.3 Indicadores de performance

3.2 MONITORAMENTO E SUPERVISÃO DA PRODUÇÃO................................. 26

3.3 TRATAMENTO DE INFORMAÇÕES PARA GESTÃO DA PRODUÇÃO...... 28

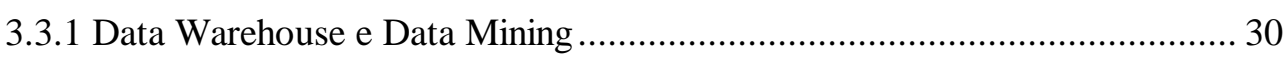

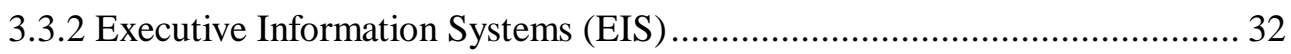

4. MODELOS CONCEITUAIS DE GESTÃO DA PRODUÇÃO............................ 34

4.1. Gerenciamento da produção e inventário .......................................................... 34

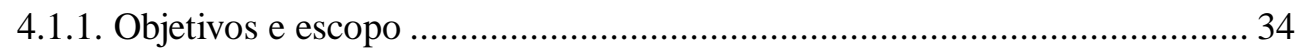

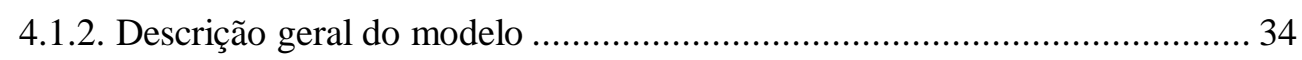

4.1.3. Gerenciamento da demanda.................................................................. 36

4.1.4. Planejamento mestre da produção............................................................... 37

4.1.5. Planejamento da capacidade ....................................................................... 39

4.1.6. Planejamento detalhado de materiais ....................................................... 41

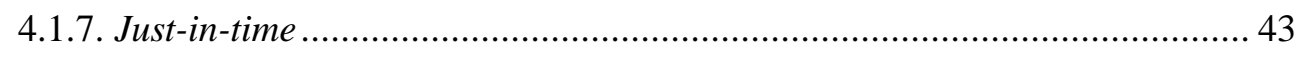

4.1.8. Controle das atividades de produção............................................................ 44

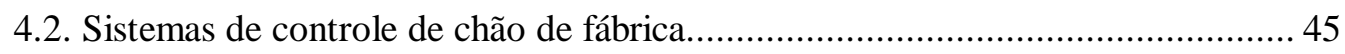

4.2.1. Introdução sobre sistemas de controle de chão de fábrica........................... 45

4.2.2. Uma arquitetura para sistemas de controle de chão de fábrica .................... 47

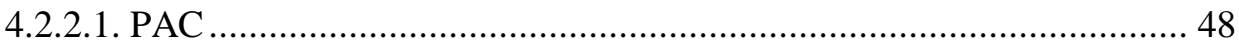

4.2.2.2. Coordenação de fábrica ................................................................... 50

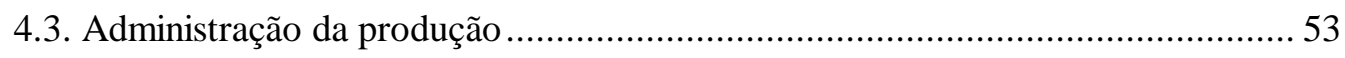

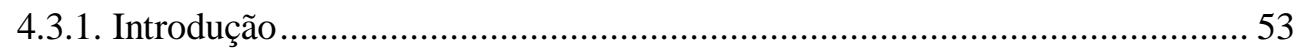

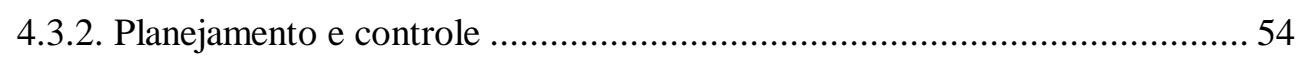

4.3.2.1. Natureza do planejamento ......................................................... 54

4.3.2.2. Planejamento e controle da capacidade ........................................... 55

4.3.2.3. Planejamento e controle de estoque ................................................. 56

4.3.2.4. Planejamento e controle da rede de suprimentos ............................... 57

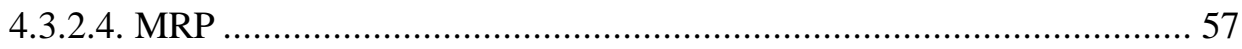

4.3.2.5. Planejamento e controle Just-in-time ............................................... 59

4.4. Planejamento, programação e controle da produção........................................... 59 
4.4.1. Introdução. 59

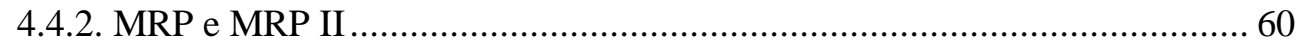

4.4.3. S\&OP - Planejamento de vendas e operações............................................. 62

4.4.4. MPS - Planejamento mestre da produção ……………………………….... 64

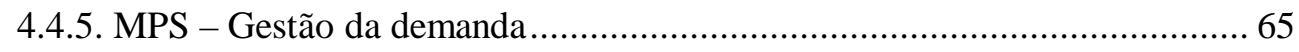

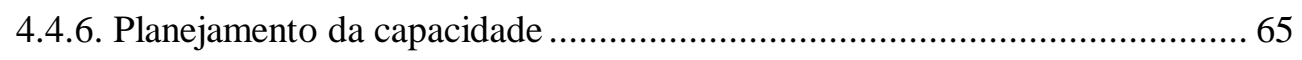

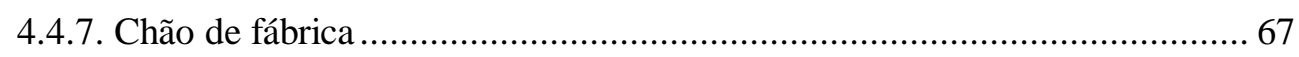

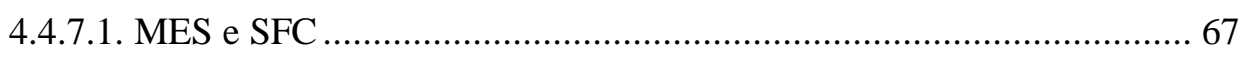

4.4.7.2. Sistemas de programação da produção com capacidade finita ............ 68

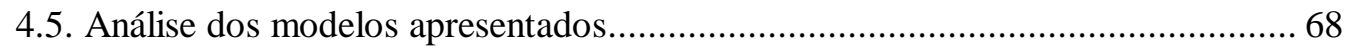

4.5.1. Modelo proposto por VOLLMANN et al. (1993)....................................... 68

4.5.2. Modelo proposto por BAUER et al. (1991).................................................. 69

4.5.3. Modelo proposto por SLACK et al. (1999) ............................................... 70

4.5.4. Modelo proposto por CORRÊA et al. (1997) ............................................. 71

4.5.5. Comparação entre os modelos ................................................................ 71

5. MODELO CONCEITUAL DE GESTÃO DA PRODUÇÃO ............................... 73

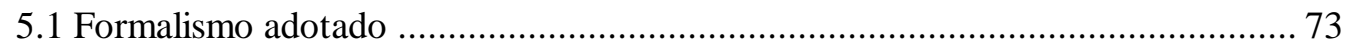

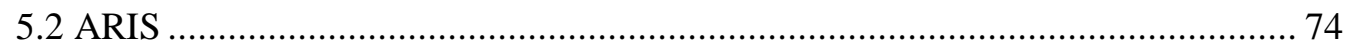

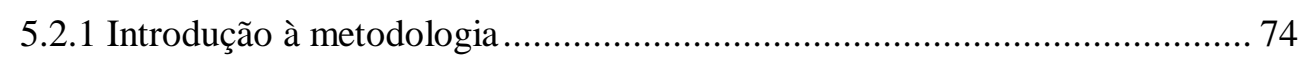

5.2.2 Processo básico de modelagem.............................................................. 74

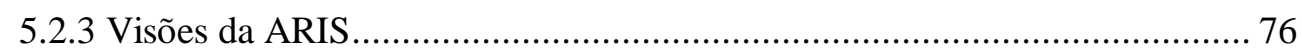

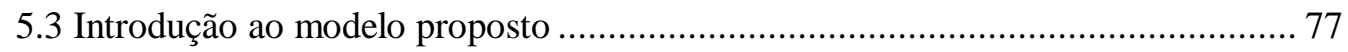

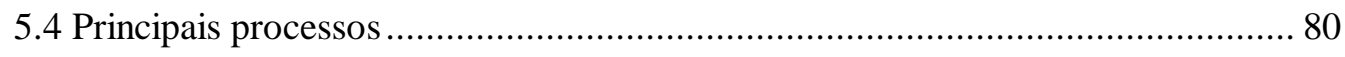

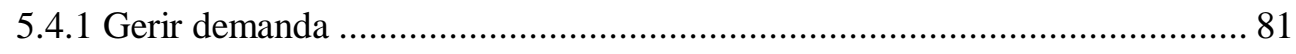

5.4.2 Planejar produção....................................................................... 83

5.4.3 Programar produção ........................................................................... 93

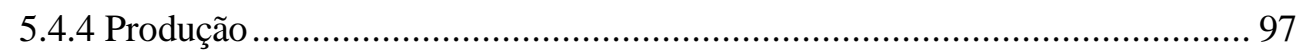

5.4.4 Controle da produção ............................................................................ 101

5.4.5 Analisar dados de produção.................................................................... 104

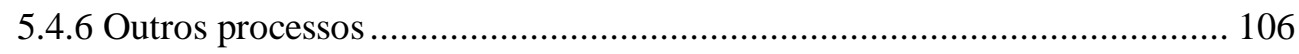

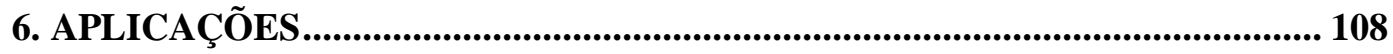




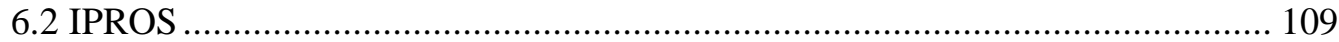

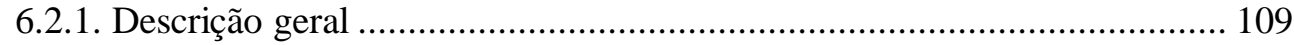

6.2.2. Cadeia de suprimentos .......................................................................... 110

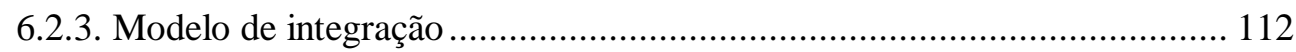

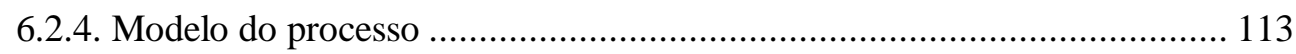

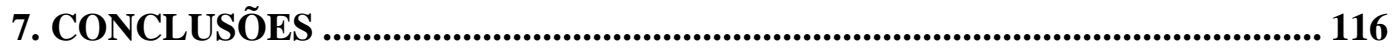

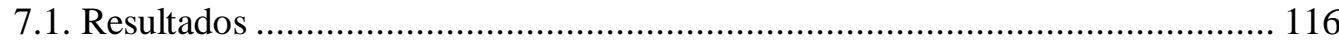

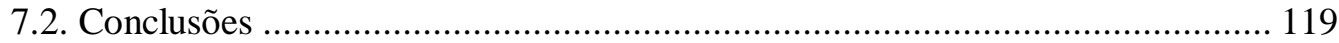

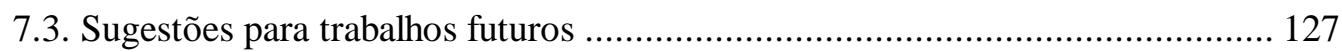

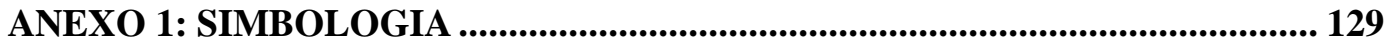

ANEXO 2: MODELO PROPOSTO ......................................................................... 131

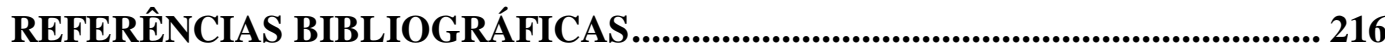




\section{LISTA DE FIGURAS}

Figura 1.1: Ciclo de geração e uso de dados de chão de fábrica 2

Figura 2.1 - Procedimento adotado para o desenvolvimento do trabalho..... 15

Figura 4.1 - Visão geral do modelo de gestão da produção e inventários (VOLLMANN et al., 1993) 35

Figura 4.2 - Principais relacionamentos do gerenciamento da demanda (VOLLMANN et al., 1993) 36

Figura 4.3 - Hierarquia do planejamento da produção (VOLLMANN et al., 1993)..... 37

Figura 4.4 - Principais relacionamentos do planejamento agregado da produção (VOLLMANN et al., 1993) 38

Figura 4.5 - Hierarquia e relacionamentos do Planejamento da capacidade (VOLLMANN et al., 1993) 40

Figura 4.6 - Uso de registros do MRP para o planejamento detalhado de materiais (VOLLMANN et al., 1993).

Figura 4.7 - Principais relacionamentos do controle das atividades de produção (VOLLMANN et al., 1993)

Figura 4.8 - Hierarquia dos sistemas de controle da manufatura (BAUER et al., 1991)

Figura 4.9 - Arquitetura do controle das atividades de produção - PAC (BAUER et al., 1991) 
Figura 4.10 - Arquitetura da Coordenação de fábrica (BAUER et al., 1991)

Figura 4.11 - Modelo geral da administração da produção (SLACK et al., 1999)........ 53

Figura 4.12 - Etapas do planejamento e controle da capacidade (SLACK et al., 1999) 55

Figura 4.13 - Esquema do funcionamento do planejamento de necessidades de materiais (SLACK et al., 1999)..................................................................... 58

Figura 4.14 - Estrutura hierárquica do MRP II (CORRÊA et al., 1997) .................... 62

Figura 5.15 - Localização do S\&OP no planejamento (CORRÊA et al., 1997) ........... 63

Figura 4.16 - Hierarquia do planejamento da capacidade (CORRÊA et al., 1997)...... 66

Figura 5.1: Modelo da cadeia de suprimentos do projeto IPROS ........................... 111

Figura 5.2: Modelo de integração do projeto IPROS .......................................... 112

Figura 5.3: Modelo da Fábrica Integrada Modelo do projeto IPROS ...................... 114

Figura 6.1: Diagrama de interação geral para o processo de "processamento de

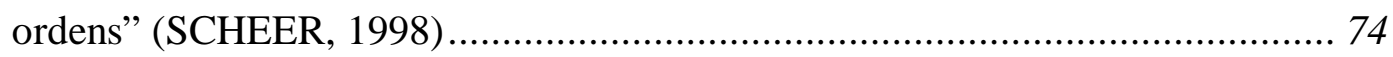

Figura 6.2: Fluxo de funções do processo (SCHEER, 1998)................................... 75

Figura 6.3: Fluxo de funções e eventos do processo "processamento de ordens"......... 76

Figura 6.4: Relacionamento entre as visões da ARIS (SCHEER, 1998)..................... 77

Figura 6.5: Visão geral do modelo proposto...................................................... 78

Figura 6.6: Modelo do processo de Gestão da demanda ........................................... 81 
Figura 6.7: Modelo do processo de Planejamento da produção.

Figura 6.8: Modelo do sub processo de desagregação do plano agregado de produção 85

Figura 6.9: Modelo do sub processo de elaboração do plano mestre de produção. 87

Figura 6.10: Modelo do sub processo de elaboração do planejamento detalhado da produção 90

Figura 6.11: Modelo do processo de programação da produção. 94

Figura 6.12: Modelo do processo de produção (Produzir) 98

Figura 6.13: Modelo do processo de controle da produção. 102

Figura 6.14: Modelo do processo de análise dos dados de produção. 105

Figura A1:Elementos utilizados nos modelos 129 


\title{
LISTA DE ABREVIATURAS E SIGLAS
}

\author{
DW - Data Warehouse \\ FIM - Fábrica Integrada Modelo \\ ERP - Enterprise Resources Planning \\ EESC - Escola de Engenharia de São Carlos \\ GP - Gestão da Produção \\ NUMA - Núcleo de Manufatura Avançada \\ PCP - Planejamento e Controle da Produção \\ USP - Universidade de São Paulo
}




\section{RESUMO}

FAVARETTO, Fábio (2001). Uma contribuição ao processo de gestão da produção pelo uso da coleta automática de dados de chão de fábrica. São Carlos, 2001, 223p. Tese (Doutorado) - Escola de Engenharia de São Carlos, Universidade de São Paulo.

O processo de gestão da produção é responsável pelo planejamento de todas as atividades de produção em empresas de manufatura. Modelos conceituais são referências para implantação e organização deste processo, e alguns não abordam o uso da coleta automática de dados de chão fábrica. É proposto um modelo conceitual que considera a coleta automática, tratamento e disponibilização destes dados, permitindo que sejam tomadas decisões com base em dados mais precisos, detalhados e fáceis de serem obtidos.

Palavras-chave: gestão da produção; integração, monitoramento da produção, coleta de dados. 


\section{ABSTRACT}

FAVARETTO, Fábio (2001). Contribution to the production management process using automatic shop floor data collection. São Carlos, 2001, 223p. Tese (Doutorado) - Escola de Engenharia de São Carlos, Universidade de São Paulo.

The production management process is in charge to plan all production activities in manufacturing enterprises. Conceptual models are references for implantation and organization of this process. Some of these models do not include automatic shop floor data collection. It is proposed a conceptual model that takes into account the automatic data collection, using, treating and making it available. This will permit a decision-making based on more detailed, accurate and easy to get information.

Key words: production management, integration, production monitoring, data collection. 


\section{INTRODUÇÃO}

O panorama mundial atual impõe que as empresas de manufatura possuam boa competitividade para se manter no mercado. Para tal, várias alternativas são possíveis, como diminuição de custos, diminuição dos prazos de entrega, melhores produtos e agilidade na tomada de decisões. Estas e outras alternativas permitem que a empresa se mantenha no mercado ou ganhe competitividade.

Internamente, esta busca pela competitividade reflete em diversas áreas e processos. Entre outros, existem os processos de vendas, compras, desenvolvimento de produtos, produção e financeiros. Um conjunto de atividades, cuja sequiência possa ser estabelecida e sua abrangência delimitada, será chamado de processo.

Um conjunto destes processos é a Gestão da Produção (GP), responsável por todas as atividades da produção, desde a compra da matéria prima até a expedição. Entre os processos de Gestão da Produção, o de Planejamento e Controle da Produção (PCP) será analisado com mais detalhes no decorrer deste trabalho. Este processo é responsável por todos os níveis de planejamento da produção, desde as estratégias de longo prazo até a seqüência de atividades de um equipamento de produção.

Várias alternativas têm sido procuradas para aumentar a eficiência dos processos de Gestão da Produção, como sistemas integrados de gerenciamento, reengenharia de processos, aplicação de técnicas japonesas de gerenciamento da produção, utilização da tecnologia de informação e automação.

Entre estas alternativas está a coleta automática de dados e monitoramento de chão de fábrica, cuja implantação e integração com outras ferramentas e tecnologias é o objeto de estudo deste trabalho.

Empresas com processo de produção contínuo utilizam com freqüência formas automáticas de coleta de dados, como maneira de atuar no controle do processo produtivo. Por exemplo, sensores monitoram a temperatura de caldeiras, e acionam válvulas automaticamente quando determinada temperatura é atingida. 
Em empresas de manufatura discreta que utilizam ordens de produção ${ }^{1}$, a aplicação da coleta automática de dados é mais recente. A situação atual observada nestas empresas quanto aos dados de chão de fábrica é exibida na figura 1.1.

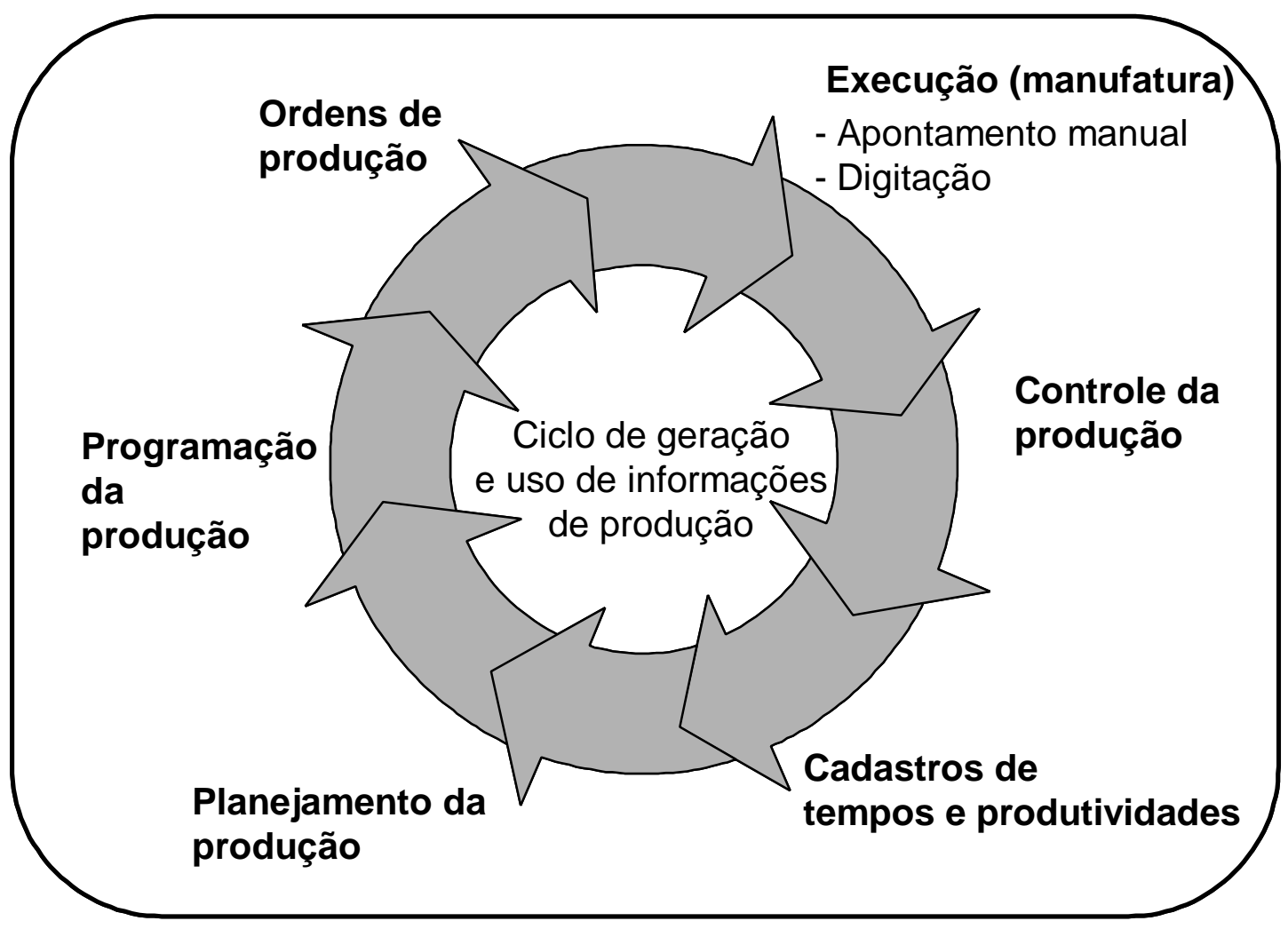

FIGURA 1.1: Ciclo de geração e uso de dados de chão de fábrica

A interpretação deste ciclo pode ser iniciada pelo ponto onde as ordens de produção são geradas, com a finalidade de informar o chão de fábrica sobre o que, quanto, quando e como produzir, para atender a demanda.

As ordens de produção servem então como instruções à manufatura. Os resultados da manufatura são itens acabados ou intermediários, que precisam ser controlados quanto às quantidades e tempos de produção, entre outros. Isto é necessário para o confronto daquilo que foi planejado com aquilo que foi realmente

${ }^{1} \mathrm{O}$ termo ordem de produção varia entre empresas, sendo também utilizados ordem de fabricação e requisição de fabricação, entre outros. 
produzido, permitindo a correção de desvios ou ações gerenciais para evitar que os erros sejam repetidos.

Nesta etapa do processo de produção, os próprios operadores dos equipamentos geralmente fazem anotações (apontamentos), indicando a produtividade, motivos e tempos de paradas e horários de início e término de operações, entre outros. Estas anotações podem conter imperfeições e imprecisões, devido as seguintes fatores:

- O registro é feito ao final de uma operação ou turno de trabalho, o que requer que o operador memorize alguns dados para depois registrá-los;

- Falta de procedimentos e sistemática adequados para realização do apontamento;

- Falta de equipamentos de medição adequados (contadores, cronômetros e outros);

- Falta de ferramentas e meios adequados para anotações e realização de registros;

- Falta de habilidade ou atenção do operador;

- Encobrimento de problemas, visto que a remuneração do operador pode estar diretamente relacionada à sua produção ou produtividade.

Este apontamento manual deve ser digitado em um sistema de informação, que irá disponibilizar estas informações com algum atraso (o tempo entre a produção e a informação estar disponível, passando pela digitação).

Com as informações dos apontamentos, é feito o controle da produção, que basicamente compara o que foi planejado com o que realmente aconteceu. As informações de controle são utilizadas para abastecer cadastros de tempos e de produtividades, que auxiliam o planejamento da produção. Estes cadastros fornecem tempos médios e históricos das operações, além da produtividade dos equipamentos e operadores. Estas informações também podem abastecer cadastros tecnológicos e de engenharia.

Um dos processos da Gestão da Produção é o planejamento da produção, que prevê meios para o atendimento da demanda prevista de um período, utilizando as informações dos cadastros citados acima, e gerando as ordens de produção. $\mathrm{O}$ 
resultado do planejamento é expresso pelas necessidades de produção. Estas são utilizadas na programação da produção, que faz um confronto com as restrições de chão de fábrica (disponibilidade dos recursos e processos tecnológicos), gerando o programa de produção.

O programa de produção apresenta as seqüências de produção, tanto para um produto como para um equipamento de produção. Na maior parte das empresas de manufatura discreta, estas sequiências são passadas ao chão de fábrica através das ordens de produção.

A efetivação destas ordens, através da sua execução nos equipamentos de produção inicia novamente o ciclo apresentado.

Caso estas informações sejam geradas contendo imprecisões e imperfeições, estes problemas irão percorrer todo o ciclo e realimentá-lo com uma visão não real do chão de fábrica, criando um ciclo vicioso ou uma seqüência de erros.

O emprego de tecnologias de coleta automática de dados de produção tem potencial para eliminar alguns dos problemas dos apontamentos manuais apresentados. Entretanto, a simples aplicação destas tecnologias não resolve os problemas de forma satisfatória. Melhores resultados podem ser obtidos com aplicações mais abrangentes, que sejam integradas com outras soluções.

Para aplicação destas tecnologias e soluções, é necessária uma referência, que indique como isto pode ser feito, sistematizando e disponibilizando um conhecimento que já foi desenvolvido. Esta referência pode ser conceitual ou prática, e deve permitir que futuros usuários tenham conhecimento de formas de aplicação usuais ou que já foram testadas.

\subsection{Objetivos}

O principal objetivo deste trabalho é propor um modelo conceitual para o processo de Planejamento e Controle da Produção de empresas de manufatura discreta, que leve em consideração a coleta automatizada de dados de chão de fábrica. Por manufatura discreta são entendidos processos de produção de lotes prédefinidos e de produtos variados, distinto do processo de produção contínuo. Este 
tipo de coleta de dados é proposto por ter potencial de eliminar alguns dos problemas apresentados anteriormente.

O foco deste modelo é a descrição do fluxo de informações, salientando suas novas possibilidades em comparação com os modelos conceituais existentes. Além dos processos de PCP, o modelo apresentará outros processos que se relacionem diretamente com este, como os processos de gestão de materiais e expedição.

Para se atingirem os objetivos, foi necessário analisar o uso de outros sistemas e tecnologias de informação, que possam contribuir para um melhor e mais abrangente tratamento e disponibilização de informações de chão de fábrica no processo de Gestão da Produção. Estas informações serão consideradas pois podem ampliar os benefícios da coleta automatizada de dados de produção.

As outras tecnologias analisadas são:

- Monitoramento da produção;

- Sistemas de Planejamento das Necessidades da Empresa (Enterprise Resources Planning - ERP);

- Sistemas de otimização da programação da produção e

- Sistemas de tratamento e armazenamento de informações (Data Warehouse) e elaboração de relatórios gerenciais.

\subsection{Justificativa}

Na Gestão da Produção, caso as informações de chão de fábrica não sejam tratadas da forma adequada, uma série de problemas pode ocorrer, sendo que o principal deles é a impossibilidade de recuperação de informações para consultas. Isto faz com que decisões sejam tomadas com base em informações desatualizadas e que podem conter imprecisões. No caso da disponibilização das informações não ser adequada, poderão ocorrer atrasos e pode ser necessário esforço para obtê-las. Este esforço é relacionado à necessidade que as pessoas terão, para entrar em contato com outras pessoas, deslocar-se ou procurar estas informações. 
Existem atualmente diversas técnicas e ferramentas para obtenção, tratamento e armazenamento de informações de chão de fábrica, como o apontamento manual, o emprego de sensores nos equipamentos de produção e coletores de dados.

Geralmente estas técnicas e ferramentas são usadas de forma isolada, somente para controle local sem ligação estreita com o processo de Gestão da Produção, ou com integrações limitadas. Neste sentido, este trabalho se apóia na integração de diversas tecnologias e ferramentas, para que as informações de chão de fábrica atendam as necessidades das empresas em relação à competitividade.

O modelo proposto formaliza o uso e integração dos sistemas e tecnologias apresentadas, permitindo sua utilização efetiva no processo de Gestão da Produção, contribuindo na manutenção ou obtenção de vantagens competitivas para empresas de manufatura discreta.

É proposto um modelo conceitual que possa ser utilizado como referência por empresas que desejem implantar parte ou todos os processos apresentados, ou que desejem atualizar soluções existentes. Caso não seja utilizada uma referência, as empresas podem não vislumbrar todas as possibilidades, ou utilizar soluções e modelos parciais. Como parte das empresas existentes não desenvolvem este tipo de pesquisa, a forma que elas possuem de conhecer uma aplicação é através destes modelos conceituais.

Alguns destes modelos que serão analisados no decorrer deste trabalho não consideram formas de coleta automática de dados de produção, e seu posterior tratamento e disponibilização. Portanto, o objetivo deste trabalho é criar um modelo conceitual atualizado, considerando as tecnologias disponíveis atualmente. 


\section{METODOLOGIA DE PESQUISA}

\subsection{Metodologia científica}

O ser humano é dotado da capacidade de conhecer e pensar, isso constitui não somente uma capacidade, mas também uma necessidade (RUIZ, 1993). A pesquisa é uma das formas de se obter o conhecimento. Existem diferentes classificações do conhecimento, como sensorial, intelectual e vulgar, e conhecimento intuitivo e científico.

Diversamente do que acontece com o conhecimento vulgar, o conhecimento científico não atinge somente os fenômenos na sua manifestação global, mas os atinge em suas causas, na sua constituição íntima, caracterizando-se desta forma, pela capacidade de analisar, de explicar, de desdobrar, de justificar, de induzir ou aplicar leis, de predizer com segurança eventos futuros (RUIZ, 1993).

Além destes, existem outros tipos de conhecimentos, como a intuição, que é uma espécie de conhecimento que, pela característica de atingir o objeto sem "meio" ou sem os intermediários das comparações, assemelha-se ao fenômeno do conhecimento sensorial. (RUIZ, 1993).

A obtenção do conhecimento pode se dar de diversas formas, relacionadas com o tipo do mesmo. Existe uma grande discussão em torno de como, ou seja, qual formalismo deve ser usado para que esta obtenção seja padronizada, e tenha chances de obter bons resultados. Para tal, existem metodologias específicas.

O método é estabelecido e aprimorado pela contribuição cumulativa, e não pode ser abandonado (RUIZ, 1993). Existem dois métodos para a pesquisa: o racional e o indutivo. No método racional é usado pensamento dedutivo quando, a partir de enunciados mais gerais dispostos ordenadamente como premissas de um raciocínio, chega a uma conclusão particular ou menos geral. Quanto ao método indutivo, a indução é um processo de raciocínio inverso ao processo dedutivo, partindo do registro de fatos singulares ou menos gerais para chegar a conclusão desdobrada ou ampliada em enunciado mais geral.

Segundo FLEURY e VARGAS (1994), a metodologia não pode ser considerada como simples coleção de métodos ou técnicas. É uma disciplina cujo 
objetivo consiste em analisar as características dos vários métodos disponíveis, em avaliar suas capacidades, potencialidades, limitações ou distorções e em criticar os pressupostos ou as implicações de sua utilização. Lida com a avaliação de técnicas de pesquisa e com a geração ou experimentação de novos métodos que dizem respeito tanto à observação quanto à projeção.

\subsection{Visão geral de metodologias de pesquisa}

Segundo GIL (1988), pesquisa é o procedimento racional e sistemático que tem como objetivo proporcionar respostas aos problemas que são propostos. Para PÁDUA (1996), a pesquisa também é uma atividade relacionada à solução de problemas, que permite elaborar um conhecimento ou conjunto de conhecimentos.

Para FLEURY e VARGAS (1994), o processo de pesquisa é decomposto nas seguintes etapas:

- Definição do problema;

- Delimitação do objeto observado;

- Formulação de hipóteses;

- Escolha de métodos e técnicas para obter os dados e verificar as hipóteses;

- Observação, experimentação, obtenção de dados e processamentos e

- Verificação das hipóteses e formulação dos resultados.

Uma dificuldade encontrada em muitos trabalhos de pesquisa consiste na falta de articulação dos lados teórico e empírico. Esta articulação praticamente não existe quando o trabalho se apresenta em duas partes distintas. Nesse caso, não há formulação de hipóteses que seriam uma ligação pela qual as idéias e os dados entrariam em relação (FLEURY e VARGAS, 1994).

Para PÁDUA (1996), o desenvolvimento da pesquisa envolve quatro etapas, que são:

- O projeto da pesquisa;

- A coleta de dados; 
- Análise dos dados e

- Elaboração escrita.

GIL (1988) também apresenta etapas para o desenvolvimento das atividades de pesquisa, porém mais detalhadas, sendo que a principal distinção é feita em etapas relacionadas ao tipo de pesquisa, que influenciará em outras atividades.

O início do projeto de pesquisa é realizado com a definição do problema e da hipótese. Para GIL (1988), o problema a ser formulado é definido como uma questão não resolvida e que é objeto de discussão, em qualquer domínio do conhecimento. PÁDUA (1996) afirma que a identificação e formulação do problema não são processos fáceis, que acontecem ao acaso; ao contrário, exigem uma reflexão crítica do pesquisador.

A hipótese é uma expressão susceptível de ser declarada falsa ou verdadeira, que oferece uma solução possível ao problema proposto (GIL, 1988). De acordo com PÁDUA (1996), a hipótese propõe uma solução para o problema levantado pelo pesquisador, e constitui uma interpretação provisória, antecipada, que a pesquisa irá confirmar ou informar. A autora classifica as hipóteses em dois grupos: descritivas e analíticas.

Segundo GIL (1988), a elaboração de uma hipótese é um processo criativo, que pode usar os seguintes elementos: observação, resultados de outras pesquisas, teorias e intuição. As hipóteses podem ser dos tipos:

- Casuísta;

- Referente à freqüência de acontecimentos;

- Relação de associação entre variáveis e

- Relação de dependência entre variáveis.

GIL (1988) afirma que as pesquisas podem ser de três tipos.

O primeiro tipo é a pesquisa exploratória, que tem como objetivo proporcionar maior familiaridade com o problema, com vistas a torná-lo mais explícito ou a construir hipóteses. Pode-se dizer que estas pesquisas têm como objetivo principal o aprimoramento de idéias ou a descoberta de intuições. 
A pesquisa descritiva é outro tipo de pesquisa. O seu objetivo principal é a descrição das características de determinada população ou fenômeno ou, então, o estabelecimento de relações entre as variáveis. Um dos estudos que pode ser classificado como descritivo é a observação sistemática.

O último tipo é a pesquisa explicativa, que tem como objetivo identificar os fatores que determinam ou que contribuem para a ocorrência dos fenômenos. Este é o tipo de pesquisa que mais aprofunda o conhecimento da realidade, porque explica a razão das coisas.

Para a classificação das pesquisas em seus tipos, é necessário que seja feito o seu delineamento, ou seja, o planejamento da pesquisa em sua dimensão mais ampla, envolvendo tanto a diagramação quanto a previsão de análise e interpretação de coleta de dados.

O procedimento mais importante para a identificação de um delineamento é o procedimento adotado para a coleta de dados. Assim, podem ser definidos dois grandes grupos de delineamentos: aqueles que se valem das chamadas fontes de "papel" e aqueles cujos dados são fornecidos por pessoas. No primeiro grupo estão a pesquisa documental e a pesquisa bibliográfica. No segundo grupo estão: a pesquisa experimental, a pesquisa ex-post-facto, o levantamento e o estudo de caso (GIL, 1988).

A seguir serão apresentadas classes de coletas de dados, e a seguir um tópico sobre a análise de dados.

\subsubsection{Classes de coleta de dados}

\subsubsection{Pesquisa bibliográfica}

A pesquisa bibliográfica é caracterizada pela consulta a material bibliográfico já existente, que mostra o que já foi produzido e registrado sobre o tema (GIL, 1988, PÁDUA, 1996).

Desde que se tenha decidido que a solução de determinado problema deverá ser procurada a partir de material já elaborado, procede-se à pesquisa bibliográfica. Seu delineamento consiste nas seguintes fases (GIL, 1988):

- Determinação dos objetivos; 
- Elaboração do plano de trabalho;

- Identificação das fontes;

- Localização das fontes e obtenção do material;

- Leitura do material;

- Tomada de apontamentos;

- Confecção das fichas e

- Redação do trabalho.

\subsubsection{Pesquisa documental}

A pesquisa documental é aquela realizada a partir de documentos, considerados cientificamente autênticos (PÁDUA, 1996). Difere da pesquisa bibliográfica basicamente pela natureza das fontes, sendo que a documental utiliza materiais que ainda não receberam um tratamento analítico, ou que ainda podem ser reelaborados de acordo com os objetivos da pesquisa (GIL, 1988).

Como esta pesquisa se assemelha com a bibliográfica, as fases para o seu delineamento são parecidas. Estas são (GIL, 1988):

- Determinação dos objetivos;

- Elaboração do plano de trabalho;

- Identificação das fontes;

- Localização das fontes e obtenção do material;

- Tratamento dos dados;

- Confecção das fichas e

- Redação do trabalho.

\subsubsection{Pesquisa experimental}

De um modo geral, o experimento representa o melhor exemplo de pesquisa científica. Essencialmente, a pesquisa experimental consiste em determinar um objeto de estudo, selecionar as variáveis que seriam capazes de influenciá-lo, definir as formas de controle e de observação dos efeitos que a variável produz no objeto 
(GIL, 1988). Estas variáveis devem determinar a relação causa-efeito proposta na hipótese (PÁDUA 1996).

As fases para a realização da pesquisa experimental são (GIL, 1988):

- Formulação do problema;

- Construção das hipóteses;

- Operacionalização das variáveis;

- Definição do plano experimental;

- Determinação dos sujeitos;

- Determinação do ambiente;

- Coleta de dados;

- Análise e interpretação dos dados e

- Redação do trabalho.

\subsubsection{Pesquisa ex-post-facto}

$\mathrm{Na}$ pesquisa ex-post-facto, tem-se um "experimento" que se realiza depois dos fatos. Não se trata exatamente de um experimento, pois o observador não tem controle sobre as variáveis (GIL, 1988).

O planejamento deste tipo de pesquisa procura aproximar-se ao máximo do planejamento da pesquisa experimental. Contudo, a manipulação de variáveis independentes não é possível nesse tipo de pesquisa. As fases para essa realização são os seguintes (GIL, 1988):

- Formulação do problema;

- Construção das hipóteses;

- Operacionalização das variáveis;

- Localização dos grupos para investigação;

- Determinação dos sujeitos;

- Determinação do ambiente;

- Coleta de dados; 
- Análise e interpretação dos dados e

- Redação do trabalho.

\subsubsection{Levantamento}

O levantamento tem como característica a interrogação direta das pessoas cujo comportamento se deseja conhecer (GIL, 1988).

Segundo GIL (1988), as fases para a realização de um levantamento são as seguintes:

- Determinação dos objetivos;

- Operacionalização dos conceitos e variáveis;

- Elaboração do instrumento de coleta de dados;

- Pré teste do instrumento;

- Seleção da amostra;

- Coleta e verificação dos dados;

- Análise e interpretação dos dados e

- Apresentação dos resultados.

\subsubsection{Estudo de caso}

Este tipo de pesquisa é realizado pelo estudo profundo e exaustivo de um ou poucos objetos, de maneira que permita o seu amplo e detalhado conhecimento, tarefa praticamente impossível mediante os outros delineamentos considerados (GIL, 1988). Além disso, pode complementar a coleta de dados em trabalhos acadêmicos (PÁDUA, 1996).

O estudo de caso é bastante flexível. Isto significa que é impossível estabelecer um roteiro rígido que determine com precisão como deverá ser desenvolvida a pesquisa. Contudo, podem ser identificadas as seguintes fases (GIL, 1988):

- Delimitação da unidade-caso;

- Coleta de dados;

- Análise e interpretação dos dados e 
- Redação do trabalho.

\subsubsection{Análise dos dados coletados}

Esta etapa do trabalho de pesquisa acorre após a coleta dos dados. Para tal é exigida criatividade, para que o trabalho não se torne uma compilação dos dados coletados (PÁDUA, 1996).

Para esta etapa, GIL (1988) especifica atividades que devem ser feitas para cada um dos tipos de coleta de dados. PÁDUA (1996) generaliza estas atividades, que envolvem:

- Classificação e organização das informações coletadas;

- Estabelecimento das relações existentes entre os dados e

- Tratamento estatístico dos dados, quando necessário.

A atividade de classificação dos dados deve relacionar os dados coletados com a estrutura do trabalho sendo realizado. A organização dos mesmos permite uma visão de conjunto da pesquisa, proporcionando ao pesquisador a possibilidade de avaliar se existe necessidade de complementação dos dados (PÁDUA, 1996).

Quanto ao estabelecimento de relações, PÁDUA (1996) sugere o emprego de categorias, que podem ser utilizadas para o agrupamento de elementos, idéias ou expressões em torno de conceitos capazes de abranger todos os aspectos dos dados coletados e do trabalho de pesquisa.

Os dados devem ser interpretados, e procurados novos relacionamentos entre eles, a partir das diretrizes das hipóteses e da relação que a hipótese mantém com o sistema teórico proposto (PÁDUA, 1996). A análise e interpretação dos dados são atividades relacionadas, porém com especificidades em função do tipo de projeto de pesquisa (GIL, 1988).

\subsection{Procedimento adotado}

\subsubsection{Desenvolvimento}

Para o desenvolvimento deste trabalho, foi feita uma adequação dos métodos de pesquisa e formas de coleta de dados apresentadas. $\mathrm{O}$ método utilizado foi o 
indutivo, segundo a definição de RUIZ (1993), e a classe de coleta de dados é a experimental, segundo a definição de PÁDUA (1996). O procedimento adotado é apresentado na figura 2.1 .

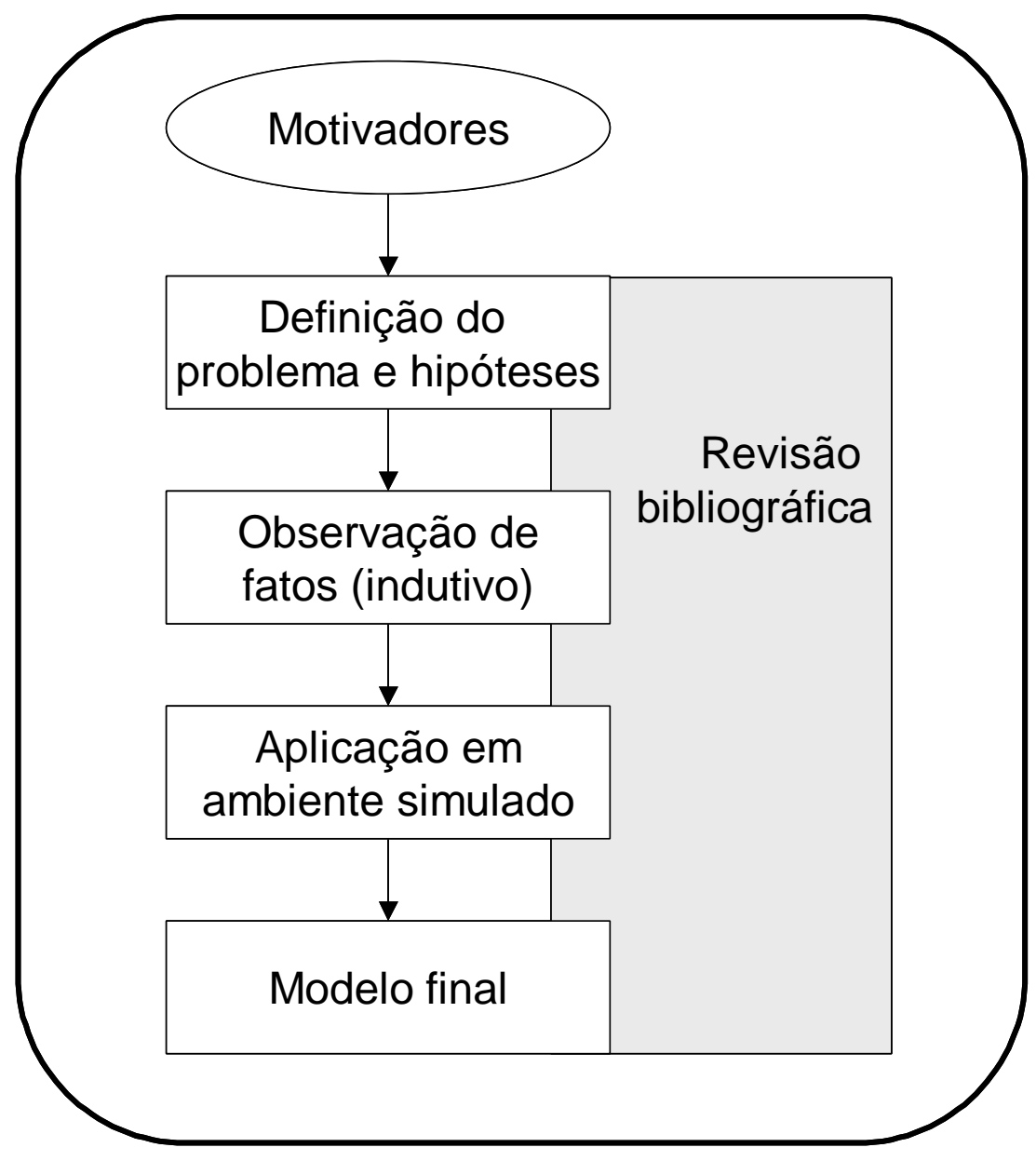

FIGURA 2.1 - Procedimento adotado para o desenvolvimento do trabalho

Um dos motivadores deste trabalho foi a análise de problemas ocorridos em grande número de empresas visitadas pelo autor, relativos à baixa qualidade e atraso das informações disponíveis do chão de fábrica. Outro motivador foi o acompanhamento da implantação de soluções localizadas em empresas de manufatura discreta, na prática e em ambientes simulados. A aplicação prática ocorreu em empresa fabricante de autopeças, contando com a implantação de sensores em uma linha de produção e um sistema de supervisão para visualização e armazenamento dos dados coletados do chão de fábrica. Estas análises permitiram a formulação do problema e das hipóteses. 
A revisão bibliográfica acompanha todo o desenvolvimento deste trabalho. Em um momento inicial foi feita pesquisa sobre os temas básicos, relacionados à gestão da produção, monitoramento e supervisão da produção e tratamento de informações para o processo de GP. Quatro modelos conceituais de Gestão da Produção foram analisados. Em todos eles, a coleta automatizada de dados de chão de fábrica através de sensores, o tratamento destes e seu uso para suporte à tomada de decisão não são contemplados.

Para resolução do problema proposto, baseado no método indutivo, foram feitas pesquisas e observações de alguns fatos:

- Análise mais detalhada da implantação citada em empresa de autopeças;

- Possibilidades observadas na implantação realizada pelo grupo de Otimização dos Processos de Fabricação do NUMA, para supervisão de retíficas através de sensoreamento acústico;

- Possibilidades observadas durante o desenvolvimento de um projeto de análise de viabilidade econômica e técnica de um sistema de supervisão em empresa metalúrgica de autopeças;

- Análise da integração de sistema ERP com bancos de dados coletados automaticamente de chão de fábrica e

- Aplicação de sistemas de Data Warehouse para geração de relatórios com indicadores pré-definidos, especificamente índices de produtividade e eficiência dos recursos produtivos.

Uma solução inicial foi então implantada em um ambiente simulado, chamado Fábrica Integrada Modelo (FIM), um projeto do Núcleo de Manufatura Avançada (NUMA) da Escola de Engenharia de São Carlos (EESC) da Universidade de São Paulo (USP). A aplicação na FIM foi baseada nos modelos conceituais existentes, com as adaptações necessárias. Várias restrições, especificidades e funcionalidades puderam ser observadas.

Para esta aplicação foi criado um cenário, integrando o trabalho de sete grupos de pesquisa de áreas relacionadas, e desenvolvida uma apresentação onde os visitantes são tratados como em visita a uma empresa, e recebem scripts (papéis a 
serem desenvolvidos) que os tornam parte integrante da apresentação. São então exibidos conceitos e sistemas envolvidos no modelo proposto, com ênfase no fluxo de informações e integrações.

Esta aplicação em ambiente simulado permitiu definir o resultado final, um modelo conceitual da aplicação da coleta automática de dados de chão de fábrica nos processos de gestão da produção.

As apresentações foram presenciadas por diversos alunos e empresários. O Sr. Murilo Bevilaqua, Diretor Geral da Exata Sistemas de Automação, em relação à visita a Fábrica Integrada Modelo, afirmou: “... a análise do problema foi bem estruturada e abrangeu problemas que são comuns a grande parte das empresas. Os pontos incluídos na coleta de dados, em especial o item de tempo de ciclo, são os pontos que todo supervisor de área ou gerente de produção necessitam para tomadas de decisões...".

Concluindo, a pesquisa indutiva é caracterizada, pois a partir da observação de fatos isolados chegou-se a um modelo geral. Como complemento, foi adotada a classe de coleta de dados da pesquisa experimental, realizada com o caso da implantação de uma solução em ambiente simulado (a FIM).

\subsubsection{Definição do problema e hipóteses}

O ponto de partida da pesquisa é uma constatação, formulada através de um problema. No presente trabalho, o problema encontrado é apresentado na forma da questão:

Os modelos conceituais de gestão da produção largamente utilizados e aceitos servem de referência para a utilização e implantação das novas tecnologias de coleta, análise e tratamento de dados de chão de fábrica?

Esta falta de suporte é suposta devido aos seguintes fatos:

- Os modelos em uso consideram que os dados e informações de chão de fábrica são precisos e disponíveis no momento necessário;

- Os modelos não abordam a forma como os dados são coletados. Desta forma, é indistinto se este processo de coleta é completamente manual ou altamente automatizado; 
- O tratamento e a disponibilização dos dados coletados não são considerados e

- A aplicação do sensoreamento em equipamentos de produção para coleta automática de dados foi originada em processos e contínuos, e sua aplicação em processos discretos é mais recente.

Chegou-se a este problema através de leituras científicas que o mencionam claramente (CAETANO, 1999, MEIRELES, 2000 e SOARES, 2000), e de reclamações e constatações ocorridas em visitas e projetos realizados pelo autor e pela equipe de pesquisa do NUMA. O ciclo que gera esta situação foi apresentado na introdução deste trabalho. Este problema tem motivado diversas pesquisas em várias áreas, porém poucas apresentam integrações entre diferentes soluções para resolver ou amenizar o problema. A maioria das soluções apresentadas é localizada e específica.

A solução de integração proposta não foi encontrada na literatura científica e comercial (fabricantes e integradores de sistemas e equipamentos).

Seguindo a abordagem de FLEURY e VARGAS (1994), a próxima etapa é delimitar o domínio ou escopo do problema. De acordo com o objetivo da pesquisa, são analisadas empresas de manufatura discreta, com escopo limitado àquelas que utilizem o conceito de ordens de produção. Esta definição cabe a uma parcela significativa das empresas brasileiras. A análise do problema também será limitada aos processos de Gestão da Produção, principalmente aqueles relacionados ao planejamento e controle da produção.

Seguindo as metodologias apresentadas, deve ser feita a definição das hipóteses, que expressam a concepção inicial do pesquisador sobre o problema, devendo ser revistas após a conclusão da pesquisa. As hipóteses são:

- H1: O apontamento manual pode ser substituído, pelo menos em parte, pela coleta automatizada de dados de chão de fábrica, em empresas de manufatura discreta;

- H2: O uso de tecnologias e sistemas complementares (sistemas ERP e de Data Warehouse) à coleta automatizada de dados do chão de fábrica 
pode trazer importantes mudanças para o planejamento e controle da produção;

- H3: A implantação da coleta automática de dados de chão de fábrica, e conseqüente disponibilização destes dados pode modificar a forma de realização de atividades relativas à gestão da produção em empresas de manufatura discreta;

- H4: Uma classe de decisões da gestão da produção da empresa, em função da dinâmica do ambiente e da concorrência, necessita de informações precisas e rápidas, em alguns casos até on-line, para garantir sua qualidade;

- H5: A geração de relatórios de forma fácil, de acordo com as necessidades do usuário, e de preferência sem necessidade de intervenção de pessoal especializado facilita a tomada de decisões para a gestão da produção e

- H6: Um modelo conceitual que considere as tecnologias e sistemas de coleta de dados e seus complementares pode facilitar e ampliar o uso destes, trazendo uma melhoria para a Gestão da Produção em empresas de manufatura discreta.

A próxima etapa do desenvolvimento do trabalho se refere à escolha do método e das técnicas para coleta e avaliação dos dados, ou como a pesquisa será realizada, no caso, de forma experimental. O experimento realizado foi a implantação de uma solução em ambiente simulado. Neste foram avaliadas variáveis e situações que permitiram a construção do modelo proposto. 


\section{REVISÃO BIBLIOGRÁFICA}

\subsection{Gestão da produção}

A gestão da produção envolve todos os processos relacionados à produção em uma empresa de manufatura. O ambiente competitivo destas empresas está se tornando cada vez mais disputado (CORREA et al. 1997, YU 1997), fazendo com que a busca por melhorias no processo de gestão da produção se dê em várias iniciativas. Entre estas melhorias, a busca por uma alta eficiência dos recursos produtivos, como forma de maximizar o rendimento operacional, é freqüentemente perseguida em muitas empresas. Este modo de pensar está fundamentado na idéia de que, ao se utilizar todos os recursos ao máximo, os ganhos econômicos são maiores (SOUZA, 1999). Uma alternativa para obtenção de uma boa posição competitiva é a utilização de um processo estruturado de gestão da produção e inventários (VOLLMANN et. al., 1993).

Segundo PORTER (1999), outra alternativa para obtenção de vantagens competitivas, que praticamente todas organizações perseguem é a mudança da produção contínua para uma produção "intermitente para contínua", alcançando benefícios da economia de escala, e ao mesmo tempo oferecendo grandes possibilidades de customização para seus produtos.

As empresas de manufatura têm sofrido um aumento considerável na pressão competitiva, expresso por uma necessidade de lead times reduzidos, menores tamanhos de lotes e estoques baixos. Aliado a isso, os clientes estão cada vez mais exigentes por produtos personalizados e de baixo custo (PORTER 1996, LINDAU 1994). Por outro lado, existe uma defasagem entre as reais necessidades competitivas das empresas de manufatura e suas práticas usuais, geralmente substanciadas por seus indicadores de desempenho adotados (SOUZA, 1999).

Outra forma encontrada por algumas empresas para obter melhores respostas e consequentemente posições no mercado, é possuir um elemento de suporte à decisão que trabalhe em tempo quase real, fornecendo conselhos inteligentes e informações para as funções de programação e liberação de ordens, no caso de distúrbios e eventos imprevistos no processo de produção controlado (SIEMIATKOWSKY e 
PRZYBYLSKI, 1997). Neste sentido, HERBON (1998), também afirma que é uma vantagem a possibilidade de reação quase automática a eventos imprevistos.

As principais atividades do processo de gestão da produção são o planejamento, a programação e o controle da produção (CORRÊA, 1997). A integração destas funções determina quão bem a empresa irá atender os seus clientes e ganhar uma posição competitiva no mercado (VOLLMANN et al., 1993). A integração das funções de planejamento e programação da produção pode introduzir melhorias significativas para a eficiência das condições de produção, através da redução de conflitos de programação, redução do tempo de fluxo e dos materiais em processo, aumento da utilização dos recursos de produção e adaptação a eventos irregulares do chão de fábrica (KIM et al., 1997). Embora a estratégia para alcançar os objetivos e metas de produção da organização seja baseada em melhorias contínuas de longo prazo, no curto prazo, gerentes têm que tomar decisões de como reagir aos problemas diários (BRAGG et al., 1999).

\subsubsection{Processos de planejamento, programação e controle da produção}

Segundo PORTER (1999), para que uma empresa encontre uma boa solução para o planejamento, programação e controle da produção, é necessário que seus principais processos de negócio sejam compreendidos.

São encontradas na literatura diversas alternativas, neste sentido SIEMIATKOWSKY e PRZYBYLSKI (1997) apresentam uma proposta de controle do chão de fábrica e planejamento da produção integrados por computador, através da criação de uma arquitetura hierárquica específica, onde são propostos três níveis.

Segundo HERBON (1998) e CORRÊA et al. (1997), o ambiente de manufatura é confrontado com mudanças freqüentes no mix de produção, quebras de equipamentos e prazos de entrega curtos. Neste ambiente, é essencial que o controle da produção seja realizado em tempo hábil, que em alguns casos pode ser em tempo real (MAHALIK, 1997), para reagir automaticamente aos vários eventos que podem ocorrer no chão de fábrica.

O lançamento e revisão de ordens fornecem a interface necessária entre o planejamento da manufatura e o sistema de execução de chão de fábrica. Os sistemas de planejamento geram ordens planejadas para itens, identificando informações de 
tempo e quantidade. Os sistemas de execução implementam os planos fazendo a relação entre os recursos necessários para completar a produção planejada (BRAGG et al., 1999).

Segundo PORTER (1999), pesquisas recentes tem mostrado que uma das áreas chave para todas as empresas de manufatura é a função de controle da produção. $\mathrm{O}$ sistema de controle ideal vai ser montado de um volume de componentes de processos de negócio (building blocks) que são genéricos, mas na sua agregação podem ser únicos para empresas específicas. CHARBONNIER et al. (1999), HEINER (1999), HERBON (1998), FELDMANN e COLOMBO (1998) e PENG e CHEN (1998), entre outros, apresentam alternativas para a integração destes componentes na formação de um sistema de controle de chão de fábrica. TITTUS e LENNARTSON (1999) afirmam que com a introdução de um controle hierárquico, a complexidade desta tarefa diminui.

Uma das críticas feitas aos processos de planejamento da produção é em relação à utilização de lead time, que é o tempo de ressuprimento de um item comprado ou fabricado, estimado para viabilizar o planejamento. De acordo com KANET e SRIDHARAN (1998), na definição destes tempos, ajustes são feitos para cobrir várias fontes de incertezas. Os tempos de processamento podem ser incertos, a movimentação entre operações pode ser incerta, o fornecimento de matérias primas pode ser incerto e os tempos de fila podem ser incertos. O maior contribuinte para que os lead times sejam grandes e inflados são os tempos de espera. Estes devem ser grandes o suficiente para antecipar todos os possíveis atrasos que um componente pode sofrer no chão de fábrica (CORRÊA e GIANESI, 1993). O tempo de execução de uma mesma operação pode variar aleatoriamente ou de acordo com alguma recorrência estatística e, desta forma, os lead times das tarefas serão na verdade valores médios ou esperados dos tempos de processamento (SOUZA, 1999).

SOON (1997) afirma que entre as funções da manufatura, a programação permanece entre as mais importantes e desafiadoras que devem ser executadas rotineiramente. Ela é a alocação dos recursos de produção disponíveis no tempo para atender alguns critérios de performance e ao plano mestre (VOLLMANN et al., 1993). Tipicamente, o problema de programação envolve um conjunto de tarefas a 
serem completadas, onde cada tarefa consiste em uma lista de operações a serem feitas.

\subsubsection{Sistemas de administração da produção}

Os sistemas de administração da produção (SAP) têm o objetivo principal de planejar e controlar o processo de manufatura em todos os seus níveis (CORRÊA e GIANESI, 1997). Os SAP devem gerir o que, quando, quanto e como produzir.

De acordo com CORRÊA et al. (1993), independente da lógica a ser utilizada pela empresa, os sistemas de administração da produção (SAP), para cumprirem o seu papel de suporte ao cumprimento dos objetivos estratégicos da empresa, devem ser capazes de apoiar o tomador de decisões a:

- Planejar as necessidades futuras de capacidade produtiva;

- Planejar os materiais comprados;

- Planejar níveis adequados de estoques;

- Programar atividades de produção;

- Saber e informar corretamente a situação corrente dos recursos e das ordens;

- Fornecer prazos aos clientes e

- Reagir eficazmente.

O conceito de SAP não envolve necessariamente a Tecnologia da Informação (TI) e sistemas computacionais, porém na literatura atual estes conceitos estão praticamente integrados. De acordo com PALVIA (1999), a Tecnologia da Informação tem avançado a uma velocidade revolucionária. A intensificação da competição e globalização, quando combinadas com a IT, tem produzido inovações em aplicações dos sistemas de informações.

Novos componentes da tecnologia de informação (TI), como computadores e sistemas, são planejados (e freqüentemente instalados) para apoio à manufatura, mas com os erros e desapontamentos de implantações de TI anteriores, como pouca participação dos usuários, pouca atenção aos objetivos do negócio ou excessiva necessidade de especialistas em computadores (TAYLOR, 1998). 
Segundo PORTER (1996), um aumento considerável na pressão competitiva entre empresas de manufatura, expresso por lead times reduzidos, menores tamanhos de lote, estoques baixos e clientes mais exigentes, tem empurrado os tradicionais sistemas de cálculo das necessidades de materiais (Material Requirements Planning - MRP) para os seus limites, e também gerado uma demanda por sistemas de controle de curto prazo, entre outros. Isto pode ser obtido através do uso de sistemas de programação com capacidade finita, muitos dos quais não necessitam trabalhar com as saídas de um sistema MRP. Posteriormente, é provável que sejam implantadas funções especiais de controle, particularmente no chão de fábrica, onde o nível de controle local, integrado com o servidor de PCP será comum.

Segundo KANET e SRIDHARAN (1998), apesar dos avanços nas capacidades dos computadores nos últimos 25 anos, existiram poucas mudanças no projeto básico de sistemas comerciais de planejamento de inventários e da produção. Além disso, a produção de artigos que relatam propostas de sistemas que não são testados é grande (REISMAN, 1997).

Um problema associado à utilização de sistemas de informação é a qualidade das informações de entrada. Vários autores apontam este problema, associado ao tempo necessário para que uma informação seja disponibilizada e também ao processo de geração e coleta dos dados. PORTER (1994) afirma que a maior fraqueza encontrada nos SAP é a falta de alguma forma de integração entre ferramentas de controle e os dados operacionais dos equipamentos. Neste sentido, se os dados do chão de fábrica não puderem ser coletados automaticamente, então facilidades especiais devem ser instaladas, caso contrário corre-se o risco de utilizar informações incorretas e atrasadas para alimentação dos sistemas. PENG e CHEN (1998) propõem um modelo para o controle e programação em tempo real, para diminuição destes problemas.

Outro fator relacionado à utilização dos SAP é o tempo de resposta. Neste sentido, sistemas com suporte à consultas em tempo real são atualmente os mais procurados e utilizados (MAHALIK, 1997, MA et al., 2000, EXON-TAYLOR, 1997, PORTER, 1996, SMITH, 1998, YUSUF, 1998)

KALS (1988) propõe um modelo dinâmico de planejamento e controle da manufatura, que parte de vários pressupostos, entre eles, que atualmente informações 
incompletas e duvidosas, principalmente nos níveis de agregação mais altos são largamente utilizadas, causando uma série de problemas.

A estratégia de integração tem o potencial para facilitar a realização da escolha correta para alcançar uma disponibilidade ampla de informações em tempo real, para ter uma vantagem competitiva sobre seus competidores (YUSUF, 1998).

WESTON (1999) apresenta uma classificação hierárquica de sistemas, de uso comum: ERP, MES (Manufacturing Execution Systems), LCS (Line Control Systems), SCADA (System Control \& Data Access) e Equipment Systems. Esta classificação parte dos sistemas mais abrangentes até sistemas dedicados aos equipamentos produtivos.

\subsubsection{Indicadores de performance}

Durante muito tempo, os relatórios financeiros têm sido a base para medidas de performance de negócios. Entretanto, tem sido documentado recentemente que sistemas financeiros são inadequados para empresas inovadores que necessitam medir uma grande variedade de fatores que direcionam a vantagem competitiva (WALKER, 1996).

A medição do desempenho tradicional tem como principal preocupação a medição em termos do uso eficiente dos recursos, sendo que bons resultados neste indicador de desempenho são constantemente perseguidos (SOUZA e PIRES, 1999). Os indicadores de desempenho mais comuns são a produtividade, o retorno sobre o investimento, o custo padrão e outros (MARTINS e COSTA NETO, 1998).

Uma proposta mais abrangente de medição de desempenho é o Balanced Scorecard (WALKER, 1996, MARTINS e COSTA NETO, 1998).

Segundo NEELY et al. (1995), a medição da performance pode ser definida como o processo de quantificar a eficiência e efetividade da ação. Uma medida de performance pode ser definida como a métrica utilizada para quantificar a eficiência e/ou efetividade de uma ação.

Uma utilização eficiente de medidas de desempenho requer que sejam adotados certos procedimentos, geralmente apresentados na forma de sistemas, como os apresentados por ROLSTADAS (1998) e MARTINS (1998). 


\subsection{Monitoramento e supervisão da produção}

Em meio ao crescente desenvolvimento tecnológico, o monitoramento da produção ainda é bastante deficiente. Os dados tecnológicos e de produção, na maior parte dos casos são coletados de forma manual e não retratam a realidade do chão de fábrica. Consequentemente, as informações geradas a partir desses apontamentos manuais são inseridas nos sistemas ERP, que por sua vez geram respostas irreais para análises em um processo de tomada de decisão (SOARES, 2000). Em um ambiente produtivo, a falta de informações confiáveis de chão de fábrica cria uma perspectiva que não retrata a realidade. Um monitoramento que forneça informações de forma rápida e confiável, pode ser um grande diferencial para manter a competitividade das empresas de manufatura (CAETANO et al., 1999)

Os sistemas de monitoramento da produção, responsáveis por esta geração de informações de chão de fábrica estão se tornando inevitáveis, devido à demanda por qualidade e rapidez destas informações (JEMIELNIAK, 1999). Sensores colocados nos equipamentos de produção podem ser integrados a sistemas que criam gráficos em tempo real para monitoramento do processo (SIEGEL, 1997).

BALLARD (1999) cita o lançamento de novas funcionalidades do sistema operacional Microsoft Windows CE, que permitem a sua integração com sistemas de controle em tempo real, desenvolvidos em padrões abertos. Este sistema pode oferecer soluções não caras de ferramentas para monitoramento em tempo real. Com isso, mais aplicações de integrações, que hoje são difíceis de serem consideradas, como acesso a dados de equipamentos em tempo real pela Internet, serão desenvolvidas.

Segundo CAETANO et al. (1999), em indústrias de manufatura, sistemas de monitoramento não são amplamente utilizados, e suas aplicações são dedicadas e específicas para resolução de alguns problemas.

Os dados coletados neste tipo de sistema podem ser de vários tipos. SOARES (2000) apresenta como exemplos análises reais de produtividade e situação (status) da produção. Segundo MEIRELES et al. (2000), um sistema de supervisão pode coletar informações tecnológicas e de produção. Referindo-se a alguns exemplos de dados tecnológicos coletados, cita os tempos de ciclo e de paradas, número de peças 
produzidas e motivos de paradas. CAETANO et al. (1999), afirma que para cada ordem de produção podem ser coletados conjuntos de informações sobre o que foi realizado, como: tempos de execução e de máquinas paradas e quantidades produzidas.

O monitoramento é feito através da utilização dos seguintes componentes: sensores, condicionadores, amplificadores e monitores. Este último analisa os sinais dos sensores para fornecer informações. (JEMIELNIAK, 1999).

Os sinais que são transformados nos dados coletados, podem ser captados por sensores ou diretamente através dos painéis de controle e botões dos equipamentos (SOARES, 2000). O uso de sensores para monitoramento fornece informações precisas e confiáveis.

SIEGEL (1997), afirma que equipamentos com controle computadorizado, como os equipamentos de controle numérico, facilitam a instalação de sensores para monitoramento de algumas variáveis do processo produtivo.

Existem diversos tipos de sensores comerciais e apresentados em pesquisa. Segundo JEMIELNIAK (1997), os principais são aqueles relacionados à medição de algum tipo de força (potência e torque, entre outros), ou de emissão acústica, pois são fáceis de serem instalados em equipamentos.

Segundo SOARES (2000), o software de supervisão deve inserir os dados gerados na supervisão em um banco de dados. O volume destes dados é normalmente muito grande, e devido a este fator é sugerida a utilização de ferramentas de Data Warehouse.

Existem algumas formas para classificação dos tipos de sistemas de monitoramento e supervisão.

EVERSHEIM et al. (1997), afirma que muito se fala em sistemas abertos. Como não existe uma padronização definitiva para a utilização do termo "sistemas abertos", muitos fabricantes de sistemas tem empregado esta denominação, com sentidos diferentes. Os autores afirmam que existem dois tipos de abertura: interna (orientada à manufatura) e externa (orientada aos usuários). Uma das características da abertura interna é a capacidade dos sistemas acessarem dados de controle. 
MAHALIK (1997) faz uma comparação entre um controle distribuído, onde para cada equipamento sensoreado existe um processador, e um controle centralizado, onde as informações de todos os sensores são processadas em um único local. Existe uma tendência para o controle descentralizado, mais apropriado para situações onde os equipamentos estão dispersos, permitindo que sejam tomadas decisões locais.

Segundo LUTTERVELT e PENG (1999), existem 6 formas de controle: controle off line, monitoramento, controle de ciclo fechado, controle de alimentação para frente, controle on line inteligente e controle off line inteligente.

CAETANO et al. (1999) apresenta uma solução denominada Sistema de Monitoramento, Supervisão e Diagnóstico da Produção, composta dos seguintes módulos funcionais:

- Monitoramento da produção: faz o sensoreamento e coleta em tempo real dos dados de produção;

- Supervisão da produção: análise dos dados coletados;

- Repositório de informações da produção: armazena as informações da produção e

- Diagnóstico do chão de fábrica: trata as informações tecnológicas.

\subsection{Tratamento de informações para gestão da produção}

De acordo com VOLLMANN et al. (1993), mesmo em empresas pequenas, a gestão da produção requer sistemas computadorizados, pois o volume de informações processadas para planejar e controlar o fluxo de materiais é enorme. Estas informações devem ser precisas, acuradas, no tempo correto e no formato apropriado. Para RAI (1997), além do volume, deve ser tratada a complexidade dos dados.

O dado, como bem da empresa, deve ser armazenado, atualizado, compartilhado e disponibilizado. Além disso deve ser de fácil interpretação e exato. Quando este dado é processado para um determinado fim, se transforma em informações, que fornecem aos usuários subsídios para tomada de decisões e 
avaliações de resultados (SOARES, 2000). Nesta linha, CORRÊA et al. (1996) afirmam que as informações necessárias ao planejamento da produção devem ser precisas, corretas e atualizadas. Estas necessidades dificilmente são supridas em ambientes onde a coleta de dados é feita através de apontamentos manuais que são digitados posteriormente.

A disponibilidade de informações em tempo real é sempre citada como parâmetro de eficiência. PORTER (1996), afirma que no futuro todas as funções dos sistemas de PCP deverão trabalhar com informações em tempo real. No modelo de controle da produção proposto por KIM (1997), entre as vantagens apresentadas, está a possibilidade de utilização de informações da situação da produção em tempo real, o que permite um vigor na tomada de decisões relacionadas às falhas. YUSUF (1998) afirma que a diferença na obtenção de uma vantagem competitiva na manufatura é ter uma infra-estrutura que possa fornecer informações corretas e em tempo real, aonde quer que elas sejam necessárias.

Uma tendência na indústria de manufatura é a diminuição de lead-times, o que torna maior a sensibilidade a atrasos, paradas e desvios. O estudo conduzido por LINDAU (1994) mostra como a introdução de informações em tempo real para os programadores, na fabricação de componentes para montadoras de automóveis afeta a performance da empresa. Como resultado é mostrado que a performance de um sistema que usa informações seqüenciais é inferior à performance de um sistema que utiliza informações de controle de chão de fábrica em tempo real.

Entretanto, níveis diferentes de gerenciamento de uma empresa requerem níveis diferentes de suporte ao tratamento de informações. ROOKS (2000) afirma que na maioria das empresas, existe uma divisão entre sistemas no nível de produção e aqueles de nível gerencial, sendo que o fluxo de informações entre estes é feito primariamente por transferência de papéis. A gerência necessita de acesso em tempo real para dados consolidados de produção. Além de diferentes níveis, existem diferentes áreas de decisões especializadas (JAYARAMAN e SRIVASTAVA, 1996), entre elas o monitoramento (interpretação contínua de sinais) e o planejamento (criação de programas de ação).

De acordo com WALKER (1996), não se pode esperar que a alta gerência converta massas de dados em informações para tomada de decisões para a vantagem 
competitiva. Eles precisam de ajuda para relacionar, encontrar e modelar estes dados. HADAVI (1997) afirma que uma vez que os dados estejam corretos e completos, e os procedimentos corretos forem escolhidos, então os sistemas de planejamento e programação da produção têm o potencial de oferecer muitas oportunidades em termos de fazer as decisões corretas e otimizar a performance do chão de fábrica, assim como de toda a cadeia de suprimentos. SPEIR et al. (1999), entretanto, alertam para o perigo de fornecimento de um volume muito grande de informações às pessoas que tomam as decisões, podendo causar um efeito chamado de information overload.

EOM (1999) afirma que atualmente, os sistemas de suporte a decisão (DSS) são equipados com uma variedade de ferramentas, como gráficos, modelagem interativa visual, técnicas de inteligência artificial, lógica fuzzy e algoritmos genéticos. Entre estas ferramentas também estão o Data Warehouse e Data Mining. Este tipo de sistema atende uma condição colocada por VOLLMANN et al. (1993), onde os próprios usuários devem ser capazes de configurar sistemas e relatórios, para atender às suas necessidades, sem necessidade de intervenção de pessoal especializado.

\subsubsection{Data Warehouse e Data Mining}

Data Warehouse (DW) é um depósito único, completo e consistente de dados obtidos de uma variedade de fontes, e disponibilizados para usuários finais de uma forma que eles podem compreender e usar no contexto do negócio. Foi criado a partir da combinação de dois conjuntos de necessidades: de uma visão mais abrangente das informações da empresa e da necessidade de um melhor gerenciamento dos dados (MA et al., 2000). Além disso, ele é distinto do bando de dados operacional, e orientado a assuntos, facilitando o suporte à decisões (EOM, 1999). Devido a estas características, existe uma tendência que o DW se torne a fonte de informações definitiva para empresas (MA et. Al., 2000). Segundo SCHEER (1998), este é um dos avanços recentes da tecnologia de banco de dados, que habilitará as empresas a armazenar grandes volumes de dados, que pode chegar a gigabytes em um curto espaço de tempo (BALLARD, 1999). 
O Data Warehouse habilita cada usuário não somente a compartilhar bancos de dados comuns, largamente distribuídos e diversos. Além disso, permite explorar analiticamente, descobrir e melhor compreender tendências e relacionamentos, usando todos os dados disponíveis, rápida e precisamente, fornecendo aos usuários informações estratégicas (GARGANO e RAGGAD, 1999).

SCHEER (1998) afirma que o DW é um conceito de sistema de informações executivas, que separa dados operacionais e de suporte à decisão.

O DW liberta a empresa de ter que constantemente programar relatórios e consultas padrões. Com isso, os usuários podem encontrar os dados que necessitam, usando ferramentas fáceis para criar suas próprias consultas (MA et al., 2000). Com isso, o poder e controle sobre a informação deixarão de ser do pessoal especializado em computação, migrando para os usuários finais de diferentes áreas e necessidades (GARGANO e RAGGAD, 1999).

De acordo com SCHEER (1998), quando consultas são feitas, o acesso direto a um DW assegura tempos de resposta rápidos. Outro benefício é que a performance do sistema operacional não é reduzida. GARGANO e RAGGAD (1999) afirmam que a necessidade de consultas em tempo real também é uma força motivadora no desenvolvimento de novos métodos e arquiteturas de DW.

Para SCHEER (1998), uma desvantagem do DW é o esforço envolvido no armazenamento de dados redundantes.

O Data Mining (DM) é o processo de descoberta de novas correlações significativas, padrões e tendências (GARGANO e RAGGAD, 1999). É também chamado de Knowledge Data Discovery (descobrimento de conhecimento em dados), permitindo uma efetividade não obtida no DW (EOM, 1999). Isto é obtido através da filtragem de grandes volumes de dados armazenados em Data Warehouses, e através do uso de tecnologias de reconhecimento de padrões, assim como técnicas estatísticas e matemáticas (SUGUMARAN e BOSE, 1999, MA et. al., 2000).

Vários tipos de sistemas complementares ao DM podem utilizados, em função da necessidade (MA et al., 2000), como:

- Gerenciadores de consultas e criadores de relatórios; 
- Planilhas;

- Bancos de dados multi dimensionais;

- Ferramentas de análises estatísticas;

- Ferramentas de inteligência artificial e análises avançadas e

- Ferramentas de visualização gráfica.

A tecnologia de DM utiliza uma grande variedade de ferramentas, tais como inteligência artificial, análises estatísticas, análise de dados multi dimensionais, visualização e monitoramento de bancos de dados (EOM, 1999). Estas ferramentas são críticas para organizações que desejem explorar grandes volumes de dados (SUGUMARAN e BOSE, 1999).

\subsubsection{Executive Information Systems (EIS)}

Os Sistemas de Informações Executivas (Executive Information System - EIS) são sistemas de informações projetados para fornecer informações relevantes e de forma fácil para as atividades da gerência, independente do nível (LEE e CHEN, 1997, LEIDNER, 1999). Um sinônimo para EIS é ESS (Executive Support System).

Os EIS constituem uma classe de software que preenche algumas necessidades de informações para executivos, como a manipulação de grandes volumes de informações, ser flexível, fácil de usar e permitir a construção de cenários sem a necessidade de envolvimento de pessoas especializadas (CHIUSOLO e KLEINER, 1999).

LEIDNER (1999) afirma que como o mundo caminha para mercados mais abertos e globalizados, onde informações precisas, oportunas e de fácil acesso são a chave para tomadas de decisões efetivas. Os EIS podem ser uma das formas de obter estas informações. Ё importante que o próprio usuário configure suas consultas e obtenha resultados rápidos, pois o pessoal técnico que desenvolve sistemas pode ter dificuldades para definir as necessidades dos usuários (RAI, 1997).

Segundo LEIDNER (1999), o uso de um EIS permite que o foco seja na análise das informações, e não na sua coleta. Isso permite análises mais profundas e tomadas de decisão mais rápidas. Além disso, os EIS providenciam à gerencia dados agregados, permitindo um aumento na qualidade das decisões (SCHEER, 1998). 
RAI (1997) realiza um estudo fazendo uma comparação entre atributos relacionados à EIS, e as perspectivas tradicionais e emergentes, para cada atributo, conforme tabela abaixo.

\begin{tabular}{|c|c|c|}
\hline Atributos relacionados aos EIS & Perspectiva tradicional & Perspectiva emergente \\
\hline Usuários & $\begin{array}{l}\text { Poucos executivos de alto } \\
\text { nível }\end{array}$ & $\begin{array}{l}\text { Executivos de todos os } \\
\text { níveis }\end{array}$ \\
\hline Tamanho da organização & Grandes empresas & $\begin{array}{l}\text { Grandes e pequenas } \\
\text { empresas }\end{array}$ \\
\hline Fontes de dados e informações & Internas & Internas e externas \\
\hline Tipo de suporte & Controle & $\begin{array}{l}\text { Comunicação, } \\
\text { coordenação, controle e } \\
\text { planejamento }\end{array}$ \\
\hline
\end{tabular}

Tabela 3.1: Atributos relacionados aos EIS (RAI, 1997) 


\section{MODELOS CONCEITUAIS DE GESTÃO DA PRODUÇÃO}

Serão apresentados neste capítulo alguns modelos de gestão da produção, baseados em livros conceituados e amplamente citados em publicações nacionais e internacionais. Será dado foco principalmente na estrutura dos modelos, no escopo restrito à gestão da produção.

\subsection{Gerenciamento da produção e inventário}

O modelo apresentado a seguir foi proposto por VOLLMANN et al. (1993).

\subsubsection{Objetivos e escopo}

Segundo os autores, o principal objetivo do modelo proposto é fornecer uma visão conceitual dos processos de planejamento da produção, dos inventários que resultam destes planos e como este gerenciamento se conecta com outros problemas críticos na manufatura. As atividades descritas são dirigidas a gerentes que atuem nesta área.

Outro objetivo apresentado é a possibilidade de integração entre vendas e produção, para que situações infelizes como uma produção inferior às vendas não ocorra.

O modelo não trata de situações de produção para projetos em larga escala, assim como para indústrias de processos.

\subsubsection{Descrição geral do modelo}

$\mathrm{Na}$ figura 4.1 é apresentada uma visão geral do modelo proposto por VOLLMANN et al. (1993). 


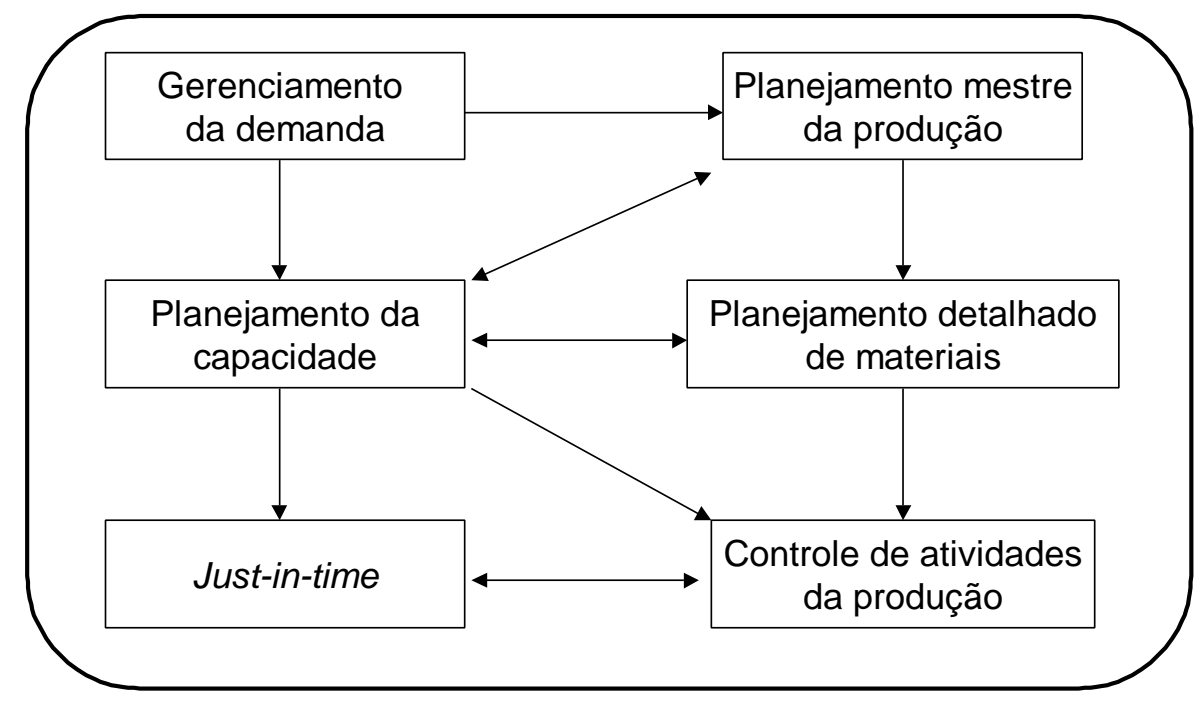

FIGURA 4.1 - Visão geral do modelo de gestão da produção e inventários (VOLLMANN et al., 1993)

A descrição do modelo começa com o Gerenciamento da demanda. Este é o processo mais relacionado com o ambiente externo. Ele serve como elo de ligação entre a produção e o mercado, tanto para o controle da entrada de recursos como para a saída de produtos. Esta atividade tem uma natureza centralizadora de informações.

O Planejamento mestre da produção descreve os conceitos empregados no desenvolvimento de um plano de produção (planejamento agregado) e do plano mestre de produção. Estes dois planos são as principais ligações entre a alta gerência da empresa e a produção. O processo de planejamento mestre da produção faz a ligação entre os planos de cada um dos outros grupos funcionais da empresa (vendas, marketing, finanças e outros) e os planos de produção.

O Planejamento da capacidade é o processo com maior número de ligações do modelo. Ele faz o balanceamento das restrições daquilo que pode ser produzido. A capacidade é tratada em termos da disponibilidade dos recursos necessários à produção, como equipamentos, mão de obra, ferramentas e outros.

O Planejamento detalhado de materiais transforma o Plano mestre nas necessidades exatas de matérias primas, peças, componentes e sub montagens para atender os planos de produção. As necessidades são tanto de produção como para compras. Um relacionamento estreito entre os processos físicos de produção e o planejamento detalhado de materiais é necessário, devido às constantes mudanças 
que ocorrem no chão de fábrica (quebras de equipamentos, falta de matéria prima, absenteísmo e outros) e que demandam por revisões nos planos.

O Just in time é um conceito que vem sendo transformado em filosofia de manufatura, onde todos os desperdícios devem ser eliminados. Níveis altos de inventário são apontados como um dos principais desperdícios. Este conceito é incluído no modelo, pois segundo os autores, nenhum tratado sobre produção integrada e gerenciamento de inventários seria completo sem isso.

O último processo do modelo é o Controle das atividades de produção, onde a performance da produção é monitorada e confrontada com os planos e programas, com as respectivas mudanças necessárias para corrigir os problemas.

\subsubsection{Gerenciamento da demanda}

O foco do gerenciamento da demanda é o consumidor, onde toda a produção e gestão de inventários começam e terminam. Este processo faz o planejamento apropriado de todas as demandas geradas, externas ou internas, para que, posteriormente, a utilização da capacidade seja melhor planejada e controlada.

Este processo engloba previsões, recebimentos de pedidos, cálculos de datas de promessa para entrega de pedidos, serviços ao consumidor, distribuição física e outras atividades que tenham contato com os clientes.

Os principais relacionamentos deste processo com outros da gestão da produção e inventários podem ser vistos na figura 4.2.

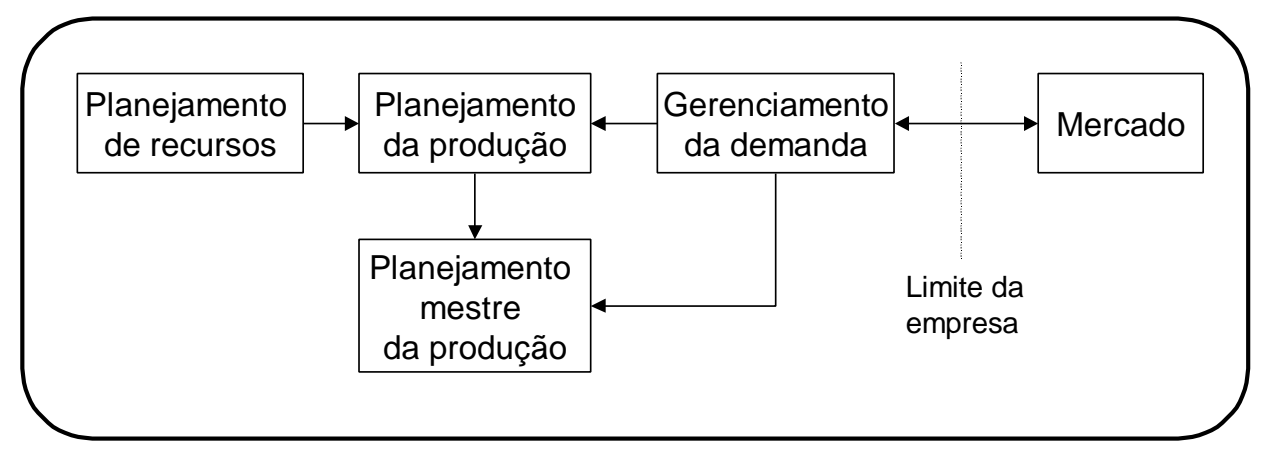

FIGURA 4.2 - Principais relacionamentos do gerenciamento da demanda (VOLLMANN et al., 1993) 
O gerenciamento da demanda tem um papel de sincronização e comunicação entre as atividades para o mercado e o planejamento da produção.

Uma das principais atividades do processo em questão é assegurar que as informações da demanda estão completas. Para tal, todas as fontes de demanda devem ser identificadas e incorporadas aos processos de planejamento da produção e dos recursos.

Em termos de sistemas de informações, um módulo de gerenciamento da demanda irá reunir informações do mercado, gerar previsões, monitorar a performance e fornecer instruções detalhadas sobre as ações para gestão da demanda e inventários.

\subsubsection{Planejamento mestre da produção}

O modelo apresenta uma hierarquia do planejamento, onde o Planejamento da produção se encontra em posição superior ao Planejamento mestre da produção. Este tópico fará uma abordagem de ambos, e seu relacionamento pode ser visto na figura 4.3 .

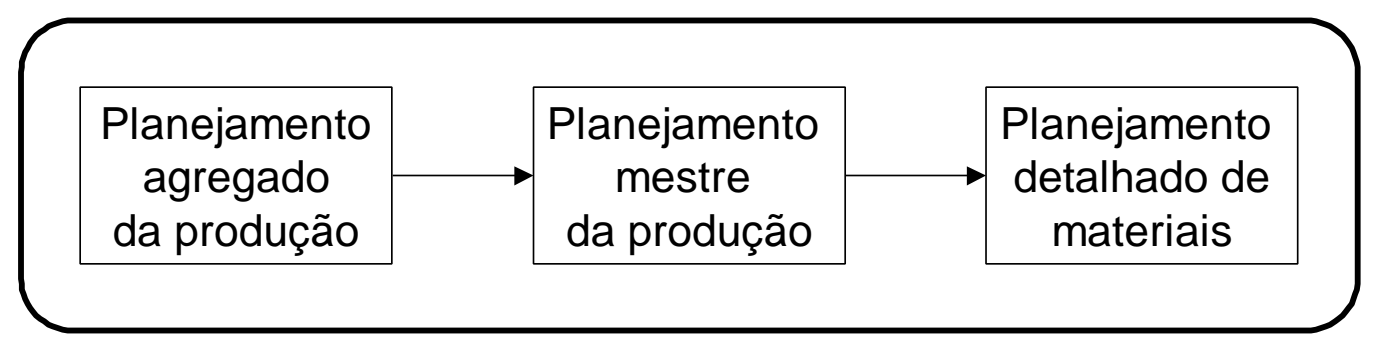

FIGURA 4.3 - Hierarquia do planejamento da produção (VOLLMANN et al., 1993)

O Planejamento da produção (também chamado de Planejamento agregado da produção) é a ligação vital entre a gestão da produção e inventários, com as decisões de planejamento de outras áreas funcionais da empresa. Planos de vendas, financeiros e de engenharia são integrados com os de manufatura através do planejamento agregado, que desta forma se torna um fator chave nas decisões da empresa.

A localização e as principais ligações do planejamento agregado podem ser vistas na figura 4.4 . 
O plano agregado pode ser estabelecido em unidades monetárias ou em unidades agregadas de produtos (famílias ou grupos de produtos) por mês, e o plano mestre é geralmente estabelecido em unidades de produtos finais por semana. $\mathrm{O}$ plano mestre é a desagregação do plano agregado, e vai, por sua vez, direcionar os planos detalhados de materiais.

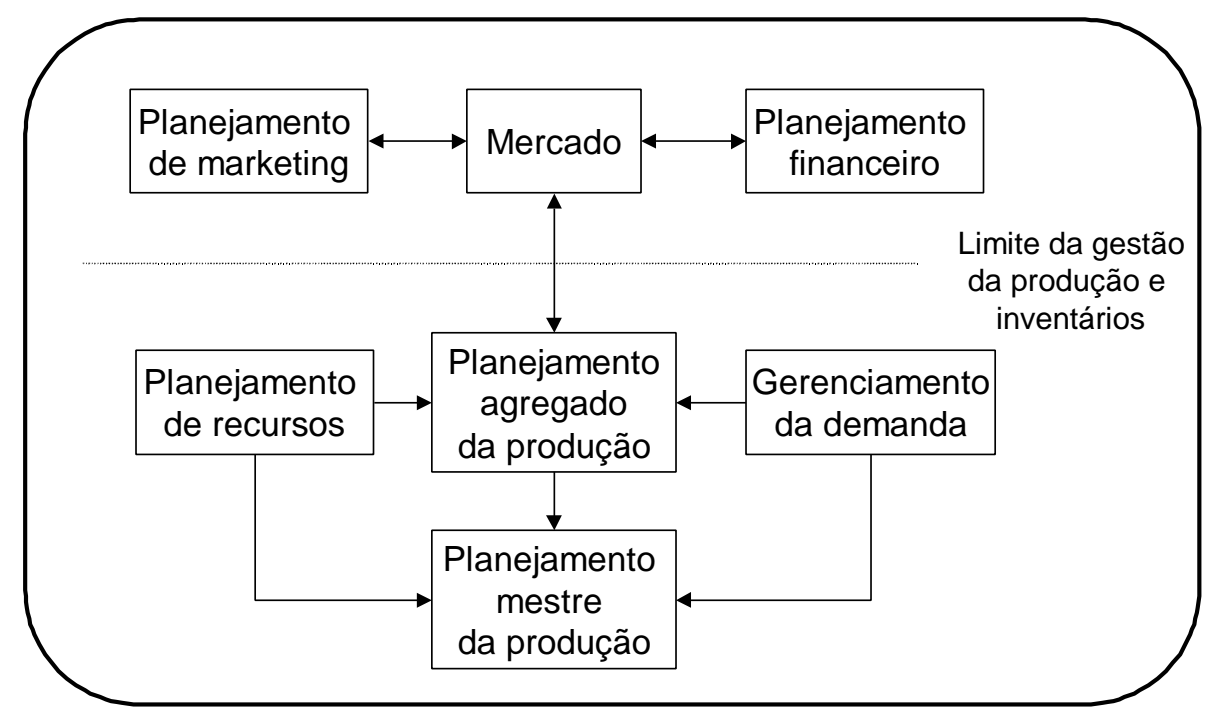

FIGURA 4.4 - Principais relacionamentos do planejamento agregado da produção

(VOLLMANN et al., 1993)

O planejamento de recursos está relacionado diretamente com o planejamento agregado da produção, porque no curto prazo, os recursos disponíveis são restrições a este planejamento. Outra restrição é a disponibilidade de materiais.

Os níveis de matérias primas, peças e submontagens limitam o que pode ser produzido no curto prazo, mesmo que outros recursos estejam disponíveis. Informações sobre isso são geralmente difíceis de serem obtidas, a menos que existam ligações efetivas entre o sistema de planejamento e bancos de dados que tenham as informações sobre a situação das restrições.

Os sistemas de suporte à gestão da produção e inventários devem ser usados para realizar tarefas rotineiras, e fornecer os dados de tal forma que o tempo de gerenciamento possa ser utilizado para tarefas importantes. Sistemas informatizados podem ajudar muito o planejador, mas julgamentos pessoais sempre serão necessários. 
A validade das atividades de planejamento da produção pode se questionada se não existe um monitoramento de sua performance. Isso necessita de ligações entre os dados de expedições e vendas. A medida da performance é um resultado importante do próprio planejamento, pois quando ocorrem desvios, medidas devem ser tomadas. Se um plano não pode ser realizado, o valor de todo o processo de planejamento da produção é questionável.

Uma grande dificuldade para o planejamento é a reunião de todas as informações necessárias. Além disso, são necessárias reuniões, análises de cenários e outras atividades de suporte. Atrasos no planejamento podem aumentar a chance que ele deixe de ser real, e também cria a oportunidade de aparecimento de controles e sistemas paralelos.

Uma questão relativa aos processos de planejamento da produção é relativa a quando mudar os planos e com que freqüência deve ser feito um replanejamento. Planos estáveis permitem uma utilização mais efetiva da capacidade instalada. Um recurso utilizado é o congelamento de um período de planejamento, onde não são permitidas mudanças.

\subsubsection{Planejamento da capacidade}

Este processo é relativo ao planejamento e controle da capacidade dos recursos. No contexto da manufatura, pessoal, tempo, equipamentos e materiais são recursos chave. Então, os planos devem ser expressos em termos das capacidades destes recursos.

O objetivo do planejamento da capacidade é assegurar a compatibilidade entre a capacidade disponível em centros de trabalho específicos e a capacidade necessária para atender a produção planejada. As soluções apresentadas no modelo permitem que as empresas façam uma estimativa da capacidade necessária. As atividades de planejamento da capacidade são realizadas paralelamente ao planejamento de materiais.

A figura 4.5 apresenta a hierarquia do planejamento da capacidade e seus principais relacionamentos com outros processos da gestão da produção e inventários. 


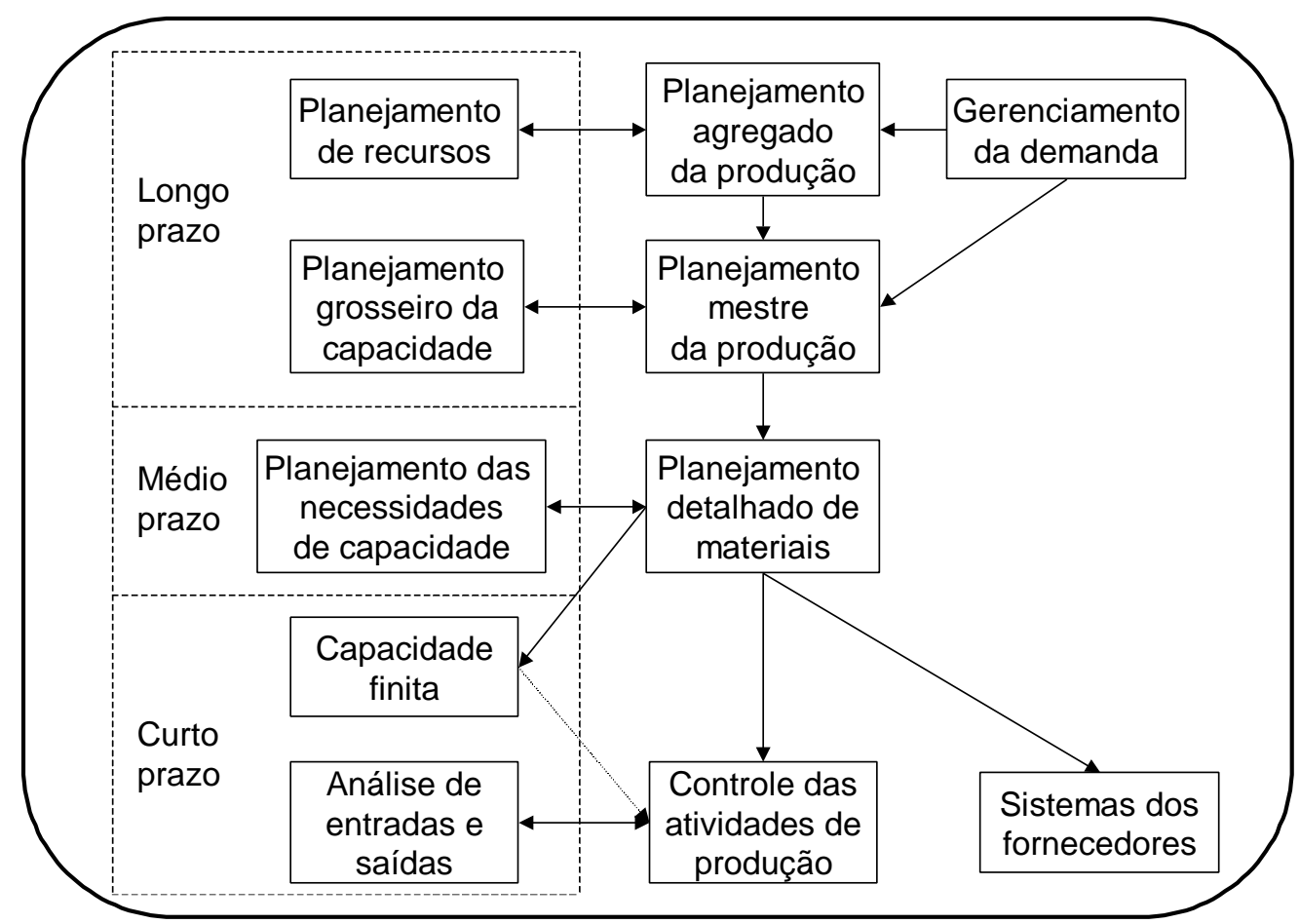

FIGURA 4.5 - Hierarquia e relacionamentos do Planejamento da capacidade (VOLLMANN et al., 1993)

O processo de Planejamento de recursos, relacionado ao Planejamento agregado da produção, é o mais agregado e de longo prazo entre as decisões de planejamento da capacidade. Converte dados agregados de produção de longo prazo em recursos agregados, como horas disponíveis de toda a planta.

O Planejamento mestre da produção é relacionado diretamente com o Planejamento grosseiro da capacidade, chamado de Rough cut capacity planning RCCP. Neste processo, a necessidade de capacidade para o cumprimento de um plano mestre pode ser estimada de várias formas. A forma apresentada no modelo em questão é chamada de "lista de capacidade", onde a lista de materiais mostra a capacidade requerida para a produção de cada item.

O processo de Planejamento das necessidades de capacidade, chamado de Capacity requirements planning (CRP), é relacionado diretamente ao Planejamento detalhado de materiais. O CRP utiliza como entrada o resultado de um sistema MRP para calcular necessidades exatas de capacidade, em função do tempo. As informações utilizadas são sobre o estoque em processo, roteiros de fabricação, recebimentos programados de materiais e ordens planejadas. O resultado do CRP 
pode determinar as necessidades de capacidade para centros de trabalho ou operadores específicos.

Para um maior refinamento dos processos de planejamento de capacidade apresentados, é considerado o carregamento atual dos recursos produtivos. Este processo é chamado de Capacidade finita, onde é feita a alocação direta das ordens de produção aos recursos produtivos.

O processo de Análise de entradas e saídas fornece um método para monitorar o consumo atual de capacidade durante a execução dos planos detalhados de produção, resultado dos sistemas MRP. Ele requer obrigatoriamente ligações com sistemas de chão de fábrica (monitoramento da produção) e bancos de dados do controle das atividades de produção. Este processo pode indicar necessidades de aumento de capacidade caso os planos em execução se desviem do esperado. O monitoramento pode também fornecer informações para correções nos planos de capacidade em andamento. Os autores consideram este processo importante, pois desvios do planejamento estabelecido acontecem por diversos motivos, e portanto devem ser corrigidos.

Além das funcionalidades apresentadas, o planejamento da capacidade pode ser utilizado para a realização de comparações entre diferentes cenários de planejamento.

\subsubsection{Planejamento detalhado de materiais}

O processo de planejamento detalhado de materiais utiliza informações de engenharia e do projeto do produto para converter o plano mestre em planos para a produção de componentes manufaturados e comprados. Este processo é largamente conhecido pela sigla MRP, do termo em inglês Material Requirements Planning.

O desenvolvimento destes planos requer uma substancial integração entre várias funções da empresa, como projeto, engenharia, sistemas de informações, manufatura (chão de fábrica) e compras. Além disso, dados recentes das operações de produção e de recebimento de compras devem ser analisados e processados para manter os planos de materiais atualizados, refletindo as atuais condições de operação.

Os sistemas computacionais chamados MRP são a ferramenta básica para realizar o planejamento detalhado de materiais. O objetivo deste processo de planejamento é que as peças corretas estejam prontas no tempo correto. 
O Planejamento detalhado de materiais é caracterizado pelo uso de registros que consideram as quantidades em função do tempo. Esta característica, além das principais ligações deste processo, pode ser vista na figura 4.6.

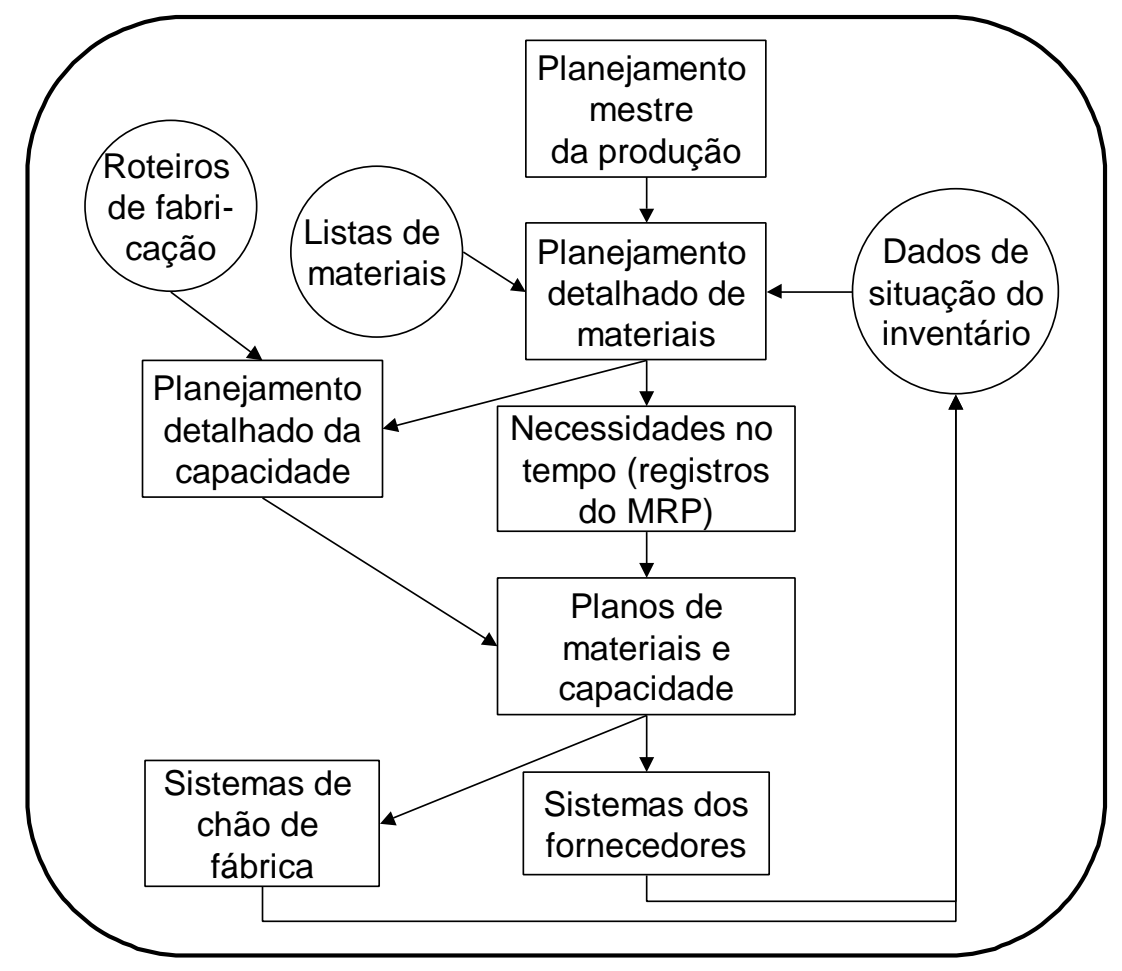

FIGURA 4.6 - Uso de registros do MRP para o planejamento detalhado de materiais

(VOLLMANN et al., 1993)

Além do plano mestre, o planejamento detalhado de materiais necessita de duas outras entradas. A lista de materiais mostra, para cada componente, quais outros componentes são necessários. A situação do inventário mostra quanto a empresa possui de inventário para cada componente, e auxilia na transformação das necessidades brutas em necessidades líquidas. O desenvolvimento dos planos detalhados de materiais e capacidade é um processo interativo.

Para empresas de manufatura que seguem este modelo apresentado, o volume de transações que envolvem o planejamento detalhado de materiais é muito grande. Isto porque deve ser feito um registro básico de MRP para cada componente de cada produto, e os resultados são inúmeras ordens de produção e de compras.

Para facilitar a tarefa dos planejadores, sistemas de MRP possuem códigos de exceção, que são mensagens indicando os principais problemas de um dado 
planejamento. Assim, o planejador sabe que deve tratar com prioridade as causas destas mensagens de exceção, para separar as poucas ações vitais que devem ser tomadas das muitas ações triviais que podem ser postergadas. Este volume de dados pode ser grande, mesmo que a empresa seja pequena.

O planejamento detalhado de materiais é feito para determinado horizonte de tempo e conjunto de situações. Caso estas condições sejam alteradas ou expire o horizonte de planejamento, é necessário que sejam feitas modificações ou novos planos. Os sistemas MRP possuem duas alternativas para o replanejamento. A primeira alternativa é o Net change, onde somente os registros afetados pelas modificações são recalculados. A outra alternativa é o método regenerativo, onde todos os cálculos são refeitos.

Além das integrações apresentadas para a realização do processo de planejamento, muitas outras informações são necessárias, entre elas as do controle das atividades de produção, que devem ser integradas ao sistema de gestão da produção e inventários.

Conforme apresentado, o planejamento detalhado de materiais pode apresentar excelentes resultados para a empresa, em termos de organização e custos, porém, para que os resultados sejam efetivos, os dados de entrada (que são em grande volume) devem ser corretos, atualizados e precisos. Esta condição para as entradas nem sempre é obtida nas empresas.

\subsubsection{Just-in-time}

No modelo apresentado em VOLLMANN et al. (1993), o Just-in-time é apresentado como uma filosofia de administração, cujos princípios são aplicados à gestão da produção e inventários. A filosofia incorpora uma grande lista de crenças sobre a maneira como a manufatura deve ser gerenciada, assim como as mudanças que são necessárias em outras empresas para alcançar uma melhora global.

Este tópico não será apresentado em detalhes, visto que aparece no modelo como uma alternativa de gestão, que não está diretamente integrada com a hierarquia de planejamento apresentada até o momento. 
4.1.8. Controle das atividades de produção

O controle das atividades de produção (PAC - Production Activity Control) está relacionado aos mais detalhados aspectos da manufatura, gerenciando passo a passo cada componente, sub montagem e produto, através da produção. Isso requer um grande volume de informações. Além disso, o PAC deve fornecer informações da situação para outras atividades da gestão da produção e inventários, assim como outras partes da empresa.

O processo de controle das atividades de produção é composto pela programação detalhada e controle das tarefas individuais nos centros de trabalho do chão de fábrica, além da programação de entregas dos fornecedores. Parte deste processo é conhecido como Controle do chão de fábrica.

O processo de planejamento detalhado das necessidades de materiais (MRP) apresentado acima, gera ordens de produção sem considerar restrições de capacidade, sendo chamado de carregamento com carga infinita. O processo de PAC é que vai fazer as devidas considerações das restrições e ocupação da capacidade.

A figura 4.7 apresenta a localização do controle das atividades de produção.

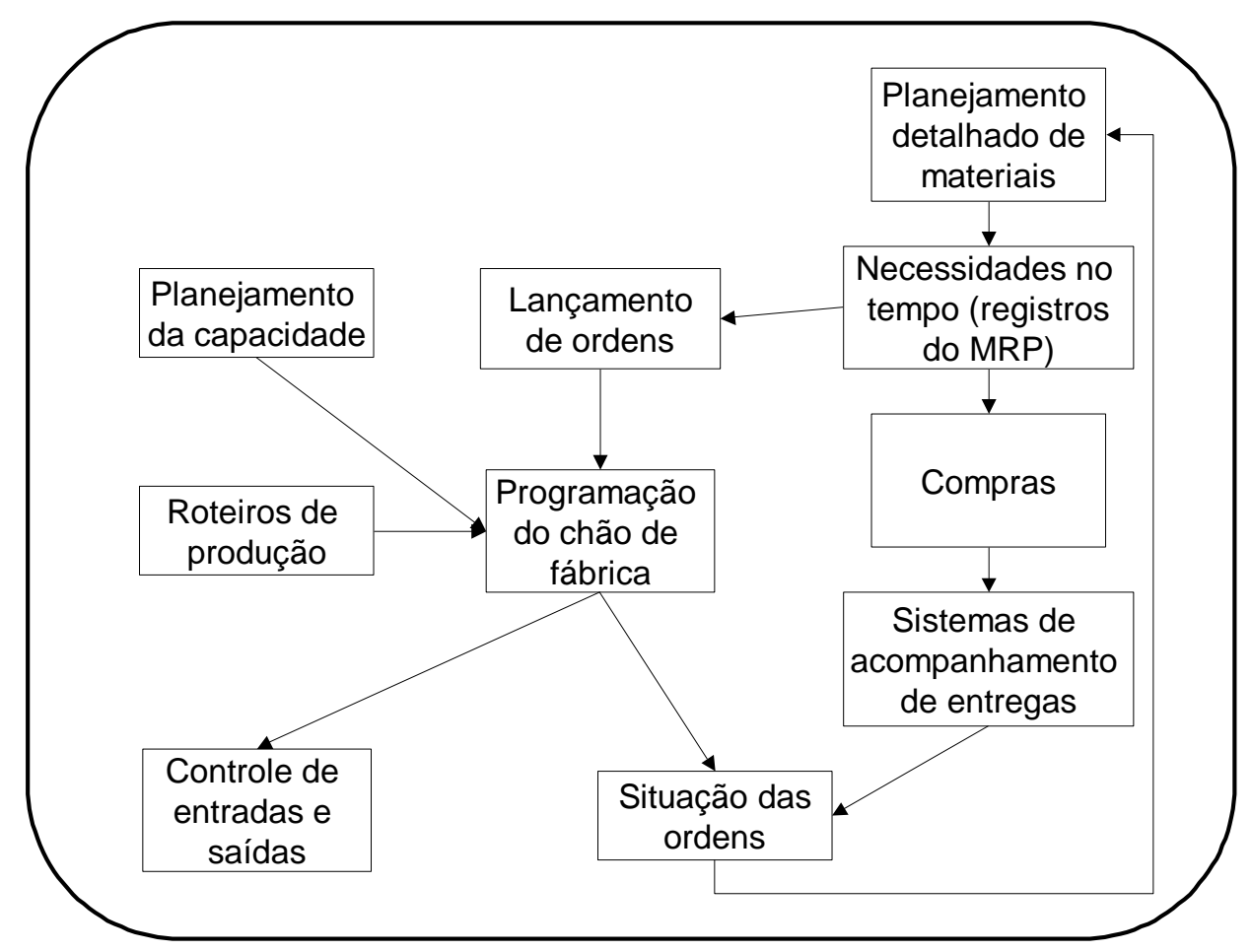

FIGURA 4.7 - Principais relacionamentos do controle das atividades de produção

(VOLLMANN et al., 1993) 
Entre os conceitos básicos do PAC, existem duas técnicas principais.

A primeira técnica é o Gráfico de Gantt, que fornece uma compreensão visual e gráfica da programação do chão de fábrica, podendo ser utilizado até de forma manual. O objetivo é preparar um programa para cada estação de trabalho. O principal problema desta técnica é a atualização das informações. Os dados atuais devem ser capturados e integrados em um ciclo de replanejamento em andamento. Além disso, é necessária uma forma de integração com o chão de fábrica, para atualização dos dados.

A segunda técnica é um conjunto de Regras de prioridade para sequenciamento, que dizem qual a próxima atividade a ser realizada em um centro de trabalho. Existem diversas regras para tal. Estas regras geralmente são relacionadas com a ordem de chegada dos trabalhos, tempo restante para a data de entrega e outros tipos de prioridades.

\subsection{Sistemas de controle de chão de fábrica}

O modelo apresentado a seguir foi proposto por BAUER et al. (1991).

\subsubsection{Introdução sobre sistemas de controle de chão de fábrica}

Na produção em lotes, o lead time ou tempo de passagem de um lote através do chão de fábrica é tipicamente muito maior que o tempo de processamento. Estes são feitos dos seguintes componentes: o tempo de preparação e o tempo de processo, que inclui os tempos de inspeção, de transporte e de espera (fila). O lead time de manufatura possui outros componentes, como tempos de preparação de ordens, espera, preparação, execução, inspeção e movimentação.

A motivação dos autores para o livro é considerar soluções modernas para sistemas do nível operacional do planejamento e controle, chamados de sistemas de controle de chão de fábrica. $O$ argumento é que existe a possibilidade de desenvolvimento de sistemas de manufatura que são capazes de produzir produtos diversos em quantidades relativamente pequenas, e são capazes de fazê-lo de forma positiva, isto é, com baixos lead times. Será esboçada uma arquitetura de sistema de informações de chão de fábrica para atender estas condições. 
O Just-in-time (JIT) é uma das soluções para a manufatura, concentrada em uma meta simples, que é produzir os itens necessários, na qualidade necessária, nas quantidades exatas e no momento exato em que são necessários. Sob esta perspectiva, são analisadas três características do JIT:

- A filosofia global de manufatura;

- As técnicas utilizadas no JIT para projetar e operar sistemas de manufatura e

- O sistema de controle de chão de fábrica do JIT, isto é o Kanban.

Outra das soluções para a manufatura é o planejamento de suas necessidades, mais conhecido pelas siglas MRP e MRP II. Os sistemas MRP convertem um plano discreto de produção de produtos em um plano de produção ou compra de seus componentes.

Os autores consideram o OPT (Optimized Production Technology) como uma extensão do MRP, cuja perspectiva principal para a manufatura de uma empresa é gerar dinheiro, através de alguns princípios básicos, que focalizam o fluxo de materiais pela fábrica.

Uma arquitetura estabelece a estrutura ou um conjunto de regras para gerenciar o desenvolvimento e operação de sistemas complexos. Claramente o planejamento e controle da produção em ambientes de manufatura orientados a lotes de componentes discretos é complexo. A arquitetura será apresentada na forma de um modelo de planejamento hierárquico e controle.

O processo de planejamento e controle da produção é visto em 3 níveis hierárquicos de atividades: estratégico, tático e operacional. Isso pode ser visto na figura 4.8, onde a sigla PAC significa Production Activity Control. 


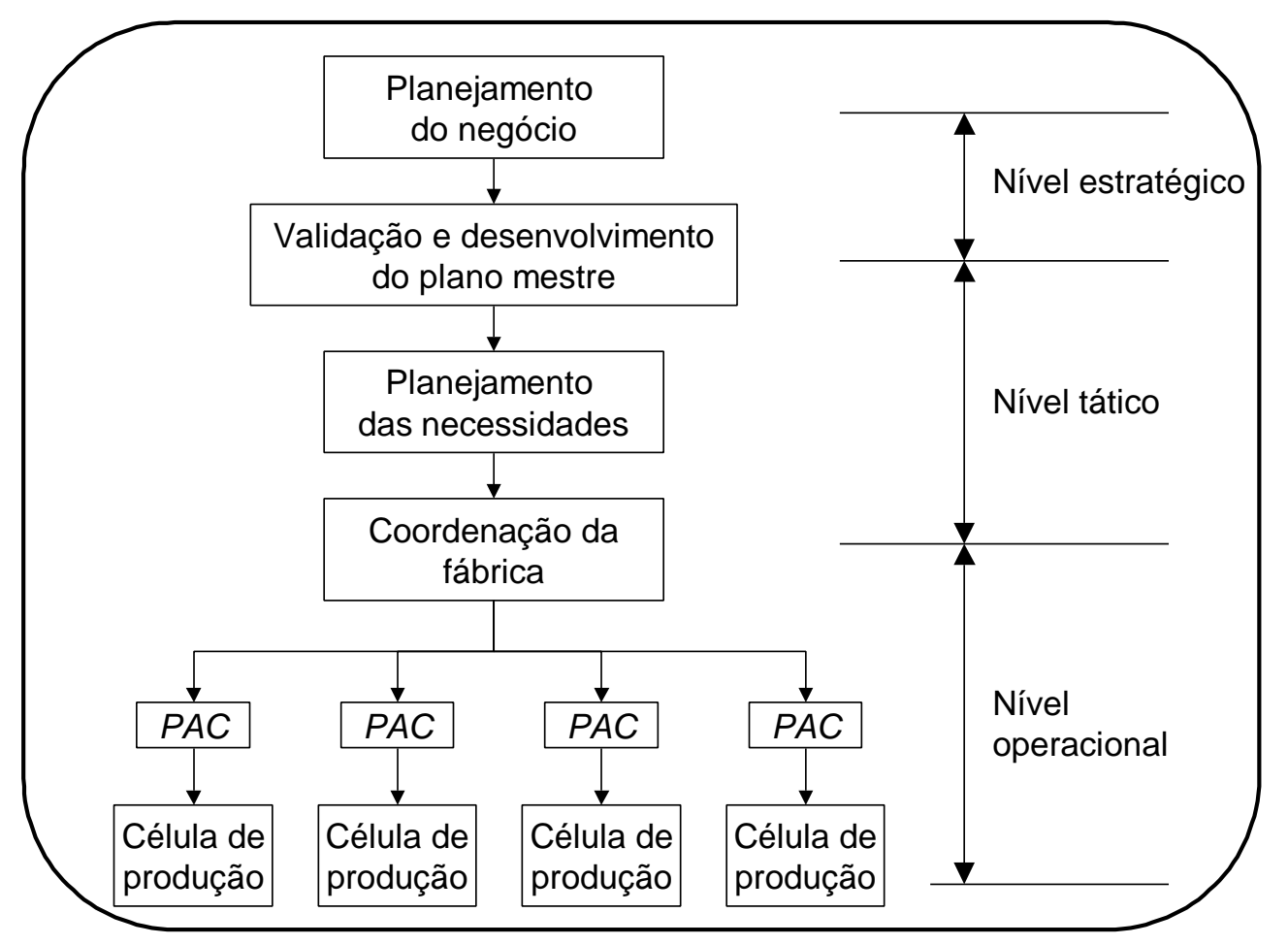

FIGURA 4.8 - Hierarquia dos sistemas de controle da manufatura (BAUER et al., 1991)

No nível estratégico é feita a determinação dos produtos a serem manufaturados para atender às expectativas do mercado e dos clientes. No nível tático é feita a geração dos planos detalhados para atender a demanda imposta pelo plano mestre de produção, que deve ser realista em termos de capacidade. Um ponto importante é que os lead times são úteis para o planejamento tático, e são apenas um guia para a programação detalhada. No nível operacional, a saída do nível tático é gerenciada em tempo quase real na manufatura, para atender as necessidades.

\subsubsection{Uma arquitetura para sistemas de controle de chão de fábrica}

Os autores (BAUER et al., 1991) apresentam uma arquitetura para as atividades que ocorrem no nível operacional, ou seja, atividades do dia a dia envolvidas no planejamento e controle da produção no chão de fábrica. O objetivo principal é apresentar quais tarefas devem ser feitas, e não como estas tarefas devem ser feitas, separadas para a Coordenação da fábrica e para o Controle das atividades de produção $(P A C)$. 


\subsubsection{PAC}

A seguir serão apresentadas atividades típicas no planejamento e controle de qualquer chão de fábrica. O supervisor da produção possui uma série de informações sobre as necessidades dos clientes que devem ser atendidas, geralmente para o prazo de uma semana. Este então fará um plano para que todas as necessidades sejam atendidas. Vários fatores podem influenciar este plano, como a disponibilidade e capacidade de recursos de produção. O plano então será a referência para a produção, porém existe grande possibilidade que seja modificado, devido a grande número de eventos imprevisíveis que podem ocorrer. Neste contexto, os principais elementos do controle de chão de fábrica são:

- Desenvolver um plano com os tempos certos e dados necessários para que todas as necessidades de produção sejam atendidas. Este plano será chamado de programa;

- Implantar este plano, considerando a situação atual dos sistemas de produção. Esta atividade é chamada de liberação;

- Monitorar a situação de componentes vitais do sistema durante as atividades de liberação. Isto pode ser feito tanto visualmente como usando métodos baseados na tecnologia.

Estas atividades geralmente são realizadas em empresas, porém muitas vezes de maneira informal. A arquitetura é mostrada na figura 4.9. 


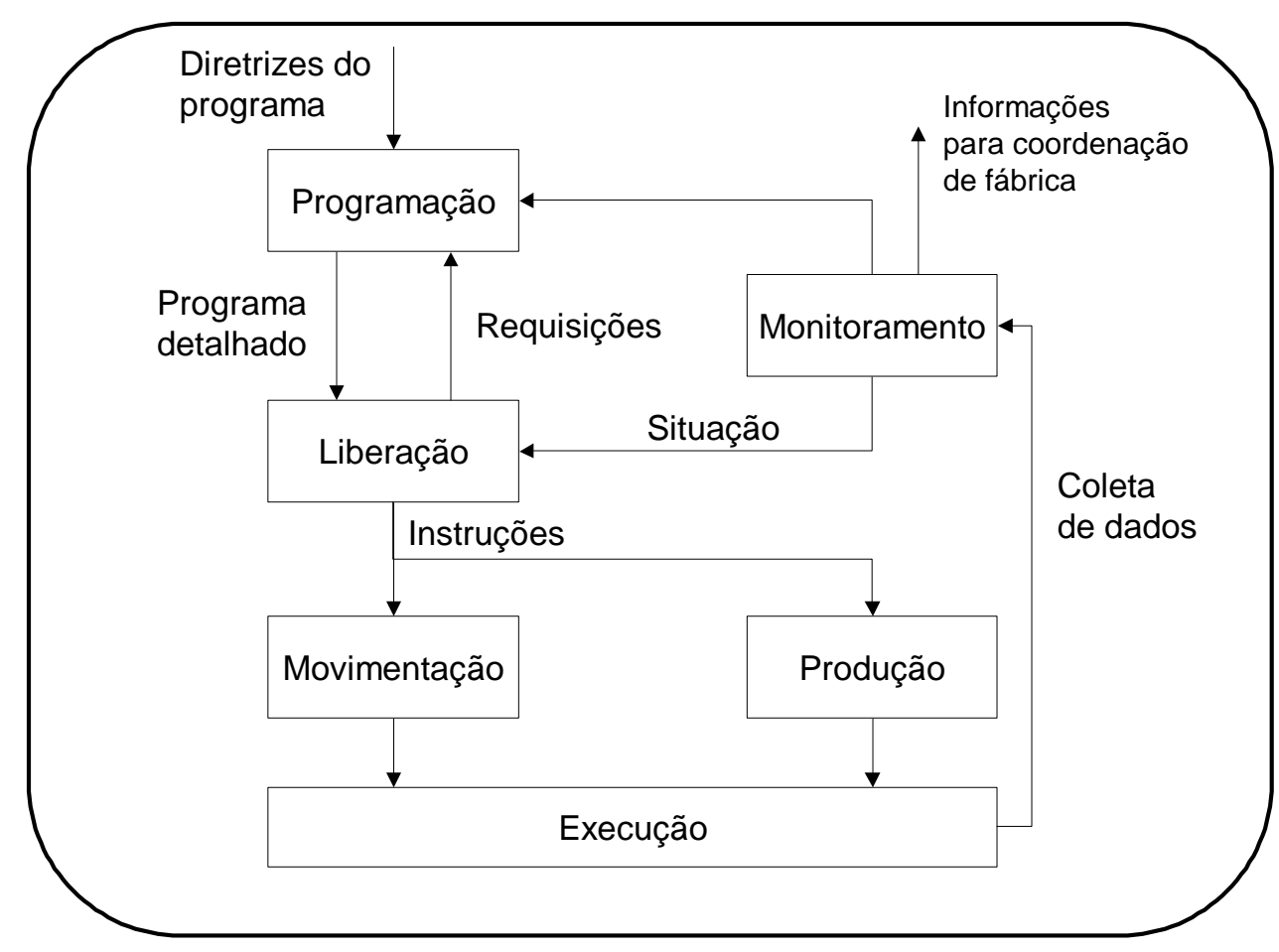

FIGURA 4.9 - Arquitetura do controle das atividades de produção - PAC (BAUER et al., 1991)

O objetivo da atividade de programação é atender as necessidades de produção de níveis superiores de planejamento (como a Coordenação de fábrica), e desenvolver um plano detalhado que indique precisamente a utilização de equipamentos, em tempos específicos. As principais tarefas são:

- Avaliação da viabilidade do plano quanto a restrições de capacidade;

- Gerar o programa e

- Passar o programa para ser liberado.

A liberação deve encontrar as melhores alternativas para que o programa seja realizado, considerando os eventos ocorridos. Para sua realização, são necessárias as seguintes informações:

- O programa, que deve detalhar os tempos das diferentes operações a realizar;

- Dados estáticos da manufatura descrevendo como as operações serão realizadas e

- O estado atual do chão de fábrica. 
É essencial que as informações da situação do chão de fábrica sejam as mais recentes possíveis, sendo que sua falta é um dos maiores obstáculos para o controle efetivo das atividades de chão de fábrica. Geralmente são utilizadas regras de liberação (ou de despacho).

O monitoramento pode ser visto como um transformador de dados em informações, com o objetivo de fornecer informações precisas para o suporte à decisão. Em todos os níveis de tomada de decisão, existe a necessidade de acesso à informações precisas, consistentes e no momento exato. No nível de controle das atividades de produção, o monitoramento supre esta necessidade. Os dados coletados no monitoramento, de acordo com esta arquitetura são os tempos de processo, situação de peças e operações, e dados de inspeções, falhas, retrabalhos e dos equipamentos.

\subsubsection{Coordenação de fábrica}

A arquitetura para o controle das atividades de produção $(P A C)$ apresentado, acontece em cada célula de produção. Os autores consideram um chão de fábrica típico formado por diversas células, cada uma controlada pelo seu sistema $P A C$ específico. A Coordenação da fábrica é o gerenciamento da diversidade de produtos e processos que fluem em ambientes típicos de produção.

Dentro da arquitetura de Coordenação de fábrica, existe uma ligação entre o projeto do ambiente de produção as tarefas de controle, e sua arquitetura pode ser vista na figura 4.10 . 


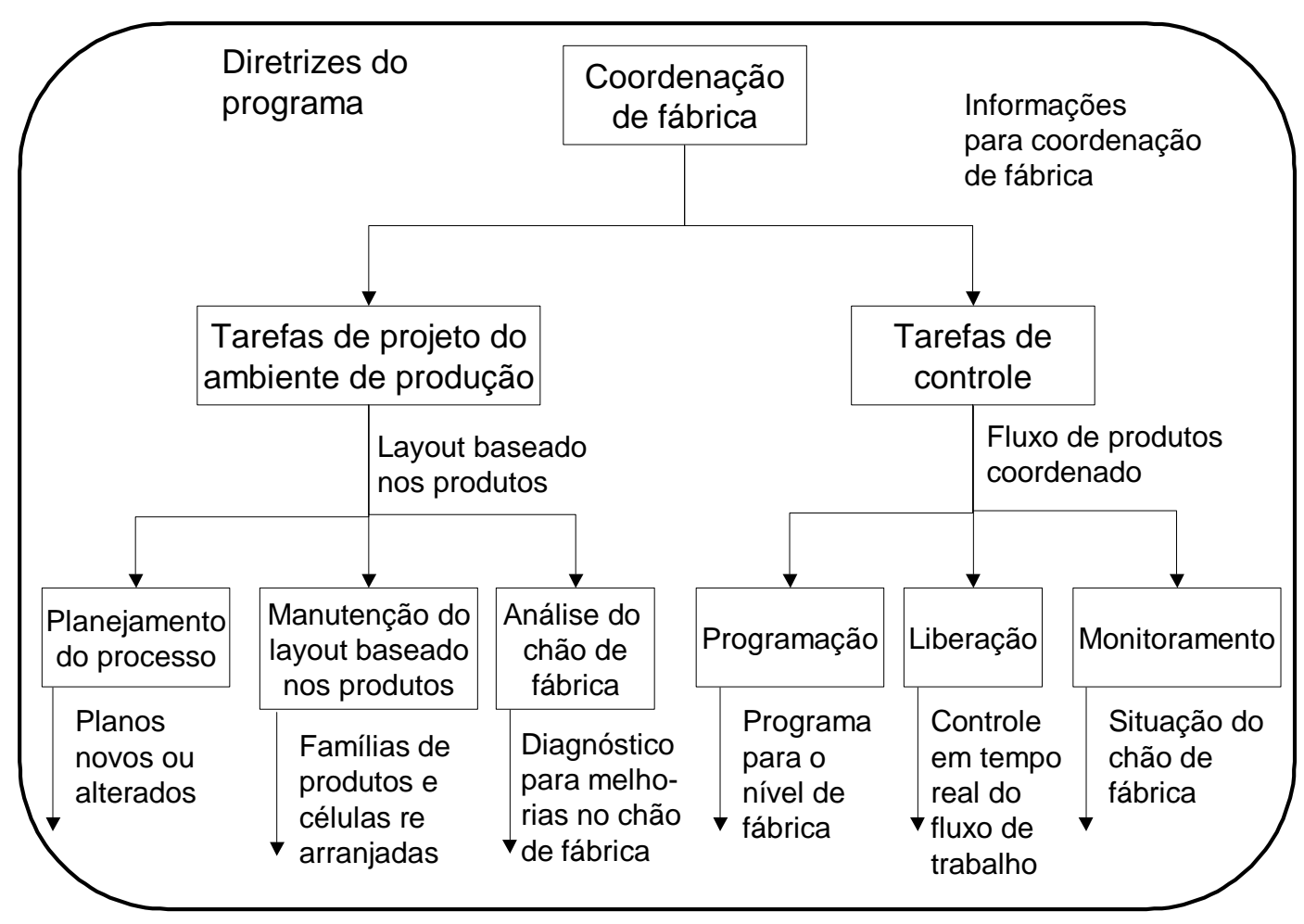

FIGURA 4.10 - Arquitetura da Coordenação de fábrica (BAUER et al., 1991)

\section{Projeto do ambiente de produção}

O principal papel das tarefas de projeto do ambiente de produção é reorganizar o sistema de manufatura, para que este seja simplificado e suporte a introdução de novos produtos. Para sua realização são necessários dados estáticos e as necessidades de produção futura, gerada pelos sistemas MRP.

Os dados estáticos incluem a lista de materiais (Bill of Materials - BOM) e os processos de produção para cada novo produto

Partindo de um layout de produção orientado aos produtos existentes, o projeto do ambiente de manufatura integra novos produtos ao ambiente de produção com o mínimo impacto. Os principais procedimentos são os seguintes:

- Planejamento do processo, que pode gerar novos planos de processos ou alterar os existentes;

- Manutenção do layout baseado nos produtos, faz o re arranjo das famílias de produtos e células e 
- Análise do chão de fábrica, responsável por diagnosticar o sistema de manufatura para melhorias.

\section{Tarefas de controle}

$\mathrm{O}$ projeto do ambiente de manufatura assegura que um sistema de manufatura seja eficiente. O principal objetivo das tarefas de controle é coordenar as atividades de cada $P A C$, através do fornecimento do programa e diretrizes em tempo real.

As tarefas de controle são, de várias formas, um nível mais alto de sistemas $P A C$, pois adotam os mesmos procedimentos de programação, liberação e monitoramento, porém para o nível de fábrica.

Estas tarefas podem ter sua complexidade simplificada caso seja feito um bom projeto do sistema de manufatura, seja feita a escolha correta do nível de formulação do problema e seja feito uso efetivo de restrições e considerações.

No modelo apresentado, é feita uma citação de VOLLMANN (1993), referindo-se às formas de programação que podem ser utilizadas para a Coordenação de fábrica: com capacidade finita ou infinita. O objetivo desta programação é planejar o trabalho para um período futuro, de forma a otimizar o sistema como um todo.

Neste nível, a liberação implementa o programa da fábrica, passando as diretrizes para o sistema $P A C$ de cada célula. Estas podem ser mudanças nas prioridades dos produtos ou dados de processo.

O monitoramento da Coordenação de fábrica possui duas tarefas: a geração de relatórios acurados para a gerência, e a entrega de dados precisos e no tempo correto para as funções de programação e liberação, e também para sistemas de planejamento de nível mais alto.

A seguir, os autores apresentam a mesma arquitetura em maior nível de detalhes usando uma técnica de modelagem chamada SADT (Structured Analisys and Design Technique). O modelo resultante é hierárquico, a os autores o representam em 3 níveis de detalhamento, especificando as atividades, relacionamentos e informações em detalhes. 
Após a apresentação do SADT, é feita a apresentação da arquitetura do ponto de vista da Tecnologia da Informação (TI). O objetivo é complementar a visão geral e fornecer a base para futuros desenvolvimentos de softwares nesta área.

Nas últimas seções do livro são feitas revisões sobre o estado da arte de programação e projeto do ambiente de produção. Finalizando, são feitas considerações sobre a implementação de sistemas de controle de chão de fábrica e controle das atividades de produção.

\subsection{Administração da produção}

\subsubsection{Introdução}

O modelo conceitual apresentado a seguir é baseado em SLACK et al. (1999).

No livro analisado são abordados vários tópicos, alguns não diretamente relacionados ao interesse deste trabalho, que serão omitidos. O modelo de administração da produção proposto é apresentado, e sua localização pode ser vista na figura 4.11.

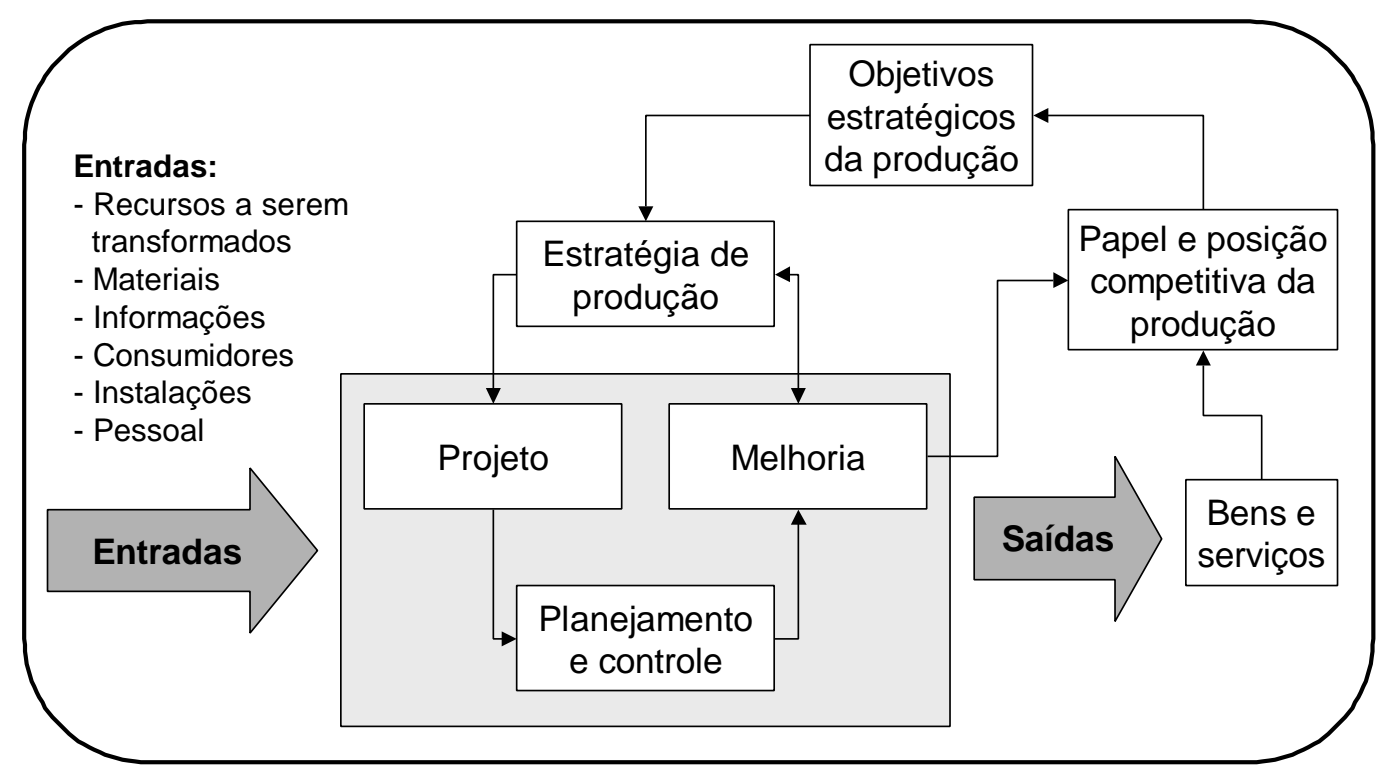

FIGURA 4.11 - Modelo geral da administração da produção (SLACK et al., 1999)

Conforme visto na figura, a administração da produção é analisada dentro de um contexto estratégico, e trata pela maneira na qual as empresas produzem bens e serviços. 
Qualquer operação produz bens ou serviços, ou um misto dos dois, e faz isso por um processo de transformação. A transformação utiliza os recursos para transformar as entradas em saídas.

Os autores definem a estratégia da produção em dois níveis, para micro e macro operações. No nível de macro operações, a estratégia é o padrão global de decisões e ações, que define o papel, os objetivos e as atividades da produção, de forma que estes apóiem e contribuam para a estratégia de negócios da organização. A estratégia de micro operações é o padrão global de decisões e ações que definem o papel, os objetivos e atividades de cada parte da produção, de forma que apóiem e contribuam para a estratégia de produção do negócio.

Após esta introdução, é apresentada uma seção a respeito de projeto, que será omitida deste trabalho.

\subsubsection{Planejamento e controle}

\subsubsection{Natureza do planejamento}

O objetivo do planejamento e controle é garantir que a produção seja eficaz e produza os produtos e serviços como deve. Isto requer que os recursos produtivos estejam disponíveis:

- Na quantidade adequada;

- No momento adequado e

- No nível de qualidade adequado.

Em qualquer operação, o fornecimento de recursos não é infinito. Isso faz com que existam limitações, principalmente a serem consideradas no planejamento e controle. Estas limitações acontecem para os horizontes de longo, médio e curto prazo, e devem ser gerenciadas.

Para conciliar o volume e o tempo da produção, são desempenhadas as atividades de carregamento, sequiência e programação.

O carregamento é a quantidade de trabalho alocado para um centro de trabalho. Existem duas abordagens para o carregamento de máquinas: finito e infinito. No 
carregamento infinito não existe a limitação de aceitação de carga de trabalho. No carregamento finito, o trabalho é alocado até um limite estabelecido.

O sequenciamento mostra a ordem na qual as tarefas são executadas. As prioridades são estabelecidas segundo regras.

A programação faz um cronograma detalhado da sequiência já estabelecida, mostrando em que momento os trabalhos devem começar e quando eles deveriam acabar, além das quantidades. A programação pode ser feita para frente (iniciando o trabalho assim que ele chega) e para trás (o trabalho termina no último momento possível).

\subsubsection{Planejamento e controle da capacidade}

A administração da produção tem a responsabilidade de atender a demanda atual e futura, e para tal, deve haver um equilíbrio entre capacidade e demanda. $\mathrm{O}$ planejamento e controle da capacidade são as tarefas de determinar a capacidade efetiva de operação produtiva, de forma que ela possa responder à demanda. As etapas desta tarefa podem ser vistas na figura 4.12.

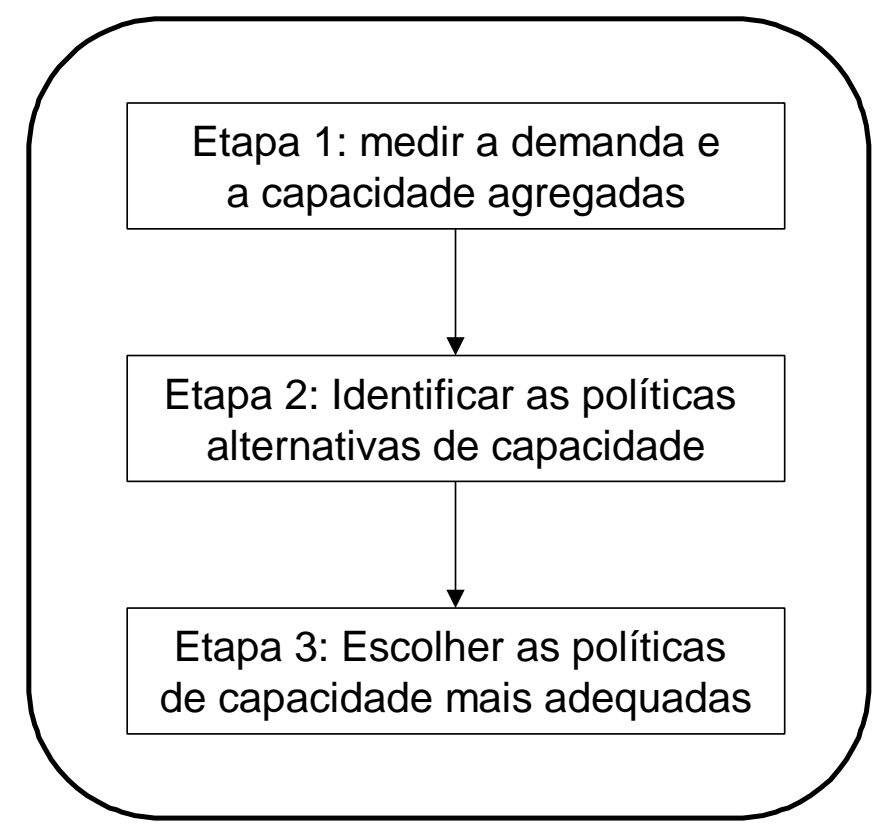

FIGURA 4.12 - Etapas do planejamento e controle da capacidade (SLACK et al., 1999)

Dentro da etapa de medição da demanda e da capacidade, algumas atividades são realizadas. A previsão da demanda, que identifica padrões e flutuações da 
demanda é uma dessas atividades. E por estar lidando com grande incerteza, deve ser tão exata quanto possível, utilizando o maior número de ferramentas possível.

Na medição da capacidade, a incerteza da demanda não torna possível precisar exatamente a disponibilidade de capacidade. A capacidade depende das atividades e sua seqüência.

Para a segunda etapa, existem três alternativas para as variações da capacidade:

- Política de capacidade constante;

- Política de acompanhamento da demanda e

- Gestão da demanda, tentando modificá-la para atender à disponibilidade de capacidade.

O modelo apresenta alguns métodos para o ajuste da capacidade, como uso de horas extras e tempos ociosos, variação do tamanho da força de trabalho e sub contratação.

\subsubsection{Planejamento e controle de estoque}

Estoque é definido como a acumulação armazenada de recursos materiais em um sistema de transformação. Quase todas as operações mantêm estoque, porque existe uma diferença de ritmo entre fornecimento e demanda. O estoque pode ser de diferentes tipos. Entre eles temos o estoque isolador ou de segurança, estoque de ciclo, estoque de antecipação e estoques no canal de distribuição.

Uma das decisões do planejamento e controle de estoques é o volume ou quantidade que deve ser pedida, para que os estoques sejam abastecidos. Para tal deve ser considerado o custo do estoque, e o nível de estoques ao longo do tempo. A abordagem mais comum para decidir quanto pedir de um item é o lote econômico de compra.

A decisão sobre quando se fazer um novo pedido para ressuprimento é complexa, pois envolve diversos fatores como variações na demanda, no ritmo de produção e no lead time do pedido, isso requer revisões dos valores e técnicas empregados.

Para lidar com esta complexidade, existem sistemas de processamento de informações, que trabalham com as circunstâncias relacionadas. Um destes sistemas 
considera prioridades de estoque, chamado de sistema $A B C$, que identifica prioridades relativas dos itens de estoque, e atribui políticas específicas.

\subsubsection{Planejamento e controle da rede de suprimentos}

Rede (ou cadeia) de suprimentos são todas as unidades produtivas que estão interligadas para fornecer produtos e serviços para os clientes finais. Entre as atividades de planejamento e controle da rede de suprimentos temos:

- Compras e desenvolvimento de fornecedores, onde são feitas considerações sobre as fontes de compras e a decisão de fazer ou comprar e

- Gestão da distribuição física, que envolve o transporte físico de produtos da empresa até o cliente.

- Além destas atividades, devem ser feitas considerações quanto às formas pelas quais mais de um dos elos da cadeia pode ser considerado como um todo integrado.

\subsubsection{4. $M R P$}

Por MRP pode-se entender tanto o Planejamento das necessidades de materiais como Planejamento dos recursos da manufatura. O MRP é um sistema que ajuda as empresas a fazerem cálculos das quantidades e tempos em que os produtos e seus componentes serão necessários. A figura 4.13 apresenta um esquema do funcionamento do planejamento das necessidades de materiais.

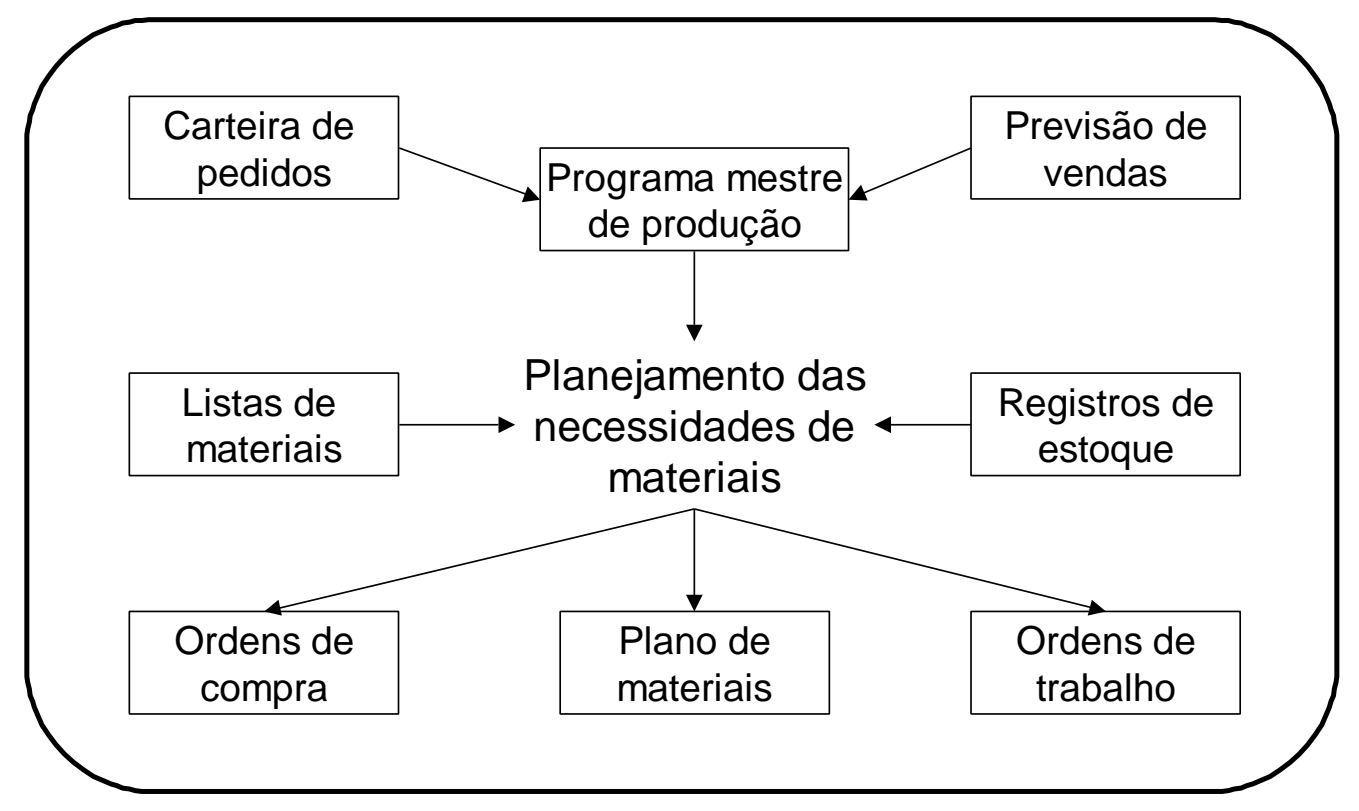


FIGURA 4.13 - Esquema do funcionamento do planejamento de necessidades de materiais

(SLACK et al., 1999)

A gestão da carteira de pedidos e da previsão de vendas, em conjunto, é chamada de gestão da demanda. Estas atividades são a ligação da empresa com o mercado consumidor, e indicam quanto deve ser produzido para atender as necessidades.

O programa mestre de produção (MPS - Master Planning Scheduling) é a fase mais importante do planejamento e controle de uma empresa, constituindo-se na principal entrada para o planejamento das necessidades de materiais. O MPS informa a quantidade e o momento em que os produtos finais devem ser produzidos, e direciona todas as operações, sendo a base para o planejamento de utilização de recursos. Para funcionar adequadamente, o plano mestre deve possuir as informações de entrada:

- Carteira de pedidos;

- Restrições chave de capacidade;

- Níveis de estoque;

- Demanda de peças para reposição;

- Necessidades de estoques de segurança;

- Necessidades de exibições e promoções;

- Demanda de Pesquisa \& Desenvolvimento;

- Demanda de empresa coligada e

- Previsão de vendas.

A lista de materiais indica quais as peças e respectivas quantidades compõem os produtos. Outras informações necessárias para o planejamento das necessidades de materiais são os registros de estoques, que indicam quanto estoque está disponível para cada produto final e seus componentes, permitindo calcular as necessidades líquidas. Com estas informações, são feitos os cálculos, e geradas as ordens de compra e de trabalho, assim como o plano de materiais. O modelo apresenta o procedimento de cálculo a ser adotado. 
De forma integrada ao planejamento de materiais, deve ser feito o planejamento da capacidade. Este modelo conceitual incorpora a parte do modelo de Gestão da produção e inventário proposto por VOLLMANN et al. (1993) de gestão da capacidade, considerando a sua hierarquia.

Finalizando este tópico, é apresentado o OPT (Optimized Production Technology), como uma técnica computadorizada que auxilia a programação da produção, a partir do ritmo dos recursos gargalo. O OPT não é uma alternativa ao MRP.

\subsubsection{Planejamento e controle Just-in-time}

O modelo analisa o JIT tanto como uma filosofia quanto como um método de planejamento e controle de operações, cujo significado principal é produzir produtos no momento em que serão necessários.

O modelo prossegue com comparações entre a abordagem do MRP e do JIT para o gerenciamento dos estoques e da capacidade. A seguir é apresentada a filosofia JIT, cujo principal objetivo é a eliminação total de desperdícios.

\subsection{Planejamento, programação e controle da produção}

O tópico a seguir é extraído de CORRÊA et. al. (1997). Será apresentada uma visão geral do modelo proposto pelos autores. Existe grande ênfase na utilização do MRP, e aspectos gerenciais relacionados.

\subsubsection{Introdução}

Sistemas de Administração da Produção (SAP) são sistemas de informação para apoio à tomada de decisões, táticas e operacionais, referentes a:

- O que produzir e comprar;

- Quanto produzir e comprar;

- Quando produzir e comprar e

- Com quais recursos produzir 
O modelo conceitual a seguir irá detalhar estas questões, apresentando a hierarquia do planejamento e atividades relacionadas. Ainda neste contexto é apresentado o conceito de planejamento e as etapas do planejamento na manufatura.

\subsubsection{MRP e MRP II}

O conceito do MRP se baseia no conhecimento das estruturas dos produtos e nos tempos de obtenção de seus componentes fabricados e comprados, em função disso e das necessidades futuras e disponibilidade do produto, são calculadas as quantidades e datas necessárias para a produção. O objetivo é que sejam produzidos os componentes e produtos na quantidade e momento exatos, evitando a formação de estoques acima do necessário.

A estrutura do produto mostra todos os relacionamentos de dependências entre os componentes de um produto, e também as quantidades necessárias para a obtenção de um item de nível superior na estrutura. Além da estrutura, também é necessário saber os tempos de obtenção, tanto de compra como de produção, para cada componente. Outra informação necessária é a posição dos estoques, tanto de produtos acabados como intermediários, ao longo do tempo, para que sejam calculadas as necessidades líquidas de produção e compras.

O funcionamento do MRP é baseado no registro básico do MRP, que é uma matriz onde as informações necessárias são consideradas, e os cálculos de necessidades podem ser realizados. Também são considerados no registro básico os períodos do horizonte de planejamento. Este cálculo das necessidades é realizado ao longo de toda a estrutura do produto.

A apresentação do modelo foca nas informações necessárias para realizar o cálculo, indicando como estas devem ser obtidas, além de outras condições. Também mostra cenários de gestão a partir da variação destes valores. Exemplos são tamanhos de lote, tempos de obtenção (lead times) e estoques de segurança.

Em empresas de manufatura, o volume de informações gerado pelo cálculo das necessidades de materiais é muito grande. Grande parte dos registros gerados irá apenas indicar a abertura de uma ordem de produção ou de compra. Em alguns registros podem aparecer problemas, como necessidade de produção de um item no passado para atender a demanda. Estes casos são chamados de exceções, e grande 
parte do esforço de gestão neste nível do planejamento é feito através do gerenciamento das exceções.

Historicamente, MRP surgiu como um sistema computacional nos anos 60, realizando apenas o cálculo das necessidades de materiais. Porém, este apresentava algumas deficiências, como não tratar da disponibilidade de capacidade ou recursos. O MRP II é diferenciado do MRP devido ao tipo de decisões que ele pode suportar, sendo que o MRP suporta decisões de o que, quando e quanto produzir, e o MRP, além disso, suporta também as decisões de como (com que recursos) produzir.

Os principais módulos do sistema MRP II são:

- Cadastros básicos;

- $\quad$ MRP - Planejamento das necessidades de materiais;

- $\quad$ CRP - Planejamento das necessidades de capacidade;

- $\quad$ MPS - Plano mestre de produção;

- RCCP - Planejamento grosseiro da capacidade;

- Gestão da demanda;

- $\quad$ SFC - Controle do chão de fábrica;

- Compras e

- S\&OP - Planejamento de compras e operações (Planejamento agregado).

A estrutura hierárquica do MRP, e seus principais módulos podem ser vistos na figura 4.14. 


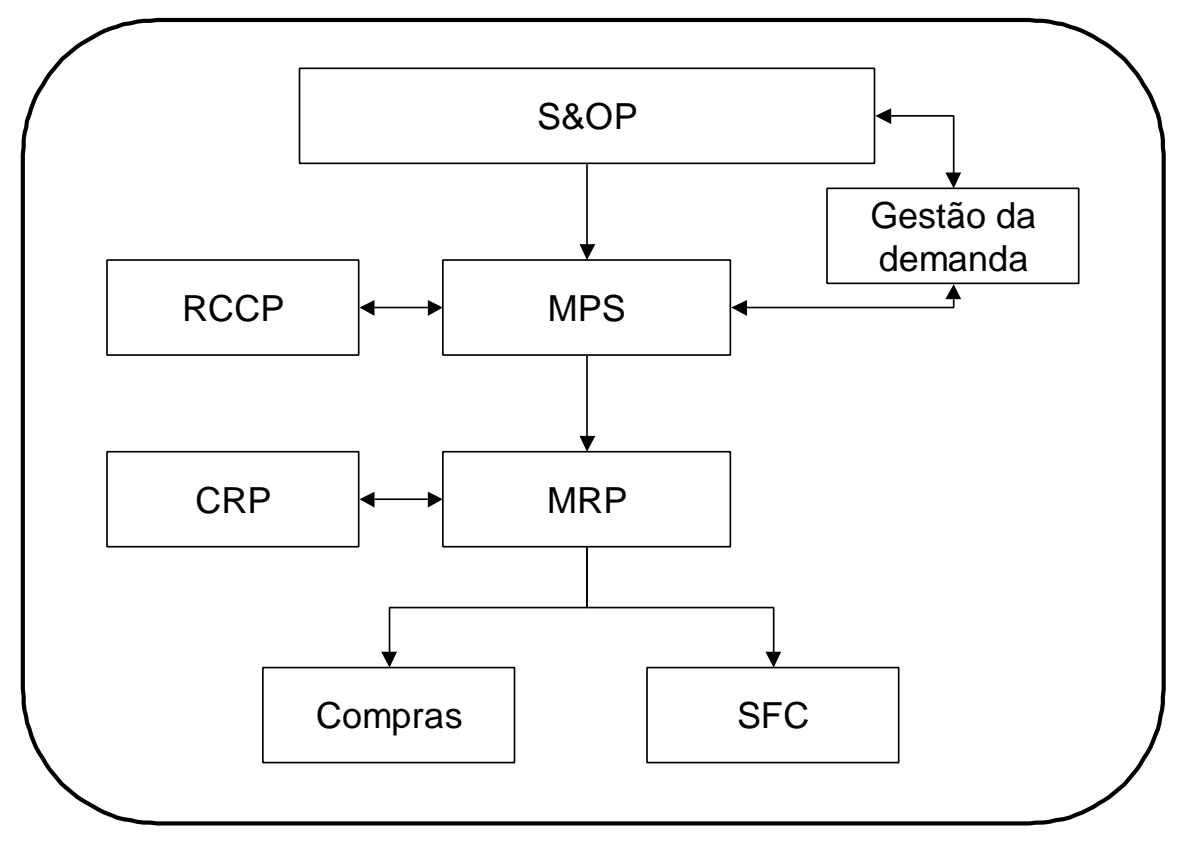

FIGURA 4.14 - Estrutura hierárquica do MRP II (CORRÊA et al., 1997)

Estes módulos serão apresentados a seguir com mais detalhes.

\subsubsection{S\&OP - Planejamento de vendas e operações}

O planejamento de vendas e operações, também conhecido como planejamento agregado, visa garantir que o que foi planejado estrategicamente em níveis mais elevados seja garantido, por meio de decisões operacionais. Outra função é a integração horizontal, com diversos departamentos.

O S\&OP é um processo de planejamento contínuo, com revisões mensais dos planos, para adaptar às flutuações do mercado, da disponibilidade de recursos e do suprimento de materiais. Os principais relacionamentos do $\mathrm{S} \& \mathrm{OP}$, e sua localização dentro do processo de planejamento podem ser vistos na figura 4.15. 


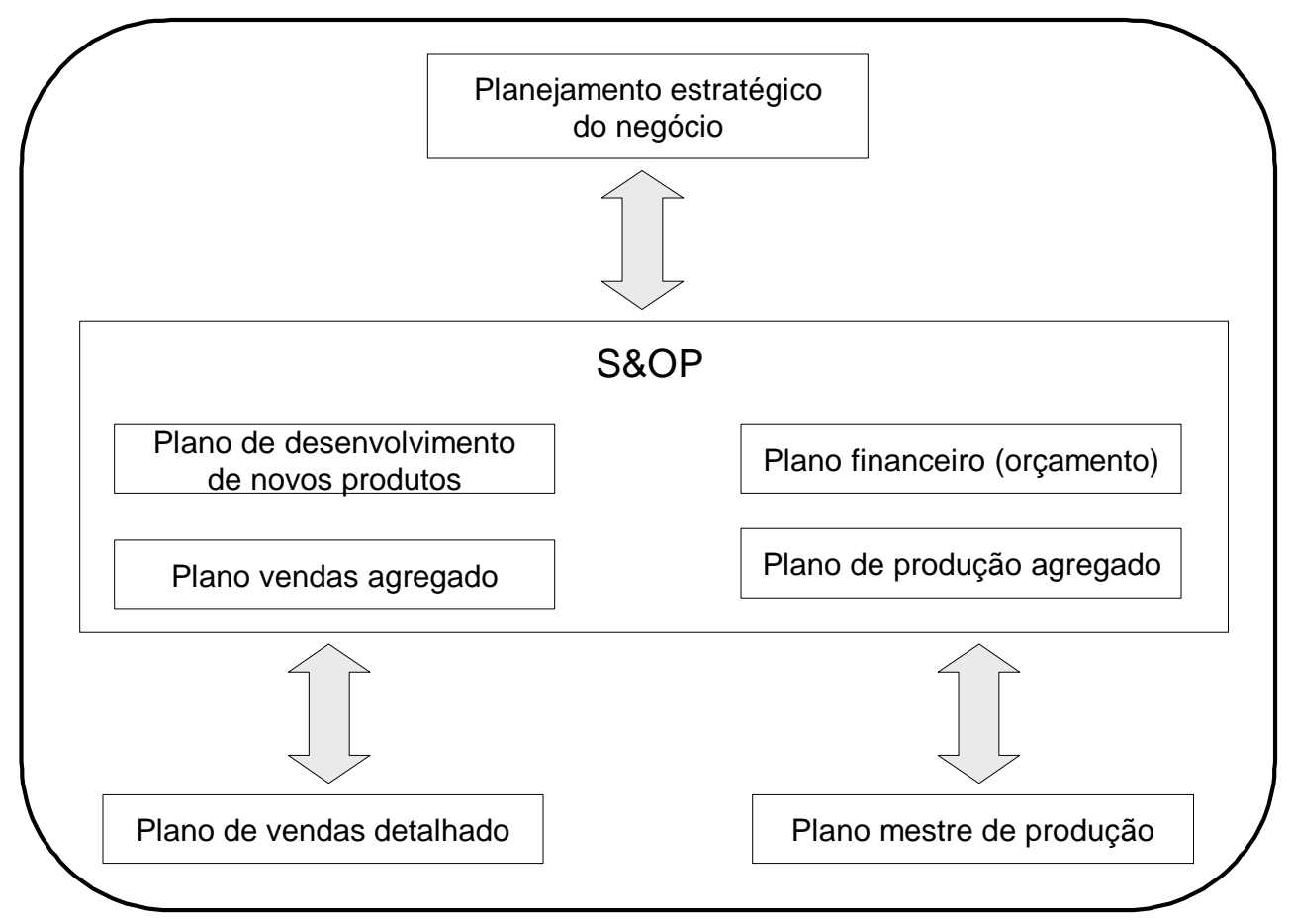

FIGURA 4.15 - Localização do S\&OP no planejamento (CORRÊA et al., 1997)

Os principais objetivos do S\&OP são:

- Suportar o planejamento estratégico do negócio;

- Garantir que os planos sejam realistas;

- Gerenciar mudanças de uma forma eficaz e

- Gerenciar os estoques de produtos finais e pedidos em carteira.

As quantidades do S\&OP são unidades de famílias ou conjuntos de produtos, por isso é chamado agregado. Para a sua efetivação, não existe a necessidade de utilização de ferramentas computacionais complexas, visto que os procedimentos de cálculo são simples, e podem ser implementados em planilhas. Para tal, é necessário que estejam disponíveis algumas informações, como o desempenho passado, o estado atual, parâmetros de conversão e previsões.

O resultado do S\&OP, é aplicado em diversas áreas (não só a manufatura), estabelecendo objetivos claros para cada área. Esses objetivos estão integrados ao objetivo corporativo. 
No modelo conceitual estudado, são apresentados aspectos relativos ao processo de realização do $\mathrm{S} \& O P$, relacionados com políticas e alternativas a serem analisadas, além da estrutura organizacional necessária.

\subsubsection{MPS - Planejamento mestre da produção}

O MPS coordena a demanda do mercado com os recursos internos da empresa, de forma a programar taxas adequadas de produção de produtos finais. É feita a desagregação do S\&OP, visto que este último trabalha com unidades de famílias de produtos, enquanto o MPS trabalha com unidades dos produtos finais, fazendo a ligação dos planos estratégicos com os planos operacionais.

O Plano Mestre de Produção indica aquilo que se espera produzir, para cada produto final, em períodos de tempo no futuro. Serve também de base para a elaboração de planos mais detalhados.

O funcionamento do MPS também é baseado em um registro básico, que é uma planilha onde são feitos cálculos e projeções, período a período. São considerados os tipos de demanda que podem ocorrer, ao longo do tempo: independente, dependente e pedidos em carteira, considerados como demanda total. Além disso, é considerado o saldo do estoque projetado para o final de cada período, em função da demanda e da produção. Outra consideração feita é a disponibilidade para promessa, que indica a quantidade de produtos que pode ser oferecida em cada período, sem que haja necessidade de alteração do plano mestre. Por fim, no registro básico é considerado o próprio plano mestre, que indicará o quanto deve ser produzido de cada produto final. O plano mestre é uma das informações de entrada para o MRP.

$\mathrm{Na}$ execução do plano mestre podem ser feitas considerações quanto aos níveis de estoque e estoques mínimos, tamanho dos lotes e número de períodos em que o planejamento não deve ser alterado ou com restrições quanto às alterações.

Da mesma forma que o MRP, o MPS é um processo até certo ponto rotineiro, onde são geradas ordens. No MPS também existe a ocorrência de mensagens de exceções, que indicam os pontos do plano que devem sofrer intervenção do planejador. 
A seguir os autores apresentam considerações sobre a utilização do MPS nos diferentes ambientes produtivos, como manufatura para estoques (MTS), montagem para ordens (MTO), manufatura para ordens (MTO) e projeto por ordens (ETO).

\subsubsection{MPS - Gestão da demanda}

A função de gestão da demanda inclui esforços em cinco áreas: previsão da demanda, comunicação com o mercado, influência sobre a demanda, promessa de prazos para entrega, e priorização e alocação.

O processo de previsão de vendas é possivelmente o mais importante da gestão da produção, porém nunca uma previsão é absolutamente correta. Para tal, existem sistemas de previsão de vendas, que são conjuntos de procedimentos de coleta, análise e tratamento de informações, que tem o objetivo de gerar uma estimativa de vendas futuras, em unidades de produtos e de tempo. Neste assunto, os autores fazem uma série de abordagens a respeito do horizonte de tempo e de informações a serem consideradas.

Em algumas empresas, existem centros de distribuição, além de uma logística para atender os clientes. Este caso pode ser gerenciado pelo planejamento das necessidades de distribuição (DRP - Distribution Requirements Planning), que considera as diferentes necessidades de diferentes unidades no planejamento.

Ainda dentro da gestão da demanda, é feita a promessa de prazos de entrega, que fornece prazos viáveis, garantindo o desempenho em confiabilidade de entrega. A forma de calcular ou estimar os prazos de entrega varia de acordo com o tipo de produção (MTS, MTO e ATO).

\subsubsection{Planejamento da capacidade}

O planejamento da capacidade é uma atividade crítica desenvolvida paralelamente ao planejamento de materiais. A relação entre ambos deve ser interativa, para que os planos sejam viáveis.

A estrutura hierárquica do planejamento é mostrada na figura 4.16. 


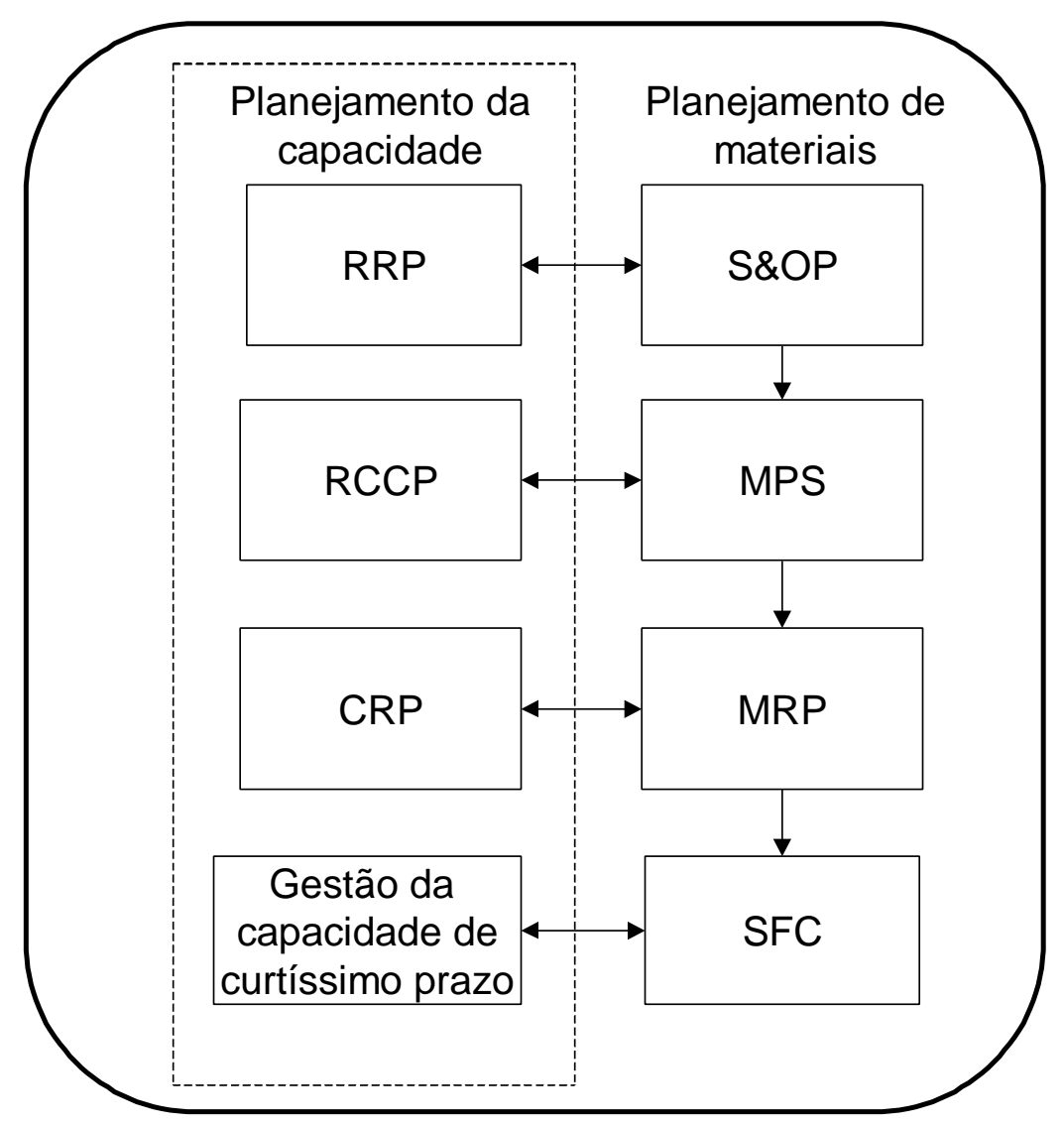

FIGURA 4.16 - Hierarquia do planejamento da capacidade (CORRÊA et al., 1997)

O planejamento da capacidade de longo prazo é chamado de RRP (Resource Requirements Planning), e seu objetivo é antecipar as necessidades de capacidade que necessitem de um longo prazo para serem obtidas. O tratamento é feito sobre quanto será a produção de cada família de produto, devido à limitações de capacidade.

O planejamento de capacidade de médio prazo é conhecido como RCCP (Rough Cut Capacity Planning). Seu objetivo principal é gerar um plano de produção de produtos finais que seja aproximadamente viável para o processamento do MRP e do CRP. Neste nível, o planejamento da capacidade é feito para os recursos críticos, e não para todos. No seu processo, são calculadas as necessidades brutas de ocupação destes recursos (em horas) e os percentuais de ocupação. Aqueles que excederem os limites estabelecidos deverão ser gerenciados.

No CRP (Capacity Requirements Planning) é feito o planejamento da capacidade de curto prazo, cujo objetivo é gerar um plano detalhado de produção e 
compras que seja viável, por meio de ajustes efetuados no plano original sugerido pelo MRP, para que este possa ser liberado para execução na fábrica. $O$ procedimento de cálculo do CRP é semelhante ao RCCP, porém são considerados um maior número de recursos, e o nível de detalhamento também é maior, pois são consideradas as operações de cada peça do produto em separado.

A gestão da capacidade de curtíssimo prazo é feita baseada no programa de produção. Neste nível, podem ser tomadas algumas ações, para ajuste do programa em termos de capacidade, e também para lidar com uma série de imprevistos que podem ocorrer. Entre estas ações, temos: redução de tempos de fila e movimentação, overlapping (sobreposição de ordens), splitting (divisão) de ordens e operações, roteiros alternativos de produção e horas extras.

\subsubsection{Chão de fábrica}

\subsubsection{MES e SFC}

O sistema de execução e controle de chão de fábrica (MES - Manufacturing Execution System) é um sistema orientado para a melhoria de desempenho que complementa e aperfeiçoa os sistemas integrados de gestão da produção. Um MES/SFC coleta e acumula informações do realizado no chão de fábrica e os realimenta para o sistema de planejamento, fazendo a ligação deste sistema com o chão de fábrica.

Entre as funções do MES/SCF está o controle, liberação e alocação da produção. As funcionalidades principais destes módulos são as seguintes:

- Gerência dos lotes de produção;

- Gestão detalhada de recursos, incluindo sequenciamento, liberação e monitoramento de equipamentos;

- Alocação e coordenação de recursos humanos e ferramental;

- Instruções de trabalho e

- Rastreabilidade. 


\subsubsection{Sistemas de programação da produção com capacidade finita}

Estes sistemas são baseados na lógica da simulação, permitindo modelagens mais sofisticadas do problema de programação. Entre suas funcionalidades, estão: a modelagem do sistema produtivo e de alguns parâmetros para a tomada de decisão (regras de liberação e objetivos a serem atendidos) e tratamento das condições reais do chão de fábrica.

As limitações dos sistemas MRP II geram programas de produção baseados em capacidade infinita, que não consideram as características tecnológicas e a capacidade do sistema produtivo e é responsável em grande parte pela utilização de sistemas de programação com capacidade finita como parte da gestão da produção. São apresentados parâmetros para implantação e avaliação destes sistemas comerciais, além dos métodos empregados para resolução de problemas. Também são apresentados os sistemas comerciais disponíveis no Brasil.

\subsection{Análise dos modelos apresentados}

A seguir será feita uma análise dos modelos apresentados acima. Será feita a análise de cada modelo, e finalizando, uma comparação entre eles.

\subsubsection{Modelo proposto por VOLLMANN et al. (1993)}

Este modelo é referência no ambiente de pesquisas sobre gestão da produção, sendo que outros modelos foram desenvolvidos a partir deste, e também se encontram diversas citações em outros trabalhos.

O foco do modelo é no fluxo de informações do modelo hierárquico de produção. A estrutura da hierarquia é apresentada no início do livro, e detalhada em uma abordagem dos níveis mais altos (estratégicos) para os mais baixos (operacionais).

Os autores, entretanto, não apresentam um modelo detalhado da estrutura, indicando quais atividades são relacionadas, principalmente através da geração e utilização de informações. Também não são apresentados vários níveis da estrutura, sendo que existe um nível geral, e o detalhamento não prossegue além deste nível. Por exemplo, é feito o delineamento da função de planejamento mestre da produção, mas as atividades que compõem este processo não são explicitadas. 
Quanto ao fluxo de informações, também não se chega a um nível mais detalhado. São indicados os conjuntos de informações que circulam e fluem entre as atividades, porém estes não são detalhados.

A respeito do tratamento de informações, é apresentado um esquema de sistema de informação que se encaixa nas definições de ERP (Enterprise Resources Planning). Alguns módulos, como o MRP, são apresentados em detalhes, inclusive com exemplos de transações e relatórios. Sistemas de suporte à decisão que ultrapassem os limites do modelo apresentado não são discutidos.

Para o chão de fábrica, é apresentado um modelo de controle das atividades de produção, que parte do princípio que as informações coletadas de produção são confiáveis e disponibilizadas no momento certo, o que é uma grande dificuldade das empresas de manufatura, principalmente discreta.

O modelo abrange todas atividades macro da gestão da produção, sendo que atividades fora do planejamento da produção, como compras e marketing são abordados com pouco detalhamento.

\subsubsection{Modelo proposto por BAUER et al. (1991)}

O modelo de sistemas de controle de chão de fábrica apresentado por BAUER et al. (1991) é restrito às atividades da gestão da produção diretamente relacionadas com o chão de fábrica. Para os níveis superiores o modelo hierárquico é respeitado, porém foge ao foco do livro.

Existe uma divisão para o controle da produção em: controle das atividades de produção e coordenação da fábrica. Para cada uma destas divisões é apresentado um modelo extremamente detalhado, tanto para as atividades como para as informações.

As atividades são detalhadas através do uso do SADT, que descreve o fluxo de informações, as atividades e o detalhamento dos processos, que atinge 3 níveis de detalhamento, chegando a atividades elementares. Quanto às informações, o detalhamento chega ao nível de um projeto de sistema de informação, indicando detalhes como campos de tabelas. 
Os autores salientam que o modelo mostra quais atividades devem ser feitas, e não como. Portanto não são apresentadas alternativas, formas de gerenciamento e avaliação para as atividades.

Para a coleta de dados de chão de fábrica são apresentadas as atividades que devem ser feitas, porém não existem indicações claras quanto à tecnologia a ser empregada, que pode ser através de apontamento manual ou completamente automatizada. Não são mencionados sistemas de suporte à decisão que ultrapassem os limites do modelo de controle de chão de fábrica.

Após a apresentação conceitual, são feitas considerações sobre a implantação e desenvolvimento (implementação) de sistemas de controle de chão de fábrica, que são baseadas nas tecnologias de desenvolvimento de sistemas disponível na época (final da década de 80).

\subsubsection{Modelo proposto por SLACK et al. (1999)}

O modelo apresentado pode SLACK et al. (1999) tem foco na didática, e tem uma abrangência maior que os processos específicos de gestão da produção. Devido a este caráter, são apresentados diversos exemplos e alternativas para algumas atividades de gestão, enfatizando o gerenciamento.

O modelo de gestão apresenta uma hierarquia, e abrange todos os níveis desta. A estrutura da hierarquia é apresentada, porém o detalhamento dos processos não é apresentado de forma estruturada.

As informações que fluem pelo processo de gestão são apresentadas, de maneira genérica e ampla. Não existe grande nível de detalhamento das informações, porém existem diversas indicações quanto ao seu processamento, como a indicação de sistemas específicos e sua funcionalidade.

Em relação à coleta de informações de chão de fábrica, não são feitas considerações de como estas podem ser obtidas e disponibilizadas.

O relacionamento das atividades e processos da gestão da produção é feito através de comparações com módulos de sistemas MRP II. 


\subsubsection{Modelo proposto por CORRÊA et al. (1997)}

Este modelo também tem foco na didática. Apresenta uma hierarquia estruturada de níveis de planejamento.

Dentro de cada nível da hierarquia, as atividades são apresentadas de forma não estruturada, ou seja, sem um modelo do relacionamento direto entre elas. As informações necessárias às atividades são apresentadas em linhas gerais, com pouco detalhamento. São apresentadas diversas alternativas e formas de gerenciamento para algumas atividades e processos, inclusive com distinções para a orientação da empresa (MTS, MTO, ATO e ETO).

Quanto aos sistemas de informação, são apresentados módulos do sistema MRP II e do ERP, sem detalhamento de aspectos específicos dos sistemas. Outros sistemas de suporte à decisões, principalmente gerenciais, são mencionados, porém sem detalhamento.

O modelo não apresenta detalhes da coleta de dados de chão de fábrica, e assume apenas algumas condições para estas informações, em relação ao tempo de obtenção e qualidade das mesmas.

As atividades e processos apresentados abrangem toda a hierarquia do planejamento, sendo também detalhados procedimentos para algumas atividades.

O modelo é mais próximo da realidade brasileira, ao considerar termos empregados e técnicas difundidas no país. Aspectos organizacionais também são mostrados.

\subsubsection{Comparação entre os modelos}

Um aspecto comum aos modelos analisados é a estrutura hierárquica do planejamento. Essencialmente ela é a mesma para todos, com algumas pequenas diferenças, principalmente em relação à terminologia. Com exceção do modelo proposto por BAUER et al. (1991), os outros não entram em detalhes das atividades e das informações que fluem na gestão da produção.

Enquanto o foco do modelo proposto por VOLLMANN (1993) é na utilização e integração de sistemas, CORRÊA et al. (1997) e SLACK et al. (1999) apresentam diversas alternativas e formas de gerenciamento para as atividades, devido ao seu 
caráter didático. Estes apresentam inclusive procedimentos detalhados para a realização de algumas atividades que são apenas descritas em VOLLMANN et al. (1993).

Todos os modelos atendem em parte aos objetivos deste trabalho, e são aplicáveis em empresas de manufatura discreta. Porém, nenhum dos modelos considera a coleta de dados de chão de fábrica automatizada (exceto BAUER et al., 1991, em parte), e principalmente a utilização destas informações, que podem ser disponibilizadas em tempo real e possuem confiabilidade elevada, por eliminar anotações manuais e digitações.

Outra semelhança entre os modelos é a não consideração de sistemas de suporte à decisão, principalmente as modernas ferramentas para geração de relatórios personalizados por requisição. 


\section{MODELO CONCEITUAL DE GESTÃO DA PRODUÇÃO}

Neste capítulo serão apresentados a justificativa do formalismo adotado, um resumo da arquitetura adotada e o modelo conceitual proposto, conforme os objetivos deste trabalho.

\subsection{Formalismo adotado}

Nesta seção, os modelos conceituais apresentados serão analisados em função de seu formalismo, para então ser proposto um padrão para o modelo proposto com este trabalho.

BAUER et al. (1991) apresenta seu modelo estruturado funcional para controle de chão de fábrica através de uma técnica de modelagem para descrição de arquiteturas, chamada de Structured Analysis and Design Technique - SADT (Técnica de Projeto e Análise Estruturada). Nesta técnica são modeladas atividades (representadas por retângulos ou caixas) e setas que conectam as atividades, indicando entradas, saídas, controles e mecanismos.

Em VOLLMANN et al. (1993), a representação do modelo não segue nenhuma técnica estruturada, tanto para a representação de processos como para indicação do relacionamento entre níveis de detalhamento. São utilizadas figuras padronizadas que indicam atividades ou processos (retângulos) e setas que representam suas conexões.

Nos modelos apresentados por CORRÊA et al. (1997) e por SLACK et al. (1999), não existe padronização na representação.

Para este trabalho, será utilizada a arquitetura ARIS (SCHEER, 1998) como referência, e as visões de funções, organizacional e de dados. Esta arquitetura permite a modelagem de processos de negócios, que atende plenamente as necessidades deste trabalho.

Segundo YU e WRIGHT (1997), a vantagem de se utilizar um método para modelar processos de negócios é a progressiva decomposição que captura todas as informações necessárias, coincidindo com a compreensão natural obtida através da construção do modelo. A ARIS oferece tal decomposição.

De acordo com SCHEER (1998), a modelagem na ARIS é a manipulação de elementos, uso de visões, fases, designações e métodos, para o propósito de 
descrever processos de negócios. É um processo criativo e pode não ser completamente direcionado por regras. Entretanto, se certos padrões forem observados, é possível que os modelos sejam compreensíveis.

A seguir será apresentado um breve resumo da arquitetura adotada.

\subsection{ARIS}

\subsubsection{Introdução à metodologia}

Toda esta seção é baseada em SCHEER (1998).

Genericamente falando, um processo de negócios é uma série contínua de tarefas da empresa, tomadas com o propósito de criar saídas. O ponto inicial, e o produto final do processo de negócios são as saídas solicitadas e utilizadas pelos clientes, externos ou internos.

Para representação destes processos são utilizados modelos que reproduzem extratos da realidade. Eles são criados pela abstração das propriedades de objetos reais, onde suas estruturas essenciais e ambientes permanecem intactas, propriedade chamada de homomorfismo.

\subsubsection{Processo básico de modelagem}

As entidades envolvidas no processo de negócio (unidades organizacionais), juntamente com suas saídas e relacionamentos de comunicação são ilustradas como diagramas de contexto ou de interação, conforme apresentado na figura 5.1. Isto fornece uma visão inicial da estrutura do processo de negócios, mostrando os fluxos que ocorrem entre unidades organizacionais.

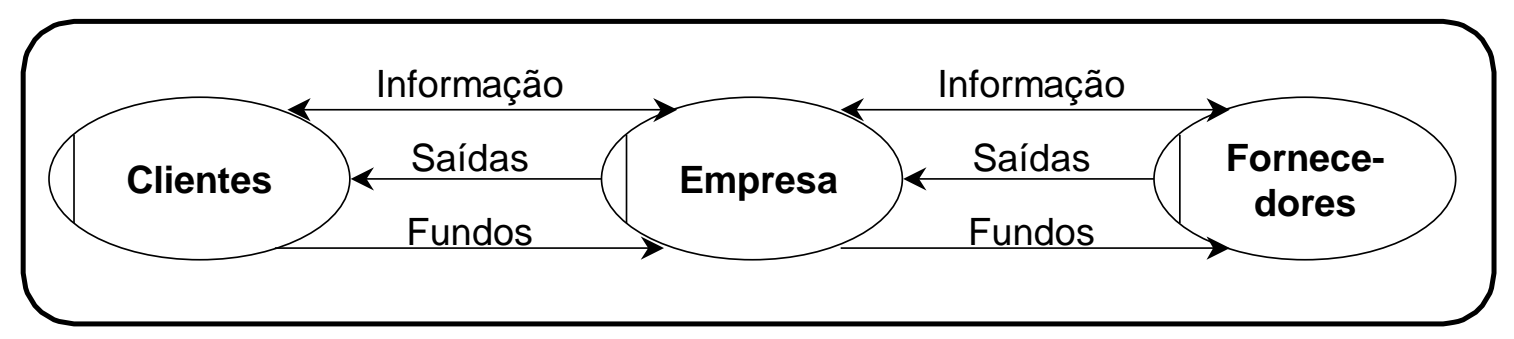

FIGURA 5.1: Diagrama de interação geral para o processo de "processamento de ordens" (SCHEER, 1998) 
A seguir, o mesmo processo de negócios é representado apenas pelas atividades (funções) a serem executadas e sua seqüência, agregando os elementos organizacionais do processo. Este fluxo de funções caracteriza o processo de negócios e pode ser visto na figura 5.2.

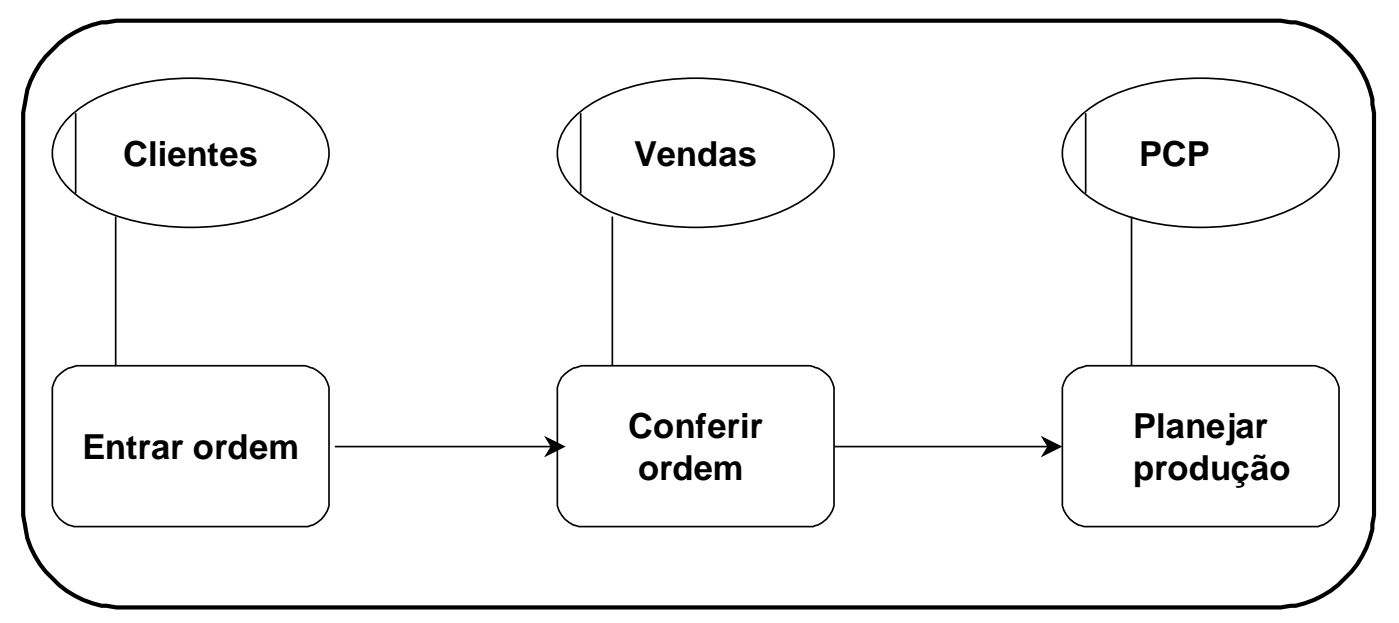

FIGURA 5.2: Fluxo de funções do processo (SCHEER, 1998)

O propósito de um processo de negócios é criar saídas, que por sua vez são entradas de outros processos. No próximo passo, as funções que criam saídas são representadas. Estas podem ser de dois tipos: informações e materiais.

Além destas, deve ser feita uma representação dos objetos de informações do processo de negócios, mostrando como os dados são utilizados.

Até o momento temos os seguintes fluxos: organização, funções, saídas e informações. Nenhum destes é capaz de representar completamente o processo de negócio. Devemos então combiná-los. O modelo de funções será usado como ponto de partida, e os outros serão integrados a este.

Os fluxos de funções são acrescidos de eventos e mensagens de controle. Isto torna possível descrever melhor a sequiência do processo. Eventos descrevem condições, e caracterizam o resultado de uma função, permitindo que a próxima função seja iniciada. Um exemplo da representação deste estágio da modelagem é visto na figura 5.3. 


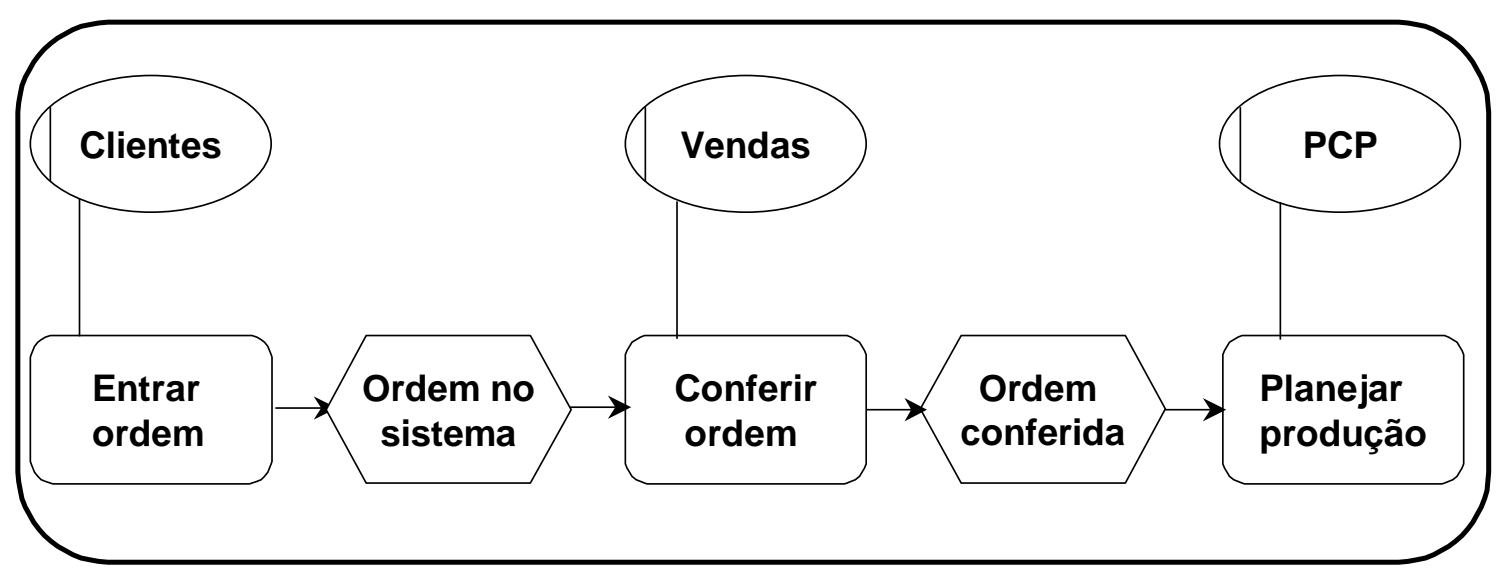

FIGURA 5.3: Fluxo de funções e eventos do processo "processamento de ordens"

O método EPC (Event-driven Process Chains) foi desenvolvido em 1992, e suporta as representações necessárias para o contexto descrito.

O modelo de processos de negócio da ARIS é hierárquico, isto é, funções podem ser explicadas em processos mais detalhados.

\subsubsection{Visões da ARIS}

A seguir são apresentadas as visões da ARIS:

- Visão de funções: mostra as transformações de entradas em saídas, além de existirem objetivos alocados às funções;

- Visão organizacional: mostras as entidades ou recursos que executam uma função;

- Visão de dados: compreende o ambiente de processamento de dados, assim como as mensagens que disparam ou são disparadas por funções;

- Visão de saídas: contém todas as saídas físicas e não físicas e

- Visão de controle (de processo): mostra o relacionamento entre as outras visões.

O relacionamento entre as visões pode ser visto na figura 5.4. 


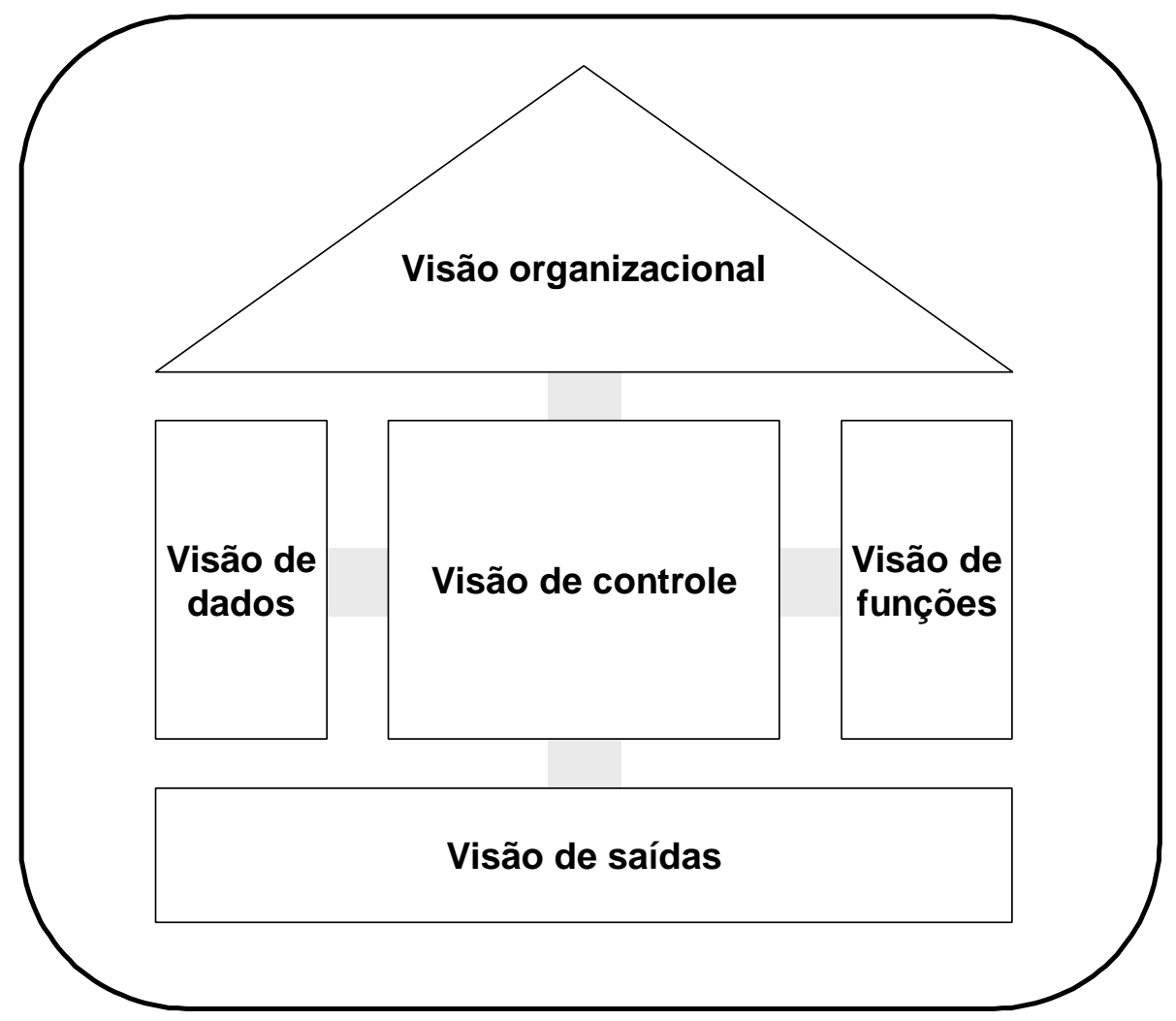

FIGURA 5.4: Relacionamento entre as visões da ARIS (SCHEER, 1998)

Por sua vez, cada visão é dividida em três fases, relacionadas ao desenvolvimento de sistemas: definição dos requisitos, projeto das especificações e descrição da implementação.

\subsection{Introdução ao modelo proposto}

O modelo não usa explicitamente a metodologia ARIS, porém são utilizados os conceitos de modelos de funções, fluxo de informações e recursos. 
Na figura 5.5 é apresentado um nível geral do modelo proposto. No Anexo 1 é apresentada a simbologia utilizada, e no Anexo 2 o modelo é apresentado na sua íntegra, e todas as atividades, sub processos e processos são detalhados.

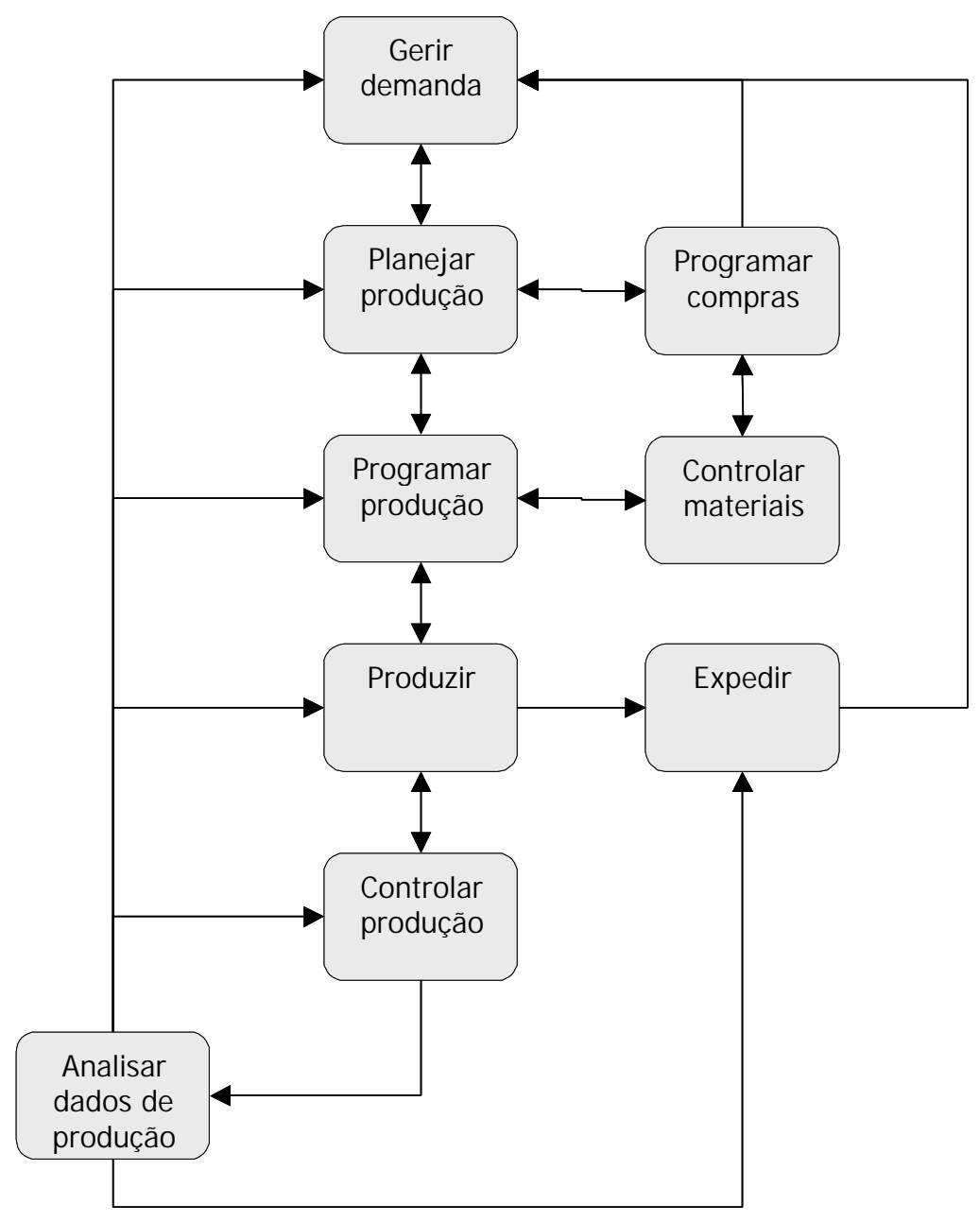

FIGURA 5.5: Visão geral do modelo proposto

Os processos de Programar compras ${ }^{2}$, Controlar materiais e Expedir não serão detalhados em atividades, por não pertencerem ao escopo deste trabalho. Eles aparecem por gerarem importantes informações para os processos de Planejamento e Controle da Produção.

${ }^{2}$ Nesta seção, os termos sublinhados indicam nomes dos processos do modelo proposto. 
Como dito na análise dos modelos conceituais estudados, estes não abordam a forma de coleta e armazenamento de dados de produção. Dentro do processo Controlar produção serão detalhadas atividades específicas para coleta de dados de produção baseadas em tecnologias como a implantação de sensores nos equipamentos de produção e eliminação de apontamento manual por parte dos operários. Para isto, além dos sensores, está prevista a utilização de outras formas de coleta automatizada de dados, como painéis de botões, coletores eletrônicos de dados, terminais de sistemas e leitores de código de barras.

Outro conjunto de atividades não explicitado nos modelos analisados é o tratamento dos dados coletados, juntamente com o suporte às decisões que se espera deste tratamento. No modelo proposto existe o processo Analisar dados de produção, que possui atividades para armazenamento e consultas destes dados, utilizando uma ferramenta computacional que é o Data Warehouse, indicado para casos onde o volume de dados é muito grande e a recuperação de dados através de pesquisas deve ser feita de forma rápida, sem prejuízo de performance ao banco de dados operacional.

Este processo de análise dos dados de produção ainda possui atividades específicas para o suporte à decisão em diferentes níveis do planejamento, atendendo a diferentes necessidades. Este processo é baseado em ferramentas com capacidade de gerar relatórios rapidamente a partir de uma extração pré-configurada de dados do Data Warehouse. Feita a extração, o próprio usuário pode criar e padronizar seus relatórios, de forma rápida e fácil, eliminando a necessidade de pessoal qualificado em informática. A principal vantagem destas ferramentas é que não existe a necessidade de alteração de sistemas corporativos, processo demorado e complexo, pois envolve pessoal qualificado e pode afetar o funcionamento de várias outras funcionalidades do sistema. Além disso, consultas e relatórios esporádicos podem ser feitos, permitindo investigações de problemas momentâneos ou que precisem ser resolvidos rapidamente.

O processo Gerir demanda realiza o primeiro nível de planejamento da produção, chamado de planejamento agregado. O processo Planejar produção é hierárquico, baseado em níveis, que são os planejamentos mestre e detalhado. Juntamente com o processo Programar produção, as atividades serão analisadas 
quanto à sua necessidade de informações, que encontrará correspondência no processo Analisar dados de produção. Os modelos analisados não apresentam suporte para tomada de decisões com informações em tempo real, o que está previsto para o modelo proposto.

BAUER et al. (1993) apresenta um processo de controle da produção detalhado e rigoroso. Porém, não é prevista a forma de coleta dos dados e tratamento dos mesmos, o que neste trabalho são considerados processos distintos. Além disso, o processo Controlar produção terá atividades específicas para interação direta de sistemas de controle e supervisão com equipamentos de produção, por exemplo impedindo que um equipamento volte a produzir caso não seja informado o motivo de uma parada.

\subsection{Principais processos}

A seguir serão apresentados os principais processos que pertencem ao modelo proposto. Serão analisados aspectos gerais, principalmente aqueles referentes ao fluxo de informações e à sequiência de atividades. Também serão destacadas a utilização das seguintes tecnologias e ferramentas:

- Data Warehouse;

- Coleta de dados automatizada;

- Sistemas ERP e

- Outros sistemas de suporte.

Descrições mais detalhadas dos processos, sub processos e atividades se encontram no Anexo 2, onde para cada atividade são apresentados:

- Descrição geral e objetivos;

- Informações necessárias;

- Informações geradas e

- Recursos necessários para a realização. 


\subsubsection{Gerir demanda}

Este processo é responsável por compreender o ambiente externo à empresa e transformar este conhecimento em previsões que irão direcionar a produção. $\mathrm{O}$ modelo deste processo é apresentado na figura 5.6.

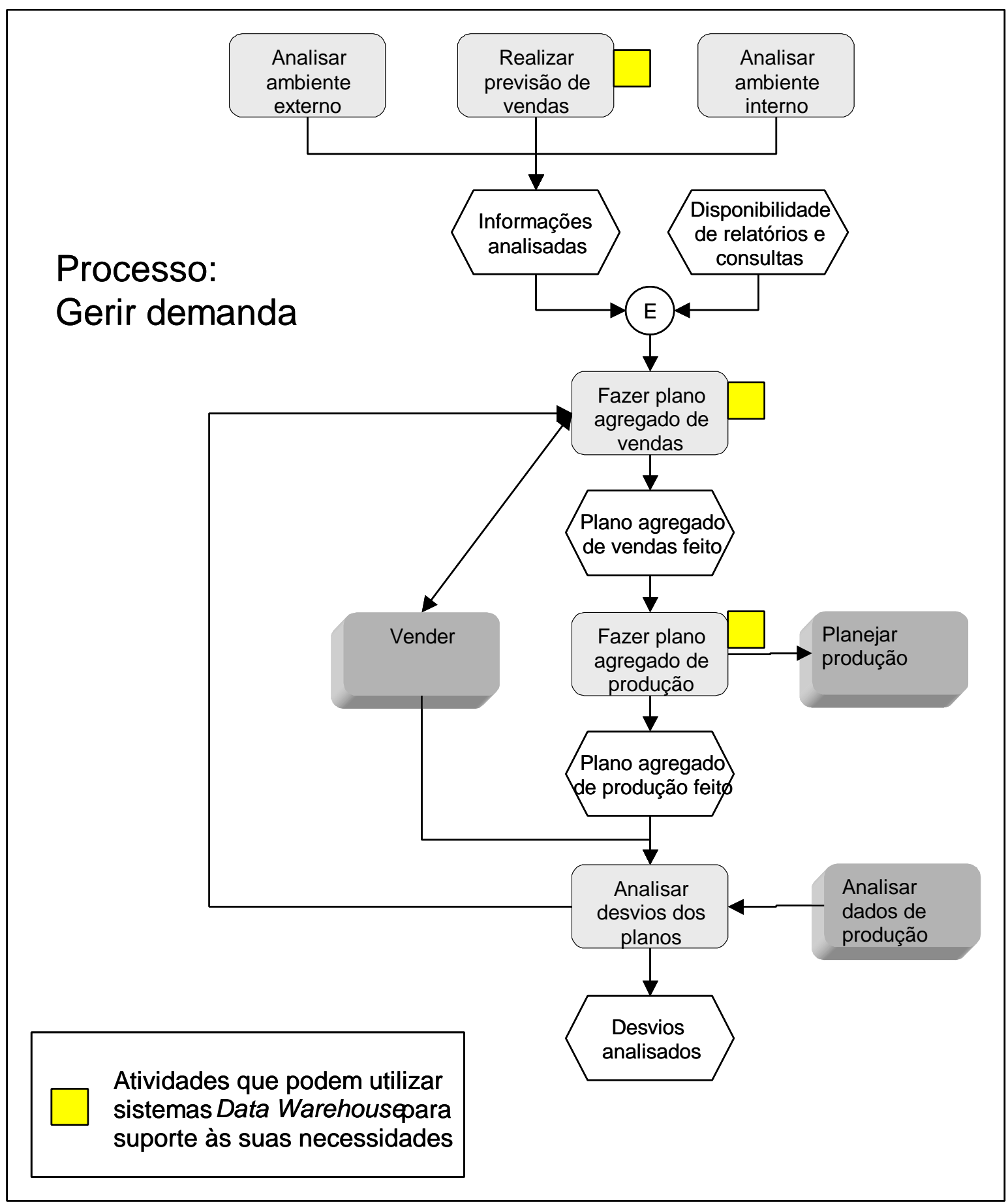

FIGURA 5.6: Modelo do processo de Gestão da demanda 
Sob o ponto de vista do planejamento da produção, este processo trata as informações da forma mais agregada, portanto dados e informações de detalhes não são utilizados. Desta forma, não são utilizadas diretamente as informações obtidas pela coleta automática de dados de chão de fábrica, sendo utilizadas de forma agregada.

Sistemas de Data Warehouse podem ser utilizados como suporte a 3 atividades deste processo.

Para a primeira delas, Realizar previsão de vendas, podem ser utilizados sistemas específicos para esta finalidade. Porém, por se tratar de uma previsão, quanto maior o número de fatores considerados, melhor a sua qualidade. Com a utilização de sistemas de Data Warehouse, podem ser feitas consultas rápidas e de forma simples sobre históricos de vendas anteriores e cruzamento de informações, como por exemplo a quantidade de um produto vendido em determinada cidade através de vendas diretas e de vendedores. Estas consultas permitem então que possa ser realizada uma previsão mais precisa, com menores desvios em relação às quantidades realmente vendidas. A previsão de vendas é ponto de partida para a elaboração do planejamento da produção em níveis mais detalhados, e quanto menores forem estes desvios, melhores serão este planos (mestre, detalhado e programação).

As atividades de Fazer plano agregado de vendas e Fazer plano agregado de produção podem utilizar sistemas de Data Warehouse para obter informações agregadas de vendas e produção, com as mesmas considerações feitas acima. Por exemplo, pode ser feito um comparativo para saber qual tipo de média (aritmética ou móvel) apresentou os menores desvios entre o plano agregado e a produção de um produto, ou a influência de uma campanha de marketing sobre as vendas de outro produto.

De maneira geral, as empresas não realizam um processo de gestão da demanda semelhante ao proposto. É comum que a previsão de vendas seja uma simples média das vendas de períodos anteriores, sem considerações adicionais. A principal consideração que poderia ser feita é sobre os desvios (diferenças) entre as previsões de vendas e a produção e vendas efetivamente realizadas nos períodos anteriores, e seus motivos. Normalmente esta previsão de vendas assume o papel de 
plano agregado de vendas e de produção, e posteriormente é desagregada, gerando o plano mestre de produção. Nesta situação, considerações posteriores deverão ser feitas, geralmente em situações emergenciais, como por exemplo a não consideração de um aumento sazonal de vendas em determinado período.

No processo proposto, são feitas considerações abrangentes sobre os ambientes internos e externos à empresa, além da previsão de vendas. Além disso, com a disponibilidade de relatórios e consultas, conforme apresentados, é possível gerar um plano agregado de vendas que seja consenso na empresa, principalmente entre as áreas que influem diretamente na produção, como vendas, compras e expedição. Este plano apresenta a expectativa de vendas da empresa, considerando as famílias de produtos. Este plano deve então ser convertido no plano agregado de produção, que deve refletir as necessidades de produção para atender à expectativa de vendas. Este último plano considera algumas políticas de produção e estoques, e restrições, principalmente a capacidade máxima ou limite de produção global da empresa. Os planos agregados são de longo prazo, geralmente vários meses, com intervalos ou períodos mensais.

Como este processo trata de previsões e informações agregadas e de longo prazo, os planos agregados de vendas e de produção podem não ocorrer na prática exatamente como previstos. Por isso, este desvio deve ser medido e analisado, para que as diferenças observadas, e os motivos que as geraram (por exemplo, um resultado maior que o esperado com um novo produto) sejam considerados em planejamentos posteriores.

\subsubsection{Planejar produção}

O objetivo deste processo é planejar todas as atividades de produção necessárias para atender à previsão da demanda em uma primeira instância, e posteriormente, atender às necessidades mais imediatas e os pedidos já colocados. Este planejamento deve prever:

- Materiais;

- Datas e

- Recursos. 
Este processo é composto de três sub processos, e seus relacionamentos podem ser vistos na figura 5.7:

- Desagregar plano agregado de produção;

- Fazer plano mestre de produção e

- Fazer plano detalhado de produção.

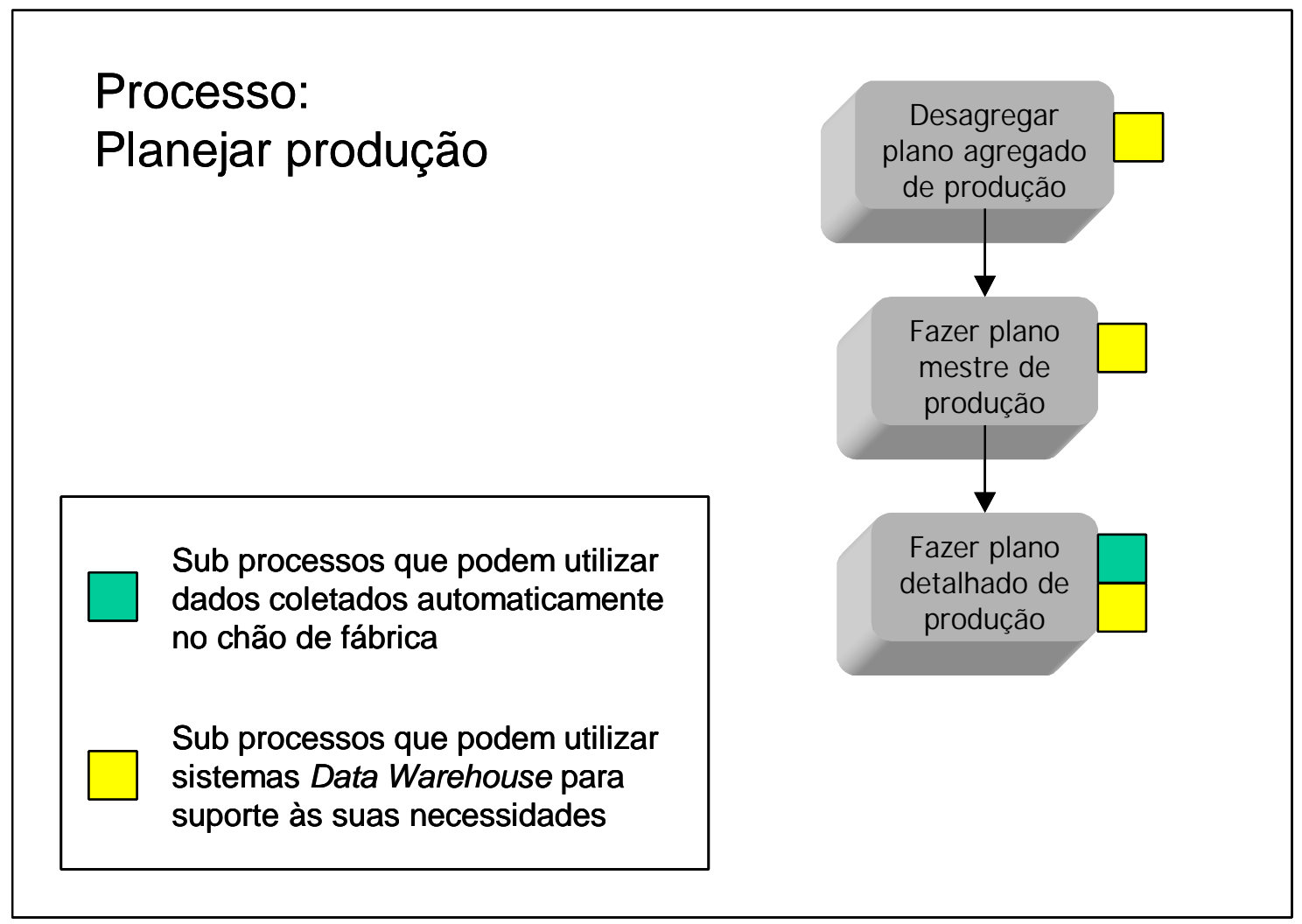

FIGURA 5.7: Modelo do processo de Planejamento da produção

Cada um destes sub processos será analisado a seguir.

Sub processo: Desagregar plano agregado de produção

A desagregação do plano agregado de produção (feito no processo Gerir demanda) é a base para elaboração do plano mestre e foi considerado como sub processo distinto, pois envolve algumas análises que devem ser realizadas separadamente. Seu modelo pode ser visto na figura 5.8 a seguir. 


\section{Sub processo: Desagregar plano agregado de produção}

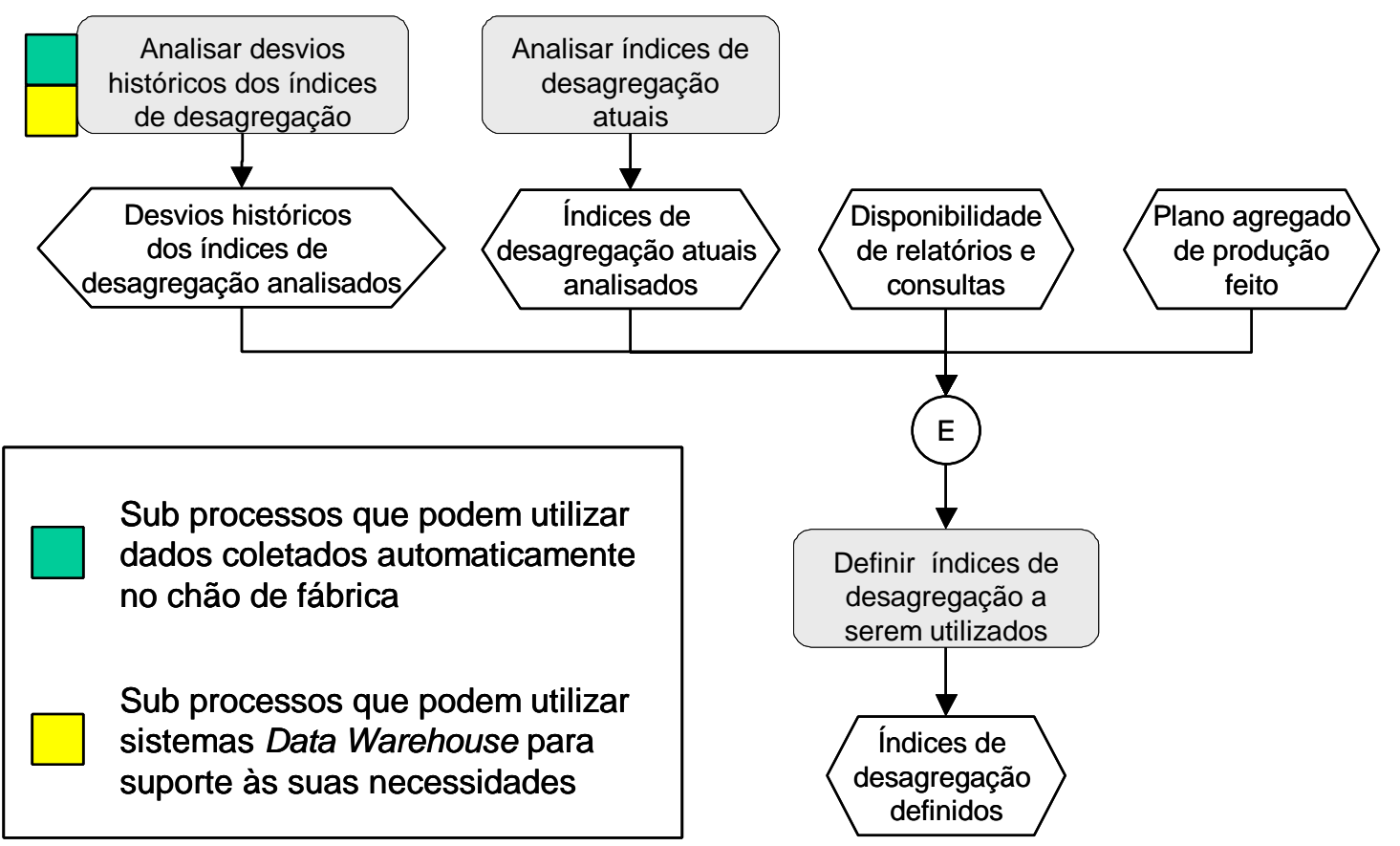

FIGURA 5.8: Modelo do sub processo de desagregação do plano agregado de produção

A desagregação do plano agregado de produção significa transformar os valores da produção necessária para as famílias de produtos nos valores de produção para os produtos que compõem cada família. Para que isto seja feito, são utilizados índices de desagregação. Estes devem ser revistos constantemente, refletindo mudanças como o lançamento de novos produtos e campanhas de promoção de produtos. Além disso, devem ser analisados os desvios ocorridos em desagregações anteriores, e seus motivos compreendidos, para serem corrigidos ou evitados.

Nesta análise dos desvios, podem ser utilizadas tanto informações geradas por sistemas de Data Warehouse como dados coletados automaticamente no chão de fábrica. No primeiro caso, podem ser geradas consultas que mostrem históricos dos desvios e seu comportamento, como por exemplo o efeito da retirada de um produto do mercado sobre os outros. Também podem ser feitas consultas sobre sazonalidades e faixas de desvio ocorridas. Informações coletadas automaticamente no chão de fábrica permitem que o desvio analisado seja preciso, refletindo exatamente aquilo 
que foi produzido em períodos anteriores, em comparação com os planos mestres correspondentes.

No modelo proposto, a desagregação é feita após estas análises dos índices e desvios históricos, além de análises de outros relatórios que podem ser configurados e solicitados, quando um novo plano agregado de produção é feito. As informações geradas neste sub processo são índices corrigidos de desagregação, que serão utilizados para criar a base do plano mestre de produção.

Geralmente este processo é realizado em empresas de manufatura discreta de forma automática, utilizando-se índices cadastrados em sistemas que sofrem poucas revisões durante o espaço de um ano, e os desvios não são monitorados. Sistemas ERP fazem esta desagregação automaticamente, porém os índices são cadastrados e devem ser alterados manualmente. Esta situação pode prolongar erros de análise, que irão acarretar no planejamento de volumes de produção que não irão atender plenamente às necessidades reais das empresas.

Sub processo: Fazer plano mestre de produção

Terminado o sub processo Desagregar plano agregado de produção, é iniciado o sub processo Fazer plano mestre de produção. O objetivo deste é fazer o planejamento da produção dos itens finais que compõem as famílias de produtos consideradas nos planos agregados. O plano mestre geralmente é feito para alguns meses, com períodos semanais, em empresas de manufatura discreta. $\mathrm{O}$ modelo deste sub processo pode ser visto na figura 6.9. As principais informações tratadas são relativas às necessidades de produtos, que deverão ser atendidas com a produção planejada. Além disso, é feita a consideração de algumas restrições, sendo a mais importante a disponibilidade de capacidade. 


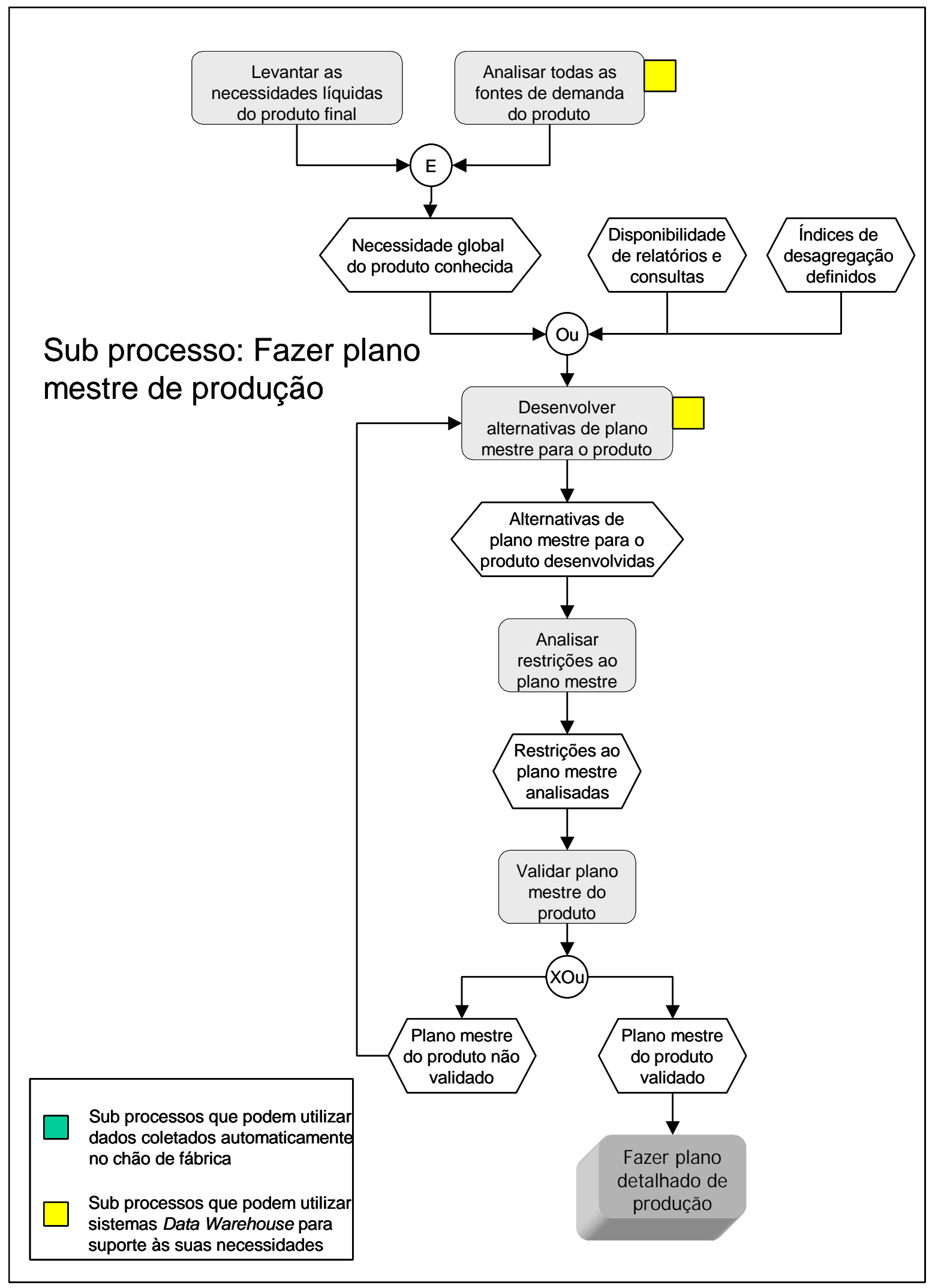

FIGURA 5.9: Modelo do sub processo de elaboração do plano mestre de produção 
Neste sub processo existem duas atividades que podem ser suportadas por sistemas de Data Warehouse.

A primeira delas é a análise de todas as fontes de demanda do produto. O plano agregado de produção atende à expectativa de demanda, porém no plano mestre devem ser feitas considerações mais detalhadas sobre as necessidades, como por exemplo testes, amostras e outras fontes. Estas podem ser conhecidas e analisadas através de relatórios com históricos destes dados.

A segunda atividade que pode ser suportada por sistemas de Data Warehouse é a elaboração de alternativas ao plano mestre de produção. É usual que um plano seja feito através de um cálculo inicial automático, gerando uma primeira alternativa. Outras alternativas podem ser feitas considerando-se informações como custos de produção, atendimento de ordens, atraso médio e outras. Estas informações permitem que sejam geradas outras alternativas ao plano mestre original, que devem ser comparadas entre si, segundo critérios definidos. Esta comparação possibilita que uma boa alternativa de plano mestre seja utilizada, permitindo otimizações e ganhos em critérios prioritários para a empresa.

O modelo proposto representa o sub processo de elaboração do plano mestre para cada produto, e portanto deve ser repetido para todos os produtos que compõem as famílias consideradas no plano agregado de produção. É iniciado com o conhecimento das necessidades globais para os produtos, que juntamente com os índices de desagregação e outras informações obtidas em relatórios e consultas dos dados de chão de fábrica possibilitam a criação de diferentes alternativas de planos. Uma vez escolhida uma destas alternativas, é necessário que as restrições sejam analisadas, principalmente de disponibilidade de capacidade e materiais. Feitas estas análises, o plano deve ser validado com as áreas ou pessoas da empresa que irão usar esta informação para suas atividades operacionais, principalmente a produção, vendas e logística (ou expedição).

Em empresas de manufatura, é usual que sejam aplicados os índices de desagregação diretamente ao plano agregado de produção, gerando automaticamente o plano mestre de produção de cada produto. Desta forma, não são consideradas uma série de informações, sendo que os planos resultantes podem não ser uma das melhores alternativas, assim como algumas necessidades de produção podem não ser 
consideradas. Esta seqüência gera um plano de produção que pode não atender plenamente as necessidades da empresa, principalmente em horizontes de tempo pequenos e no curto prazo.

Sub processo: Fazer plano detalhado de produção.

O último sub processo do processo Planejar produção é a elaboração do plano detalhado de produção. O plano mestre é um detalhamento do plano agregado de produção. Por sua vez, o plano detalhado é o detalhamento do plano mestre. Esta seqüência é conhecida como planejamento hierárquico da produção. O plano detalhado tem o objetivo de planejar as necessidades de compra e de produção dos componentes dos produtos finais. Usualmente é feito para algumas semanas, com períodos diários. Este sub processo pode ser visto na figura 5.10. 


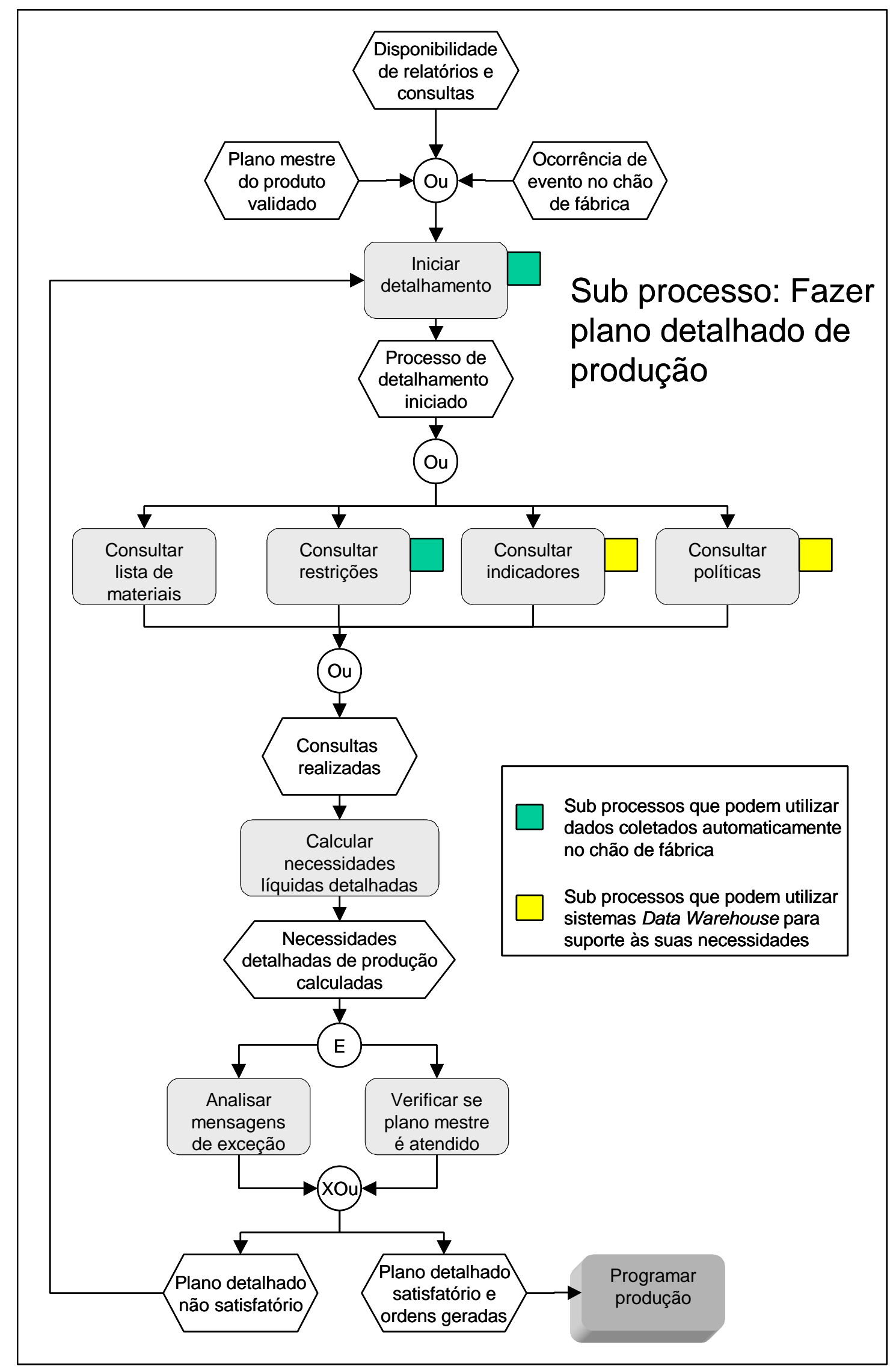

FIGURA 5.10: Modelo do sub processo de elaboração do planejamento detalhado da 


\section{produção}

Este sub processo utiliza informações de sistemas de Data Warehouse e dados coletados automaticamente no chão de fábrica.

Duas atividades podem utilizar dados coletados de chão de fábrica. A primeira delas é Iniciar detalhamento. Esta atividade pode ser iniciada automaticamente, a partir da ocorrência de algum evento, detectado no chão de fábrica. Caso isto seja feito, o detalhamento será iniciado rapidamente, caso contrário, a informação da ocorrência do evento deve chegar ao conhecimento da pessoa que inicia esta atividade. Estes eventos podem ser, entre outros:

- Quebra de equipamento;

- Falta de material e

- Atraso no processamento de operações de produção.

A ocorrência destes eventos acarreta desvios do plano original, sendo então necessário que sejam geradas novas ordens de produção, através do planejamento detalhado da produção. Podem ser geradas novas ordens apenas para substituir aquelas que tiveram problemas, ou então todas as ordens atuais podem ser substituídas.

Outra atividade que pode utilizar dados coletados automaticamente no chão de fábrica é Analisar restrições. Uma destas restrições é a disponibilidade de capacidade em recursos de produção. Como o planejamento detalhado trabalha no nível diário, é necessário o conhecimento atualizado do carregamento dos recursos, que pode ser obtido através de sistemas de monitoramento. Caso isto não seja feito, o tempo entre a necessidade da informação até a sua obtenção pode ser grande, inviabilizando este tipo de consulta.

Duas atividades deste sub processo podem utilizar sistemas de Data Warehouse, que são consultas a indicadores e a políticas da empresa. Os indicadores são valores que permitem o monitoramento de alguns fatores, como número de ordens atrasadas, volume de refugos, volumes de estoques e outros. A utilização destes permite medir o resultado de ações tomadas no passado, para saber se a orientação é correta ou deve ser modificada. O acompanhamento de alguns indicadores pode interferir ou direcionar a elaboração do planejamento detalhado. 
As principais políticas consultadas são de estoques e produção. As políticas de estoques indicam produtos estratégicos, níveis mínimos e máximos e estoques de segurança dos produtos. A realização de consultas permite o acompanhamento destes valores, que podem ser constantemente refinados.

Este sub processo é iniciado com a ocorrência de alguns eventos conforme indicado anteriormente, ou com a liberação de um novo plano mestre de produção. Caso estejam disponíveis, devem ser utilizadas informações provenientes de consultas e relatórios sobre os dados de chão de fábrica armazenados. Feito isto, o próximo passo é relativo às seguintes consultas:

- Listas de materiais, para identificação da estrutura do produto;

- Restrições, principalmente disponibilidade de recursos e materiais (estoques);

- Políticas e

- Indicadores

Estas consultas permitem que sejam feitas considerações importantes à realização do planejamento detalhado, cujo cálculo pode ser iniciado. Este é chamado de cálculo das necessidades de materiais, ou simplesmente MRP (Material Requirements Planning), e gera as necessidades líquidas de produção, para cada componente, para cada período. $\mathrm{O}$ volume de informações gerado é grande, porém o cálculo é simples.

O procedimento de cálculo pode encontrar alguns problemas, que são apresentados na forma de mensagens de exceção, que devem ser analisadas, e os problemas corrigidos na medida do possível. Uma das mensagens mais comuns é quando existe uma necessidade que não pode ser atendida, pois a produção deveria ser iniciada no passado. Estes problemas devem ser solucionados manualmente.

Além das mensagens de exceção, deve ser verificado se o plano mestre está sendo atendido, ou então qual a porcentagem ou necessidades que não são cobertas pela produção planejada.

Caso o resultado destas análises não seja satisfatório, o detalhamento deve ser refeito. Caso contrário, o processo Programar produção pode ser iniciado. 
Usualmente, este sub processo é realizado de forma automática, diretamente após o lançamento de um novo plano mestre. Isto faz com que uma série de informações não seja considerada, principalmente aquelas mais atualizadas sobre a disponibilidade dos recursos de chão de fábrica.

\subsubsection{Programar produção}

Este processo consiste na tarefa de programar as atividades de produção. Especificamente, é feito o sequenciamento das ordens de produção geradas no planejamento detalhado da produção. Este sequenciamento consiste em alocar estas ordens a recursos de produção, sendo que o tempo esperado para o processamento de cada ordem fica reservado, utilizando a disponibilidade do recurso. Este processo pode ser visto na figura 5.11. 


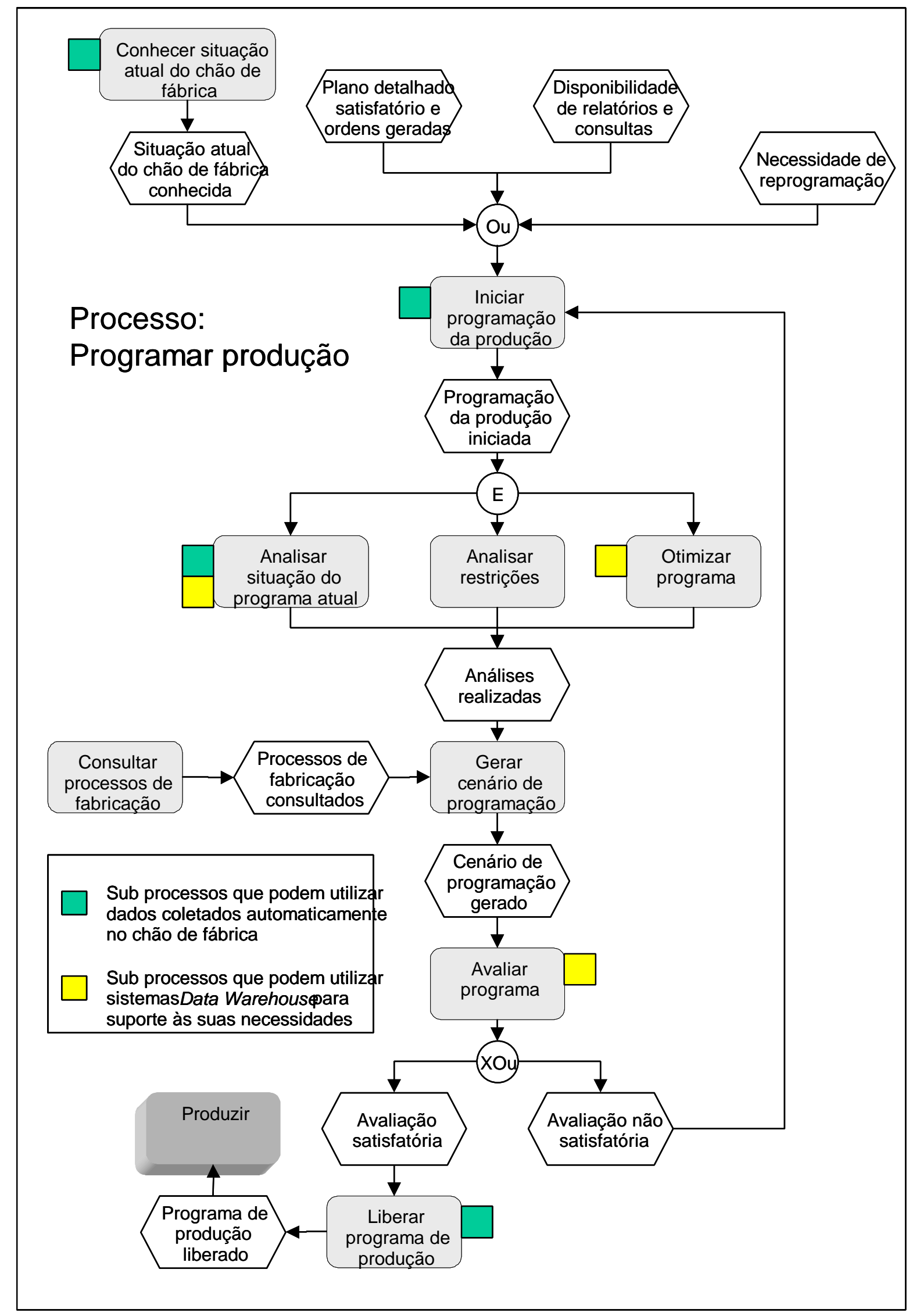

FIGURA 5.11: Modelo do processo de programação da produção 
Este processo possui atividades suportadas por sistemas de Data Warehouse e outras que utilizam informações coletadas automaticamente no chão de fábrica.

A informação trabalhada neste processo é o planejamento detalhado, expresso em ordens de produção, para todos os itens de todos os produtos que devem ser produzidos. O programa de produção deve ser detalhado ao nível de horas ou minutos, e possuir um horizonte de tempo não inferior a alguns dias.

A atividade Conhecer a situação do chão de fábrica é dependente dos dados coletados no chão de fábrica. A forma de coleta irá definir a agilidade na disponibilização dos mesmos. Caso seja feita manualmente através de apontamentos, os dados serão conhecidos, totalizados e disponibilizados com considerável atraso, geralmente de um dia. Caso a coleta seja feita eletronicamente, os dados podem ser conhecidos em tempo real, aumentando a eficiência desta atividade. O objetivo de conhecer a situação atual é saber quando existe a necessidade de se fazerem correções no programa atual ou uma completa reprogramação. Fatores como atrasos e quebras de recursos podem gerar estas necessidades, que devem ser conhecidas o mais rápido possível.

Alguns eventos ocorridos no chão de fábrica podem gerar automaticamente a necessidade de se iniciar a atividade Iniciar programação da produção. Por exemplo, caso um recurso produtivo importante, como um recurso gargalo, quebre e fique indisponível por alguns dias, as ordens que já estavam alocadas a ele devem ser remanejadas, para que os prazos de entrega possam ser atendidos. Com a coleta automática de dados de chão de fábrica, a ocorrências destes eventos pode ser percebida imediatamente, fazendo com que as correções possam ser feitas rapidamente.

A atividade Liberar programa de produção consiste em disponibilizar uma parte do programa de produção, para que os responsáveis pelas operações ou supervisores tomem as providências necessárias à realização do programa. Esta liberação compreende um período próximo à data atual, como por exemplo uma ou duas semanas, e dependendo de políticas da empresa, não são permitidas alterações no programa que já está liberado. Isto permite que sejam feitas otimizações, principalmente quanto ao tempo de preparação dos equipamentos. Caso seja feita a coleta automática de dados de chão de fábrica, podem ser estabelecidos parâmetros 
ou eventos que façam a liberação automática do programa. Por exemplo, pode ser configurado para que quando determinada ordem seja finalizada, um novo programa seja liberado.

A atividade Analisar situação do plano atual pode ser suportada por sistemas de Data Warehouse e utilizar dados coletados automaticamente no chão de fábrica. Através de relatórios e consultas, é possível acompanhar indicadores que mostrem o quanto o programa atual foi cumprido, ou que indiquem outros fatores, como eficiência, paradas e tempos médios. Além disso, é necessário o conhecimento de quais operações de produção estão em andamento ou finalizadas, o que pode ser obtido em tempo real através da coleta automática de dados de chão de fábrica.

Um programa de produção indica uma das sequiências de operações possível. Programas diferentes podem ser feitos, com prioridades diferentes, como o tempo de preparação dos recursos, número de ordens atrasadas, importância dos clientes ou a taxa de ocupação dos recursos. Estes fatores podem ter peso maior que outros, sendo que neste caso eles são otimizados em relação aos outros. O tempo de preparação é um dos fatores mais considerados otimização. Caso a atividade Otimizar programa de produção tenha o suporte de sistemas de Data Warehouse, podem ser feitos relatórios sobre as melhores sequiências para otimização, ou podem ser analisados os resultados de otimizações já realizadas. Com um acompanhamento prolongado destas consultas, é possível a geração de um conhecimento que permite a geração de regras específicas de otimização.

Para iniciar o processo Programar produção, a situação atual do chão de fábrica deve ser conhecida, devem existir ordens de produção geradas e existir a necessidade de reprogramação. Além disso deve haver a disponibilidade de relatórios e consultas dos dados de chão de fábrica. Com o atendimento de algumas destas condições, a programação da produção pode ser iniciada.

Paralelamente, devem ser feitas três análises: da situação do programa atual e de otimizações, que já foram comentadas, e as restrições do programa. Estas podem ser diversas, sendo as principais a disponibilidade de capacidade e de materiais. Feitas estas análises e consultados os processos de fabricação dos componentes, é possível a geração de cenários de programação. Cada sequiência de operações estabelecida representa uma situação que pode ser executada no chão de fábrica, 
caracterizando um cenário, e vários podem ser feitos, utilizando-se diferentes critérios de sequenciamento ou de otimização. Estes cenários devem ser então avaliados, principalmente para verificar se o limite de capacidade disponível foi respeitado. Caso contrário, o programa não poderá ser cumprido, e portanto deve ser refeito. Se a avaliação for satisfatória, o programa, ou parte dele pode ser liberado.

Este processo ocorre necessariamente em todas as empresas de manufatura discreta que utilizam ordens de produção, e pode ser feito de forma centralizada (para todos os recursos produtivos) ou podem ser feitos vários programas, para os vários conjuntos de recursos. É usual que o sequenciamento seja feito por supervisores de produção ou pelos próprios operadores, que recebem um volume de ordens para serem processadas e utilizam critérios simples para programação. Desta forma, grande parte das análises propostas neste processo não são feitas, aumentando a possibilidade de que o programa global não seja cumprido e deva ser refeito.

\subsubsection{Produção}

O processo Produzir proposto corresponde à realização das operações de produção responsáveis pela transformação sucessiva dos componentes até a finalização do produto. Neste trabalho, o foco será no trânsito de informações, e não nas operações de produção. Este processo pode ser visto na figura 5.12. 


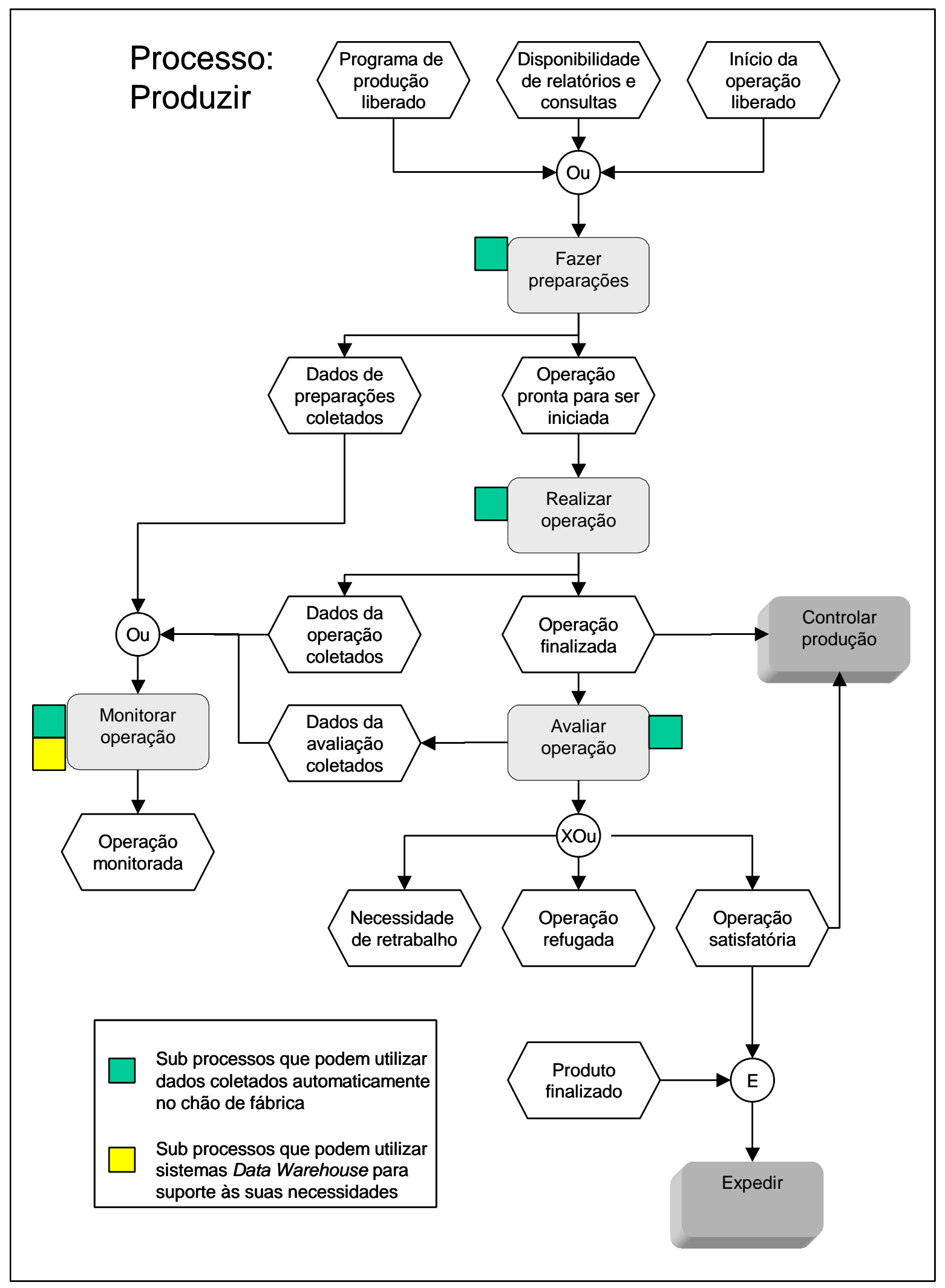

FIGURA 5.12: Modelo do processo de produção (Produzir) 
A execução deste processo gera os dados a serem coletados no chão de fábrica. É realizado para cada componente de cada produto, e seu tempo corresponde a duração da operação. O fluxo de informações é relativo às instruções da operação a aos dados de preparações, operações e avaliações.

No modelo proposto, algumas atividades deste processo geram dados, que são monitorados em uma atividade específica.

A atividade Fazer preparações tem o objetivo de tornar o equipamento ou recurso operacional, possibilitando que a operação de produção seja iniciada. É importante que alguns dados, como tempos, ferramentas e regulagens utilizadas, entre outros, sejam registrados, para que sejam utilizados posteriormente. Isso possibilita que boas preparações (aquelas de menor tempo ou custo) e suas condições sejam repetidas. Além disso, o evento que finaliza o final da preparação deve ser conhecido, para que as providências necessárias ao início da operação sejam realizadas.

Com o final da preparação, a atividade Realizar operação pode ser iniciada. Vários dados são gerados e devem ser coletados, para que sejam utilizados em diversos processos da empresa. Os dados podem ser, entre outros:

- Tempos;

- Identificação das operações;

- Paradas e

- Quantidades.

Estes dados coletados são utilizados em diversas atividades, conforme apresentado nesta seção do trabalho. Devem ser utilizados sensores e coletores de dados eletrônicos, possibilitando que os dados sejam disponibilizados imediatamente após a ocorrência dos eventos que os geraram. Dados podem também ser coletados diretamente de alguns tipos de equipamentos, principalmente aqueles comandados por microcomputadores. Os eventos de início e término das operações também devem ter seus dados coletados.

Após a realização da operação, a atividade Avaliar operação pode ser realizada. Esta avaliação irá indicar se a operação precisa ser refeita ou refugada (descartada), 
ou ainda se foi satisfatória. Podem ser avaliados vários aspectos, como medidas, quantidades e acabamento superficial. Os dados resultantes desta avaliação, tanto as medidas como os resultados, devem ser coletados e disponibilizados.

A atividade Monitorar operação concentra os dados gerados nas atividades acima. Sistemas de monitoramento devem permitir sua visualização em tempo real, para que possam ser tomadas ações em várias áreas, como planejamento da produção, manutenção, qualidade e expedição. Por exemplo, o planejador da produção de uma empresa pode ser usuário de um sistema de monitoramento, e verificar se as operações de um pedido já foram iniciadas, caso contrário estas podem ser atrasadas e pode ser aceito um pedido urgente. Outro exemplo é a utilização do monitoramento pelo pessoal de manutenção, que pode ficar sabendo da quebra ou parada de um equipamento, assim que este evento ocorre. O volume dos dados coletados tende a ser grande, sendo então necessária a utilização de sistemas especiais para a sua armazenagem, como o Data Warehouse, que possui esta característica, além de possibilitar a criação de consultas e relatórios de forma prática e rápida.

No modelo proposto, este processo é iniciado com a liberação do programa de produção e do início da atividade. Além disso, pode ser necessária a disponibilidade de relatórios e consultas dos dados de chão de fábrica. Como exemplo, pode ser necessário um relatório sobre a melhor regulagem para a preparação do equipamento, para realização de determinada operação. Outro relatório pode ser relativo à performance do uso de diferentes tipos de ferramentas.

Com as condições acima atendidas, é iniciada a preparação do equipamento, que consiste principalmente na troca de ferramentas e regulagens. Estas devem seguir um plano definido, dando as instruções necessárias. Terminada a preparação, a operação pode ser realizada, e após o seu término deve ser avaliada. Todos os dados gerados nesta seqüência devem ser disponibilizados através do monitoramento das operações.

De forma geral, as empresas de manufatura realizam a mesma seqüência proposta (preparação, operação e avaliação), porém a coleta e geração dos dados são feitas de forma diferente. É comum que exista um apontamento (anotação) manual, realizado ao término de cada operação ou turno de trabalho. Estes consistem em 
relatórios preenchidos após o término das operações, o que não possibilita que os eventos e condições ocorridos durante a operação sejam conhecidos. Além disso, o apontamento manual deve ser digitado, o que atrasa ainda mais a disponibilidade de informações. Além do atraso, o apontamento pode trazer outro problema, relativo a confiabilidade dos dados, uma vez que em muitas situações o operário deve memorizar algumas informações para depois anotá-las, o que pode gerar erros. A ocorrências destes problemas (atraso e baixa confiabilidade dos dados de chão de fábrica) foi um dos motivadores da realização deste trabalho, e podem ser solucionados com a utilização da coleta automática de dados de chão de fábrica.

\subsubsection{Controle da produção}

Este processo tem o objetivo de acompanhar a produção realizada, para que seja comparada com o planejamento. O resultado do planejamento é aquilo que se deseja que seja realizado, porém, na prática, ocorrem problemas e outros eventos que impedem que o planejamento seja cumprido exatamente em todos os seus detalhes. Com o controle da produção, é possível saber aquilo que foi e não foi cumprido do planejamento. O modelo deste processo pode ser visto na figura 5.13. 


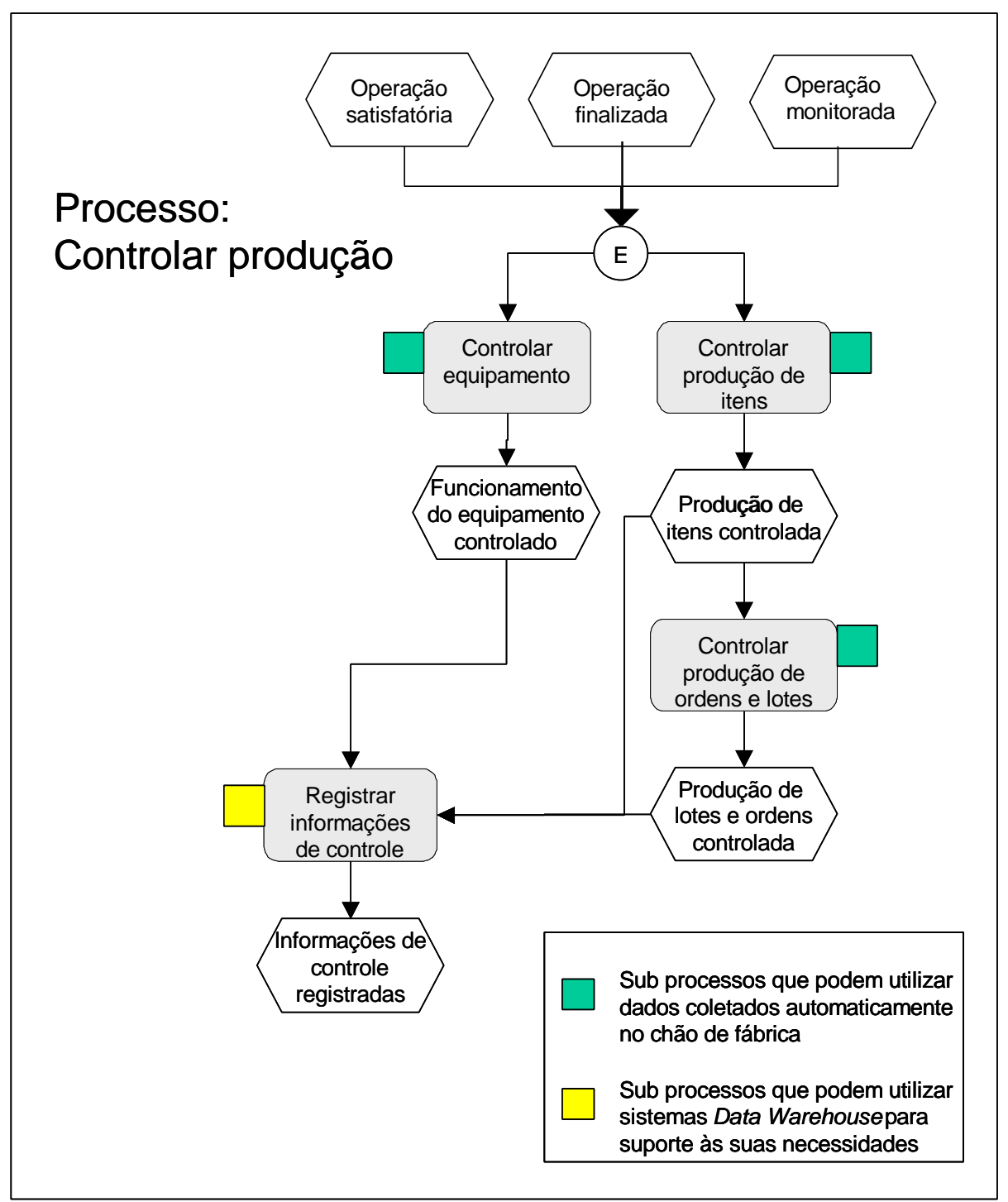

FIGURA 5.13: Modelo do processo de controle da produção

Neste processo existem três atividades de controle, relacionadas aos equipamentos, itens, ordens e lotes. Nestas, o planejamento ou funcionamento esperado são conhecidos, e são confrontados com os dados coletados no processo Produzir. O fluxo de informações é essencialmente de dados de controle, que refletem eventos ocorridos no momento ou recentemente.

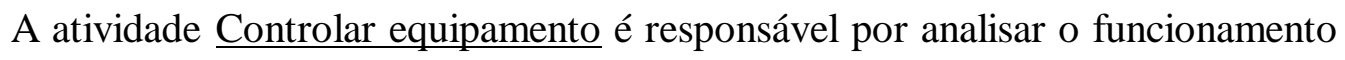
do equipamento, comparando-o com um padrão esperado. Os controles mais comuns são quanto ao funcionamento ou não, e paradas. Sistemas de monitoramento possuem funcionalidade para mostrar graficamente quando um equipamento está funcionando ou não. Isso permite uma série de avaliações, como por exemplo a taxa de ocupação média. Os controles de paradas podem ser feitos de várias formas, sendo uma delas da seguinte forma: quando um equipamento quebra e fica parado, esta 
situação é indicada, e o mesmo só voltará a ser liberado para funcionamento quando o motivo de parada for informado. Este controle de paradas permite que sejam feitas manutenções e outras medidas corretivas para evitar os motivos de paradas mais freqüentes. Também podem ser controlados outros aspectos tecnológicos, como ferramentas, temperaturas e velocidades. Para que este controle seja feito, é necessário que existam sensores e coletores de dados no equipamento, e que os dados sejam coletados automaticamente ou com a mínima interferência humana.

Outra atividade que requer coleta de dados automática é Controlar a produção de itens. Neste controle, alguns parâmetros da produção do item são controlados, como medidas, temperaturas e outras características. Caso os valores coletados não estejam dentro de faixas permitidas, o item deve ser avaliado, assim como o equipamento, para correção dos problemas. Caso esta informação esteja disponível em tempo real, as perdas e os tempos de parada podem ser diminuídos.

A atividade Controlar produção de ordens e lotes também utiliza dados coletados automaticamente no chão de fábrica. Para tal, cada operação de produção deve ser identificada, o que pode ser feito de diversas formas, sendo a mais comum através da utilização de códigos de barras. Com a operação identificada e o conhecimento do programa de produção, é possível saber se os prazos estão sendo cumpridos ou não. Além disso, é possível o acompanhamento das operações de cada ordem, sendo que alguns sistemas de programação da produção permitem que a situação da ordem seja visualizada de forma gráfica, através de mudanças de cores ou do preenchimento.

Os dados de controle, que indicam a comparação entre aquilo que foi planejado e aquilo que ocorreu devem ser registrados, para consultas e análises posteriores. A atividade Registrar dados de controle utiliza um sistema de Data Warehouse para tal finalidade, pois o volume dos dados tende a ser grande, e uma série muito grande de consultas pode ser feita, como por exemplo o tempo médio para processamento de determinado tipo de produto, ou a quantidade média dos lotes de processamento.

No modelo proposto, após a finalização de uma atividade satisfatória, é iniciado o processo de controle da produção, que especificamente irá controlar o equipamento, os itens, lotes e ordens produzidas. Este controle gera uma série de dados que devem ser armazenados. 
Usualmente, este processo ocorre de maneira não formalizada em empresas de manufatura discreta. Nestas empresas é feito o apontamento da produção (conforme já descrito), que não permite agilidade suficiente para fazer controles em tempos de resposta satisfatórios. Desta forma, com o atraso na disponibilização dos dados de produção coletados, o controle é defasado, e as correções dos problemas ocorridos fica comprometida. Além disso, não é comum que os dados de controle (e não os de produção) sejam registrados, visto que poucos sistemas de planejamento possuem este tipo de funcionalidade.

\subsubsection{Analisar dados de produção}

No processo Produzir são gerados dados que são coletados e utilizados para controle no processo Controlar produção. Além disso, após sua coleta, os dados são armazenados para que sejam feitas análises, na forma de consultas e relatórios.

Várias atividades do modelo proposto utilizam estes dados coletados automaticamente, de duas formas diferentes. Uma delas é quando os dados são utilizados diretamente após sua coleta, e outra é quando os dados são armazenados e consultados posteriormente.

O processo Analisar dados de produção pode ser visto na figura 5.14. 


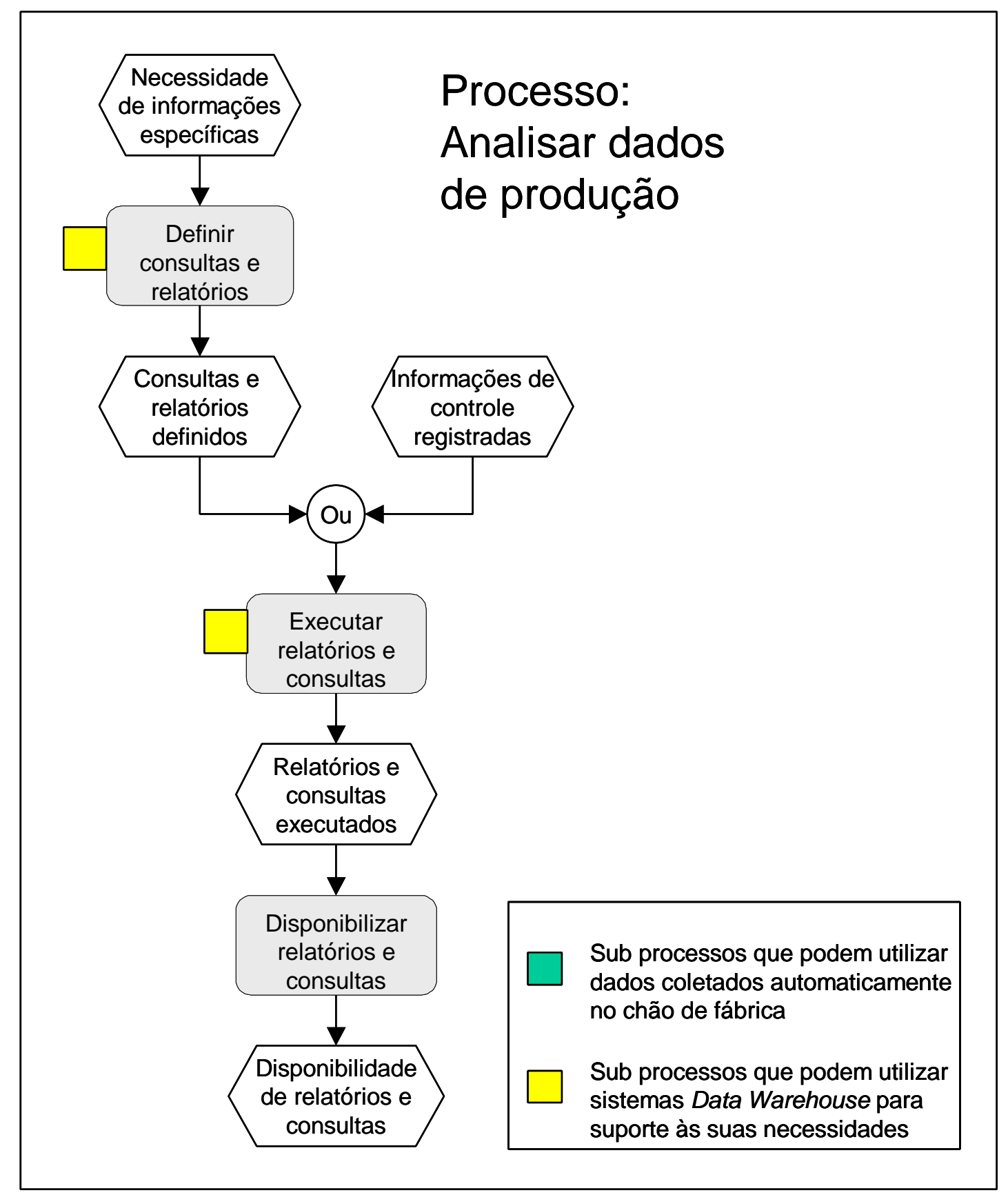

FIGURA 5.14: Modelo do processo de análise dos dados de produção

Neste processo não existem atividades que utilizem dados coletados de chão de fábrica de forma direta, e duas atividades utilizam sistemas de Data Warehouse para suportar suas necessidades. O fluxo de informações relativo às definições de consultas e relatórios indica quais as necessidades de informações dos usuários, que devem definir os resultados e formas de elaboração. Por exemplo, um programador da produção que necessite saber o tempo médio de transporte de peças entre dois equipamentos, deve passar quais as informações que necessita e onde podem ser 
encontradas, calculadas ou organizadas. Na atividade Definir consultas e relatórios, estas necessidades dos usuários devem configurar mecanismos de recuperação e geração dos dados coletados no chão de fábrica. Algumas ferramentas permitem que o próprio usuário desenvolva sua consulta, através de uma tecnologia chamada tabela dinâmica.

Uma vez definidas estas consultas e relatórios, elas devem ser executadas, o que pode ser feito periodicamente ou através de requisições dos interessados. Sua execução consiste na recuperação e preparação para exibição dos dados. Os sistemas de Data Warehouse realizam um processo chamado de extração dos dados, que ainda devem ser adaptados para exibição.

Usualmente, este processo não ocorre em empresas de manufatura. Um motivo é o fato dos dados coletados no chão de fábrica (independente da forma, manual ou automática) não serem centralizados de forma sistemática, e que facilite a realização de consultas e relatórios. Outro motivo é não existirem meios da disponibilização destes dados. Desta forma, onde algum tipo de informação de chão de fábrica é necessária, são feitos depósitos de dados específicos e restritos localmente. Com isso, somente algumas pessoas têm acesso a esta classe de informações, dificultando sua integração, possibilitando a criação de controles paralelos.

Outro motivo da não utilização efetiva dos dados coletados no chão de fábrica é a dificuldade de configuração e realização de consultas e relatórios. Isto geralmente requer modificações no código fonte ou o desenvolvimento de novos sistemas, o que significa que existe a necessidade de pessoal qualificado, e que o tempo de execução pode ser longo (alguns dias). Esta falta de agilidade impede que as informações sejam utilizadas logo após sua geração, limitando sua utilização.

\subsubsection{Outros processos}

Neste tópico será analisado o fluxo de informações dos processos não detalhados nesta seção.

O processo Programar compras se relaciona com três outros processos. O processo Planejar produção gera as necessidades de compras que são planejadas, e ao mesmo tempo é restringido pelo planejamento de compras. Da mesma forma, o planejamento das compras é uma restrição ao processo Gerir demanda. 
$\mathrm{O}$ processo Controlar materiais também possui um relacionamento com o processo de planejamento de compras, pois faz o controle do recebimento e movimentação de materiais, que são informações necessárias ao planejamento de compras. Além disso, o controle de materiais troca informações com o processo Programar produção, para que sejam incluídas nos programas apenas ordens que tenham disponibilidade de materiais, e no outro sentido, o controle de materiais deve conhecer o programa de produção para preparar e disponibilizar os materiais que serão necessários.

O processo Expedir trata dos materiais e produtos que sofreram operações de produção do processo Produzir, além de informações específicas para expedição e armazenamento. Este processo fornece informações sobre entregas para a gestão da demanda, permitindo a promessa de datas de entregas. Informações coletadas no chão de fábrica também podem ser utilizadas no processo de expedição, através de consultas e relatórios que podem ser configurados e executados. 


\section{APLICAÇÕES}

Neste capítulo serão apresentadas aplicações do uso da coleta automática de dados de produção em ambientes de manufatura discreta. A primeira delas não segue o modelo proposto, porém serviu de base para sua validação. A segunda aplicação apresentada ocorreu em ambiente simulado e seguiu o modelo conceitual proposto como referência, servindo também para sua validação.

\subsection{Fábrica de autopeças}

A aplicação descrita a seguir foi realizada pelo grupo de Otimização dos Processos de Fabricação do NUMA, em fábrica de autopeças, durante o ano de 2000. Esta fábrica atende ao escopo desta tese, ou seja, é uma empresa de manufatura discreta que utiliza ordens de produção. As características do projeto serão apresentadas em linhas gerais. Maiores detalhes podem ser obtidos em MEIRELLES (2000).

Foram instalados sensores acústicos e de potência em uma linha de 5 retíficas, que realizam operações de acabamento. $O$ transporte das peças entre os equipamentos é feito automaticamente, através de condutos aéreos. Este implantação foi um piloto, para que os benefícios pudessem ser analisados, com a possível expansão para outras linhas de equipamentos.

Os dados coletados são, para cada equipamento:

- Situação do equipamento (parado, operando, carregando ou descarregando);

- Tempos de operação para cada componente;

- Vida útil da ferramenta (rebolo) e

- Quantidades.

Estes dados são transmitidos dos sensores para um sistema de supervisão, através de uma rede de campo.

O primeiro objetivo desta implantação foi o monitoramento das trocas e afiação (dressagem) das ferramentas, para aumento da vida útil das mesmas, e conseqüente diminuição dos custos de produção. Em alguns equipamentos, a vida 
útil das ferramentas foi aumentada consideravelmente. Outras informações tecnológicas, das ferramentas, equipamentos e transporte também podem ser monitoradas.

Em um segundo estágio do projeto, ocorreram análises para utilização dos dados coletados como suporte às atividades de planejamento e programação da produção.

Os dados coletados são armazenados em um banco de dados relacional, com algumas consultas e visões já programadas. A visualização do sistema de monitoramento é compartilhada em rede local, permitindo que várias pessoas possam ter acesso às informações coletadas em tempo real.

\subsection{IPROS}

\subsubsection{Descrição geral}

A proposta do projeto IPROS (Integrated production and supply chain management) foi vencedora do concurso SAP GREAT AWARDS 99, realizado nos Estados Unidos, em Novembro de 1999, o que proporcionou um prêmio em dinheiro para o Núcleo de Manufatura Avançada da EESC-USP.

Foi proposta a integração de sete sub projetos de pesquisa, que estavam em andamento na época, porém sem aplicações em conjunto. $\mathrm{O}$ objetivo da proposta era construir um Management Cockpit, ou seja, um conjunto de sistemas que permitissem suporte à tomada de decisões de planejamento na empresa e na cadeia de suprimentos, com base em consultas e relatórios obtidos de dados coletados automaticamente no chão de fábrica.

A execução do projeto foi de fevereiro a dezembro de 2000, e envolveu cerca de 36 alunos ( 1 de doutorado, 15 de mestrado e 20 de iniciação científica), além de 7 professores que fazem parte do NUMA.

Os sub projetos do IPROS são:

- Controle de chão de fábrica;

- Gestão da demanda;

- Sensoreamento e monitoramento da produção; 
- Data Warehouse e Data Mining;

- Desenvolvimento de produtos e Gerenciamento de mudanças de engenharia;

- Indicadores de produção e

- Gestão da cadeia de suprimentos.

O objetivo do projeto foi a construção de um cenário de apresentação, que demonstrasse a integração dos sub projetos, mostrando um processo simulado da gestão da produção de uma fábrica de moto redutores, e o processo de produção de um eixo componente de um dos produtos finais.

A seguir o projeto IPROS será detalhado.

6.2.2. Cadeia de suprimentos

A figura 6.1 apresenta uma representação da cadeia de suprimentos simulada no projeto IPROS. 


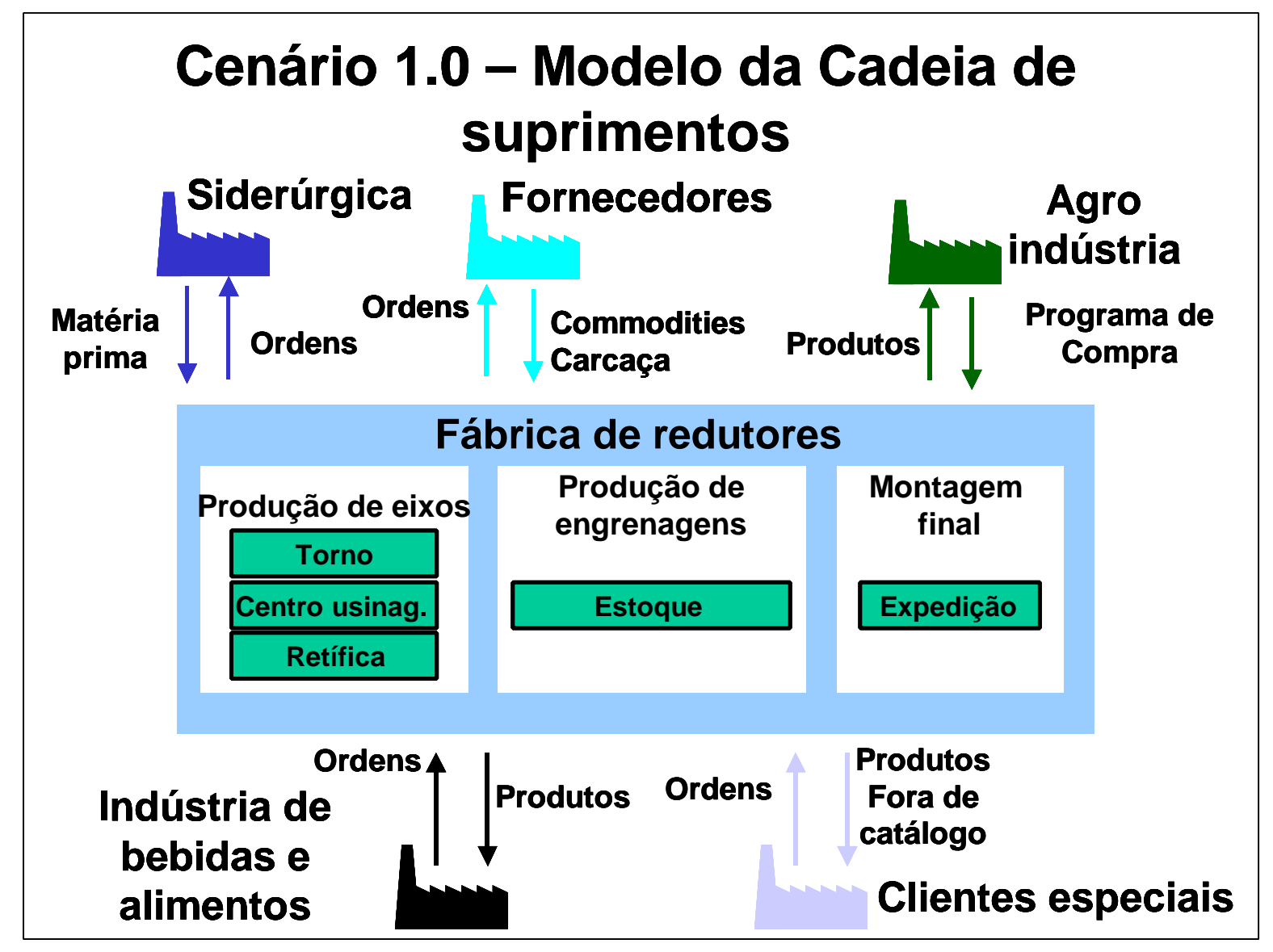

FIGURA 6.1: Modelo da cadeia de suprimentos do projeto IPROS

A fábrica simulada no projeto IPROS chama-se Fábrica Integrada Modelo (FIM), e além de seus fornecedores, possui relacionamento com três classes de clientes:

- Agro indústria, utiliza redutores de catálogo para implementos agrícolas e máquinas de elevação. O fornecimento se dá através de um programa de compra estabelecido para alguns meses. O volume de compras é grande, e a periodicidade de entrega é pequena;

- Indústria de bebidas e alimentos, utiliza produtos de catálogo e especiais, para desenvolver instalações industriais. O fornecimento se dá através de pedidos, que surgem quando alguma instalação está sendo construída. O volume de cada compra é grande, porém a periodicidade é pequena e incerta e 
- Clientes especiais, que utilizam moto redutores para as mais diversas finalidades, sendo geralmente produtos fora de catálogo (especiais). A compra é feita por pedidos, com volume e periodicidade variável.

Para a apresentação final, foram considerados somente os clientes de agro indústria, que fornecem um programa de compras para seis meses no futuro, sendo que para o próximo mês o detalhamento do programa de entregas é diário, e para os outros meses é mensal.

\subsubsection{Modelo de integração}

A figura 6.2 apresenta o modelo de integração e dos sistemas utilizados no projeto IPROS.

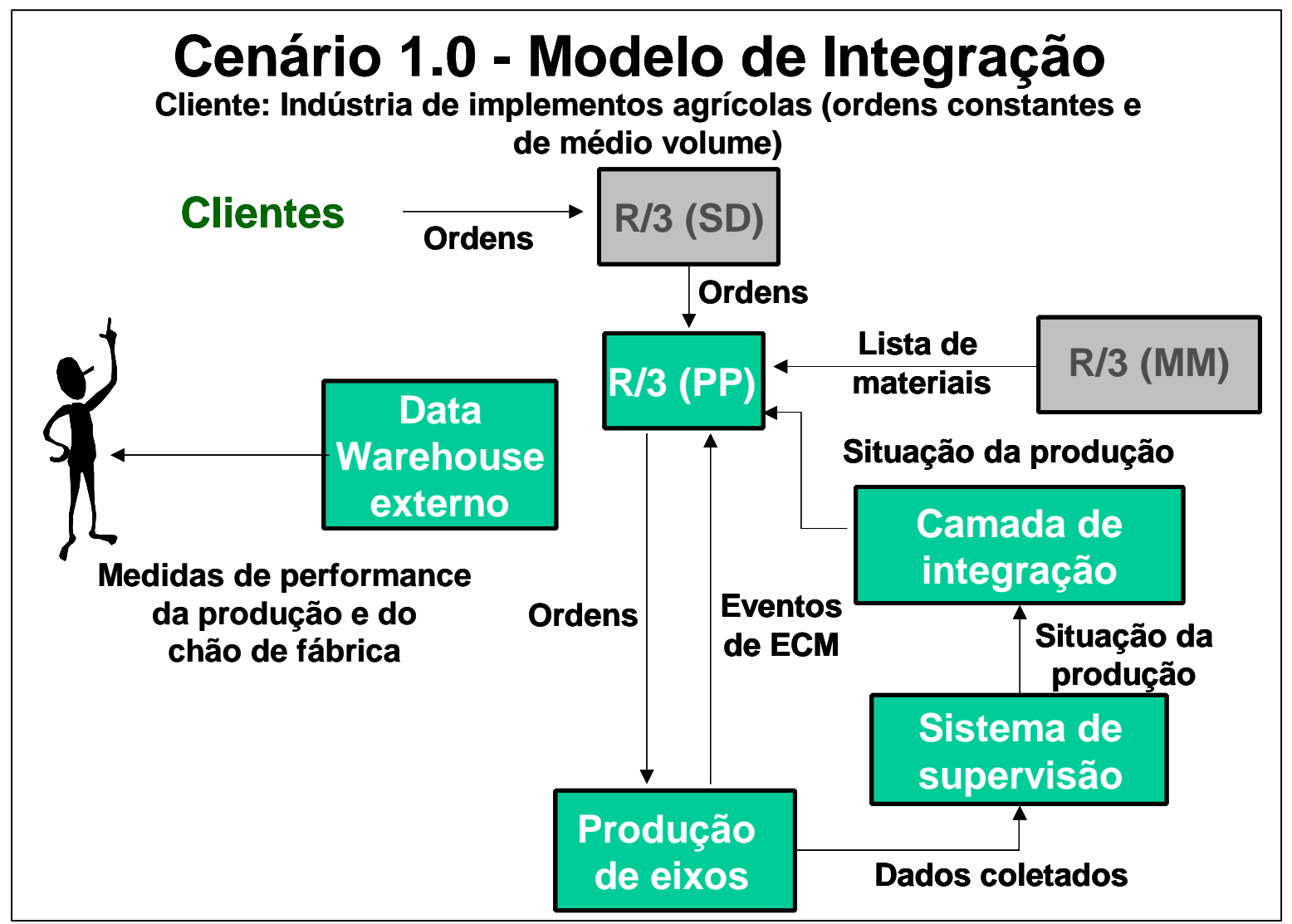

FIGURA 6.2: Modelo de integração do projeto IPROS

Foram utilizados três módulos do sistema R/3 da SAP:

- SD (Vendas e distribuição), utilizado para concentrar os pedidos e gerar as necessidades de produção, expressas em ordens; 
- PP (Planejamento da produção). Este módulo recebe as necessidades de produção, as listas de materiais e a situação atual do chão de fábrica, para em função disso fazer o cálculo das necessidades detalhadas e a programação da produção e

- MM (Gerenciamento de materiais), responsável pela manutenção das listas de materiais dos produtos e a movimentação de materiais.

A produção dos eixos foi feita em equipamentos de produção instalados no chão de fábrica da FIM, que possuem sensores acústicos e de potência, cujos dados são coletados e disponibilizados por um sistema de supervisão.

Para a integração entre o sistema de supervisão e o sistema $R / 3$ foi desenvolvida uma camada de integração, que através de arquivos do tipo texto faz a troca de dados entre os sistemas, nos dois sentidos.

O sistema de supervisão também disponibiliza os dados coletados no chão de fábrica para um sistema de Data Warehouse, integrado através de uma rede local, e que fornece indicadores elaborados a partir destes dados.

\subsubsection{Modelo do processo}

A seguir será descrita a seqüência de atividades que formam o processo utilizado na apresentação simulada da Fábrica Integrada Modelo, do Projeto IPROS. O modelo pode ser visto na figura 6.3. 


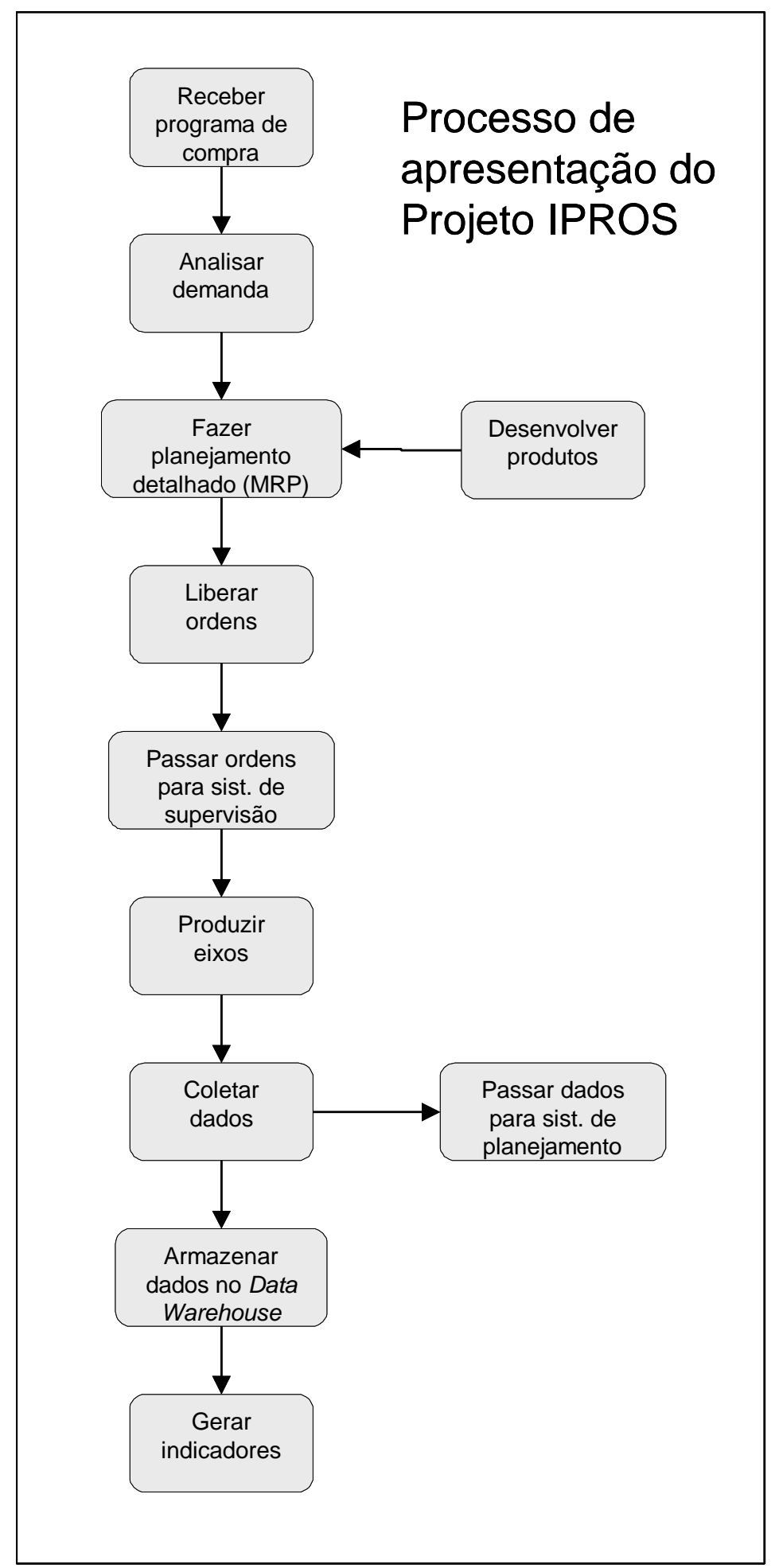

FIGURA 6.3: Modelo da Fábrica Integrada Modelo do projeto IPROS

O processo começa com o recebimento do programa de compras dos clientes de agro indústria da FIM. Estes programas são consolidados para gerar as necessidades brutas de produção. A seguir é realizada uma atividade diária, que 
analisa a demanda em função do planejamento já existente, para serem decididos quais pedidos vão entrar no próximo planejamento.

Paralelamente a estas atividades é feito o desenvolvimento de produtos e manutenção dos dados de engenharia. Esta atividade tem o objetivo de fornecer as listas de materiais atualizadas dos produtos, para que seja feita a explosão das necessidades dos componentes no planejamento detalhado da produção, também conhecido simplesmente por MRP.

O resultado do MRP é um conjunto de ordens que são analisadas, para posteriormente serem liberadas. O sistema desenvolvido para a camada de integração filtra estas ordens do banco de dados do sistema $R / 3$ e as envia para o sistema de supervisão. Este último disponibiliza as ordens para serem executadas.

As operações de produção (furação, torneamento e retífica) são então realizadas, e sensores instalados nos equipamentos, além de um painel de botões, coletam dados e os enviam automaticamente ao sistema de supervisão. Estes dados também são enviados, novamente pela camada de integração, para o sistema de planejamento, indicando a situação (status) das ordens.

O sistema de supervisão alimenta diretamente um sistema de Data Warehouse com os dados coletados no chão de fábrica. Este último gera relatórios contendo indicadores, que são utilizados como suporte ao planejamento da produção, permitindo que este ciclo seja reiniciado. 


\section{CONCLUSÕES}

\subsection{Resultados}

Conforme apresentado no capítulo 2 deste trabalho, a pesquisa foi desenvolvida com base em um problema, apresentado na forma da seguinte questão: Os modelos conceituais de gestão da produção largamente utilizados e aceitos servem de referência para a utilização e implantação das novas tecnologias de coleta, análise e tratamento de dados de chão de fábrica?

A resposta a esta pergunta é negativa, pois os modelos analisados, representativos do universo de modelos conceituais adotados dentro e fora do país, não contemplam os resultados das tecnologias apresentadas. Devido a esta negativa, foi proposto um modelo que sirva de referência.

Estes resultados são relacionados a uma substituição dos métodos tradicionais de coleta de dados, baseados em apontamentos manuais, por métodos que gerem dados mais precisos, mais rapidamente e mais fáceis de serem obtidos.

O uso de modelos conceituais é uma referência para ambientes de empresas, que procuram comparar a sua situação com estes modelos. Isto pode ser feito tanto na implantação das tecnologias empregadas e na comparação, para efeito de diagnóstico, da situação atual da empresa com uma situação de referência. Além disso, o modelo conceitual permite que as pessoas da empresa possam visualizar situações que podem ser atingidas, e traçar planos para alcançá-las. Devido a esta importância dos modelos conceituais, os mesmos devem ser sempre atualizados, contemplando as tecnologias mais recentes que estejam disponíveis.

A seguir será feita a análise das hipóteses, também apresentadas no capítulo 2.

A primeira hipótese era que o apontamento manual da produção poderia ser substituído, ao menos em parte, pela coleta automatizada de dados de produção em empresas de manufatura discreta. Esta hipótese é verdadeira, pois foi provado com o modelo proposto que isto pode ocorrer com vantagens, relacionadas aos seguintes fatores:

- Mais rapidez na obtenção dos dados; 
- Maior precisão e nível de detalhamento;

- Dados obtidos durante o processo de produção de maneira contínua e

- Maior abrangência na disponibilidade dos dados.

Além disso, a implantação da coleta automatizada de dados pode gerar outros dados que geralmente não são coletados pelo apontamento, principalmente informações tecnológicas a respeito do equipamento e ferramentas como as obtidas nas atividades Controlar equipamento e Fazer preparações. Além disso, podem ser conhecidas informações sobre custos relacionados à produção, obtidos com o consumo de recursos que possam ser mensurados, como por exemplo o tempo de utilização de um equipamento que consuma energia elétrica.

A segunda hipótese é que o uso de tecnologias e sistemas complementares à coleta automatizada de dados do chão de fábrica pode trazer importantes mudanças para o planejamento e controle da produção. Esta hipótese também é correta, pois o modelo proposto faz largo uso destas tecnologias e ferramentas, principalmente sistemas Data Warehouse. Estes complementos permitem que seja agregada uma classe de relatórios e consultas dos dados do chão de fábrica, que interferem em praticamente todos os processos da gestão da produção, conforme pode ser visto no detalhamento das atividades apresentado no Anexo 2.

A hipótese de que poderiam ocorrer mudanças na forma de realização de algumas atividades do processo de gestão da produção com a disponibilização de dados coletados automaticamente no chão de fábrica também foi verificada. Isto pode ser percebido nas duas aplicações práticas analisadas. Além disso, na construção do modelo pode ser verificado que a disponibilidade destes dados podem complementar a realização de atividades, modificando-as.

A próxima hipótese é que uma classe de decisões da gestão da produção necessita de informações precisas e rápidas, em alguns casos até on-line. Isto é correto e foi largamente utilizado no modelo proposto. Esta consideração também pode ser observada nos casos práticos analisados, onde em função da disponibilidade de dados on-line, alguns procedimentos de planejamento e programação foram modificados, para incorporar esta funcionalidade. 
A quinta hipótese é de que a geração de relatórios de forma fácil, em acordo com as necessidades do usuário, e de preferência sem necessidade de intervenção de pessoal especializado, facilita a tomada de decisões para a gestão da produção. Isto também é verdadeiro e foi incorporado ao modelo proposto, com base em sistemas de Data Warehouse. Várias atividades propostas realizam consultas rápidas e configuradas pelo usuário em dados previamente preparados, de acordo com as suas necessidades momentâneas.

Por fim, a última hipótese é de que um modelo conceitual, que considere as tecnologias e sistemas de coleta de dados e seus complementares, pode facilitar e ampliar o uso destas tecnologias, trazendo uma melhoria para a gestão da produção em empresas de manufatura discreta. O modelo proposto possui este objetivo, e foi utilizado em parte nos casos práticos analisados. Sua utilização pode ser uma referência para a implantação das tecnologias de coleta automática de dados de chão de fábrica e seu tratamento.

Uma das características da metodologia de pesquisa indutiva adotada é a geração de novas hipóteses. Algumas destas podem ser:

- Os dados de produção coletados automaticamente podem ser utilizados por processos de negócio além daqueles relacionados à gestão da produção, como financeiros, de gerenciamento de custos, de vendas e de relacionamento com os clientes e fornecedores;

- A utilização de dados de produção coletados automaticamente pode interagir diretamente com o processo de produção, como o acionamento ou parada de equipamentos automaticamente, devido à ocorrência de eventos;

- O processo de desenvolvimento de produtos pode utilizar dados de produção, para identificar possíveis melhorias no projeto e processo de produção dos produtos;

- O sistema de coleta automática de dados de produção pode ser utilizado para o Controle Estatístico do Processo (CEP);

- Os responsáveis pela manutenção dos equipamentos de produção podem utilizar a estrutura de coleta de dados de produção de uma 
empresa para diagnosticar o funcionamento dos equipamentos a distância;

- O processo de coleta de dados de produção apresentado pode ser adaptado para utilização em empresas de outros tipos, além daquelas de manufatura discreta.

Além disso, podem ser gerados novos problemas (expressos por perguntas) que podem ser respondidos por pesquisas posteriores e complementares a esta, como:

- Sistemas ERP podem gerenciar de forma eficiente os dados de produção coletados automaticamente?

- A utilização de sistemas de Data Mining pode complementar o modelo proposto?

- É possível o desenvolvimento de um modelo de custeio de operações industriais completamente baseado na coleta automática de dados de produção?

\subsection{Conclusões}

Uma das conclusões deste trabalho é que a coleta automática de dados de chão de fábrica é viável para empresas de manufatura discreta que trabalham com ordens de produção. Além disso, contribui com o processo de gestão da produção nos seguintes aspectos:

- Rapidez no fornecimento e disponibilização dos dados coletados;

- Fornecimento de dados detalhados;

- Confiabilidade dos dados e

- Monitoramento e supervisão da produção e dos equipamentos

Estes aspectos permitem que sejam tomadas melhores decisões, por estarem baseadas em um maior volume de informações, por sua vez mais confiáveis e disponíveis no momento adequado.

Conforme pode ser visto no modelo proposto, praticamente todos os processos da gestão da produção podem utilizar muitos e mais precisos dados de chão de fábrica, permitindo melhores decisões. Estes dados são mais precisos que aqueles 
gerados por processos manuais, devido à eliminação de algumas fontes de imprecisão, como a anotação (escrita) e digitação.

Devido ao caráter original, o modelo proposto pode ser usado como referência na implantação de sistemas de coleta de dados automática de chão de fábrica, integrados com os sistemas de apoio citados ou isoladamente.

A utilização de modelos conceituais é importante, pois pode ser utilizada como referência para empresas interessadas na implantação das tecnologias apresentadas, evitando esforços de desenvolvimento de conceitos já empregados.

A disponibilidade de dados de chão de fábrica em tempo real permite que sejam tomadas ações corretivas mais rápidas para determinados problemas, em comparação com ambientes onde os dados são coletados manualmente. Permite também:

- Atualizações em tempo real de sistemas de programação e planejamento;

- Acompanhamento de ordens por parte de vendedores e clientes e

- Rastreabilidade de produtos e componentes.

Outra conclusão é que, além de coletados, os dados devem ser tratados, armazenados e disponibilizados de forma eficiente, o que pode ser feito por sistemas de Data Warehouse, que atendem estes requisitos. Outra funcionalidade destes sistemas, a facilidade de geração de relatórios e consultas pelos usuários finais, é essencial para o modelo proposto.

Outros complementos para a coleta automática de dados são indicadores de performance. Eles permitem o acompanhamento e monitoramento de índices utilizados como apoio às tomadas de decisões, por exemplo indicadores de produtividade e atraso de pedidos. Estes indicadores podem ser gerados por sistemas de Data Warehouse.

De acordo com um dos objetivos do trabalho, as seguintes tecnologias foram analisadas:

- Monitoramento da produção; 
- Sistemas de Planejamento das Necessidades da Empresa (Enterprise Resources Planning - ERP);

- Sistemas de otimização da programação da produção e

- Sistema de tratamento e armazenamento de informações (Data Warehouse) e elaboração de relatórios gerenciais.

Todas estas tecnologias foram incluídas como recursos necessários ao modelo proposto, e portanto foram validadas para a aplicação proposta.

A seguir será apresentada uma séria de conclusões relacionadas diretamente à coleta de dados de forma automática:

- Os dados de chão de fábrica, coletados de forma automatizada como foi apresentado neste trabalho, podem ser utilizados nos seguintes processos relacionados à gestão da produção: planejar produção, programar produção, produzir, controlar produção e controlar materiais;

- Os dados de produção coletados podem gerar informações sobre os índices de desagregação (de famílias em itens finais) reais, ou seja, a quantidade exata dos itens produzidos de cada família, que fornecem um histórico preciso que possa ser utilizado para desagregações futuras;

- O histórico dos dados de chão de fábrica coletados pode auxiliar na análise das fontes de demanda dos produtos. Isto pode ser feito pois, para cada item efetivamente produzido, pode ser relacionada a sua fonte de demanda. Desta forma, mesmo pequenas demandas, como por exemplo testes e amostras grátis, são identificadas e consideradas em previsões futuras. Estas fontes podem ser identificadas e seu comportamento compreendido, contribuindo com a realização da atividade de realização de previsão da demanda;

- A coleta de dados pode detectar eventos que acionam automaticamente atividades, sem interferência humana. Um exemplo é relacionado a eventos como quebras de equipamentos ou atrasos, que podem inviabilizar algumas ordens de produção já liberadas, necessitando que o planejamento detalhado seja refeito, e novas ordens de produção 
geradas. Desta forma, a ocorrência de alguns eventos pré-definidos poderia automaticamente iniciar a atividade de atualização do planejamento detalhado da produção;

- Para realização do planejamento detalhado da produção, algumas restrições devem ser verificadas, como a disponibilidade de equipamentos e ferramentas. Algumas destas informações podem ser obtidas de forma rápida e precisa, através do sistema de coleta de dados de chão de fábrica. Além dos dados coletados, os sensores utilizados para tal finalidade podem monitorar algumas condições que restringem o planejamento, como quebras de equipamentos e finalização de ordens;

- O conhecimento da situação atual do chão de fábrica é uma das condições para a realização da programação da produção. Por se tratar de um planejamento de curto e curtíssimo prazo, a rapidez no acesso a estas informações é fundamental. Com o emprego da coleta automatizada de dados de chão de fábrica, esta situação pode ser conhecida em tempo real, aumentando a possibilidade de que os programas gerados sejam factíveis e efetivamente cumpridos;

- Eventos ocorridos no chão de fábrica podem inviabilizar um programa de produção ou parte deste, como a quebra de um equipamento ou a ocorrência de um índice de refugos maior que o esperado. Estes eventos podem ser detectados e monitorados pela coleta automatizada de dados proposta neste trabalho. Isto permite até que uma reprogramação da produção seja iniciada automaticamente após a ocorrência de determinados eventos;

- A preparação dos equipamentos de produção gera uma série de dados que devem ser controlados. Além disso, estes dados devem ser analisados para que a preparação seja aperfeiçoada constantemente. Como exemplo, pode ser feita uma consulta sobre qual a ferramenta, entre as várias utilizadas, tem o melhor rendimento para determinada operação, sendo então priorizada sua utilização; 
- Os dados resultantes da avaliação das operações realizadas, principalmente quanto a aspectos dimensionais, de qualidade geral e de acabamento, devem ser registrados. Isto permite a realização de consultas de parâmetros como índices de produtividade e de refugos. A forma tradicional de apontamento de recursos indica qual a quantidade total de refugos obtidos em um lote de produção. Com o sistema de coleta de dados proposto é possível saber a ocorrência de refugos ao longo da produção, permitindo identificar se existe concentração destas ocorrências no início ou final de processamento do lote. Além disso, estas informações poderiam ser utilizadas para realização de Controle Estatístico do Processo (CEP), e para que possam ser feitas intervenções no processo, como por exemplo interromper um processo quando o índice de refugos exceder um valor determinado;

- A maior parte dos dados coletados e utilizados no modelo proposto são gerados pela atividade "Monitorar produção". Quando estes dados são utilizados em sistemas de Data Warehouse, grande parte das possibilidades de obtenção de informações propostas no modelo apresentado podem ser utilizadas;

- A distinção de controles proposta (do equipamento, da produção de itens e da produção de ordens e lotes) neste trabalho permite que sejam utilizadas informações mais precisas e direcionadas para necessidades específicas. Nos modelos conceituais analisados não foi encontrada esta diferenciação;

A seguir serão apresentadas conclusões relacionadas com a utilização de sistemas de Data Warehouse:

- A utilização de sistemas de Data Warehouse pode diminuir significativamente a necessidade de alterações dos sistemas computacionais corporativos em utilização na empresa, para geração de relatórios específicos. Estas alterações necessitam de pessoal altamente qualificado para sua execução e demandam tempo e recursos. Além disso, alterações que requerem modificação no código dos sistemas, 
necessitam de especificações detalhadas que geralmente não são feitas pelos usuários finais, e podem não atender suas necessidades iniciais. Com a utilização de sistemas de Data Warehouse, o próprio usuário pode configurar os relatórios que necessita;

- A utilização de sistemas de Data Warehouse pode suportar as seguintes atividades do processo de Gestão da Demanda: Realizar previsão de vendas, Fazer plano agregado de vendas e Fazer plano agregado de produção. Todas estas atividades geram planos de médio e longo prazo, que devem ser monitorados constantemente para verificação de desvios. Estes devem ser controlados, para que atitudes corretivas possam ser tomadas com rapidez;

- Para a desagregação do plano agregado de produção podem ser utilizadas informações condensadas dos dados de produção, obtidas através de relatórios específicos que podem ser gerados por sistemas de Data Warehouse. Estas informações são relativas ao histórico das proporções reais de desagregação das famílias de produtos em itens finais;

- A utilização de sistemas de Data Warehouse favorece a utilização de indicadores de performance, pois estes podem ser obtidos através de consultas específicas, que uma vez construídas, podem ser geradas facilmente pelos usuários finais. Uma das aplicações deste conjunto pode ser na geração de indicadores que indiquem parâmetros de avaliação relacionados ao plano mestre de produção. Por exemplo, pode ser gerada uma consulta que indique o número de ordens que irão atrasar ou a proporção da utilização da capacidade disponível de um equipamento gargalo. Estes indicadores poderiam fornecer suporte para a escolha de diferentes alternativas de plano mestre de produção para determinada situação de demanda;

- Para realização do planejamento detalhado da produção é necessária a consulta de alguns indicadores, como a proporção de ordens atrasadas e produtividade dos equipamentos. Estes e outros indicadores podem ser 
obtidos através de consultas e relatórios gerados por sistemas de Data Warehouse que sejam abastecidos com dados coletados no chão de fábrica. Além deste indicadores, podem ser consultadas políticas que direcionam o planejamento detalhado, como políticas de produção que determinem o tamanho do lote a ser processado, com base no histórico do rendimento de um equipamento específico para diferentes tamanhos de lotes;

- É importante para a empresa acompanhar o cumprimento do programa de produção em vigor, para que os desvios sejam corrigidos, evitando problemas como atrasos de entregas e custos maiores que os previstos. Com base nos dados coletados e na utilização de sistemas de Data Warehouse, podem ser gerados relatórios que permitem este acompanhamento através de indicadores, como o número de ordens atrasadas e os custos decorrentes deste atraso;

- Um programa de produção deve atender às necessidades de entrega de produtos e outros critérios, como os custos de produção. Além disso alguns parâmetros podem ser otimizados, por exemplo o tempo de preparação de equipamentos, que pode ser diminuído caso um equipamento processe uma seqüência de itens que utilizem a mesma preparação. Com a realização de consultas sobre os dados coletados, podem ser feitas otimizações nos programas. Como ilustração, pode ser feita uma consulta para que sejam classificados todos os tempos de preparação considerando a operação realizada anteriormente. Isto poderia fazer que fosse escolhida uma seqüência de processamento que considere sempre as seqüências de produtos com menor tempo de preparação entre um e outro;

- A utilização de sistemas de Data Warehouse para armazenar os dados de produção coletados permite que usuários finais tenham mais facilidade na obtenção de informações específicas aos diversos processos e atividades considerados no modelo proposto; 
- A definição de consultas e relatórios pode ser feita por usuários finais, sem a necessidade de pessoal altamente qualificado, caso seja utilizado um sistema de Data Warehouse pré-configurado (cujos dados já foram extraídos dos bancos de dados originais);

Serão listadas a seguir conclusões obtidas na elaboração deste trabalho e na sua aplicação em ambiente simulado:

- Os modelos conceituais existentes não contemplam o tratamento dos dados de chão de fábrica coletados como proposto neste trabalho. Por tratamento entende-se o armazenamento, manutenção e disponibilização destes dados, necessário para que possam ser largamente utilizados em diversas atividades. Nestes modelos é assumido que estes dados estão disponíveis e atendem às expectativas;

- Índices de desagregação de famílias de produtos em itens devem ser monitorados constantemente, pois mesmo pequenos desvios nestes podem propagar grandes distorções para os níveis mais detalhados de planejamento. Seu monitoramento permite conhecer o comportamento dos mesmos;

- Políticas de estoques podem ser definidas com base nos procedimentos de coleta de dados apresentados. Isto pode ser obtido através de históricos precisos do consumo e rotação de estoques, obtidos com dados reais, gerando por exemplo, estoques mínimos que atendam todas as condições necessárias para determinada situação de produção;

- A liberação de um programa resulta no conhecimento destes nos locais onde ocorrerão as operações de produção. Na prática, isto significa que os operadores devem conhecer as ordens de produção que irão realizar. Isto pode ser feito em parte, caso sejam utilizados coletores de dados, que além de gerar dados de controle, possuam recursos para recebimento e exibição de informações;

- As operações de produção, além de gerar inúmeros dados, podem utilizar históricos destes dados, para aumentar sua eficiência ou performance em determinados parâmetros. Por exemplo, pode ser 
utilizado um histórico sobre as melhores condições de usinagem (velocidades, avanços, tipos de ferramentas) para cada tipo de peça para que seja feita uma preparação adequada do equipamento;

\subsection{Sugestões para trabalhos futuros}

A seguir serão apresentadas sugestões de continuidade para este trabalho:

- Verificação da eficiência e relevância na aplicação da coleta automática de dados de produção em processos financeiros e econômicos de empresas de manufatura;

- Expansão do modelo apresentado para um nível mais detalhado de controle do processo produtivo, principalmente na sua interação com os equipamentos de produção;

- Agregação do processo de Desenvolvimento de Produtos e outros relacionados à engenharia, além daqueles apresentados, utilizando dados coletados de produção;

- Criação de procedimentos de qualidade, principalmente o Controle Estatístico do Processo (CEP) utilizando dados coletados automaticamente;

- Desenvolvimento de uma sistemática de manutenção preventiva e corretiva de equipamentos de produção baseada na utilização de dados de produção coletados automaticamente;

- Adaptação do modelo proposto para outros tipos de indústria, como de processos e de serviços;

- Análise da efetividade de utilização de dados de produção coletados automaticamente em sistemas ERP;

- Agregação de sistemas de Data Mining ao modelo proposto;

- Análise da viabilidade da utilização dos dados de produção coletados automaticamente em sistemas e métodos de custeio da produção.

- Detalhamento do modelo proposto, principalmente dos processos de planejamento e programação da produção; 
- Definição de conjuntos de relatórios e pesquisas dos dados coletados de chão de fábrica, em função do tipo de atividade e forma de gestão da empresa, segundo a tipologia;

- Detalhamento de indicadores de performance que podem ser utilizados para suporte às atividades propostas;

- Definição de uma arquitetura de integração dos sistemas tratados (coleta automática de dados de chão de fábrica, supervisão, monitoramento, Data Warehouse e geradores de relatórios);

- Desenvolvimento de uma metodologia de implantação do modelo proposto;

- Análise de sistemas comerciais para suporte ao modelo proposto;

- Expansão do modelo para outros processos de empresas, além da gestão da produção;

- Desenvolvimento de técnicas de aperfeiçoamento de sistemas de apontamento 


\section{ANEXO 1: SimBOLOGIA}

A simbologia apresentada a seguir é baseada na arquitetura ARIS, apresentada na seção 6.2, e foi utilizada para apresentar o modelo proposto neste trabalho.

Este modelo representa principalmente a sequiência de atividades, e os eventos que ocorrem antes ou depois destas atividades. Além disso, no Anexo 2 é apresentada uma descrição destas atividades, contendo informações geradas e produzidas, e os recursos necessários. Estas informações adicionais não foram incorporadas ao modelo proposto para facilitar sua interpretação.

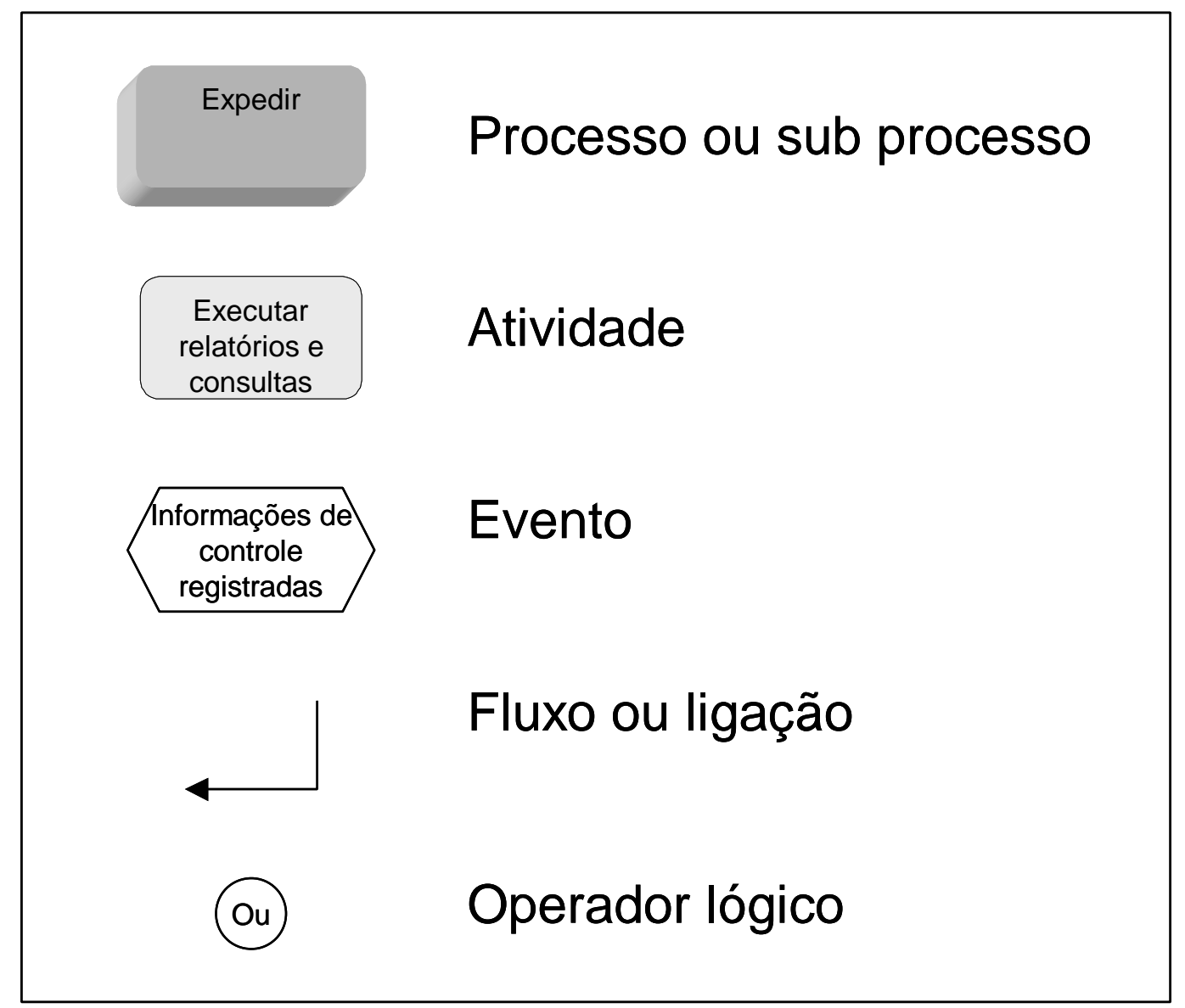

A figura A1 apresenta os elementos utilizados nos modelos deste trabalho.

FIGURA A1:Elementos utilizados nos modelos

O primeiro elemento é um retângulo com cantos arredondados sombreado, e indica um processo ou sub processo. Este elemento representa um conjunto de atividades, que podem ser detalhadas. 
O segundo elemento utilizado é um retângulo com cantos arredondados, que representa uma atividade. Representa funções bem definidas, que denotam uma ação. Requer informações de entrada, e as transforma em resultados. São necessários recursos para a realização das tarefas, que podem ser materiais como mesas e papéis, e também podem ser relacionados a equipamentos e sistemas de informática.

Outros elementos utilizados são os eventos, representados por hexágonos. Os eventos são acontecimentos bem definidos no tempo, e sua ocorrência sinaliza o final ou início de uma atividade.

O fluxo entre os elementos é representado por uma seta orientada. Representa a transmissão de informações entre elementos, e também indicam a seqüência lógica do modelo.

Por fim, são utilizados operadores lógicos, que podem ser: E, Ou e XOu. O operador $\underline{E}$ indica que todas as condições (eventos ou atividades) devem ocorrer para que o(s) elemento(s) após o operador também ocorra $(\mathrm{m})$. O operador $\underline{\mathrm{Ou}}$ indica que não necessariamente todas as condições devem ocorrer, mas somente uma. $\mathrm{O}$ último operador, representado por XOu é chamado de "ou exclusivo" e indica que somente uma das condições ou resultados pode ocorrer. 


\section{ANEXO 2: MODELO PROPOSTO}

Sumário deste anexo

PROCESSO GERAL .......................................................................... 133

Processo: Gerir demanda...

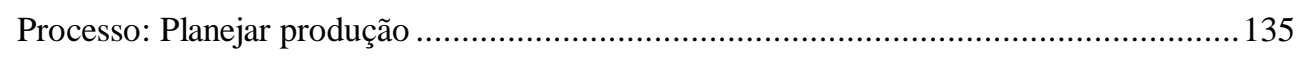

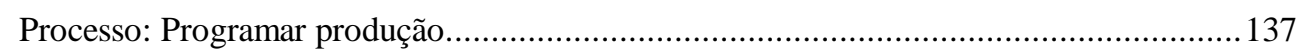

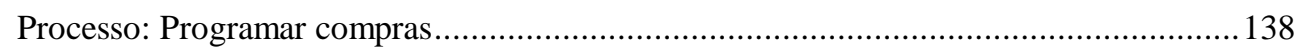

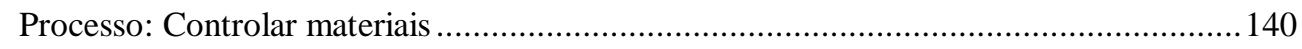

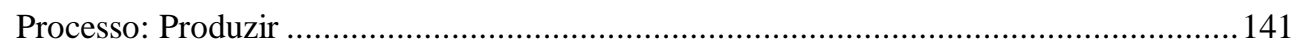

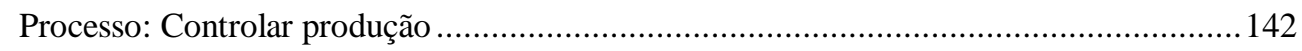

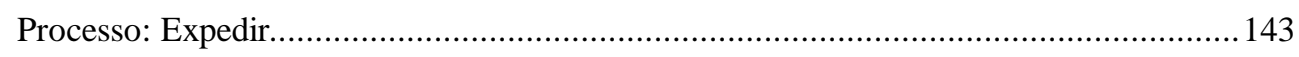

Processo: Analisar dados de produção ......................................................................... 144

PROCESSO: GERIR DEMANDA …............................................... 146

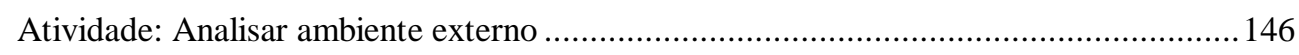

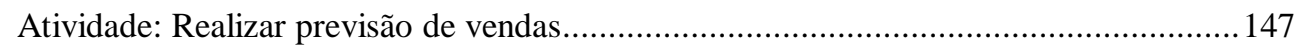

Atividade: Fazer plano agregado de produção ……………………………………........ 150

Atividade: Analisar desvios dos planos .................................................................. 152

PROCESSO: PLANEJAR PRODUÇÃO .................................................... 154

Sub processo: Desagregar plano agregado de produção ……………………………....... 154

Sub processo: Fazer plano mestre de produção................................................................... 155

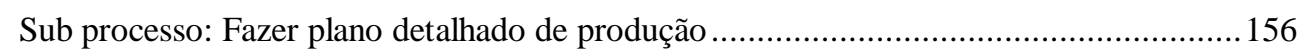

\section{SUB PROCESSO: DESAGREGAR PLANO AGREGADO DE PRODUÇÃO 159}

Atividade: Analisar desvios históricos dos índices de desagregação..................................159

Atividade: Analisar índices de desagregação atuais ......................................................... 160 
Atividade: Definir índices de desagregação a serem utilizados ................................. 161

SUB PROCESSO: FAZER PLANO MESTRE DE PRODUÇÃO .................... 163

Atividade: Levantar as necessidades líquidas do produto final................................ 163

Atividade: Analisar todas as fontes de demanda do produto ...................................... 164

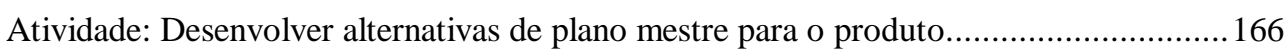

Atividade: Analisar restrições ao plano mestre ................................................. 167

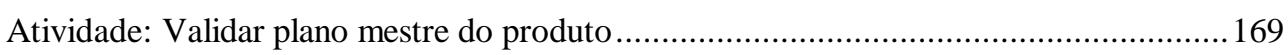

SUB PROCESSO: FAZER PLANO DETALHADO DE PRODUÇÃO .......... 171

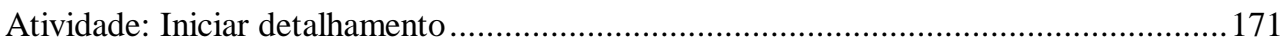

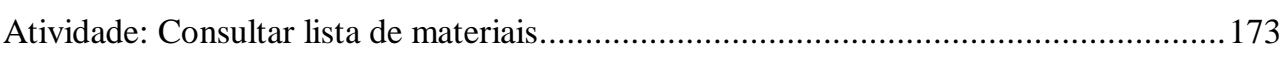

Atividade: Consultar restrições .................................................................... 174

Atividade: Consultar indicadores ...................................................................... 177

Atividade: Consultar políticas................................................................ 178

Atividade: Calcular necessidades detalhadas........................................................ 180

Atividade: Analisar mensagens de exceção ......................................................... 182

Atividade: Verificar se plano mestre é atendido ..................................................... 183

PROCESSO: PROGRAMAR PRODUÇÃO ................................................. 185

Atividade: Conhecer situação atual do chão de fábrica ......................................... 185

Atividade: Iniciar programação da produção .......................................................... 186

Atividade: Analisar situação do programa atual ..................................................... 188

Atividade: Analisar restriçõos .................................................................... 189

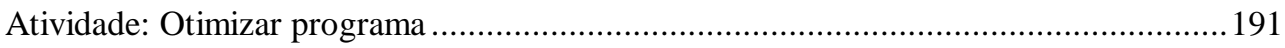

Atividade: Consultar processos de fabricação .................................................... 192

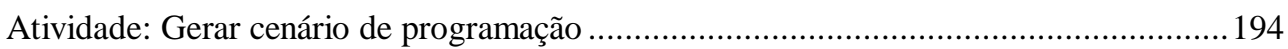

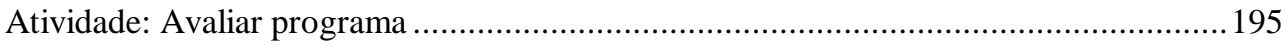


Atividade: Liberar programa de produção 197

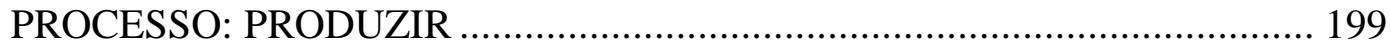

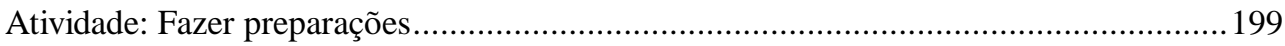

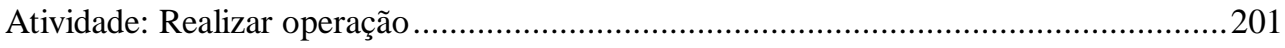

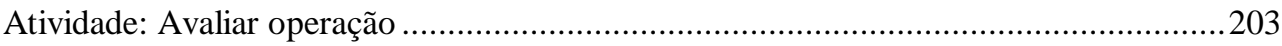

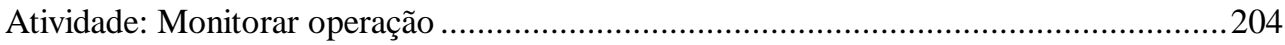

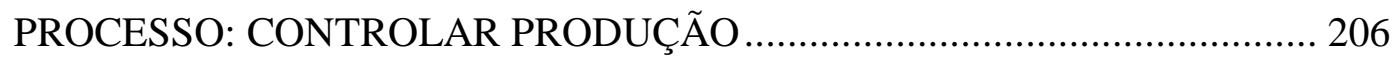

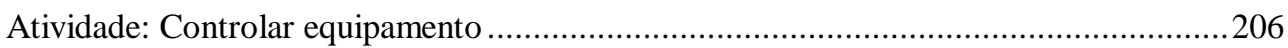

Atividade: Controlar produção de itens......................................................... 207

Atividade: Controlar produção de ordens e lotes .................................................208

Atividade: Registrar informações de controle.........................................................210

PROCESSO: ANALISAR DADOS DE PRODUÇÃO ................................. 212

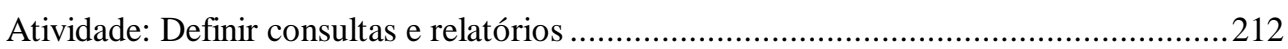

Atividade: Executar relatórios e consultas........................................................213

Atividade: Disponibilizar relatórios e consultas ......................................................2214

\section{GERAL}

Processo: Gerir demanda

\section{Descrição e objetivo}

Este processo é responsável pela geração dos planos agregados de vendas e produção, que devem refletir as expectativas da empresa em relação ao mercado. Neste processo é feita uma previsão da demanda, que direciona os planos acima.

A gestão da demanda deve conciliar esta necessidade com os recursos e a capacidade disponível, para que sejam criadas condições realistas de produção para atendimento da demanda. 
São feitas análises externas e internas que fornecem informações para elaboração dos planos agregados. Estes são de longo prazo (vários meses ou alguns anos), e por isso seus desvios devem ser monitorados, para que sejam tomadas medidas corretivas.

\section{Informações necessárias}

São necessárias informações geradas nos processos:

- Planejar produção;

- Programar compras;

- Expedir e

- Analisar dados de produção.

Os planos de produção e compras já existentes devem ser considerados na previsão da demanda e dos planos agregados. Dados de logística, como freqüências e prazos de entregas também são considerados na gestão da demanda.

A análise de dados de produção permite que uma série de informações seja considerada, como o histórico de produção e o comportamento de determinados produtos, em relação à ocorrência de eventos.

Informações geradas

As principais informações geradas na gestão da demanda são os planos agregados de produção e vendas. Estes são utilizadas no planejamento da produção e no processo de vendas, que não faz parte do escopo deste trabalho. Além disso, é feito um monitoramento dos desvios destes planos, que também gera informações que podem ser utilizadas posteriormente.

\section{Recursos}

Um dos conjuntos de recursos necessários para a realização desta atividade deve permitir o acesso a dados internos e externos à empresa, que devem ser analisados.

A previsão de vendas requer recursos específicos, que realizam cálculos usando diversas considerações, como tipos de médias e fatores que influem na demanda, como promoções e a época do ano. Existem sistemas automatizados 
específicos para esta funcionalidade. Alguns sistemas ERP suportam algumas destas funcionalidades.

Ferramentas de Data Warehouse podem dar suporte para algumas das funcionalidades apresentadas, principalmente as análises de grandes volumes de dados, necessários para que condições acontecidas anteriormente sejam conhecidas e consideradas nos planejamentos atuais.

Processo: Planejar produção

\section{Descrição e objetivo}

O processo de planejamento da produção é hierárquico e dividido nos seguintes níveis:

- Planejamento mestre da produção e

- Planejamento detalhado da produção.

No planejamento agregado gerado na gestão da demanda são tratadas as necessidades de longo prazo, geralmente com horizonte maior que um ano e períodos mensais. São consideradas famílias de produtos, e restrições agregadas de capacidade e produção.

Este plano é então desagregado, para gerar o plano mestre de produção, que trata das necessidades de produtos finais para um prazo médio, de alguns meses, com períodos semanais.

Finalmente, o plano mestre é detalhado, sendo que as necessidades dos produtos finais são transformadas em necessidades dos itens que os compõem. Esta atividade é conhecida como explosão das necessidades, ou simplesmente MRP (Material Requirements Planning).

Informações necessárias

Para realização deste processo são necessárias informações geradas nos seguintes processos:

- Gerir demanda;

- Programar compras; 
- Programar produção e

- Analisar dados de produção.

Na gestão da demanda é gerado o plano agregado de produção, que deverá ser desagregado no planejamento, e indica as previsões de necessidades de produção de famílias de produtos.

A programação de compras fornece previsões das chegadas de materiais, e fornece as informações necessárias para que o planejamento da produção considere as restrições de materiais e matérias primas comprados.

A programação faz um detalhamento dos planos de produção, e também considera restrições mais detalhadas de disponibilidade da capacidade. Desta forma, é possível saber se um plano de produção é realista e possível de ser realizado. Caso não seja possível (devido à falta de capacidade), deve ser refeito.

A análise de dados de produção e operações deve permitir que sejam feitas consultas rápidas e simples a um grande volume de dados, gerando consultas e relatórios sobre dados históricos, que permitem a otimização de parâmetros e definição de regras. Também permitem que seja feito o acompanhamento de indicadores de performance, que possibilitam julgar os resultados de ações corretivas, mudanças ou investimentos realizados.

Informações geradas

Os resultados do processo de planejamento da produção são:

- Desagregação do plano agregado;

- Plano mestre de produção e

- Plano detalhado de produção.

Estes planos são utilizados em diversos processos e atividades da empresa, e direcionam todas as operações de produção da empresa.

\section{Recursos}

Atualmente existem diversos sistemas automatizados para realização deste processo de planejamento. Sistemas ERP possuem todas as funcionalidades 
necessárias. Porém este processo pode ser realizado manualmente, ou com auxílio de recursos simples, como planilhas de cálculo e bancos de dados relacionais.

Processo: Programar produção

Descrição e objetivo

A programação é o maior detalhamento dos planos de produção. Ela indica a sequiência de processamento de operações de produção para cada recurso produtivo.

O planejamento detalhado gera as necessidades de produção de cada componente de cada produto final, na forma de ordens de produção, com data de início e término de produção. Porém, este nível de planejamento não indica qual o recurso produtivo será utilizado, e qual a seqüência das operações do mesmo, sendo então necessária a programação destas operações.

O horizonte de tempo trabalhado é de algumas semanas, com períodos de horas ou até minutos, para cada recurso produtivo.

A elaboração do programa é um processo crítico, pois um grande número de restrições deve ser considerado, além de condições que devem ser atendidas. É comum o programa de recursos críticos ser revisado diariamente.

Informações necessárias

As seguintes informações são necessárias para a programação da produção:

- Conhecimento da situação atual do chão de fábrica;

- Plano detalhado de produção;

- Restrições à programação;

- Regras de programação e otimização;

- Consultas e relatórios sobre dados de controle e monitoramento da produção e

- Planos de processo dos produtos. 
Estas informações são necessárias para gerar o programa. Além delas, é necessário saber quando um novo programa deve ser feito, para refletir correções no plano atual ou para atender novas necessidades de produção.

\section{Informações geradas}

A informação gerada neste processo é o programa de produção, que indica, para cada recurso produtivo a seqüência de operações a serem realizadas. Sob outro ponto de vista, o programa indica, para cada item de produto final, os recursos onde as operações de produção devem ser realizadas.

\section{Recursos}

Diversos recursos são necessários para a realização deste processo.

Para o conhecimento da situação atual do chão de fábrica, são necessários sistemas de informação apropriados. Sistemas de monitoramento apresentam de forma gráfica a situação de alguns ou todos os recursos de produção. Alguns sistemas de programação possuem funcionalidades que indicam quais operações já foram iniciadas, estão em andamento ou terminadas. Desta forma é possível um bom conhecimento da situação do chão de fábrica, que deve ser o mais próximo possível de apresentar as informações em tempo real, ou com pouco atraso.

Sistemas ERP possuem algumas das funcionalidades acima, e ainda permitem que sejam conhecidas todas as operações de produção que devem ser programadas, além dos planos de processo, que também são necessários.

Além destes são necessários recursos que permitam a realização de consultas e obtenção de relatórios de dados históricos de operações.

\section{Processo: Programar compras}

\section{Descrição e objetivo}

Este processo tem o objetivo de garantir o abastecimento de matérias primas e outros recursos comprados para suprir as necessidades de produção. A disponibilidade destes materiais é considerada como restrição em algumas atividades de planejamento. 
Informações necessárias

São necessárias todas as informações relacionadas à compra de materiais, que ocorrem em todos os níveis de planejamento:

- Planejamento agregado;

- Planejamento mestre;

- Planejamento detalhado e

- Programação da produção.

Estes geram necessidades brutas de produção, que são confrontadas com as informações sobre estoques e depósitos, provenientes do processo de controle de materiais, para o cálculo das necessidades líquidas. $\mathrm{O}$ atendimento destas necessidades deve ser programado, para que o prazo de entrega dos fornecedores atenda o planejamento e outras necessidades da empresa.

Informações geradas

A realização deste processo gera um programa de compras, que indica:

- Materiais;

- Quantidades;

- Fornecedores e

- Previsão de entrega.

Estas informações são consideradas restrições ao planejamento e programação da produção, pois sem os materiais disponíveis as operações não podem ser realizadas.

\section{Recursos}

Os recursos necessários para realização deste processo devem permitir:

- Conhecer as necessidades de produção, resultado dos três níveis de planejamento;

- Obter informações sobre fornecedores e

- Disponibilizar o programa de compras. 
Sistemas ERP possuem algumas funcionalidades que suportam estas necessidades.

Processo: Controlar materiais

\section{Descrição e objetivo}

O objetivo deste processo é controlar as quantidades, posições e situações dos materiais utilizados na empresa. Este controle pode ser feito de várias formas. Uma delas é que o processo seja completamente manual com preenchimento de fichas e requisições para movimentação, entrada e saída de materiais. Alternativamente, podem ser utilizados sensores e coletores eletrônicos de dados, que permitem o controle em tempo real dos materiais.

Este processo é relacionado com a programação de compras de materiais da empresa, pois recebe deste um planejamento que deverá ser controlado. Também se relaciona com o processo de produção, na disponibilização de materiais para serem processados e no armazenamento daqueles já processados.

\section{Informações necessárias}

Para o controle de materiais é necessário que seja conhecido o programa de compras, que por sua vez é fruto do planejamento da produção. Também são necessárias informações da programação da produção, que faz reservas e requisições de materiais para serem processados.

\section{Informações geradas}

O controle de materiais faz a comparação entre o planejamento de materiais (programação de compras) e aquilo que realmente aconteceu, além dos controles já mencionados de quantidades, situações e localização de materiais.

Uma importante informação gerada é sobre a disponibilidade de materiais, uma das restrições consideradas na programação da produção.

\section{Recursos}

Os recursos necessários para o controle de materiais devem permitir o acompanhamento da movimentação e transformação dos mesmos. Podem ser feitos 
apontamentos e requisições manuais, e também pode haver a utilização de sensores e coletores de dados.

Assim como no controle da produção, o volume de informações tratadas é grande, e requer um recurso compatível com esta necessidade.

Processo: Produzir

\section{Descrição e objetivo}

O objetivo desta atividade é a produção de itens e produtos finais, através da transformação de materiais e realização de operações de produção. O maior número possível de informações geradas neste processo devem ser coletadas e registradas pelo processo de controle da produção.

Informações necessárias

Para que o processo de produção seja iniciado, é necessário que exista um programa da produção que defina a operação a ser realizada, que também deve estar liberada para ser iniciada.

Além destas são necessárias informações sobre a preparação e regulagem do equipamento de produção, em função da operação a ser realizada.

Informações geradas

Neste processo são geradas as informações de controle da produção. São geradas informações sobre a preparação, execução e avaliação das atividades de produção.

\section{Recursos}

Para o processo de produção são necessários recursos produtivos que realizam as operações necessárias à obtenção dos produtos e componentes comercializados pela empresa. 
Processo: Controlar produção

\section{Descrição e objetivo}

Este processo tem o objetivo de coletar informações sobre o andamento da produção, para que aquilo que está sendo executado seja comparado com o planejamento. Esta comparação é necessária para que desvios sejam corrigidos e não comprometam o resultado final.

Caso não ocorressem estes desvios, este processo não seria necessário, pois tudo ocorreria de acordo com o planejado. Porém uma grande série de imprevistos pode ocorrer, interferindo no plano original, como por exemplo quebras de equipamentos, falta de materiais ou atraso no recebimento de matérias primas.

\section{Informações necessárias}

Para o controle da produção são necessárias informações sobre cada operação de produção realizada, além dos itens, lotes e ordens processados.

Estas informações podem ser obtidas por meios eletrônicos ou manuais. A forma mais tradicional de coleta destas informações é através de apontamentos, que são feitos em fichas específicas, e retratam a produção e eventos que já ocorreram. Meios eletrônicos como sensores e coletores de dados geram informações sobre aquilo que está acontecendo, permitindo um melhor gerenciamento da situação, principalmente para correção de erros e problemas enquanto eles estão ocorrendo. Além do conhecimento sobre a forma como as operações estão sendo realizadas, é necessária a identificação dos itens sendo processados.

Independente da forma de geração destas informações, seu volume é grande, e requer recursos adequados.

\section{Informações geradas}

São geradas informações principalmente para avaliação da execução do planejamento e programação da produção. Também são geradas informações de rastreamento, que permitem identificar quais itens e operações já foram realizados. Ordens e pedidos específicos também podem ser acompanhados, e vendedores podem obter prazos de entrega mais realistas para novos pedidos. 


\section{Recursos}

Conforme mencionado, os recursos disponíveis para a realização desta atividade devem suportar o armazenamento de um grande volume de dados, e sua disponibilização, possibilitando que aquilo que foi executado seja comparado com aquilo que foi planejado.

Outros recursos envolvidos são aqueles relacionados com a coleta e geração dos dados de produção. Caso sejam utilizados meios manuais, os recursos devem prever mecanismos e uma sistemática para que as informações sejam registradas em apontamentos e disponibilizadas onde for necessário. No caso de utilização de recursos eletrônicos, devem haver sensores instalados nos equipamentos ou coletores de dados operados por pessoas, além de uma estrutura para circulação e integração destas informações, chamada de rede de campo.

Processo: Expedir

\section{Descrição e objetivo}

O objetivo deste processo é permitir que os produtos da empresa sejam entregues aos consumidores. É responsável pelo transporte e logística relacionados. Em algumas empresas também é responsável pelo armazenamento de produtos finais.

A expedição é uma das restrições consideradas no planejamento e programação da produção, pois deve ter a capacidade de escoar a produção, evitando a formação de estoques de produtos finais.

Informações necessárias

Para a realização do processo de expedição, são necessárias as seguintes informações:

- Características dos produtos e embalagens (volume, peso e manuseio);

- Destino final de cada produto e

- Logística (rotas, meios de transporte, datas e outras). 
Outras informações também podem ser utilizadas, como prioridades de clientes e pedidos, condições de armazenagem de produtos e volumes estocados.

Informações geradas

A expedição gera uma séria de informações, porém, para o escopo deste trabalho, são relevantes aquelas que são utilizadas no processo de gestão da demanda. Estas são utilizadas para a promessa de datas de entrega fornecidas aos clientes, fazendo parte de uma análise mais ampla do ambiente externo. São geradas informações sobre condições de entrega, duração e frequiência de rotas de entrega.

\section{Recursos}

Para realização do processo de expedição são necessários recursos principalmente relacionados à logística, como depósitos e meios de transporte.

Processo: Analisar dados de produção

\section{Descrição e objetivo}

Este processo permite a execução e disponibilização de consultas e relatórios sobre dados de produção coletados. Esta análise é realizada como auxílio para todos os níveis de planejamento, permitindo a geração de um conhecimento mais detalhado e preciso sobre a produção.

Possui relacionamento com outros processos, através da disponibilização de informações solicitadas.

Informações necessárias

Este processo necessita que sejam armazenadas todas as informações possíveis sobre a produção e os equipamentos. Também necessita conhecer quais são as necessidades de informações, para configuração de consultas e relatórios que deverão ser disponibilizados aos interessados.

Informações geradas

São geradas informações a partir de requisições específicas. Estas informações podem ser apresentadas na forma de relatórios (listagens elaboradas) ou consultas 
(cruzamento e classificação de informações). Todas as informações relacionadas a este processo são relativas à produção ou ao funcionamento dos equipamentos.

\section{Recursos}

O recurso para realizar este processo deve ser capaz de armazenar um grande volume de dados de operações, a definição e elaboração de consultas e a disponibilização dos resultados. 
Processo: Gerir demanda

Atividade: Analisar ambiente externo

Descrição e objetivo

Esta atividade consiste em analisar tendências e eventos ocorridos fora do ambiente da empresa e de sua(s) cadeia(s) produtiva(s). São analisados fatores econômicos, políticos, sociais e ambientais, e sua possível influência na demanda da empresa.

Também são analisados os concorrentes e suas ações.

Informações necessárias

Para esta atividade, todas informações disponíveis são aproveitadas.

Necessariamente, devem ser analisadas informações acerca do ambiente sócio econômico. Todos os indicadores disponíveis das empresas da cadeia produtiva também devem ser analisados.

Uma das fontes de informações a serem utilizadas são pesquisas de marketing, conduzidas pela própria empresa ou por terceiros. Estas pesquisas indicam o desempenho de produtos e ações (promoções, lançamento de produtos, novidades) sobre o mercado, em regiões geográficas e canais de distribuição distintos.

Informações geradas

Esta atividade gera diretrizes utilizadas no planejamento da produção, em relação à demanda e produção. Como as informações de entrada não são rigidamente definidas, as informações de saída também não podem ser definidas, principalmente em relação à sua forma.

De forma geral, são gerados indicadores sobre perspectivas de aumento ou declínio de vendas e produção de determinados produtos, em determinadas regiões geográficas e determinados canais de distribuição. Também devem ser consideradas oportunidades de lançamento e retirada de produtos do mercado. 


\section{Recursos}

Para a realização desta atividade, são utilizados todos os recursos disponíveis para obtenção de informações.

Uma das fontes são notícias, que podem ser obtidas em jornais, revistas, propagandas, internet, e outros.

Outras fontes importantes de informações são as pessoas da empresa que trabalham com contato externo, como vendedores e compradores, que estão em relacionamento direto com o ambiente a volta da empresa. Também devem ser consideradas informações obtidas informalmente, como conversas e contatos telefônicos.

Para a empresa, é importante que todas estas informações analisadas e consultadas sejam retidas, para que possam ser consultadas em outras oportunidades, gerando assim um conhecimento sólido sobre o ambiente externo. Isso pode ser feito através de relatórios impressos ou de forma digital, em computadores.

Atividade: Realizar previsão de vendas

\section{Descrição e objetivo}

A previsão de vendas é o principal direcionador da produção e da força de vendas da empresa, e representa a expectativa de venda dos produtos no futuro. Por isso, merece especial atenção em sua elaboração.

A previsão de vendas deve possuir um horizonte de tempo longo (acima de 12 meses), porém o nível de detalhamento pode variar de acordo com o espaço de tempo entre o presente e o momento considerado. Por exemplo, pode ser feito um detalhamento no nível de famílias para os próximos dois meses, e para os restantes é feita uma previsão agregada para todos os produtos.

Por ser extremamente importante, a previsão de vendas deve ser resultado de um consenso, principalmente entre as áreas industrial e comercial. Outras áreas e departamentos podem estar envolvidos. 
Por se tratar de uma previsão, a ocorrência de desvios é inevitável. Porém estes devem ser analisados, em atividade distinta.

\section{Informações necessárias}

Uma das informações necessárias à realização desta atividade é o histórico de vendas da empresa. Quanto maior o período coberto pelo histórico, melhor este será. Sempre que possível, devem ser considerados dados de um período mínimo de 2 anos para realização da previsão de vendas.

O detalhamento das informações de entrada também deve ser compatível com a disponibilidade das mesmas. Informações básicas que devem estar presentes são relacionadas com a venda de produtos (ou famílias), em determinados períodos de tempo, através de determinados canais de distribuição (vendedores, representantes, vendas diretas, distribuidores, entre outros) e em determinadas regiões geográficas. O conjunto destas informações tende a ser volumoso, e seu tratamento exige ferramentas computacionais compatíveis ao tratamento desejado.

Podem ser utilizados diversos métodos para a previsão de vendas, sendo o mais comum destes o cálculo de médias, principalmente média simples e ponderada. A precisão e aplicabilidade de cada método variam para cada caso.

\section{Informações geradas}

O resultado desta atividade é a própria previsão de vendas, condensada em um documento que é a base para geração do plano agregado de vendas. Não existe um padrão para a apresentação destas informações, porém é comum que retrate a expectativa de vendas (e não de produção) para determinada família de produto em um horizonte de tempo curto, de pelo menos um mês.

É comum que a previsão de vendas varie o seu nível de detalhamento de acordo com o horizonte de tempo. Para ilustração, para determinada empresa, a previsão pode ser apresentada por famílias de produtos, quinzenalmente, para os próximos dois meses; por famílias de produtos mensalmente para os próximos quatro (a partir do segundo); e para todos os produtos da empresa (agregados), para os próximos 6 meses (a partir do sexto mês). 
O acesso à previsão de vendas deve ser amplo, sendo que principalmente a área industrial (responsável pela produção) e de vendas devem ter participado de sua elaboração e ter pleno conhecimento de seu conteúdo.

\section{Recursos}

Devido ao volume de informações, é necessária a existência de um sistema para seu tratamento. Este sistema pode ser informatizado, o que permite maior flexibilidade para elaboração de consultas e relatórios, além de permitir que o volume de dados analisados seja maior.

Bancos de dados relacionais permitem um tratamento limitado das informações, sendo que consultas específicas e complexas (como por exemplo o cruzamento de três informações diferentes) podem requerer um programador para sua realização.

Ferramentas como o Data Warehouse, e seu respectivo front end ${ }^{3}$ (planilhas, tabelas dinâmicas) permite que o próprio usuário construa rapidamente consultas complexas, possibilitando seu uso rotineiro e com consultas não específicas. Isso permite uma grande flexibilidade para o uso das informações disponíveis. Além disso, por suas características, é possível usar esta ferramenta para explorar dados históricos e outros fatores relacionados ao tempo de geração ou atualização dos dados.

O Data Minning é outro processo que pode ser utilizada na execução da previsão de vendas, pois permite a análise e descoberta de tendências, como o relacionamento de duas ou mais variáveis.

\footnotetext{
${ }^{3}$ Front end: nome usualmente dado a aplicativos que recebem dados trabalhados (agregados ou relacionados) de outros sistemas (como por exemplo um Data Warehouse), e são utilizados apenas para sua exibição. Os exemplos mais comuns são as planilhas eletrônicas.
} 
Atividade: Fazer plano agregado de produção

\section{Descrição e objetivo}

O plano agregado de produção representa a expectativa das quantidades a serem produzidas das famílias de produtos da empresa, e também uma projeção dos níveis de estoques das mesmas. É baseado na previsão de vendas.

$\mathrm{O}$ atendimento das vendas previstas deve ser feito através da produção de produtos e componentes. Porém existem políticas nas empresas que direcionam a forma como a produção vai atender as vendas, principalmente aquelas relacionadas a estoques.

Além das políticas mencionadas, outros fatores devem ser considerados, como a capacidade de produção, restrições logísticas e financeiras. A consideração destes fatores faz com que o plano agregado de vendas se transforme em uma orientação direcionada à fabrica e à produção, sendo a base para planejamentos mais detalhados e de curto prazo para a produção.

O horizonte de tempo e o detalhamento do plano agregado de produção devem ser compatíveis com o plano de vendas. Porém, é aconselhável que o horizonte mínimo seja de 3 a 4 meses, considerando famílias de produtos.

Informações necessárias

A base para elaboração do plano agregado de produção é a previsão (ou plano agregado) de vendas. Esta deve estar disponível no maior grau de detalhamento e horizonte de tempo disponível. Estas informações iniciais devem ser confrontadas com algumas restrições.

Uma consideração a ser feita na realização desta atividade é a respeito das políticas de estoque da empresa. Estas regem os estoques mínimos de armazenamento, produção e compras. Durante o horizonte de tempo considerado, o nível de estoque projetado para cada família de produto também deve ser considerado.

A principal restrição a ser considerada é a capacidade produtiva. Por se tratarem de níveis agregados de produção, a capacidade também deve ser. A unidade mais comum é a quantidade limite de unidades que podem ser produzidas em um 
período, usualmente um mês. Como exemplo pode ser usada a restrição de 610 toneladas/mês de determinado produto. Outra grandeza que pode ser considerada é a capacidade total de produção da empresa, independente do produto.

Outra restrição considerada é relacionada à logística. Isso pode compreender a capacidade de armazenagem de matérias primas, produtos intermediários e acabados. Esta restrição pode estar relacionada também à capacidade de movimentação e transporte interno e entre unidades da mesma empresa.

Além disso, o plano agregado de produção deve ser confrontado com um planejamento financeiro, que pode restringir a ocupação de capacidade ou a formação de estoques em determinados períodos.

Podem ser considerados os erros e desvios de planos anteriores para correção do plano sendo elaborado.

De acordo com o que foi apresentado, o volume de dados e informações necessários à realização do plano agregado de produção também pode ser grande, sendo que as mesmas considerações feitas para realizar a previsão de vendas devem ser consideradas.

Informações geradas

O resultado desta atividade é o plano agregado de produção, que deve mostrar a expectativa de produção para atender a expectativa de vendas. Para o planejamento da produção, quanto maior for o horizonte dos planos agregados, maior a capacidade de otimizar a ocupação de recursos. Portanto, o horizonte de tempo do plano agregado de produção deve ser o maior possível.

Este plano apresenta a quantidade que deve ser produzida por período (mensal ou quinzenal), para cada família de produto, para atender as vendas projetadas. Estas informações devem ser de conhecimento de todas as áreas diretamente relacionadas com a produção, como compras e manutenção.

O plano de produção gerado será utilizado de base para realização do plano mestre de produção. 


\section{Recursos}

Assim como para a previsão de vendas, a tendência é que o volume de informações seja grande, sendo necessária a utilização de um sistema. Este pode ser informatizado ou automatizado, quando houver necessidade. Este sistema deve prever que todas as informações necessárias (apresentadas acima) estejam disponíveis no momento em que são necessárias, e com precisão compatível com as necessidades de análise das mesmas.

As considerações sobre Data Warehouse e Data Mining feitas para a realização da previsão de vendas também são válidas.

Geralmente existem sistemas ou módulos de sistemas especializados na consideração de restrições agregadas de capacidade, o que permite que o plano agregado de produção seja realizado em conjunto com a consideração desta restrição, permitindo que seja refinado e se aproxime da realidade, evitando que sejam gerados planos que não considerem a ocupação da capacidade de produção de forma efetiva (sobrecarga ou sub utilização dos recursos).

Outro recurso necessário é para a divulgação das informações geradas, que devem ser conhecidas e estarem disponíveis para consultas.

Atividade: Analisar desvios dos planos

\section{Descrição e objetivo}

Os planos de vendas e de produção considerados são baseados em previsões e consideram longos horizontes de tempo (geralmente acima de seis meses), e portanto estão sujeitos a erros e desvios.

O objetivo desta atividade é monitorar e analisar estes desvios, para que os próximos planos sejam mais precisos, fornecendo informações para as devidas correções.

Para a realização desta atividade, deve ser feito um acompanhamento daquilo que é realizado, tanto em vendas como em produção, e comparado com as previsões do período. Todos os desvios devem ser considerados, independentemente se o realizado ficou acima ou abaixo da previsão. 
Informações necessárias

Como esta atividade trata de um monitoramento das vendas e da produção, para a sua realização devem estar disponíveis informações atualizadas sobre aquilo que foi realizado.

Vale lembrar que as informações a serem confrontadas com as previsões devem possuir a mesma agregação considerada.

Informações geradas

A informação gerada nesta atividade é uma representação dos desvios ocorridos na previsão de vendas e no plano agregado de produção. Além disso, podem ser documentadas as análises dos desvios ocorridos, identificando suas prováveis causas e comportamentos.

Estas informações são utilizadas na elaboração dos próximos planos e também para possíveis correções no direcionamento das vendas e da produção, em função dos desvios verificados.

\section{Recursos}

Não existe um formalismo estabelecido para a geração e registro das informações sobre os desvios ocorridos. O importante é que estas informações sejam consideradas.

Por não se tratar de informações complexas, os recursos necessários para a realização desta tarefa não exigem sofisticação, podendo serem utilizados bancos de dados comuns ou planilhas eletrônicas, tanto para seu armazenamento como para elaboração. 
Processo: Planejar produção

Sub processo: Desagregar plano agregado de produção

Descrição e objetivo

O plano agregado de produção contempla a produção prevista para famílias de produtos, em um horizonte de tempo acima de um mês. Este plano não é operacional, ou seja, não pode ser utilizado como única fonte de informações para direcionar a produção diária de uma empresa de manufatura discreta.

Para que seja operacional, este plano deve ser desagregado, tratando das necessidades de produção de produtos finais, para intervalos de tempo não superiores a um mês. Isto é feito com base em índices de desagregação, que direcionam a porcentagem da produção de cada item, para formar a necessidade total de produção da família.

\section{Informações necessárias}

São duas as principais informações necessárias para a realização deste sub processo: o plano agregado de produção e os índices de desagregação. A primeira informação foi detalhada no sub processo de Gestão da demanda. Os índices de desagregação serão tratados com detalhes na descrição das atividades que compõem o sub processo desagregar o plano agregado de produção.

Além destas, são necessárias informações que permitem monitorar como a desagregação prevista ocorre efetivamente. Estas informações devem refletir a realidade da produção da fábrica, tanto na sua precisão e confiabilidade quanto ao atraso em que são disponibilizadas após a ocorrência de eventos no chão de fábrica. Portanto, a coleta automática de dados para a geração destas informações é aconselhável, permitindo atender aos requisitos colocados de forma mais fácil.

Outras informações necessárias são aquelas que permitem que os índices de desagregação sejam constantemente avaliados e aperfeiçoados. 
Informações geradas

O resultado da desagregação do plano agregado serve de base para a elaboração do plano mestre de produção.

Deve apresentar a necessidade de produção de cada um dos produtos finais da empresa, para intervalos de tempo não maiores que um mês, prevendo um horizonte de alguns meses à frente, porém sem a consideração de algumas restrições.

\section{Recursos}

O mecanismo de desagregação é simples, e por si só não requer o auxílio de sistemas automatizados. Porém um volume muito grande de produtos e informações a serem consideradas pode requerer um sistema automatizado para a realização deste sub processo. Ferramentas como sistemas Data Warehouse podem permitir que sejam feitas diversas consultas a dados históricos de desagregação, permitindo que estratégias anteriores para esta finalidade sejam avaliadas, além dos valores históricos dos índices de participação dos produtos na demanda da família.

Alguns sistemas ERP possuem um módulo específico para realizar a desagregação do plano agregado.

Sub processo: Fazer plano mestre de produção

\section{Descrição e objetivo}

A desagregação do plano agregado de produção fornece a base para elaboração do plano mestre de produção. Até chegar à sua versão final, este plano deve ser confrontado com algumas restrições como as disponibilidades de produtos em estoques e de capacidade para produção. A disponibilidade de capacidade é uma restrição ao plano mestre, e é calculada de forma agregada, considerando tempos totais de obtenção de cada produto final.

O plano mestre indica as necessidades de produtos finais, expressas em datas e quantidades que estes devem estar disponíveis. O horizonte de tempo é de alguns meses, com períodos de semanas. 
Informações necessárias

Para que o plano mestre seja feito é necessário o acesso aos planos agregados e aos índices de desagregação, gerados no sub processo anterior.

Além destas, também é necessário o conhecimento sobre todas as fontes de demanda do produto (vendas, testes, amostras e outras) e sobre as necessidades líquidas do produto final. Esta última, além das necessidades expressas no plano agregado, deve fazer outras considerações, como perdas de processo, otimização da produção e condições de armazenagem.

Informações geradas

O resultado deste sub processo é o plano mestre de produção, que será utilizado em vários processos e atividades da empresa, principalmente para seu detalhamento até a geração das ordens de produção e compras.

\section{Recursos}

O mecanismo de cálculo do plano mestre é simples, porém o volume de dados trabalhados é grande, o que pode requerer o auxílio de um sistema automatizado. Sistemas ERP e MRP possuem as funcionalidades necessárias. Em situações menos complexas podem ser utilizadas planilhas eletrônicas.

Sub processo: Fazer plano detalhado de produção

\section{Descrição e objetivo}

O plano mestre expressa as necessidades de produção dos produtos finais. Porém estes são compostos de itens, que também possuem necessidades de produção que são expressas no plano detalhado de produção.

O plano detalhado geralmente é feito para algumas semanas, e possui períodos de dias ou até de horas. Indica as datas e quantidades que os componentes devem estar disponíveis, e as datas que as produções devem ser iniciadas ou liberadas, em função do tempo de obtenção (lead time) de cada componente.

Este plano é operacional, e pode ser utilizado para direcionar diretamente algumas operações de chão de fábrica, como liberação de materiais e ajustes macro. 
Porém ainda é necessário mais um detalhamento, que ocorre na programação da produção, para tornar os planos completamente operacionais.

Para elaboração deste plano, são consideradas as restrições de disponibilidade da capacidade, agora de forma mais detalhada que nos sub processos anteriores. É considerada a disponibilidade de cada equipamento de produção, para o processamento de cada item dos produtos finais.

\section{Informações necessárias}

A principal informação necessária é o plano mestre de produção, pois o planejamento detalhado deve satisfazer as necessidades de produtos finais. Além disso, é necessário o conhecimento da ocorrência de alguns eventos de chão de fábrica, que podem requerem que sejam feitos ajustes no plano atual, ou mesmo que um novo plano seja feito. Estes eventos estão relacionados com desvios que podem ocorrer, como atrasos, falta de materiais e substituições.

Também é necessário o acesso a dados históricos de produção, que permitem que erros e desvios do passado sejam corrigidos, além de permitir o acompanhamento de indicadores relacionados a estratégias e mudanças adotadas.

Devem ser consideradas restrições de disponibilidade de capacidade e de materiais, além dos estoques disponíveis. Estes últimos permitem que as necessidades brutas sejam convertidas em necessidades líquidas, considerando a disponibilidade projetada de estoques ao longo do tempo.

Outras informações necessárias são geradas em consultas às listas de materiais, para que seja conhecida a estrutura do produto, ou seja, os itens que compões o produto final. Outro conjunto de informações necessário é relacionado às políticas de planejamento, estoques e lotes de produção.

Informações geradas

O resultado deste sub processo é o plano detalhado de produção, expresso através de tabelas chamadas de registro básico do $M R P$, que mostram em forma de tabela as seguintes quantidades, período a período:

- Necessidades brutas de disponibilidade de componentes;

- Recebimentos programados; 
- Estoque projetado;

- Disponibilização de itens produzidos ou comprados e

- Liberação para início de produção e compra de itens.

Estes registros podem ser distribuídos para planejadores de níveis mais operacionais, como supervisores de produção, para que direcionem algumas atividades de curto e médio prazo.

Além disso, são geradas as ordens de produção e compras, que identificam o item, a quantidade e as datas de início (liberação para início do processo) e término (disponibilização para ser utilizado em operações de outros itens).

\section{Recursos}

Assim como no plano mestre, o mecanismo de cálculo é simples, porém o volume de dados é muito grande. Existem diversos sistemas automatizados para este cálculo, sendo inclusive uma das primeiras funções a serem informatizadas em empresas de manufatura. Este tipo de sistema é conhecido como cálculo das necessidades de materiais, ou MRP (Materials Requirements Planning). Sistemas ERP possuem todas as funcionalidades necessárias. 
Sub processo: Desagregar plano agregado de produção

Atividade: Analisar desvios históricos dos índices de desagregação

\section{Descrição e objetivo}

Os índices de desagregação utilizados refletem uma expectativa da participação de determinado produto na produção total de sua família. Como a quantidade a ser produzida de cada produto final da empresa é refletida em uma série de desdobramentos, os desvios em questão devem ser os menores possíveis.

A análise dos desvios ocorridos tem o objetivo de aperfeiçoar constantemente os índices de desagregação. Os dados tratados para esta análise devem ser tão confiáveis e precisos quanto possíveis. Uma forma obter dados com estas qualificações é através de sistemas de monitoramento da produção, que acompanham os equipamentos de produção de forma constante (e não através de médias e intervalos de tempo, como nos apontamentos manuais).

Qualquer desvio deve ser analisado, e suas causas compreendidas, para evitar que ocorra novamente. Mesmo no caso de pequenos desvios ou casos de acerto dos índices, deve ser feita uma análise da situação.

Informações necessárias

Para a realização desta atividade devem ser obtidas informações sobre os índices de desagregação planejados anteriormente, e os valores que ocorreram na prática. Quanto menor o intervalo de tempo considerado, como dias, melhor será esta análise.

Devem ser considerados os desvios para cada produto e para as famílias.

Informações sobre a produção real podem ser obtidas através da coleta automática de dados de chão de fábrica, com o uso de sensores, coletores de dados e sistemas de supervisão. Isso permite que as informações sejam obtidas rapidamente, possibilitando a tomada de ações corretivas em curto espaço de tempo. 
Informações geradas

O resultado desta atividade é um relatório ou análise dos desvios ocorridos entre os índices de desagregação previstos e aqueles que realmente ocorreram. Pode ser apresentado através de um banco de dados ou planilha eletrônica.

\section{Recursos}

Para a realização desta atividade, os recursos necessários devem suportar o volume de dados e informações analisadas. Caso este seja muito grande, pode ser necessária a utilização de um sistema automatizado.

Recursos auxiliares que permitam o cruzamento de mais de uma informação e realização de outras consultas elaboradas e forma rápida podem auxiliar na realização destas análises.

Atividade: Analisar índices de desagregação atuais

\section{Descrição e objetivo}

Esta atividade tem o objetivo de questionar como os índices de desagregação utilizados foram gerados ou calculados, e se ainda continuam válidos. Os critérios utilizados para a elaboração destes índices devem ser continuamente analisados e validados ou não.

\section{Informações necessárias}

As informações necessárias são os índices atuais e a forma como foram gerados.

De forma geral, a geração dos índices de desagregação reflete índices históricos, obtidos principalmente através de diferentes tipos de médias.

A representação dos índices atuais é simples, e pode ser feita em bancos de dados ou planilhas eletrônicas. Sistemas ERP trabalham com esta informação, e podem gerar relatórios específicos. Porém, as informações sobre o processo de geração destes índices podem ser complexas e não apresentar uma uniformidade que permita o seu registro de forma ordenada. Desta forma, os processos de geração dos índices de desagregação podem ser restritos ao conhecimento de algumas pessoas. 
Informações geradas

O resultado desta atividade é a atualização dos índices de desagregação e o registro dos processos que os geraram.

\section{Recursos}

Os recursos necessários para estas análises devem permitir que os índices em questão e os processos que os geraram sejam conhecidos e possam ser analisados e porventura modificados.

Atividade: Definir índices de desagregação a serem utilizados

\section{Descrição e objetivo}

Esta atividade é referente tanto à modificação e aperfeiçoamento de índices de desagregação existentes como para a criação de novos. Neste último caso, devem ser analisados todos os dados que possam estar diretamente relacionados com o novo produto, como produtos similares ou da mesma família.

Após as análises apresentadas nas atividades anteriores, os índices de desagregação podem então ser atualizados, para que sejam usados no exercício atual.

Informações necessárias

Para que esta atividade seja realizada, é necessário acesso aos índices atuais e aos resultados das análises das atividades anteriores deste sub processo.

Informações geradas

Os resultados desta atividade de definição são os índices de desagregação para todos as famílias e produtos da empresa, que serão utilizados no exercício atual.

\section{Recursos}

O recurso necessário nesta atividade é o mesmo responsável pelo armazenamento dos índices atualmente utilizados. Trata-se de uma relação simples, onde são listados os produtos e o seu respectivo índice. Portanto, não existe a necessidade de sistemas automatizados específicos para esta finalidade. Porém, caso seja de interesse da empresa em conhecer o histórico das modificações destes índices, pode ser necessário o suporte de alguma ferramenta computacional. 
Alguns sistemas ERP fazem esta desagregação automaticamente, e portanto possuem estes índices cadastrados. No caso de atualização dos mesmos, é necessário que este cadastro também seja atualizado. 
Sub processo: Fazer plano mestre de produção

Atividade: Levantar as necessidades líquidas do produto final

\section{Descrição e objetivo}

Os números fornecidos pela desagregação do plano agregado de produção para cada produto indicam a quantidade de cada produto final que deve ser produzida para atender o plano agregado de vendas. Estes números são calculados por uma lógica simples, porém não apresentam considerações extras e subjetivas além do cálculo de desagregação.

Uma destas considerações é a necessidade líquida de produção dos produtos finais, que pode indicar quantidades de produção diferentes daquelas apresentadas pela simples desagregação. Estas considerações podem ser estendidas a componentes críticos.

Algumas destas considerações citadas podem ser:

- Oportunidades de compra de matéria prima ou venda vantajosa de produtos;

- Logística de fornecimento de matérias primas;

- Estoques estratégicos e

- Antecipação ou adiamento de entregas de produtos devido a condições vantajosas.

Estas considerações não são caracterizadas como restrições da produção, que serão analisadas separadamente.

Como exemplo, pode ser citada uma situação onde a produção de um item comum para um cliente seja adiantada, para que a entrega seja feita em conjunto com outro produto mais importante para o cliente. Neste caso, o produtor poderia atender melhor o seu cliente e obter economias na entrega dos produtos. 
Informações necessárias

As considerações analisadas nesta atividade são na sua maioria subjetivas, e portanto de difícil padronização e classificação. São necessárias informações de vários setores da empresa, e também do ambiente externo.

Devido à natureza das informações, o seu armazenamento pode ser complexo. Entretanto, quanto o maior o número de informações atuais e históricas consultadas, melhor será o plano mestre de produção final.

Informações geradas

Como resultado desta atividade, são feitos ajustes nos números gerados pela desagregação do plano agregado de produção, para cada produto final da empresa.

\section{Recursos}

Para esta atividade, os recursos necessários são difíceis de serem estabelecidos, devido a grande variedade de tipos e conteúdos de informações tratadas. Deve haver um registro das alterações relativas às quantidades de produto final, para que isso crie um conhecimento e compreensão do histórico do planejamento da produção.

Atividade: Analisar todas as fontes de demanda do produto

\section{Descrição e objetivo}

Um produto final pode ter algumas fontes de demanda. Entre elas temos a demanda independente, que relaciona diretamente a quantidade de produtos finais com o plano agregado de vendas. Outra demanda é chamada de dependente, que ocorre quando um produto final também faz parte de outro produto final como um componente, e sua demanda depende do produto final da qual é componente. Estes dois tipos de demanda são estimados, pois são baseados em previsões.

Outras fontes de demanda são os pedidos em carteira. Estes representam pedidos fechados ou firmes, que indicam quantidades necessárias reais, e não estimadas. As quantidades de produtos finais que aparecem como pedidos em carteira devem ser abatidas da demanda independente, porém não existe definição quanto ao máximo, mínimo e regras para que estes abatimentos sejam feitos. 
Além destas, outras fontes de demanda são pedidos atrasados ou programados para entregas ou transferências internas. Testes com novos produtos ou modificações nos existentes também devem ser considerados. No caso de empresas que oferecem amostras grátis de produtos, isto também deve ser considerado como uma fonte de demanda.

De forma indireta, os estoques de segurança ou mínimo também são uma fonte de demanda, visto que existe a necessidade de produção para que as exigências sejam atendidas.

O objetivo desta atividade é conhecer e considerar todas estas fontes de demanda na elaboração do plano mestre de produção para cada produto final da empresa.

Informações necessárias

Os planos agregados de produção e vendas são fontes de informações quanto às demandas independentes dos produtos finais. Juntamente com estas, as listas de materiais são necessárias para determinação da demanda dependente, que ao contrário da demanda independente, é calculada e não estimada.

As informações sobre pedidos em carteira podem ser obtidas com a área de vendas ou em sistemas ERP. Devem ser precisas e atuais, para garantir um bom resultado. Informações sobre outros pedidos (atrasados, internos, testes, amostras) devem ser conhecidas e estarem disponíveis para consulta.

As políticas de estoques para cada produto também devem ser conhecidas.

Para todas as informações necessárias deve ser considerado o horizonte de tempo mais longo possível.

Informações geradas

Esta atividade gera as informações sobre as demandas de cada produto que serão consideradas nos cálculos do plano mestre de produção. Estas informações são consideradas período a período, geralmente semanais. O horizonte de tempo deve ser de pelo menos um mês. 


\section{Recursos}

Vários sistemas são necessários para disponibilizar e tratar todas as informações necessárias apresentadas. Geralmente, sistemas ERP podem disponibilizar várias delas. O principal módulo envolvido é o de vendas, que deve fornecer informações sobre os pedidos em carteira e o plano de vendas agregado.

Recursos como Data Warehouse podem permitir análises mais precisas e rápidas destas informações.

Atividade: Desenvolver alternativas de plano mestre para o produto

\section{Descrição e objetivo}

As atividades deste sub processo descritas anteriormente permitem que seja elaborado um plano mestre de produção para cada produto final da empresa. Porém, mais de um plano mestre pode ser feito para cada produto, variando-se as considerações feitas e pesos atribuídos a determinadas variáveis.

Para que estas alternativas sejam desenvolvidas, devem haver critérios ou indicadores que permitam a comparação objetiva de dois planos mestres distintos para o mesmo produto no mesmo período de tempo. Estes indicadores podem ser, entre outros, a utilização da capacidade de produção, o custo de produção ou o número de pedidos atendidos no prazo.

Estes critérios ou indicadores podem ser otimizados, gerando soluções boas ou ótimas. Assim, um plano mestre desenvolvido pode ser refinado indefinidamente até que determinada condição seja alcançada.

Cada alternativa de plano mestre pode ser comparada a um cenário de produção, que serve de comparação com outros cenários.

Informações necessárias

As principais informações necessárias são os planos mestres de produção calculados para cada produto final da empresa. Além destes deve ser estabelecida uma política ou sistemática para consideração de critérios e indicadores para avaliação e comparação de cada plano mestre desenvolvido para o mesmo produto. 
Cada plano mestre desenvolvido deve ser identificado, para que possa ser registrado e recuperado posteriormente.

Informações geradas

A informação gerada nesta atividade é o conjunto de planos mestres de produção refinados ou otimizados. Além disso, é gerado um conhecimento sobre condições, critérios e valores de variáveis que permitem o desenvolvimento de melhores planos.

\section{Recursos}

Para esta atividade é necessário o suporte de um sistema automatizado. Isto porque o volume de informações e dados trabalhados é grande. Além disso, para a realização da atividade deve ser possível a recuperação rápida de planos distintos, para comparação.

Uma forma interessante de analisar as diferenças entre diferentes planos é através de gráficos indicando os valores de alguns indicadores utilizados para comparação.

Sistemas de Data Warehouse podem permitir a realização de comparações mais elaboradas, que considerem um número maior de indicadores e situações.

Atividade: Analisar restrições ao plano mestre

\section{Descrição e objetivo}

As atividades descritas até o momento para este sub processo tratam do desenvolvimento do plano mestre, considerando todas as fontes de demanda e seu aperfeiçoamento. Entretanto, ainda não foram considerados fatores que podem restringir estes planos.

A principal restrição a ser considerada é a capacidade produtiva. Isto pode ser feito através do planejamento de longo prazo da capacidade, também chamado de Rough Cut Capacity Planning (RCCP). Este planejamento confronta a capacidade de produção necessária para atender os planos mestres desenvolvidos com gargalos de produção e recursos produtivos chave. Este confronto mostra a viabilidade de cada plano, e caso os limites de capacidade sejam excedidos, o plano deve ser refeito. A 
capacidade de produção é considerada de forma agregada, com unidades como horas ou dias necessários para a produção completa de determinado produto final. A mesma unidade é usada para estabelecer a disponibilidade de capacidade dos recursos produtivos analisados.

Outras restrições que podem ser consideradas:

- Volumes (de matérias primas, produtos intermediários e acabados) máximos permitidos durante o processo de produção, por questões tecnológicas;

- Volumes de armazenagem;

- Capacidade de transporte (interno e externo);

- Disponibilidade de matéria prima;

- Disponibilidade de recursos (pessoal, ferramentas, moldes e outros) e

- Importância estratégica dos clientes e pedidos.

Informações necessárias

São necessárias informações sobre todas as restrições citadas, que são em parte tecnológicas e podem ser facilmente obtidas, através de setores de engenharia, manutenção ou em projetos dos equipamentos e instalações. Porém estas informações devem ser precisas, atualizadas e confiáveis, o que pode ser obtido caso estejam armazenadas em sistemas de informação.

As disponibilidades de matérias primas e recursos devem ser atualizadas constantemente, fato que geralmente ocorre em sistemas ERP.

Outra informação necessária é sobre a importância de clientes e pedidos, que pode ser obtida informalmente caso esta classificação seja subjetiva ou que pode ser obtida através de sistemas que trabalhem com estas informações. Um tipo de sistema e conceito que trabalha com estas informações é o Costumer Relationship Management (CRM). 
Informações geradas

Como resultado desta atividade de consideração de restrições é feito um refinamento dos planos mestres calculados, geralmente garantindo que os mesmos sejam viáveis.

\section{Recursos}

Para consulta e análise do impacto das restrições citadas, é necessário o suporte de um sistema automatizado. Sistemas ERP possuem módulos e funcionalidades que suportam a maioria das restrições, além de calcular o RCCP automaticamente ao se fazer o plano mestre.

O recurso deve também garantir a atualidade e disponibilidade das informações.

Atividade: Validar plano mestre do produto

\section{Descrição e objetivo}

Uma vez estabelecido o plano mestre de produção de cada produto final, os mesmos devem ser validados por outros setores da empresa, principalmente vendas e transportes (ou logística). Estas outras áreas ou pessoas devem tomar conhecimento dos planos desenvolvidos e analisá-los segundo suas próprias restrições, podendo sugerir mudanças ou mesmo vetando planos que conflitem fortemente com outros objetivos e metas da empresa. Para facilitar esta validação, o plano pode ser desenvolvido em conjunto por todas as partes envolvidas.

Portanto, o objetivo desta atividade é garantir que os planos gerados são viáveis.

Informações necessárias

As informações necessárias são os próprios planos mestres de produção gerados, que devem ser disponibilizados para quem necessitar consultá-los. 


\section{Informações geradas}

Os resultados desta atividade são os planos mestres de produção definitivos, e que serão então utilizados como direcionadores da produção e do planejamento da produção dos componentes dos produtos finais.

\section{Recursos}

Os recursos para esta atividade devem prover a disponibilidade das informações necessárias para áreas fora do planejamento da produção, e obter o retorno destas avaliações externas. 
Sub processo: Fazer plano detalhado de produção

Atividade: Iniciar detalhamento

Descrição e objetivo

Esta atividade marca o início da seqüência de atividades relacionadas ao planejamento detalhado da produção. É comum ser utilizado o termo "disparar o processo" para este tipo de situação.

Esta atividade pode ser realizada em três situações. A primeira é quando um novo plano mestre foi feito, ou quando este é modificado. A segunda situação é quando um plano detalhado é gerado, porém não satisfaz alguns requisitos e necessita que seja refeito. Por fim, esta atividade pode ser realizada quando ocorrem eventos no chão de fábrica que necessitam que o plano em andamento seja refeito, como por exemplo falta de material, quebra de equipamento ou atraso no processamento de uma operação de produção.

Efetivamente não é realizada nenhuma atividade específica ou bem definida, apenas a seqüência de atividades é iniciada. No formalismo adotado para a representação neste trabalho, a realização do plano detalhado de produção é tratada como sub processo. Porém, visto isoladamente como uma seqüência de atividades, pode ser chamada de processo, sendo que esta atividade poderia então ser chamada de iniciar o processo de detalhamento.

Informações necessárias

Para que esta atividade seja iniciada é necessário uma das seguintes informações:

- O plano detalhado que está sendo realizado não satisfaz o plano mestre de produção;

- O plano mestre de produção atual foi modificado ou refeito e

- Ocorrência de evento que necessite que o plano detalhado atual (ou parte dele) necessite ser refeito. 
No sub processo de elaboração do plano detalhado de produção (a qual esta atividade pertence), existe uma atividade que verifica se o plano que está sendo elaborado satisfaz esta condição. Isto pode ocorrer quando o prazo de entrega de algum produto final excede o planejado anteriormente, ou quando restrições detalhadas de capacidade impedem que a quantidade correta de um produto seja feita.

Para saber se o plano mestre atual foi modificado ou refeito, deve existir um procedimento de comunicação na empresa, ou então um sistema que controle a seqüência das atividades, chamados de sistemas Work Flow. Este tipo de sistema utiliza uma modelagem desta seqüência, e tem informações de quais atividades já foram realizadas, e quais aquelas que poderão ser iniciadas, de acordo com a ocorrência de determinados eventos, originados pela utilização ou não dos sistemas.

Quanto à ocorrência de eventos no chão de fábrica, é necessário que a empresa possua um sistema que permita que estas informações estejam disponíveis no momento correto. De forma geral, o espaço de tempo entre a ocorrência de um destes eventos até que uma decisão seja tomada deve ser o mínimo possível. Para tal, sistemas de monitoramento integrados com os sistemas de gestão atendem este requisito, pois acompanham continuamente recursos do chão de fábrica, e informam automaticamente a ocorrência de eventos pré-programados. Estes eventos que forçam modificações no plano atual são todos aqueles que impedem que o planejamento atual seja cumprido, como por exemplo:

- Parada e quebra de equipamentos;

- Falta de material;

- Tempo de processamento maior ou menor que o planejado e

- Eventos que interfiram na disponibilidade de capacidade.

Em empresas com sistemas de apontamento manual, as informações sobre estes eventos podem demorar a serem conhecidas, geralmente com um atraso que impossibilita que sejam tomadas medidas corretivas (no planejamento e tecnológicas) efetivas. 
Informações geradas

A informação gerada nesta atividade é a de que a seqüência de atividades para planejamento detalhado da produção pode ser iniciada.

\section{Recursos}

Os recursos necessários para a realização desta atividade são aqueles que permitem que as informações necessárias estejam disponíveis nos sistemas e para as pessoas que as necessitem, no momento correto.

Sistemas com um controle do tipo Work Flow podem ser utilizados. Alguns sistemas ERP possuem esta funcionalidade incorporada.

Para que as informações relacionadas a eventos de chão de fábrica sejam disponibilizadas de forma rápida e com grande precisão, é necessário que exista um sistema de monitoramento da produção, integrado a coletores de dados e sensores instalados nos equipamentos de produção.

Atividade: Consultar lista de materiais

\section{Descrição e objetivo}

Esta atividade possui como objetivo informar todos os componentes de cada produto final que aparece no plano mestre, e que portanto devem ser produzidos. Esta informação também é conhecida por BOM (Bill of materials). Além dos componentes, a lista de materiais deve indicar a quantidade de cada componente necessário, e os relacionamentos entre estes (relacionamento "pai-filho" ou árvore do produto).

Informações necessárias

A informação necessária é a própria lista de materiais, que obrigatoriamente deve conter as seguintes informações para cada produto final: componentes, relacionamento entre os componentes e quantidades necessárias.

Este tipo de informação é comum em cadastros de vários tipos de sistemas, como ERP's, sistemas de engenharia e de processos. Estas informações devem ser atualizadas, o que requer uma manutenção regular das mesmas, principalmente em empresas com freqüentes inovações nos seus produtos. 
Outras informações que devem estar presente na lista de materiais são os tempos de obtenção de cada componente, também chamado de tempo de obtenção, suprimento ou lead time. Este tempo geralmente é expresso em dias.

Informações geradas

As informações geradas com a consulta à lista de materiais são as próprias listas de materiais, ou seja a estrutura de cada produto final que tenha necessidade de produção no plano mestre.

\section{Recursos}

Como mencionado, vários tipos de sistemas informatizados possuem cadastros destas informações, e portanto podem disponibilizá-las quando necessário. Caso não exista este tipo de sistema na empresa, estas informações devem ficar registradas de outra forma, que também possibilite consultas rápidas.

\section{Atividade: Consultar restrições}

\section{Descrição e objetivo}

São três os principais tipos de restrições consideradas: capacidade de produção, estoques disponíveis de produtos finais e componentes e a disponibilidade de materiais para processamento.

A capacidade de produção limita a quantidade que pode ser produzida em determinados recursos, retratando o turno efetivo de funcionamento ou disponibilidade destes recursos. Neste nível de planejamento, a capacidade é considerada geralmente em horas disponíveis do recurso por dia, que deve ser confrontado com a necessidade em horas para se processar determinada operação de um lote de componentes. Várias considerações específicas podem ser feitas relacionadas a este tópico, porém seu detalhamento foge ao escopo deste trabalho.

Além de ser considerada a restrição da capacidade disponível de uma forma geral (disponibilidade nominal), deve ser considerada a ocupação destes recursos que já está comprometida no momento de realização deste planejamento.

O cálculo das necessidades detalhadas de produção apresenta as necessidades brutas do componente, que se refere à quantidade necessária para atendimento do 
plano mestre de produção do produto final ("pai" do componente em questão). Porém podem haver quantidades deste componente disponíveis no momento ou projetadas para o futuro, que devem ser diminuídas das quantidades brutas, para o cálculo da necessidade líquida. As ordens de compra e de produção para os componentes serão geradas com base na sua necessidade líquida, por isso então é feita esta consideração.

As quantidades mencionadas acima são relativas a projeção de estoques. Outra restrição a ser considerada no planejamento detalhado da produção é a disponibilidade de matéria prima ou material para ser processado. A quantidade disponível para processamento no momento deve ser compatível com a produção necessária (necessidades líquidas). Para garantia desta condição, um bom processo de gerenciamento das compras é necessário.

Principalmente as restrições acima devem ser consideradas para que o planejamento detalhado da produção gere informações realistas e próximas da realidade. Outras restrições também podem ser consideradas, como disponibilidade de mão de obra e ferramentas, espaço físico para processamento e armazenamento, disponibilidade de programas e processos de produção, entre outras.

Informações necessárias

Por se tratar de uma atividade abrangente, são várias as informações necessárias. Relacionado a capacidade de produção, trabalha-se normalmente com a unidade de horas disponíveis por dia, e as informações necessárias são:

- Capacidade total disponível de cada equipamento de produção (correspondente ao período de trabalho normal do equipamento), chamada de capacidade nominal;

- Ocupação do recurso produtivo para processamento das operações necessárias nos componentes;

- Fatores de conversões. Equipamentos diferentes possuem produtividades diferentes para a mesma operação do mesmo produto e 
Capacidade do recurso já alocada em planejamentos anteriores. Neste tópico também influi a situação atual do recurso, que pode ser controlada através de um sistema de monitoramento.

Para informações sobre a restrição de disponibilidade de estoques, usadas para o cálculo das necessidades líquidas de produção, é necessário que as posições atual e projetada de estoque dos componentes sejam conhecidas. Estas informações devem ser precisas, o que exige que exista em funcionamento um sistema preciso de controle de estoques, que pode envolver até fatores culturais da empresa, como o controle das pessoas com acesso aos estoques.

Para as informações relacionadas à disponibilidade de materiais para processamento, também é necessário que exista um preciso sistema de controle de estoques de matérias primas e produtos intermediários. Estas informações são geradas em almoxarifados e pelo planejamento e controle de compras da empresa.

Como esta atividade trata de consulta a restrições ao planejamento detalhado, várias outras informações podem ser necessárias. Todas informações disponíveis e que possam interferir ou restringir este planejamento devem ser consideradas.

Informações geradas

Com a realização desta atividade, são geradas informações sobre as quantidades limites que poderão ser produzidas para cada componente para cada período de tempo do planejamento. Além das quantidades, são geradas informações que permitem que as datas de início e término, e os períodos de produção a serem considerados no planejamento detalhado reflitam a realidade.

\section{Recursos}

Vários recursos são necessários para a realização desta atividade.

Para as informações de disponibilidade de capacidade, devem ser conhecidas as disponibilidades de cada equipamento, o que pode ser cadastrado em sistemas simples. Porém, para informação sobre disponibilidades já alocadas, existe uma complexidade maior, pois é necessário conhecer o programa atual de produção e a situação atual dos equipamentos de produção. O programa pode ser obtido diretamente em sistemas específicos ou através de relatórios ou quadros de 
programação visual. A situação atual dos recursos de produção pode ser conhecida através de sistemas de monitoramento da produção.

Para consulta das informações sobre os estoques disponíveis, é necessário que exista um controle rígido sobre a movimentação de materiais. Atualmente, diversos recursos têm sido empregados com esta finalidade, entre eles podemos citar coletores de dados e leitores/impressoras de códigos de barras, que alimentam um sistema com informações de entrada/saída e movimentação dos materiais e dos estoques. Estes recursos também podem ser utilizados para o controle de movimentação das matérias primas e produtos intermediários.

Atividade: Consultar indicadores

\section{Descrição e objetivo}

Esta atividade consiste em consultar e analisar relatórios e outras fontes de indicadores que podem restringir o planejamento detalhado ou fornecer diretrizes para sua elaboração.

Indicadores financeiros podem ser uma restrição à efetivação de um cenário de planejamento, por exemplo na situação onde os custos de produção planejados são incompatíveis com um planejamento financeiro anterior. Outros indicadores podem atuar da mesma forma.

Conforme já mencionado neste trabalho, ferramentas do tipo Data Warehouse foram desenvolvidas com a finalidade de ser um grande repositório de dados e permitir a elaboração de consultas complexas de forma rápida e simples. Assim, relatórios padrões podem ser desenvolvidos e emitidos com uma frequiência fixa, e também relatórios esporádicos podem ser utilizados uma única vez. De qualquer uma destas formas, podem ser consultados e até criados indicadores que auxiliam na elaboração do planejamento detalhado.

Informações necessárias

Para realização desta atividade não existe um rigor e um formalismo estabelecidos, sendo então utilizadas todas as informações pertinentes disponíveis. 
Informações e indicadores financeiros podem ser utilizados com maior frequiência, pois podem ser grandes restrições ao plano detalhado de produção.

Informações geradas

Devido a falta de rigor e formalismo desta atividade, não é possível precisar quais informações são geradas. A condição é que estas possam auxiliar na elaboração do planejamento detalhado da produção.

\section{Recursos}

Para esta atividade podem ser utilizados todos os recursos disponíveis e pertinentes. De forma complementar, ferramentas de Data Warehouse podem ser utilizadas para armazenamento de informações e geração de relatórios contendo indicadores.

Atividade: Consultar políticas

\section{Descrição e objetivo}

Serão consideradas nesta atividade duas políticas: de estoques e de produção.

As políticas de estoques dizem respeito às quantidades mínimas e máximas que devem ser estocadas de cada componente. Os estoques mínimos também podem ser de segurança.

As políticas de produção vão indicar os tamanhos de lotes a serem produzidos de cada vez para cada produto.

O objetivo desta atividade é orientar estes aspectos mencionados (estoques e lotes de produção) na elaboração do plano detalhado de produção.

Estas políticas não devem indicar valores fixos por longos períodos de tempo, pois estes devem ser constantemente atualizados.

Informações necessárias

Para a definição da política de estoques, são necessárias informações sobre:

- Capacidade física de armazenagem e volume ou peso dos componentes; 
- Valor admissível para ser empregado ou investido em estoques;

- Importância do componente ou produto intermediário e

- Outras restrições que interfiram na quantidade estocada.

As políticas de produção são definidas com base nas informações:

- Lote econômico de produção;

- Tempos de preparação;

- Características do equipamento, principalmente em relação aos volumes produzidos;

- Importância do produto;

- Restrições de transporte e

- Otimização do programa de produção.

Estas informações apresentadas estão mais relacionadas com a geração e criação das políticas mencionadas. Entretanto a manutenção destas políticas também é importante e deve ser executada com freqüência. Para tanto, ferramentas como Data Warehouse são úteis, pois permitem um acompanhar o histórico destes valores e entender a causa de desvios.

Informações geradas

As informações geradas nesta atividade são necessárias para o cálculo das necessidades detalhadas de produção, e podem ser expressas para cada produto como o lote mínimo de produção e o estoque mínimo que deve ser mantido a cada período do planejamento.

\section{Recursos}

Os sistemas automatizados que fazem o cálculo das necessidades de materiais (MRP) possuem um cadastro das informações geradas nesta atividade. Sistemas mais complexos como os ERP's também possuem e necessitam deste cadastro.

Além destes cadastros, podem ser necessários recursos para que sejam feitos a manutenção e acompanhamento destes valores. 
Atividade: Calcular necessidades detalhadas

\section{Descrição e objetivo}

Esta atividade é conhecida pelo termo "rodar o MRP", e pode ser descrita como a explosão das necessidades dos produtos finais geradas pelo plano mestre em necessidades dos componentes deste produto.

O procedimento de cálculo é simples, e pode ser visto com detalhes em CORRÊA et al. (1997). Resumidamente, o cálculo considera a quantidade de estoque projetado para o período menos as necessidades, e o resultado são as quantidades a serem produzidas ou compradas, para cada período de tempo considerado. Usualmente, o horizonte trabalhado no planejamento detalhado é de algumas semanas, e os períodos (divisões do horizonte total) são em dias. Para que estas necessidades sejam atendidas, é então considerado o tempo de obtenção do componente, sendo então calculada a data em que a produção ou compra do componente deve ser iniciada.

Apesar de simples, este cálculo torna-se complexo devido à grande quantidade de componentes que devem ser considerados. Caso ocorram problemas, como por exemplo quando existe a necessidade de iniciar uma produção no passado ou quando o estoque inicial do produto não é suficiente para atender as necessidades ao longo do tempo, são gerados alertas, chamados de mensagens de exceção.

\section{Informações necessárias}

Todas as informações geradas em atividades anteriores deste sub processo são necessárias para este cálculo. Além disso, as seguintes informações também são necessárias:

- Necessidades brutas, indica a quantidade, por período, que deve estar disponível do componente;

- Recebimentos programados, indica quantidades que devem estar disponíveis no período estabelecido, mas que não são geradas pelo planejamento sendo feito, ou podem ser fruto de transações entre unidades ou departamentos da mesma empresa; 
- Estoque projetado inicial, é referente a quantidade de produtos que deve estar disponível ao início do primeiro período considerado no planejamento detalhado;

- Lote mínimo de produção, é resultado da política de estoques, e indica o tamanho mínimo do lote de produção, ou então um valor cujo lote de produção deve ser múltiplo deste;

- Tempo de obtenção (Lead time), é o tempo projetado entre o início do processo de obtenção (compra ou produção) de um componente e sua efetiva disponibilização e

- Estoque mínimo, é a mínima quantidade do produto que deve estar disponível em estoque. Também é resultado da política de estoques da empresa e reflete aspectos estratégicos.

Além destas, é necessária a informação gerada no plano mestre indicando quais produtos finais possuem necessidades de produção.

Informações geradas

Os resultados desta atividade são ordens de compra e de produção de componentes e matérias primas, para cada período considerado no horizonte de tempo. Estas ordens indicam quantidades e as datas que o processo (de produção ou de compra) deve ser iniciado e terminado.

Outras informações geradas são as projeções de estoque para cada período.

Conforme mencionado, também podem ser geradas mensagens de exceção, que indicam problemas que o procedimento automático de cálculo não consegue resolver, e que portanto devem ser objeto de análise posterior.

\section{Recursos}

O procedimento de cálculo é simples e pode ser realizado sem o auxílio de recursos e sistemas automatizados. Porém o volume de componentes e de cálculos pode requerer a utilização de recursos automatizados, como planilhas eletrônicas e sistemas especializados. Este tipo de sistema é comum e faz parte de sistemas ERP ou MRP. 
Atividade: Analisar mensagens de exceção

\section{Descrição e objetivo}

Mensagens de exceção são alertas gerados pelos sistemas de cálculo das necessidades de materiais (MRP), para indicar a ocorrência de situações onde não é possível atender as necessidades brutas do componente.

Segundo VOLLMANN et al. (1993), as principais mensagens de exceção são as seguintes:

- Componentes que precisam ter produção ou compra iniciada no período atual ou no passado;

- Quantidades ou prazos de ordens não satisfatórios, por exemplo quando a necessidade de produção de um período é maior que o lote máximo de produção, ou quando o estoque projetado será menor que o estoque mínimo e

- Mudanças ou problemas de engenharia, como a substituição ou atualização de componentes.

Na prática, o cálculo de MRP não é acompanhado em detalhes, sendo que esta atenção especial é dada apenas às mensagens de exceção, o que é chamado de "gerenciamento de (por) exceções".

A forma destas mensagens pode variar, sendo que os sistemas MRP apresentam listagens, que podem ser ordenadas de acordo com a importância da exceção. Sistemas mais simples ou planilhas eletrônicas podem apresentar estas mensagens ou simplesmente interromper o cálculo, esperando a intervenção de um planejador.

Informações necessárias

Para a realização desta atividade são necessárias as mensagens de exceção, que podem ser acessadas de diversas formas pelos sistemas e ferramentas de cálculo de necessidades de materiais. 
Informações geradas

Com a realização desta atividade, o planejador (ou equipe de planejamento) terá condições de interferir no planejamento detalhado calculado, corrigindo ou modificando situações problemáticas.

\section{Recursos}

Os recursos necessários para executar esta atividade são os mesmos utilizados para o cálculo das necessidades de materiais, que devem permitir alguma forma de interferência no planejamento calculado.

Atividade: Verificar se plano mestre é atendido

\section{Descrição e objetivo}

O procedimento de cálculo das necessidades detalhadas procura garantir que as necessidades dos componentes serão atendidas através de estoques e quantidades a serem produzidas. Porém não existem garantias que o plano mestre do produto final a qual o componente pertence será atendido plenamente.

Desta forma, deve haver um mecanismo que faça esta análise, verificando se todas as necessidades de componentes são atendidas, para que por sua vez, a necessidade de produtos finais seja atendida.

\section{Informações necessárias}

Para realizar esta atividade são necessários o plano mestre atual e o resultado do planejamento detalhado (ordens de compra e produção), para que a verificação possa ser feita.

Informações geradas

O resultado desta atividade deverá indicar problemas no atendimento do plano mestre indicando quais os produtos e possíveis alternativas para que as situações possam ser contornadas ou amenizadas.

\section{Recursos}

O recurso utilizado para esta atividade pode ser o mesmo que gera o plano mestre e o plano detalhado de produção, sendo que neste caso não haveria 
necessidade de integrações. Caso esta situação não seja possível, devem ser utilizados recursos que permitam a visualização dos referidos planos, assim como a análise da produção de todos os componentes de um produto. Sistemas MRP usualmente possuem esta funcionalidade. 
Processo: Programar produção

Atividade: Conhecer situação atual do chão de fábrica

Descrição e objetivo

O objetivo desta atividade é levantar informações sobre o chão de fábrica que auxiliem a elaboração do programa de produção. Estas informações podem ser de vários tipos, entre eles:

- Paradas de equipamentos, por quebras ou outros motivos;

- Produtividade dos recursos;

- Situação de ordens de produção liberadas;

- Situação e disponibilidade de recursos auxiliares, como ferramentas e dispositivos;

- Rastreamento da posição e situação de materiais;

- Situação de recursos de transportes, tanto internos com externos (expedição) e

- Informações de qualidade, como índices de refugos e dados de CEP (Controle estatístico do processo).

Esta atividade não possui tarefas definidas e formalizadas, e depende da disponibilidade das informações apresentadas acima e de outras que possam auxiliar a elaboração do programa de produção.

As informações relacionadas podem ser obtidas de diversas formas, como:

- Relatórios;

- Contato visual;

- Contato telefônico ou pessoal com outras pessoas;

- Sistemas de informação não específicos, como os sistemas ERP e

- Sistemas específicos, como os sistemas de supervisão e monitoramento da produção apresentados no item 4.2 deste trabalho. 
Como exemplo da realização desta atividade, algumas empresas realizam reuniões diárias ou semanais, chamadas de "reunião de programação", onde estão presentes pessoas de diversos setores da empresa, como produção, vendas e logística. Nestas ocasiões, cada um dos participantes apresenta dados e informações de sua área que afetam o programa de produção.

Informações necessárias

Conforme mencionado, esta atividade depende da disponibilidade de informações sobre o chão de fábrica. Portanto, todas as informações que puderem ser disponibilizadas devem ser utilizadas.

Informações geradas

Com a realização desta atividade, é gerado um conhecimento, tão abrangente quanto possível, da situação do chão de fábrica. Este será utilizado pelo programador ou por uma equipe para elaboração do programa de produção.

\section{Recursos}

Para esta atividade devem ser utilizados todos os recursos disponíveis que possam fornecer informações atuais sobre o chão de fábrica ou outros fatores que possam afetar a programação da produção.

Atividade: Iniciar programação da produção

\section{Descrição e objetivo}

Esta atividade não é formal, e apenas marca o início das atividades que efetivamente geram o programa de produção. Ela ocorrerá em conseqüência de alguns eventos que geram a necessidade de reprogramação ou da geração de um novo programa de produção. Ocorrerá também quando houver a finalização na elaboração de um novo planejamento detalhado (geração de ordens).

Alguns eventos que podem ocorrer no chão de fábrica e geram a necessidade de reprogramação:

- Atraso no início ou término de uma operação;

- Tempo previsto para uma operação maior ou menor que o real; 
- Atraso ou falta de disponibilidade de materiais e matérias primas;

- Imprevistos que prejudiquem o programa atual;

- Não disponibilidade imprevista de recursos de produção e

- Necessidade de utilização de processos alternativos de produção.

A frequiência da ocorrência desta atividade é variável, podendo oscilar entre alguns dias e algumas horas. Esta variação é função dos eventos mencionados e também dos recursos disponíveis.

Informações necessárias

Uma das informações necessárias para a realização desta atividade é a disponibilização de atualizações ou de novas ordens de produção, resultado da elaboração do planejamento detalhado da produção.

Em relação aos eventos mencionados acima, deve haver uma convenção ou política para definir quais devem ser considerados para se iniciarem modificações no programa de produção existente. Alguns parâmetros também devem ser definidos, como por exemplo o tempo que um equipamento deve ficar parado ou uma ordem ficar atrasada, até que seja realizada então outra programação. Portanto, são necessárias tanto informações da ocorrência dos eventos como informações sobre alguns parâmetros destas ocorrências.

Além destas, são necessárias informações sobre a situação atual do chão de fábrica, obtidas com a realização da atividade anterior.

Informações geradas

A realização desta atividade gera a informação de que um novo programa da produção deve ser feito, ou o atual deve ser modificado.

\section{Recursos}

Para a disponibilização de um novo plano detalhado (ordens) de produção, o próprio sistema utilizado pode ser utilizado. De forma geral, a programação da produção é feita com auxílio de sistemas de informação especializados, e que não fazem parte de sistemas corporativos e ERP's, sendo necessária alguma forma de integração. 
Em relação ao conhecimento da ocorrência de eventos e da situação atual do chão de fábrica, os recursos devem permitir que estas informações sejam disponibilizadas da forma mais rápida possível, o que pode ser obtido com sistemas de supervisão e monitoramento alimentados por sensores colocados nos equipamentos de produção e coletores de dados integrados.

Atividade: Analisar situação do programa atual

\section{Descrição e objetivo}

Esta atividade consiste em analisar quanto foi cumprido e qual a situação do programa atual. Esta análise serve de base para reprogramações ou para a elaboração de um novo programa. Em uma situação perfeita onde não ocorressem imprevistos, não haveria necessidade de realizar esta análise, porém, na prática, ela é necessária.

Esta análise deve considerar principalmente aspectos como ordens de produção atrasadas e não concluídas, e pendências em geral. Mudanças de prioridades de ordens também devem ser consideradas.

O horizonte de tempo que deve ser considerado nesta análise deve ser definido em função de características da empresa, como duração média das ordens. Devem ser consideradas principalmente as pendências ocorridas mais recentemente.

\section{Informações necessárias}

São necessários dois conjuntos de informações: o programa atual de produção (aquele que está em vigor) e o controle daquilo que realmente aconteceu. Com estas informações é possível fazer a análise da situação do programa de produção atual.

\section{Informações geradas}

Como resultado desta atividade, são conhecidos os problemas e disfunções que ocorreram no programa atual, e que portanto devem ser corrigidos e evitados na elaboração dos próximos programas.

A representação dos resultados desta análise não é formalizada, porém podem ser utilizadas ferramentas para controlar e monitorar índices históricos de desvios, gerando um conhecimento sobre determinado aspecto do chão de fábrica. Para isto podem ser utilizados sistemas de Data Warehouse, que permitem o armazenamento 
de um grande volume de informações e a rápida elaboração de consultas e relatório. Como ilustração de uma aplicação deste tipo, pode ser elaborado um relatório que mostre o relacionamento entre a produtividade de um equipamento e a sequiência de ordens programadas.

\section{Recursos}

São necessários dois recursos para a realização desta atividade: um para a visualização do programa atual e um para a visualização das informações de controle da produção.

Os próprios recursos utilizados para elaboração do programa permitem a sua visualização, e podem ser automatizados (Sistemas de programação da produção com capacidade finita ou sistemas de Scheduling), ou serem feitos manualmente com auxílio de recursos visuais como quadros e painéis.

Alguns sistemas que fazem a programação da produção possuem funcionalidades para tratamento do controle da produção, podendo até em alguns casos mostrar estas informações de forma visual, como por exemplo modificar a cor da representação de uma ordem, quando sua produção foi iniciada ou finalizada. Caso isto não seja possível, devem ser consultadas informações de controle em relatórios ou listas, que refletem dados gerados no apontamento manual da produção.

Um cenário interessante para esta situação seria um sistema de programação integrado com um sistema de supervisão da produção, onde sensores instalados nos equipamentos informam a situação dos mesmos e das ordens processadas. Aliada a isso, poderia ser feita a visualização do programa da produção com informações em tempo real sobre aquilo que realmente acontece no chão de fábrica.

Atividade: Analisar restrições

\section{Descrição e objetivo}

Esta atividade consiste em verificar todos os aspectos que podem influenciar um programa de produção. As principais restrições são:

- Disponibilidade de capacidade;

- Disponibilidade de materiais; 
- Disponibilidade de mão de obra, ferramentas e dispositivos;

- Logística (transporte e armazenamento) e

- Prioridades de clientes e ordens.

Na execução do programa de produção, além das necessidades de produção (expressas através das ordens), devem ser consideradas todas as restrições das quais se possuem informações.

A principal restrição considerada é a disponibilidade de capacidade, pois uma vez excedida a carregamento admissível de um equipamento, o programa gerado não é real, e deve ser refeito.

Informações necessárias

São necessárias todas as informações disponíveis sobre as restrições apresentadas e outras que possam influenciar o programa de produção.

Para consideração da capacidade de produção disponível, é feito um cálculo do tempo total disponível do recurso (em função dos turnos de trabalho), e da capacidade que já está alocada em programas anteriores.

Devido à diversidade das informações necessárias, a forma de obtenção das mesmas pode ter grandes variações de empresa para empresa.

Informações geradas

São geradas informações que restringem e limitam o programa de produção, e que portanto devem ser consideradas na sua elaboração.

A formalização ou registro destas informações geradas pode ocorrer diretamente na elaboração do programa, ou ficar registrada no sistema que realiza esta função.

\section{Recursos}

Da mesma forma que todas as informações disponíveis sobre as restrições devem ser utilizadas, todos os recursos que puderem fornecer estas informações também devem ser utilizados. 
Para informações sobre disponibilidades de capacidade, podem ser utilizados sistemas de engenharia ou de planejamento do processo, que possuem estes cadastros.

A disponibilidade de materiais deve ser informada através de consultas aos controles de estoques e almoxarifados, que devem por sua vez fornecer dados precisos sobre as quantidades armazenadas.

Sistemas de apoio às funções de logística também podem ser considerados, fornecendo informações sobre a disponibilidade de espaço e volume para armazenagem de produtos finais ou intermediários, e informações sobre transportes.

Sistemas ERP podem fornecer grande parte das informações necessárias para a realização desta atividade.

\section{Atividade: Otimizar programa}

\section{Descrição e objetivo}

O objetivo das atividades deste sub processo de gerar um programa de produção é que todas as necessidades de produção sejam atendidas com os recursos disponíveis. Porém, em algumas situações, o resultado deste programa ainda pode ser melhorado em determinados critérios. Entre os critérios de otimização mais utilizados, podemos citar:

- Ocupação de recursos de produção, principalmente aqueles considerados gargalos ou críticos;

- Tempo de preparação de equipamentos e

- Número de ordens terminadas após o prazo.

De uma forma geral, a otimização de um programa permite ganhos, que podem ser em custos, tempo ou qualidade. Pode-se conseguir o atendimento de um número maior de ordens em um programa otimizado.

A otimização pode ser feita com base em regras, por exemplo o Algoritmo de Johnson (MARTINS e LAUGENI, 1998) e outras regras, como Maior tempo de processo e Primeiro que entra primeiro que sai. Estas permitem que a ocupação dos recursos de produção seja otimizada, em diversas circunstâncias. 
Além destas, podem ser criadas regras internas, que refletem um conhecimento específico. Recursos como Data Warehouse e Data Mining podem auxiliar na elaboração destas regras, através da observação sistemática de dados históricos. Por exemplo, pode ser encontrado um tamanho de lote de produção que atenda critérios de custo e que permita que o tempo de preparação de determinado equipamento possa ser otimizado.

Informações necessárias

Para que esta atividade seja realizada, é necessário conhecer as regras e parâmetros de otimização utilizados, além de todas as ordens de produção que devem ser programadas.

Informações geradas

O resultado desta atividade é um programa de produção com alguns parâmetros otimizados com a utilização de regras.

Juntamente com o resultado das atividades Analisar restrições e Analisar situação do programa atual, o programa otimizado irá compor um cenário de programação, que será detalhado em atividade específica.

\section{Recursos}

Para registro do conhecimento sobre regras de otimização podem ser utilizados diversos recursos, desde editores de texto até sistemas mais complexos. De forma geral, estas regras são de conhecimento de algumas pessoas envolvidas com a programação, e não ficam registradas.

A otimização do programa pode ser feita utilizando-se o próprio recurso que faz a programação. Diversos sistemas automatizados e específicos para esta função possuem ferramentas próprias e ainda podem incorporar novas regras de otimização.

Atividade: Consultar processos de fabricação

Descrição e objetivo

O objetivo desta atividade é conhecer os processos de fabricação dos componentes dos produtos finais. $\mathrm{O}$ processo de fabricação indica a sequiência de 
processamento de cada componente, também conhecida como roteiro de fabricação. $\mathrm{O}$ processo de fabricação pode conter roteiros alternativos para o mesmo componente.

Estas informações são necessárias devido ao seguinte fato: cada ordem de produção indica o componente e quantidade a ser fabricado, e além disso, deve indicar também todas as operações, para que a utilização dos respectivos recursos seja reservada e programada.

Informações necessárias

As informações necessárias para a realização desta atividade são os processos de fabricação dos produtos e componentes. Estes processos devem conter:

- Roteiro de fabricação, que é a seqüência de operações;

- Roteiros alternativos;

- Tempos de processamento e

- Ferramentas e outros dispositivos necessários.

Informações geradas

A realização desta atividade gera um conhecimento sobre os roteiros de fabricação, que será utilizado na elaboração do programa de produção.

\section{Recursos}

Existem sistemas específicos para planejamento do processo de produção, chamados de CAPP (Computer Aided Process Planning), que podem fornecer as informações necessárias.

Sistemas ERP também possuem funcionalidades para cadastro e gerenciamento destas informações.

Além de sistemas automatizados, os processos de fabricação podem ser registrados e utilizados na forma de fichas impressas, que são passadas ao operador dos recursos juntamente com as ordens de produção. 
Atividade: Gerar cenário de programação

\section{Descrição e objetivo}

O resultado do planejamento detalhado da produção é um conjunto de ordens. As ordens de produção devem ser programadas, isto é, suas operações devem ser alocadas nos respectivos recursos, considerando a disponibilidade do mesmo e outras restrições. O procedimento de geração deste programa pode ser feito manualmente, porém isso acarreta em grande esforço para consultar todas as informações e fazer todas as considerações necessárias. Existem diversos procedimentos e algoritmos definidos para elaboração deste programa, como exemplo, pode ser citada a regra de primeiro que entra primeiro que sai, onde então as ordens são alocadas aos recursos na mesma seqüência em que são geradas. Além desta, existem outras regras que consideram um número maior de restrições. Este procedimento também pode ser completamente automatizado, através de sistemas específicos.

Após a realização das atividades Analisar situação do programa atual, Analisar restrições e Otimizar programa, e com a utilização dos procedimentos citados acima, é então gerado um cenário de programação.

Informações necessárias

Para a realização desta atividade são necessários dois conjuntos de informações: as ordens de produção geradas (mais o conhecimento sobre os processos e restrições) e os procedimentos de programação.

O primeiro conjunto é obtido com a realização das atividades anteriores a esta, neste sub processo.

De forma geral, assim como as regras de otimização, as regras de programação são de conhecimento de algumas pessoas, porém não existe registro formalizado das mesmas. Sistemas específicos de programação da produção com capacidade finita utilizam regras e procedimentos pré-definidos, e outros que podem ser definidos ou modificados pelos usuários.

Existem, na literatura especializada, diversos algoritmos de programação específicos para determinadas condições, que podem ser utilizados manualmente ou incorporados a sistemas automatizados. 
Informações geradas

O resultado desta atividade é um cenário de programação. Este apresenta a alocação de ordens em todos os recursos de produção, para determinado período de tempo. É chamado de cenário pois representa uma situação que poderá ser modificada manualmente, para que sejam comparadas segundo critérios objetivos.

Este cenário pode ser representado graficamente em quadros e painéis, ou então consultado e visualizado diretamente em sistema automatizados específicos.

\section{Recursos}

Conforme mencionado, esta atividade pode ser realizada manualmente ou através de sistemas.

Algumas empresas trabalham com quadros de programação onde são exibidas, de forma gráfica e respeitando uma escala de tempo, a sequiência de ordens de produção para serem processadas em determinados recursos. Para este tipo de representação é utilizado o gráfico de Gantt (MARTINS e LAUGENI, 1998).

Sistemas automatizados também utilizam este tipo de gráfico para exibição do programa de produção, que também pode ser impresso em listagens e relatórios. Estes sistemas são chamados de Programação da produção com capacidade finita, e devem ser integrados com sistemas de planejamento detalhado da produção (MRP), e receber dados de controle da produção.

Atividade: Avaliar programa

\section{Descrição e objetivo}

Uma vez gerado um cenário de programação, este deve ser avaliado segundo alguns critérios estabelecidos. Entre estas avaliações, as principais são:

- Ocupação dos recursos e

- Ordens atendidas fora do prazo.

Deve ser feita uma análise das situações onde a alocação de um recurso excede a sua disponibilidade, e também nos casos pouca utilização da disponibilidade. Os casos onde a capacidade é excedida (conhecidos como overload de capacidade) 
devem ser solucionados com o aumento da disponibilidade ou reprogramação, para que o programa final seja realista.

Dependendo do procedimento de programação adotado, algumas ordens podem ser programadas para terminarem após o prazo estabelecido pelo planejamento detalhado. Devem ser avaliadas alternativas a este programa, para que exista o menor número de ordens atrasadas possíveis.

\section{Informações necessárias}

Para a realização desta atividade, é necessário acesso ao cenário de programação gerado na atividade anterior. Também é necessário que exista uma definição sobre quais critérios devem ser avaliados.

Podem ser necessárias informações históricas sobre os critérios avaliados, permitindo um refinamento nas avaliações realizadas.

Informações geradas

O resultado da realização desta atividade é uma avaliação do programa gerado, segundo critérios e parâmetros estabelecidos. Caso a avaliação não seja satisfatória, o programa deverá ser refeito, em um processo interativo.

Os valores obtidos com a avaliação podem ser registrados, na forma de históricos.

\section{Recursos}

Alguns sistemas que fazem a programação da produção possuem funcionalidades para avaliação, principalmente da ocupação da capacidade, e outras que podem ser configuradas. Algumas destas avaliações podem ser visualizadas de forma gráfica. Também podem ser gerados alertas ou mensagens de exceção para casos onde a ocupação do recurso produtivo excede sua disponibilidade.

Esta avaliação também pode ser feita manualmente, para todos os recursos, quando isto for possível, ou somente para recursos críticos ou ordens prioritárias. 
Atividade: Liberar programa de produção

Descrição e objetivo

Quando um programa novo ou modificado recebe uma avaliação satisfatória, ele deve ser liberado para que seja acessado onde estas informações forem necessárias.

O programa liberado será acessado principalmente pelos operadores ou encarregados (supervisores) que fazem a distribuição das ordens no chão de fábrica.

Outras pessoas ou funções da empresa também podem consultar o programa, como por exemplo vendedores que desejem acompanhar a produção de determinados produtos ou pedidos.

Quando o programa está liberado, a produção pode ser iniciada.

Existe um formalismo que varia muito entre empresas, relacionado à situação (ou status) das ordens de produção, que podem assumir algumas das situações: liberadas, programadas, planejadas e firmes, entre outros. Esta situação das ordens não deve ser confundida com a situação do programa de produção apresentada nesta atividade.

Informações necessárias

Para a realização desta atividade são necessárias: a informação que determinado cenário de programação foi avaliado satisfatoriamente, e também o próprio programa de produção, para que seja liberado.

Informações geradas

A informação gerada nesta atividade é o programa liberado para que a produção possa ser iniciada. Este programa consiste em um conjunto de ordens alocadas em determinados recursos, com datas e horários previstos de término e início das operações.

Dependendo da empresa, a mesma ordem de produção é utilizada para todas as operações que o componente sofre, ou então é gerada uma ordem para cada operação de cada componente. 


\section{Recursos}

O recurso necessário para realização desta atividade deve permitir que o programa liberado seja acessado onde for necessário.

Em ambientes onde existem terminais ou coletores de dados no chão de fábrica e próximos aos equipamentos de produção, as liberações e transmissões de informações podem ser feitas eletrônica e automaticamente. Caso isso não seja possível, as ordens podem ser impressas e distribuídas manualmente.

Outra forma é a atualização de quadros e painéis de programação com o programa liberado. 
Processo: Produzir

Atividade: Fazer preparações

Descrição e objetivo

Esta atividade tem o objetivo de tornar operacional o recurso produtivo, configurado e preparado para processar determinado componente. Ocorre para cada operação de cada componente dos produtos finais. Como exemplo, para fabricação de um eixo (componente) de um redutor (produto final), podem ser feitas as seguintes operações: corte, torneamento e retífica. Cada uma destas operações requer uma preparação específica. Esta atividade também é conhecida por set up.

Estas preparações podem ser de diversos tipos, entre eles:

- Ajuste de distâncias ou posições;

- Troca de ferramentas e dispositivos;

- Disposição de materiais;

- Regulagens;

- Troca de tintas e

- Limpeza.

Uma preparação é iniciada quando existe um programa para a operação e quando o início da operação correspondente é liberado. Esta liberação deve estar de acordo com o programa, e ocorre quando a operação anterior foi finalizada e todas as outras condições para seu início estão satisfeitas.

Uma condição não necessária à realização da operação é o acesso a informações de produção disponíveis em consultas e relatórios. Com a utilização de ferramentas apropriadas, os usuários podem fazer consultas de forma fácil e rápida aos dados de produção, gerando um conhecimento específico. Bancos de dados relacionais permitem este tipo de consulta, porém necessitam de pessoal qualificado para realizar o desenvolvimento necessário. Ferramentas como o Data Warehouse permitem que o usuário final desenvolva suas consultas acessando uma base de 
dados já preparada. Esta consiste na extração dos dados de seus repositórios operacionais, de forma a permitir uma otimização em sua recuperação.

Os dados gerados na preparação podem ser coletados e armazenados através de sistemas de monitoramento, para que sejam feitas análises visando otimizações no tempo e esforço de preparação dos equipamentos. Com a utilização de coletores de dados e sensores, parâmetros da preparação podem ser coletados e registrados em bancos de dados, para análises posteriores ou em tempo real.

Informações necessárias

Para cada equipamento e para cada operação que este pode processar devem existir instruções específicas, definidas e registradas. Em indústrias, este tipo de informação é chamado de carta ou folha de processo, e traz as instruções para preparação do equipamento, indicando valores de regulagens, ferramentas e dispositivos a serem utilizados.

Sob vários aspectos, objetiva-se que os tempos de preparação dos equipamentos sejam sempre o menor possível. Portanto, é importante que estas tarefas sejam padronizadas e otimizadas.

Informações geradas

A atividade de preparação gera um resultado físico, que é o equipamento de produção estar operacional. Além disso, com o seu monitoramento, são gerados alguns tipos de informações, como por exemplo eventos de início e término da preparação e tempos de troca de ferramenta, limpeza, regulagem e outros

O evento de término da preparação informa que a operação pode ser iniciada.

\section{Recursos}

Os recursos utilizados para realizar esta atividade são ferramentas e outros acessórios específicos para a preparação de cada equipamento de produção. Para seu monitoramento, podem ser utilizados sensores e coletores de dados. 
Atividade: Realizar operação

Descrição e objetivo

Esta atividade consiste em realizar algum tipo de transformação em materiais ou componentes. Estas operações podem ser de diversos tipos, entre eles temos:

- Usinagem;

- Mistura;

- Extrusão;

- Cozimento;

- Embalagem e

- Costura.

A realização da operação deve ser monitorada, e seus dados registrados. Eventos também devem ser monitorados, como quebras de ferramentas ou início de operação.

Com a finalização da operação, o material transformado está pronto ou pode ser encaminhado para a operação seguinte.

Informações necessárias

As mesmas instruções para realização da operação mencionadas na atividade anterior são necessárias, pois também trazem informações sobre a operação, além da sua preparação. Várias condições da operação devem ser conhecidas.

Além destas instruções, são necessárias informações das ordens de produção, que indicam o produto, a quantidade e os horários de início e término.

Também são necessárias algumas informações adicionais, como a localização de materiais e ferramentas, padrões de qualidade, instrumentos de medição e padrão de armazenagem, entre outros.

Informações geradas

Cada operação de produção gera principalmente três conjuntos de informações: de qualidade, tecnológicas e de produção. 
As informações de qualidade geradas em uma operação de produção podem ser variadas, como quantidade de refugo e dimensões utilizadas para Controle Estatístico do Processo (CEP).

As informações tecnológicas são relacionadas ao equipamento e às ferramentas, como por exemplo motivos de parada, desgaste e vida útil de ferramentas, potência utilizada, quantidades produzidas entre paradas e parâmetros de operação como velocidades e quantidades.

Relacionadas à produção, as informações geradas são de tempos e quantidades relacionados a ordens ou operações, que também precisam ser identificadas.

Todos estes tipos de informações são gerados nas operações. Entretanto, para que sejam conhecidas e acessadas, devem ser coletadas e registradas. Existem duas formas para realizar esta coleta de dados: manual e eletrônica.

Para coleta manual, os dados devem ser anotados, e são gerados pela observação direta do operador ou de um operário especializado, geralmente chamado de apontador da produção. Estas anotações podem ser realizadas durante as operações, ao seu término e ainda ao final de um turno de trabalho. Para serem cadastrados em sistemas, estes dados devem ser digitados.

A coleta eletrônica de dados pode ser feita por sensores ou coletores de dados. Sensores são instalados nos equipamentos, e geram informações continuamente ou devido a eventos. Coletores de dados podem receber informações de sensores, de leitores (de código de barras e magnéticos, entre outros) e de digitações. Estes equipamentos podem ser instalados próximos aos equipamentos de produção, permitindo que recebam informações com grande freqüência.

Além das informações citadas, deve ser gerada uma informação relativa ao término de cada operação, permitindo que a próxima operação programada para o mesmo recurso seja iniciada.

\section{Recursos}

Os recursos são aqueles necessários para que as operações sejam efetivadas, geralmente equipamentos de produção, ou ferramentas para operações manuais. 
Para coleta dos dados e informações apresentados acima, são necessários sensores, coletores de dados, equipamentos de produção que possam fornecer dados diretamente, ou outros equipamentos específicos para esta finalidade. Não são do escopo desta atividade os recursos necessários à disponibilização das informações coletadas, que envolvem redes de campo, módulos de controle e protocolos de comunicação.

Atividade: Avaliar operação

\section{Descrição e objetivo}

Quando uma operação é finalizada, ela deve ser avaliada segundo parâmetros específicos, para identificar se o resultado foi satisfatório, se a operação deve ser refugada (perdida ou descartada) ou refeita.

Estes parâmetros são específicos para o equipamento e a ordem de produção, e podem ser, entre outros:

- Quantidades;

- Dimensões;

- Acabamento e

- Aparência.

Estas avaliações podem ser feitas manualmente ou através de equipamentos automatizados. Podem ser feitas ao término ou durante a operação.

Avaliações realizadas durante a operação permitem que problemas sejam corrigidos rapidamente, evitando desperdícios.

Informações necessárias

Para a realização desta atividade são necessárias informações sobre quais parâmetros devem ser avaliados, e quais os níveis tolerados. Também são necessárias informações e dados sobre a forma e condições de medição destes parâmetros. 
Informações geradas

A realização desta avaliação gera informações a respeito das medições e observações realizadas, permitindo que estas sejam registradas para diversas finalidades, como rastreamento de produtos e sistemas de qualidade.

Além das informações relativas aos parâmetros avaliados, são geradas informações das quantidades de operações satisfatórias, refugadas e que devem ser refeitas.

\section{Recursos}

São necessários equipamentos e recursos para realizar as medições e outras observações. Estes podem ser equipamentos de medição e contadores, entre outros.

São necessários também recursos para disponibilizar as informações geradas.

Atividade: Monitorar operação

\section{Descrição e objetivo}

Esta atividade centraliza as informações geradas e coletadas na preparação, realização e avaliação de cada operação de produção. Além disso permite que alguns parâmetros e eventos sejam monitorados. O objetivo do monitoramento é gerar informações para tomada de decisões, e permitir o acompanhamento de determinadas situações. Por exemplo, o monitoramento de um equipamento pode ser para acompanhamento de paradas por quebra de ferramenta, ou para identificar a ordem e a quantidade produzida em determinados recursos.

Outro objetivo do monitoramento é organizar os dados da operação para que sejam registrados em bancos de dados.

\section{Informações necessárias}

Para realização do monitoramento, além das informações coletadas da operação, são necessárias informações sobre quais parâmetros devem ser monitorados e quais as faixas de valores admissíveis. Também podem ser necessárias diretrizes para ações que devem ser tomadas devido à ocorrência de eventos acompanhados pelo monitoramento. 
Informações geradas

A atividade de monitoramento gera o registro ou a visualização das informações coletadas na preparação, realização e avaliação das operações de produção.

As ações tomadas em decorrência do monitoramento também podem ser registradas. Como exemplo, quando a temperatura de determinado equipamento atinge um valor específico, é aberta uma válvula, e a quantidade de vezes que isso ocorre durante uma operação deve ficar registrado.

\section{Recursos}

Os recursos utilizados nesta atividade devem permitir que os dados das operações coletados sejam acompanhados e registrados. Isto pode ser feito principalmente através de sistemas automatizados de monitoramento, que de maneira geral possuem interfaces gráficas para visualização de alguns parâmetros.

Caso o monitoramento seja feito com base em informações coletadas eletronicamente por sensores, o volume destas pode ser grande, e necessitar que o registro seja feito com recursos específicos, como ferramentas de Data Warehouse. 
Processo: Controlar produção

Atividade: Controlar equipamento

Descrição e objetivo

O objetivo desta atividade é controlar aspectos tecnológicos dos equipamentos de produção. Podem ser controlados todos os parâmetros passíveis de serem obtidas informações, como:

- Vida útil de ferramentas;

- Posições e medidas;

- Desgastes de componentes;

- Quantidades e motivos de paradas e

- Regimes de funcionamento (operando, carregando, preparando e outros).

Com estes controles é possível obter um histórico do comportamento e rendimento dos equipamentos, que permite que seja feito um acompanhamento do mesmo, como por exemplo para manutenções e testes de dispositivos e configurações. Análises deste histórico podem permitir otimizações no rendimento e custos das operações, como por exemplo com a utilização de velocidades de avanço maiores ou menor freqüência de troca de ferramentas.

Informações necessárias

Para a realização desta atividade, são necessários informações e dados coletados através de sensores instalados nos equipamentos, durante a operação do equipamento. Existem diversos tipos de sensores, e cada um destes gera um conjunto de dados distinto. O tipo de dado e a freqüência de sua coleta devem ser definidos em função das necessidades da empresa. Além dos sensores, também é necessário que os dados sejam transmitidos ou disponibilizados para outras aplicações, o que pode ser feito por redes locais ou de campo. 
Informações geradas

As informações geradas pelo controle da operação de um equipamento de produção são os dados coletados pelos sensores, e que atendam os objetivos desta atividade.

\section{Recursos}

Os recursos necessários para a realização desta atividade são aqueles que permitem que as informações sejam coletadas e disponibilizadas, que são sensores, coletores de dados, redes de campo, sistemas SCADA e redes de comunicação.

Atividade: Controlar produção de itens

\section{Descrição e objetivo}

Esta é uma das atividades que geram informações para o controle da produção, especificamente em relação a cada item produzido em cada operação de produção.

Em empresas de manufatura discreta que trabalham com ordens de produção, não é usual este tipo de informação, pois usualmente o controle é feito para o lote ou operação completa, exceto em casos especiais de produtos com grande valor agregado, ou que requerem um rastreamento detalhado.

O objetivo desta atividade é gerar informações que poderão ser utilizadas para obter um maior conhecimento da operação e do chão de fábrica.

Caso exista um sistema de monitoramento ou de programação da produção integrado a esta atividade, o andamento da produção poderá ser acompanhado de forma visual e em tempo real, permitindo consultas precisas (por exemplo de vendedores para promessa de datas de entrega) e correções rápidas quando forem necessárias.

\section{Informações necessárias}

Para a realização desta atividade são necessárias informações sobre horários de início e término de operações, identificação da operação sendo realizada e quantidades produzidas. Outras informações complementares podem ser utilizadas, como custos, condições da operação, operadores envolvidos e outras. 
Informações geradas

As principais informações geradas são as seguintes:

- Horário de início e término de cada operação de cada ordem e

- Quantidades produzidas em relação ao tempo.

Estas informações devem permitir o acompanhamento da produção de cada operação de cada ordem. Deve existir a possibilidade de saber quais operações estão sendo processadas, seus horários de início e término e as quantidades produzidas.

De forma geral, sistemas ERP e de programação da produção não tratam este tipo de informação, sendo necessário que sejam armazenadas em outros sistemas integrados.

\section{Recursos}

Os recursos necessários para a realização desta atividade são sensores e coletores de dados que possuem a capacidade de gerar as informações necessárias e atender o objetivo desta atividade.

Os sensores podem ser de diversos tipos, porém um fator a ser evitado é a instalação unicamente de sensores de potência (baratos e de fácil instalação), pois estes indicam quando o equipamento está ativado, não necessariamente produzindo (ciclos em vazio e testes).

Atividade: Controlar produção de ordens e lotes

\section{Descrição e objetivo}

Esta atividade gera informações sobre a produção de ordens e lotes para o controle da produção. Algumas ordens de produção podem ser realizadas em mais de um lote, por isso o controle de ambos. Em situações onde cada ordem é processada em um lote único, este controle é indistinto.

A realização desta atividade permite o acompanhamento dos programas de produção, sabendo quais operações de cada ordem já foram iniciadas ou finalizadas.

De forma geral, esta atividade é realizada em empresas de manufatura discreta através do apontamento da produção, que informa quais ordens foram encerradas ou estão sendo processadas. $\mathrm{O}$ apontamento geralmente é feito ao término de cada 
operação ou do turno de trabalho, sendo que as informações são registradas manualmente e necessitam serem digitadas para que estejam acessíveis para sistemas automatizados.

O registro destas informações permite a geração de um conhecimento sobre a produção, assim como a identificação de comportamentos que possam permitir otimizações e economias.

\section{Informações necessárias}

Para a realização desta atividade, são necessárias informações sobre quais lotes ou ordens de produção tiveram suas operações iniciadas ou finalizadas. Para tanto são necessários os seguintes dados:

- Identificação da operação, da ordem de produção e do lote;

- Horários e datas e

- Situação da operação (iniciada, em andamento ou finalizada).

Caso estejam disponíveis, podem ser utilizadas informações complementares como condições da operação e operadores envolvidos.

Informações geradas

As principais informações geradas com esta atividade são relacionadas à situação de ordens de produção e suas respectivas operações. Estas são utilizadas para acompanhamento do programa de produção e dos planejamentos realizados.

Também podem ser utilizadas para geração de indicadores que permitam análises históricas ou estejam relacionados ao cumprimento de metas e objetivos.

\section{Recursos}

Para a realização desta atividade são necessários sensores e coletores de dados que permitam a obtenção das informações relacionadas. Alternativamente, estas informações podem ser obtidas através de apontamentos manuais registrados em fichas ou relatórios.

É importante que existam recursos para a identificação da ordem ou da operação sendo processada em cada equipamento. Sensores instalados diretamente nos equipamentos não possuem esta funcionalidade, sendo então necessário o uso de 
recursos complementares, como por exemplo coletores de dados onde o operador digita a identificação necessária. Leitores de código de barras são largamente utilizados para esta finalidade.

Atividade: Registrar informações de controle

\section{Descrição e objetivo}

Esta atividade tem o objetivo de concentrar e registrar todas as informações de controle coletadas nas operações de produção. Com isso é alimentado um repositório de dados que servirá para consultas e para a geração de relatórios e indicadores de desempenho a serem utilizados por toda a empresa. No modelo proposto, estas informações serão utilizadas em todos os níveis de planejamento da produção.

O registro das informações não precisa ser necessariamente de forma eletrônica em bancos de dados, podendo ser na forma de relatórios impressos.

Informações necessárias

As seguintes informações são necessárias:

- Controle do funcionamento dos equipamentos;

- Controle da produção de itens e

- Controle da produção de ordens e lotes.

Além destas, podem ser registradas quaisquer outras informações de controle disponíveis.

Informações geradas

Como o objetivo desta atividade é o registro de informações, não são geradas informações de forma direta. Indiretamente, as informações registradas irão gerar informações e relatórios, porém isso será tratado em atividades específicas.

\section{Recursos}

Para a realização desta atividade, é assumido que as informações necessárias estarão disponíveis para serem armazenadas. 
O volume de informações a serem registradas caso exista alguma forma de monitoramento ou coleta de dados automatizados tende a ser grande. Neste caso, devem ser usadas ferramentas compatíveis, como por exemplo ferramentas de Data Warehouse, que além de suportar um grande volume de informações, ainda possui funcionalidades para a geração de relatórios e execução de consultas de forma simples.

Estas informações também podem ser registradas em recursos mais simples, como bancos de dados relacionais ou de forma impressa. 
Processo: Analisar dados de produção

Atividade: Definir consultas e relatórios

Descrição e objetivo

O objetivo desta atividade é formalizar a obtenção de informações de operações, necessárias para diversas finalidades no processo de Gestão da Produção. Os sub processos listados a seguir geram estas necessidades, e utilizam as informações na forma de consultas e relatórios:

- Gerir demanda;

- Planejar produção;

- Programar produção;

- Produzir e

- Controlar produção.

Estas consultas podem ser regulares ou esporádicas. No caso de consultas regulares, deve ser feito um esforço para que sejam incorporadas ao sistema de informação existente.

Informações esporádicas geralmente são necessárias com urgência, pois devem atender situações não previstas, como por exemplo dúvidas surgidas em reuniões diárias de programação. Por isso as consultas devem ser realizadas de forma fácil, e o tempo de resposta deve ser curto.

Informações necessárias

Para a realização desta atividade, é necessário que o usuário tenha uma definição das informações que necessita, e uma forma de obtê-las. Como exemplo, um operador pode necessitar uma informação sobre qual é a vida útil de determinada ferramenta, para que solicite a quantidade correta em função do tamanho de lote a ser produzido. 
Informações geradas

O resultado desta atividade é a definição de uma consulta ou relatório a ser realizado no repositório de dados de operações. Esta definição pode ser armazenada para acessos posteriores.

\section{Recursos}

O recurso necessário para a realização desta atividade está relacionado com a forma como a consulta e o relatório serão executados ou gerados, e devem ser compatíveis.

As ferramentas de Data Warehouse são as mais apropriadas para a realização desta atividade, e devem ser configuradas e preparadas para atenderem às necessidades do usuário.

O recurso deve permitir que sejam recuperados consultas ou relatórios já realizados.

Atividade: Executar relatórios e consultas

\section{Descrição e objetivo}

Uma vez definidos os relatórios e consultas, eles devem ser executados, para que as informações necessárias sejam geradas e disponibilizadas.

Esta execução significa extrair somente as informações desejadas de um grande volume de dados. Depois de extraídos, estes dados devem ser formatados e preparados para exibição, que pode ser através de listagens ou gráficos. Também podem ser feitos cálculos para geração de indicadores de performance.

A execução não deve ser demorada, permitindo maior flexibilidade e agilidade aos processos de tomada de decisão.

Não é objetivo desta atividade analisar o conteúdo das informações geradas.

\section{Informações necessárias}

Para a realização desta atividade, o relatório ou consulta já deve estar definido e configurado. Portanto, é necessário que seja identificado qual o relatório ou consulta deve ser executado. 
Informações geradas

Os resultados desta atividade são os próprios relatórios e consultas desejados, que contém as informações de operações e produção que atendam as necessidades identificadas. Estes resultados podem ser utilizados em todos os níveis do planejamento da produção.

\section{Recursos}

O recurso necessário para a realização desta atividade deve possuir funcionalidades para o gerenciamento de grandes volumes de dados, e para a recuperação de dados através de consultas elaboradas.

Ferramentas de Data Warehouse possuem estas finalidades, com a vantagem de não necessitarem de pessoal qualificado para montar as consultas sobre dados já extraídos. Desta forma, cada usuário teria a oportunidade de montar e executas suas próprias consultas e relatórios, com a possibilidade de recuperá-los em outras oportunidades.

Atividade: Disponibilizar relatórios e consultas

\section{Descrição e objetivo}

Com o final da atividade anterior, os dados estão gerados e prontos para serem disponibilizados onde foram solicitados. Isso pode ser feito de forma eletrônica ou impressa.

O objetivo desta atividade é que as informações geradas pelas consultas cheguem a quem as solicitou. Algumas informações podem ser disponibilizadas regularmente para uma ou mais pessoas. Caso o sistema de geração destas informações seja ágil e de fácil configuração, os processos de tomada de decisões da empresa são suportados por um maior volume de informações, que geram conhecimentos complementares sobre a produção, podendo gerar contribuições no âmbito geral da empresa.

Estes relatórios e consultas permitem o monitoramento e acompanhamento de indicadores de performance específicos, não somente para a empresa, mas para toda a cadeia produtiva. 
Informações necessárias

A informação necessária para a realização desta atividade é qual relatório ou consulta foi solicitado, e por qual(is) pessoa(s). Para isso, cada consulta ou relatório deve possuir uma identificação, que permite que seu destinatário também seja identificado.

Além disso, é necessário saber o formato e o meio que as informações serão disponibilizadas ou transmitidas. Também deve ser conhecida a frequiência na qual os relatórios e consultas devem ser executados, ou o relacionamento destes com eventos que possam ocorrer.

Informações geradas

A realização desta atividade não gera informações. Ela disponibiliza informações que já estejam geradas.

\section{Recursos}

Para a realização desta atividade, o recurso necessário é o meio de disponibilização das informações. Os meios mais comuns são redes locais de computadores, que integram sistemas e usuários de forma simples. No caso de relatórios impressos, a disponibilização pode ser feita manualmente.

Podem ser utilizados para esta finalidade sistemas de Work flow, que direcionam o tráfego de informações localmente, segundo a ocorrência de ventos programados. 


\section{REFERÊNCIAS BIBLIOGRÁFICAS}

1. BALLARD, A. (1999). Windows CE brings real time control to the PC plataform. Assembly Automation, Vol. 19, No. 4, pp. 306-307.

2. BRAGG, D. J.; DUPLAGA, E. A.; WATTS, C. A. (1999). The effects of partial order release and component reservation on inventory and costumer service performance in an MRP environment. International Journal of Production Research, Vol. 37, No. 3, pp. 523-538.

3. BRAGLIA, M.; PETRONI, A. (1999). Shortcomings and benefits associated with the implementation of MRP packages: a survey research. Logistics Information Management, Vol. 12, No. 6, pp. 428-438.

4. BAUER, A.; BOWDEN, R.; BROWNE, J.; DUGGAN, J.; LYONS, G. (1991). Shop floor control systems: from design to implementation. Chapman \&Hall.

5. CAETANO, A. G. L. S; MEIRELES; G. S. C.; OLIVEIRA, J. F. G.; LEÃO E SOUZA, G. W. (1999). Informações de chão de fábrica num ambiente de manufatura integrada. Congresso e Exposição Internacionais da Tecnologia da Mobilidade (SAE Brasil 99), SAE Technical Paper Series.

6. CHIUSOLO, E., KLEINER, B. H. (1999). The most useful software for executives. Industrial management \& data systems, Vol. 95, No. 10, pp. 25-28.

7. CORRÊA, H. L.; GIANESI, I. G. N. (1993). Just in time, MRP II e OPT: um enfoque estratégico. Editora Atlas, São Paulo.

8. CORRÊA, H. L.; GIANESI, I. G. N.; CAON M. (1997). Planejamento, programação e controle da produção: MRPII/ERP. Editora Atlas, São Paulo.

9. CHARBONNIER, F.; ALLA, H.; DAVID, R. (1999). The supervised control of discrete-event dynamic systems. IEEE Transactions on control systems technology, vol 7, no. 2, march, pp. 175-187.

10. EOM, S. B. (1999). Decision support systems research: current state and trends. Industrial Management \& Data Systems, Vol. 99, No. 5, pp. 213-220.

11. EVERSHEIM, W.; KLOCKE, F.; PFEIFER, T.; WECK, M. (1997). Manufacturing excellence in global markets. Chapman \& Hall. 
12. EXON-TAYLOR, M. (1997). Beyond MRP - the operation of a modern scheduling system. Supply chain management, Vol. 2, No. 2, pp. 43-48.

13. FELDMANN, K.; COLOMBO, A. W. (1998). Material flow and control sequence specification of flexible production systems using coloured Petri nets. The International Journal of Advanced Manufacturing Technology, No. 14, , pp. 760-774.

14. FLEURY, A. C.; CORRÊA, A.; VARGAS, N. (1994). Organização do trabalho: uma abordagem interdisciplinar. Editora Atlas, São Paulo.

15. GARGANO, M. L.; RAGGAD; B. G. (1999). Data Mining: a powerful information creating tool. OCLC Systems \& Services, Vol. 15, No. 2, pp. 81-90.

16. GIL, A. C. (1988). Como elaborar projetos de pesquisa. Editora Atlas, São Paulo.

17. GROVER, V. (1999). From business reengineering to business process change management: A longitudinal study of trends and practices. IEEE Transactions on Engineering Management, Vol. 46, No. 1, Fevereiro, pp. 36-46.

18. HERBON, A. (1988). On line production control of a flexible multi-cell manufacturing system operating in a highly dynamic environment. International Journal of Production Research, vol. 36, no. 10, pp. 2771-2791.

19. HADAVI, K. C. (1997). Delivering on-time performance: what's wrong with planning and scheduling systems. APICS Magazine TPA, Vol. 7, No. 3, March.

20. HEINER, M.; DEUSSEN, P.; SRANGER, J. (1999). A case study in design and verification of manufacturing system control software with hierarchical Petri nets. The International Journal of Advanced Manufacturing Technology, No. 15, pp. 139-152.

21. JAYARAMAN, V.; SRIVASTAVA, R. (1996). Expert systems inproduction and operations management: current applications and future prospects. International Journal of Operations \& Production Management, Vol. 16, No. 12, pp. 27-44.

22. JEMIELNIAK, K. (1999). Commercial tool condition motoring systems. The International Journal of Advanced Manufacturing Technology, No. 15, pp. 711721. 
23. KALS, H.; GIEBELS, M.; ZIJIM, H. (1988). Dynamic manufacturing planning and control. Industry Week, No. 21, Setembro.

24. KANET, J. J.; SRIDHARAN, S. V. (1998). The value of using scheduling information in planning material requirements. Decision Sciences, Vol. 29, No. 2, Spring, pp. 479-497.

25. KIM, K. H.; SONG, J. Y.; WANG, K. H. (1997). A negotiation based scheduling for items with flexible process plans. Computers in Industrial Engineering, Vol. 33, No. 3-4, pp. 785-788.

26. LEE, S. M.; CHEN, J. Q. (1997). A conceptual model for executive support systems. Logistics information management, Vol. 10, No. 4, pp. 154-159.

27. LEIDNER, D. E.; CARLSSON, S.; ELAM, J.; CORRALES, M. (1999). Mexican and Swedish Managers perceptions of the impact of EIS on organizational intelligence, decision making and structure. Decision Sciences, Vol. 30, No. 3, Summer, pp. 633-657.

28. LINDAU, R. A.; KANFLO, T.; LUMSDEN, K. (1994). Impact of real-time information for scheduling a car-body shop - a simulation study. International Journal of Operations \& Operations Management, Vol. 14, No. 3., pp. 114-125.

29. LUTTERVELT, C. A.; PENG, J. (1999). Symbiosis of modeling and sensing to improve the accuracy of workpieces in small batch machining operations. The International Journal of Advanced Manufacturing Technology, No. 15, pp. 699710.

30. MAHALIK, N. P.; MOORE, P. R. (1997). Fieldbus technology based, distributed control in process industries: a case study with LonWorks Technologies. Integrated Manufacturing Systems, Vol.8, No. 4, pp. 231-243.

31. MA, C.; CHOU, D. C.; YEN, D. C. (2000). Data warehousing, technology assessment and management. Industrial Management \& Data Systems, Vol. 100, No. 3, pp. 125-134.

32. MARTINS, R. A.; COSTA NETO, P. L. O. (1998). Indicadores de desempenho para a gestão pela qualidade total: uma proposta de sistematização. Gestão \& Produção, Vol. 5, No. 3, Dezembro, pp. 298-311. 
33. MARTINS, P. G.; LAUGENI, F. P. (1998). Administração da produção. Editora Saraiva, São Paulo.

34. MEIRELES, G. S. C.; MEDAlHA, G. C.; CAETANO, A. G. L. S.; DANTAS, D.; OLIVEIRA, J. F. G. (2000). Sistema de supervisão para operações de retificação. In: $55^{\circ}$.CONGRESSO DA ABM, Rio de Janeiro, 2000. Anais. Rio de Janeiro.

35. MEIRELES, G. S. C. (2000). Sistema de supervisão da produção. São Carlos. Dissertação (mestrado) - Escola de Engenharia de São Carlos, Universidade de São Paulo.

36. NEELY, A.; GREGORY, M.; PLATTS, K. (1995). Performance measurement system design: a literature review and research agenda. International Journal of Operations Management, Vol. 15, No. 4, pp. 80-116.

37. PADUA, E. M. M. (1996). Metodologia da pesquisa: abordagem teóricoprática. Editora Papirus, São Paulo.

38. PALVIA, P. C.; BASU, S. C. (1999). Information systems management issues: reporting and relevance. Decision Sciences, Vol. 30, No. 1, Winter, pp. 273-290.

39. PENG, C.; CHEN, F. F. (1998). Real time control and scheduling of flexible manufacturing systems: an ordinal optimization based approach. The International Journal of Advanced Manufacturing Technology, No. 14, pp. 775786.

40. PORTER, J. K.; JARVIS, P.; LITTLE, D.; LAAKMANN, J.; HANNEN, C.; SCHOTTEN, M. (1996). Production planning and control system developments in Germany. International Journal of Operations in Production Management, Vol. 15, No. 1, pp. 27-39.

41. PORTER, K.; LITTLE, D.; PECK, M.; ROLLINS, R. (1999). Manufacturing classifications: relationships with production control systems. Integrated Manufacturing Systems, Vol. 10, No. 4, pp. 189-198.

42. RAI, A.; BAJWA, D. S. (1997). An empirical investigation into factors relating to the adoption on executive information systems: an analysis of EIS for collaboration and decision support. Decision Sciences, Vol. 28, No. 4, Fall, pp. 939-974. 
43. RAO, S. S. (2000). Enterprise resource planning: business needs and technologies. Industrial Management \& Data Systems, Vol. 100, No. 2, pp. 8188.

44. REISMAN, A.; KUMAR, A.; MOTWANI, J. (1997). Flow shop scheduling/sequencing research: a statistical review of the literature, 1952-1994. IEEE Transactions on Engineering Management, Vol 44, no. 3, august, pp. 316328.

45. ROLSTADAS, A. (1998). Enterprise performance measurement. International Journal of Operations \& Production Management, Vol. 18, No. 9/10, pp. 989999.

46. ROOKS, B. (2000). Winning ways for manufacturing. Assembly Automation, Vol. 20, No. 1, pp. 35-39.

47. RUIZ, J. A. (1993). Metodologia científica: guia para a eficiência nos estudos. Editora Atlas, São Paulo.

48. SCHEER, A. W. (1998). ARIS-Business process frameworks. Springer-Verlag Berlin.

49. SIEGEL, D. S.; WALDMAN, D. A.; YOUNGDAHL, W. E. (1997). The adoption of Advanced Manufacturing Technologies: human resource management implications. IEEE Transactions on Engineering Management, Vol. 44, No. 3, august, pp. 288-298.

50. SIEMIATKOWSKI, M.; PRZYBYLSKI, W. (1997). A system solution for integration of process planning and control in flexible manufacturing. Integrated manufacturing systems, Vol. 8, No. 3, pp. 173-180.

51. SLACK, N.; CHAMBERS, S.; HARLAND, C.; HARRISON, A.; JOHNSTON, R. (1999). Administração da produção (edição compacta). Editora Atlas, São Paulo

52. SMITH, D. (1998). Creating the data collection infrastructure that maximizes ERP funcionality. APICS On-line, Vol. 8, No. 5. 
53. SOARES, D. D.; MEIRELES, G. S. C.,; OLIVEIRA, J. F. G.; BIFFI, M. (2000). Otimização de operações de retificação via supervisão e diagnóstico a distância. In: CONGRESSO USINAGEM 2000, 2000. Anais. São Paulo, Setembro.

54. SOON, T. H.; SOUZA, R. (1997). Intelligent simulation-based scheduling of workcells: an approach. Integrated Manufacturing Systems, Vol. 8, No. 1, pp. 623.

55. SOUZA, F. B.; PIRES, S. R. I (1999). Análise e proposições sobre o balanceamento e uso de excesso de capacidade em recursos produtivos. Gestão \& Produção, Vol. 6, No. 2, ago., pp. 111-126.

56. SPEIR, C.; VALACICH, J. S.; VESSEY, I. (1999). The influence of task interruption on individual decision making: an information overload perspective. Decision Sciences, Vol. 30, No. 2, Spring, pp. 337-360.

57. SUGUMARAN, V.; BOSE, R. (1999). Data analysis and mining environment: a distributed intelligent agent technology application. Industrial Management \& Data Systems, Vol. 99, No. 2, pp. 71-80.

58. TAYLOR, J. C. (1998). Participative design: linking BPR and SAP with an STS approach. Journal of Organizational Change Management, Vol. 11, No. 3, pp. 233-245.

59. TITUS, M.; LENNARTSON, B. (1999). Hierarchical supervisory control for batch process. IEEE transactions on control systems technology, Vol. 7, No. 5, pp. 542-554.

60. VOLLMANN, T. E.; BERRY, W. L.; WHYBARK, D. C. (1993). Integrated production and inventory management. Business One Irwin.

61. WALKER, K. B. (1996). Corporate performance reporting revisited - the balanced scorecard and dynamic management reporting. Industrial Management \& Data Systems, Vol. 96, No. 3, pp. 24-30.

62. WESTON, R. (1999). Model driven, component-based approach to reconfiguring manufacturing software systems. International Journal on Operations \& Production Management, Vol. 19, No. 8, pp. 834-855. 
63. YU, B.; WRIGHT, D. T. (1997). Software tools supporting business process analysis and modeling. Business Process Management Journal, Vol. 3, No. 2, pp. 133-142.

64. YUSUF, Y.; LITTLE, D. (1998). An empirical investigation of enterprise-wide integration of MRPII. International Journal of Operations \& Production Management, Vol. 18, No. 1, pp. 66-86. 